\title{
Eva-Maria Houben
}

\section{Musikalische \\ Praxis als \\ Lebensform}

Sinnfindung und Wirklichkeitserfahrung beim Musizieren

[transcript] Milusik und Klangkultur 
Eva-Maria Houben

Musikalische Praxis als Lebensform

Musik und Klangkultur | Band 27 
Eva-Maria Houben (Prof. Dr. phil.), geb. 1955, lehrt Musikwissenschaft mit dem Schwerpunkt Musiktheorie an der TU Dortmund. Sie ist auch als Komponistin, Organistin und Pianistin tätig. 
Eva-Maria Houben

\section{Musikalische Praxis als Lebensform}

Sinnfindung und Wirklichkeitserfahrung beim Musizieren 
Dieses Werk ist lizenziert unter der Creative Commons Attribution-Share Alike 4.0 Lizenz (BY-SA).

Diese Lizenz erlaubt unter Voraussetzung der Namensnennung des Urhebers die Bearbeitung, Vervielfältigung und Verbreitung des Materials in jedem Format oder Medium für beliebige Zwecke, auch kommerziell, sofern der neu entstandene Text unter derselben Lizenz wie das Original verbreitet werden. (Lizenz-Text: https://creativecommons.org/licenses/by-sa/4.o/deed.de)

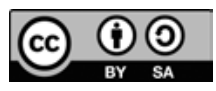

(C) 2018 Eva-Maria Houben

Erschienen 2018 im transcript Verlag, Bielefeld

\section{Bibliografische Information der Deutschen Nationalbibliothek}

Die Deutsche Nationalbibliothek verzeichnet diese Publikation in der Deutschen Nationalbibliografie; detaillierte bibliografische Daten sind im Internet über http://dnb.d-nb.de abrufbar.

Umschlaggestaltung: Kordula Röckenhaus, Bielefeld Umschlagabbildung: mekcar / fotolia.com

Satz: Justine Buri, Bielefeld

Druck: Majuskel Medienproduktion GmbH, Wetzlar

Print-ISBN 978-3-8376-4199-8

PDF-ISBN 978-3-8394-4199-2

Gedruckt auf alterungsbeständigem Papier mit chlorfrei gebleichtem Zellstoff.

Besuchen Sie uns im Internet: http://www.transcript-verlag.de

Bitte fordern Sie unser Gesamtverzeichnis und andere Broschüren an unter: info@transcript-verlag.de 


\section{Inhalt}

\section{Vorwort 9}

\section{ERSTER TeIL}

\section{Zugänge $\mid 15$}

1.1 Eine musikalische Situation: Tun und Geschehen-Lassen $\mid 15$

1.2 Musik - wozu? Angesichts $\mid 17$

1.3 (Er-)Finden von Praktiken $\mid 20$

1.4 Üben: Exercises $\mid 27$

1.5 Brauchbar? Notation und Wirklichkeit der Ausführung | 33

\section{Musikalische Praxis $\mid 37$}

2.1 Annäherung an den Begriff. Brennpunkte, Schnittmengen | 37

2.2 Sinn und Bedeutung $\mid 47$

2.3 Wirklichkeiten? - Welten? 60

2.4 Sprechen, Rede, Redeweise $\mid 66$

\section{Sprachfindungen $\mid 73$}

3.1 Intersubjektive Sinngebungen -

Sinnzusammenhänge (Alfred Schütz) | 73

3.2 Verkörperungen (Simone Mahrenholz) $\mid 86$

3.3 Grenzen, Schwellen - und Übergänge $\mid 98$

\section{ZWEITER TEIL}

1. Tasten $\mid 111$

1.1 Ludwig van Beethoven: Klaviersonate Nr. 32 c-moll op. 111,

1. Satz (Maestoso. Allegro con brio ed appassionato) (1821/22).

Einzelereignisse - Desorientierung. Neuorientierung? | 113

1.2 Johann Sebastian Bach: Fantasia in g für Orgel BWV 542 (um 1720).

Historische Positionierung: handgreiflich | 117

1.3 Frédéric Chopin: Prélude Nr. 2 a-moll, aus: 24 Préludes op. 28 (publ. 1839). 
Zärtliche Verbindungen in verstörendem Kontext:

der zweihändige Pianist $\mid 123$

1.4 Aurèle Stroë: $3^{\text {eme }}$ Sonate pour Piano (en palimpseste)

(1947/1957/1990-1991).

Brüche - das Klavier als Trommel. Raumgreifende Bewegungen | 125

1.5 Robert Schumann: Kreisleriana. Fantasien für Piano-Forte op. 16 (1838; rev. 1850).

Praxis körperlichen Zeigens: Alles auf einmal | 133

1.6 Luigi Nono: .....sofferte onde serene... per pianoforte e nastro magnetico (1976).

Pulsationen: Lebenszeichen. Tasten als Verlängerungen des Körpers, der Finger $\mid 137$

2. Viele $\mid 139$

2.1 Anton Webern: Fünf Stücke für Orchester op. 10, I (1911-1913) Christian Wolff: For 1, 2 or 3 people (1964).

Allein, zu zweit, zu mehreren im Gruppenverbund (1) 140

2.2 Wolfgang Amadeus Mozart: Serenade in B (»Gran Partita«) (KV $\left.36_{1}\right)$, Largo/Molto allegro - Adagio (vermutlich 1783-84).

Allein, zu zweit, zu mehreren im Gruppenverbund (2) | 145

2.3 Ludwig van Beethoven: Symphonie Nr. 5 c-moll op. 67 (UA 22.12.1808).

Einzelner und Gruppenverbund: das Recht, in Erscheinung zu treten - die Verheißung und die Herausforderung des Wir 149

2.4 John Cage: Music for (1984-87).

Koinzidenz. Gemeinsame Erfahrung eines Wir als Auch-da-Sein 159

3. Solo $\mid 163$

3.1 Claude Debussy: Syrinx pour flûte seule (1913) Anastassis Philippakopoulos: song 6 for bass flute or alto flute or flute (2010).

Sich-selbst-Zuhören - Atembögen - das abwesende Du | 164

3.2 Johann Jacob Froberger: Lamentation (Partita in C; FbWV 612)

(1654) - Meditation (Partita in D; FbWV 620) (1660).

Nachhören - »avec discrétion «| 168

3.3 Istvàn Zelenka: »The trumpet shall sound! «-

Stillstück für einen Violoncellisten, mit gleichzeitigen

Umweltklängen und ohne Publikum (1990).

Beschäftigung »per se« - im offenen Raum | 174 
3.4 Antoine Beuger: pour être seul(e), sans réserve für klavier (2009). Allein-Sein: sich verlieren, sich verloren geben | 177

4. Duo 179

4.1 Federico Mompou: Cantar del Alma. Pour Piano et Chant (1951).

Text: Saint Jean de la Croix.

Getrennt-Sein in der Liebe $\mid 180$

4.2 Jürg Frey: Buch der Räume und Zeiten für zwei Ausführende (1999) Jürg Frey: Ohne Titel (Zwei Violinen) (1995/96).

Auch-da-Sein - nicht identifizierbare Differenz $\mid 183$

4.3 Ludwig van Beethoven: Violinsonate Nr. 10 G-Dur op. 96, 2.

Satz (Adagio espressivo) (1812).

Aufeinander-zu-Gehen. Näherungen | 188

5. Trio $\mid 191$

5.1 Franz Schubert: Trio in Es D 929 op. 100, 2. Satz

(Andante con moto) (1827).

Unterschiedliche Schicksale - gemeinsam | 191

5.2 Arnold Schönberg: Streichtrio op. 45 (1946).

Trio-Körper in Pulsation: drei Körper sein, ein Körper werden.

Ein Körper bleiben? | 196

5.3 Mathias Spahlinger: 128 erfüllte augenblicke. systematisch geordnet, variabel zu spielen. für stimme, klarinette und violoncello (1975).

Kontinuität als Utopie. Werden von (je eigenen) Ordnungen 198

6. Quartett $\mid 203$

6.1 Ludwig van Beethoven: Streichquartett Nr. 10 Es-Dur op. 74 (»Harfenquartett«), 1. Satz, Einleitung Poco Adagio (18०9).

Aufeinander-angewiesen-Sein in Freiheit | 204

6.2 Helmut Lachenmann: Gran Torso. Musik für Streichquartett (1971/72; rev. 1978).

In-Erscheinung-Treten im Freien | 208

7. Über Grenzen hinaus $\mid 213$

7.1 Risiko? Hans-Joachim Hespos: seiltanz.

szenisches abenteuer (1982) | 214

7.2 Virtuosität? Franz Liszt: Etudes d'exécution transcendante $(1826,1838,1851) \mid 217$

7.3 Unvorhersehbarkeit? Karlheinz Stockhausen:

Spiral für einen Solisten (1968) | 221 
8. In der "Arche des Augenblicks" | 223

Werkeverzeichnis | 225

Literatur | 231 


\section{Vorwort}

Musik - wozu?

"Es wird Klang gegeben. Es gibt Klang, es gibt Klänge. Es wird still.

Das ist alles, was ich auf die Frage nach dem Wozu von Komposition zu sagen weiß." ${ }^{1}$

Mit der Frage nach der »Musikalischen Praxis als Lebensform« wird der Akzent auf das Tun der Ausführenden verlagert; es sind weniger die Komponisten, auch weniger die Zuhörer, als vielmehr die Ausführenden, die in diese Situation des Hörens hineingestellt werden: eine Situation des Tuns und Geschehen-Lassens. ${ }^{2}$ Als Ausführender bin ich zugleich auch Hörer; und Hören kann einerseits ein (aktives) Tun sein, widerfährt einem aber auch, stößt einem auch zu. Wenn vom Musizieren oder von der Ausführung gesprochen wird, kommt leicht das Tun der Ausführenden allein in den Blick. Sobald aber Stille mit ins Spiel kommt (und nicht nur dann - aber in stillen Momenten wird es womöglich öfter offensichtlich), spitzt sich die Situation des Miteinander-DaSeins, des Für-Sich-Da-Seins zu. Ich kann mich als Ausführender zwischen Tun und Geschehen-Lassen begeben; kann die Erfahrung machen, dass ich nicht alles im Griff haben muss - und es auch nicht kann. Die Situation öffnet sich für Geschehen und Teilhabe.

Die Ausführenden spielen nicht nur ein Instrument oder singen nicht nur, sie setzen sich zugleich auch einer Situation aus - einer Situation in einem bestimmten Raum, an einem bestimmten Ort, in einer bestimmten Beziehung zu anderen Mitspielern, zu Personen auch, die an- oder abwesend sein können.

Istvàn Zelenka macht eine spezifische Haltung der Ausführenden aus: »Der >Musiker soll mit der gleichen Intensität sein Instrument zum Klingen bringen und seiner Umwelt zuhören, sie betrachten. Diese Aktionsfolge (Komposition) soll das aufmerksame Betrachten, das intensive Zuhören und

1 | E.-M. Houben: Hector Berlioz, S. 188.

2 I Im folgenden Text wird weitgehend die maskuline grammatische Form verwendet. Das geschieht aus Gründen der besseren Lesbarkeit. 
die unermüdlich Fragen stellende Reflexion friedlich fördern. ${ }^{3}$ Ausführung umfasst hier vielerlei Arten von Aktivitäten.

Nicht-Handeln wird ebenso wichtig wie hörbares und/oder sichtbares Handeln. Stille (und mit Stille den verschwindenden Klang) einzulassen, bedeutet, sich auch dem auszusetzen, was jetzt und hier, in dieser Situation, geschehen oder passieren kann. Antoine Beuger verweist auf den Zusammenhang zwischen Stille und Ereignis: Stille als Ruhe vor dem Sturm oder auch nach dem Sturm. ${ }^{4}$ Er unterscheidet zwischen »Sein« und »Stattfinden«: Ein Ereignis findet statt - danach sind die Dinge anders als zuvor: »such a difference can be life changing or of historical significance.« Diese Andersheit kann große Resonanzen auslösen: kann ein individuelles Leben ändern oder auch von historischer Tragweite sein. Ein Still-Werden: »there is silence: speechlessness; absence of images; vanishing of any representations, that might have been effective before, but suddenly obsolete now; loss of concept. $~^{5}$

In Stille erfahren wir unsere Körperlichkeit. Auch beim Spielen des Instruments und beim Singen - aber in Stille vielleicht noch konzentrierter. Hier ist jeder ganz da und nur da, in seiner je eigenen körperlichen Existenz. Die existentielle Erfahrung des Verschwindens erfährt jeder, der es mit Musik zu tun bekommt, am eigenen Leib. Musikmachen, Hören, Komponieren verbrauchen Lebenszeit: Und im eigenen Da-Sein erfährt jeder, wie er nicht allein, sondern immer zugleich auch da ist, gemeinsam mit anderen in der Welt ist. Jede musikalische Praxis bedeutet die Erfahrung: Wir. Selbst die Praxis des Für-Sich-Allein-Seins im Solo (per se) ist eingebettet in Gemeinsamkeit. Musik - wozu? Wenn ich diese Frage stelle, kann es nicht um weniger gehen als um existentielle Erfahrung.

Beuger spricht nicht nur mehr oder weniger lange Pausen innerhalb eines Stücks an, sondern auch Stille vor und nach der Ausführung. ${ }^{6}$ Sobald ich den Musikraum verlasse, gelange ich mehr und mehr ins tägliche Leben hinein: Wann ist eine musikalische Situation zu Ende? Diese Frage ist gar nicht leicht zu beantworten, ist vielleicht ebenso vertrackt wie die Frage: Wo geht Musik, wo geht Klang hin - nach dem Aufhören? Jeder, der sich auf Musik einlassen will, kann dem Stück begegnen; aber eine Begegnung gibt es nur im Vorübergehen. Wir können die in musikalischer Praxis gemachten Erfahrungen ins Leben hineintragen, können, umgekehrt, von in musikalischer Praxis gemachten Erfahrungen so berührt werden, dass das Leben widerhallt. Wo ist die Schwelle zwischen Musikpraxis und (Alltags-)Leben?

3 | E.-M. Houben/I. Zelenka: 1 Milieu, S. 216.

$4 \mid$ A. Beuger/S. Vriezen: Asking questions, trying answers, S. 36; die folgenden Zitate ebd.

5 | Ebd.

6 | Vgl. E.-M. Houben: Hector Berlioz, S. 123-134. 
Musik - wozu?

Vielleicht lässt sich die Frage spezifizieren: Wozu Musik als Lebensform? Wir tun gemeinsam oder allein etwas für uns Sinnvolles mit Klängen; dies möchten wir dann wiederholen. Der Sinn erschließt sich über die Handlungen und Geschehnisse in ihrer Körperlichkeit und Sinnlichkeit und muss nicht verbalisiert werden. Wir verstehen Welt und verstehen einander auf nichtsprachliche Weise - im sinnhaften Tun, das auf Wiederholung ausgerichtet ist.

Musik - wozu? Diese Fragestellung kann auf Transparenz zwischen Musik und Leben vertrauen: Musik wird Lebensform und gibt etwas über das Leben zu erfahren, gibt etwas zu verstehen - im (für uns) sinnhaften Tun.

Wie wirklich sind musikalische Aktivität und musikalisches Geschehen? Gibt es zwei Welten, eine Welt des Alltags, des Lebens und eine Welt der Kunst, der Musik? Vollzieht sich musikalische Ausführung in einem abgeschlossenen ästhetischen Bereich? Oder agieren wir, mit Blick auf die Möglichkeit »künstlerischer Lebensform «7 , einmal diesseits, einmal jenseits einer mehr oder weniger hohen Grenze zwischen Musik und Leben? Wie wirklich ist Musik?

Musik - wozu? Diese Frage führt schließlich zu Musik als »Musik selbst ${ }^{8}$, die nicht durch Zeichen oder konkrete Klänge, nicht durch ihr Material oder ihre Strukturen, nicht durch Programmatik und verbale Verweisung Bezug nimmt, sondern durch Da-Sein der Menschen, Dinge und Klänge, durch Beziehung und Geschehen - an einem Ort, zu einer Zeit.

Die Zugänge im »Ersten Teil« zeichnen Wege nach, die zum Thema und zu den Untersuchungen geführt haben. Komponieren als Komponieren von Praktiken? Musizieren als Wahrnehmung einer bestimmten Praxis, die eine Komposition zum Angebot macht? Danach der Versuch, den Begriff der Musikalischen Praxis einzukreisen: Welche Schnittmengen, welche Brennpunkte wären zu nennen? Wie könnte die Frage nach der Grenze oder Schwelle zwischen Musizieren und Alltags- oder Lebenswelt (vorläufig) gestellt werden? Wie lässt sich über Erfahrungen, Erinnerungen und Hoffnungen, über Begegnungen und Beziehungen, die einem mitten im Musizieren, mitten in einer musikalischen Situation zufallen können, sprechen? Muss man überhaupt sprechen? Hier beginnt ein Weg der Sprachfindung: Zum Thema intersubjektiver Sinngebung eröffnen Alfred Schütz' Darstellungen zur Lebenswelt und zur sinnhaften Erfahrung sowie seine Unterscheidung »geschlossener Sinnbereiche« Möglichkeiten des Brückenschlags zwischen den Welten - zumal Schütz sich als Philosoph und Soziologe auch dem Thema »gemeinsamen

7 | K. Stockhausen: SPIRAL, S. 136.

8 | W. Rihm: ... zu wissen, S. 147. 
Musizierens« (Schütz) gewidmet hat. Vor dem Hintergrund des Ansatzes von Simone Mahrenholz wird metaphorische Redeweise vorgestellt und reflektiert. Obgleich Mahrenholz nicht explizit die Ausführenden in den Blick nimmt, trägt ihr Ansatz doch dazu bei, die Transparenz zwischen Musik- und Lebenswelt zur Sprache zu bringen.

Das Kapitel »Tasten« zu Beginn des »Zweiten Teils« führt über eine Beschreibung des körperlichen Zugangs zum Instrument zur Unterscheidung heterogener Spielsituationen. Im Anschluss daran werden weitere unterschiedliche Situationen musikalischer Praxis vorgestellt: das Musizieren allein (für sich, per se), im Duo, im Trio, im Quartett, das Musizieren im Ensemble von mehreren Spielern, von vielen Spielern, im Orchester. Es sind verschiedene Situationen, in die ich mich als Musiker hineinbegebe, in denen ich mich wiederfinde. Die beiden letzten Kapitel (»Über Grenzen hinaus« sowie »In der >Arche des Augenblicks«) verstehen sich als Ausblick.

Dieses Buch entstand auf der Grundlage langjähriger Gespräche mit Freundinnen und Freunden. Ihnen allen möchte ich an dieser Stelle für die Anregungen danken. Auch den Mitarbeitern an der TU Dortmund (Institut für Musik und Musikwissenschaft), die das Manuskript gelesen und bei der Erstellung der Abbildungen mitgewirkt haben, sei herzlich gedankt: Andreas Feilen, Gabriel Vishchers und Lucas Badouin. Aus dem Kreis der Freunde, die mich unterstützt haben, seien besonders Antoine Beuger und Istvàn Zelenka genannt: Antoine Beuger hat die Publikation durch kritische Nachfragen, Gespräche und wertvolle Hinweise auf Literatur und Musik gefördert, Istvàn Zelenka durch einen jahrelangen regen Gedankenaustausch und durch seine Komplizenschaft als Co-Autor bei den Publikationen »1 Milieu - ein Buch nicht nur zum Lesen« sowie »und/oder - 1 Sammlung«. 
Erster Teil 



\section{Zugänge}

\subsection{Eine musikalische Situation: TUN UND GeSchehen-LASSEN}

Eine Situation wie in einer stillen Bibliothek, jeder arbeitet so vor sich hin still, beschäftigt, ins Tun versunken. Eine musikalische Situation, Aufführung der Komposition Stones (1968) (aus Prose Collection) von Christian Wolff:

"Klänge mit Steinen, aus Steinen erzeugen, dabei verschiedene Größen und Arten (und Farben) verwenden, meist für sich allein stehend, manchmal aber auch in schneller Abfolge. Zumeist Stein auf Stein schlagen, aber auch Stein auf andere Oberflächen (zum Beispiel im Inneren einer offenen Trommel) oder anders als geschlagen (zum Beispiel gestrichen oder verstärkt). Nichts zerbrechen." ${ }^{1}$

Jeder Einzelne ist für sich und zugleich inmitten der anderen Ausführenden. Der Ort: ein Platz, an dem man sich aufhält. Ein Ort zum Handeln - aber auch ein Ort, der zum Da-Sein, zum Still-Werden einlädt. Die Beteiligten begeben sich in eine Situation und einen Prozess hinein, durchleben gemeinsam eine gewisse Zeit: üben eine Praxis aus, in der sie Sinn erfahren und die sie wiederholen möchten. Die Praxis diesmal: Jemand mitten unter vielen anderen zu sein, die auch da sind, und dieses Auch-Da-Sein klanglich zum Ausdruck zu bringen. Mehr als durch Kommunikation ist diese Situation von Koinzidenz geprägt. Die Situation: Man lässt einander Raum - und sucht eben nicht den Kontakt. Hingabe an eine stille Tätigkeit, Sensibilität für die stille Situation inmitten (vieler) anderer, die einer ähnlichen Beschäftigung nachgehen. Nicht nur die Tätigkeit, »mit Steinen, aus Steinen [Klänge] zu erzeugen«, prägt diese Situation und dieses Miteinander der Teilnehmenden, sondern auch das StillWerden. Diejenigen, die gerade nichts tun, sind einbezogen durch ihr körperliches Da-Sein. Interaktionsprozesse werden seitens der Partitur nicht nahegelegt. Dass hier eine bindende Kommunikationsstruktur fehlt, charakterisiert speziell diese Praxis.

1 | Chr. Wolff: Stones, aus: Prose Collection, in: Ders., Cues, S. 464-481, hier S. 471. 
Die Sammlung von verbalen Aufführungsanweisungen Prose Collection, zu der Stones gehört, entstand in den Jahren 1968 bis 1974, zur Zeit der Entstehung des Ensembles Scratch Orchestra, und hatte zunächst den Zweck, dass auch Personen ohne spezielle Ausbildung an einer Aufführung teilhaben konnten. ${ }^{2}$ Das Scratch Orchestra wurde von Cornelius Cardew zusammen mit Howard Skempton und Michael Parson initiiert (1969): ein Orchester, das sich aus Komponisten und Künstlern unterschiedlicher Sparten, auch aus Amateuren und Laien zusammensetzte. »Es waren musikalische >Randfiguren sozusagen (ich benutze diesen Ausdruck nicht so gerne), ausgefallene Leute, die nicht in das sogenannte normale Musikleben passten, für die das nicht das Wichtigste war. ${ }^{3}$

Wolff hatte die Idee zu Stones bei einem Strandspaziergang:

"Der Ursprung von 'Stones` war aber einfach der, daß ich eines Tages an einem steinigen Strand ausprobierte, wie verschiedene Steine klingen, wenn man sie gegeneinander schlägt, und entdeckte, daß sie (die Klänge) hinsichtlich ihrer Resonanzqualitäten erstaunlich vielseitig, charakteristisch (und schön) sind. In Erinnerung daran schrieb ich dieses Stück ein halbes Jahr später und zeigte es Cornelius Cardew, der mir daraufhin schmunzelnd den Paragraph I von 'The Great Learning، zeigte, an dem er gerade arbeitete. In diesem Stück sollen die Choristen Steine benutzen, um Klanggesten nach chinesischen Schriftzeichen des Textes von Konfuzius zu improvisieren, die er in seinem Stück vertont hatte. Auf diese Idee war er durch den Gebrauch gestimmter Steinplatten in der klassischen chinesischen Musik gekommen." ${ }^{4}$

Eine Aufführung von Stones kann den Ausführenden die Erfahrung vermitteln, einer unter vielen, einer inmitten vieler anderer zu sein. Die Praxis wird gekennzeichnet durch einen Ort des gemeinsamen Tuns und durch eine gemeinsam durchlebte Zeit, in der Erfahrungen gemacht werden, die sich mit den Lebenserfahrungen jedes Einzelnen verbinden.

In einer musikalischen Situation wie dieser wird eine Welt erschaffen, die zu uns gehört und Teil unseres Lebens werden kann. Es wird also nicht die eine oder andere Interpretation einer Komposition erarbeitet, sondern eine Komposition wird daraufhin befragt, zu welcher Praxis sie Gelegenheit bietet.

2 | Chr. Wolff: Stones (1968), Werknotiz, in: Ders., Cues, S. 494-497, hier S. 497.

3 | Chr. Wolff, zitiert in: E.-M. Houben: immer wieder anders, S. 27.

4 | Chr. Wolff: Stones (1968), Werknotiz, S. 497; vgl. Chr. Wolff: What Is Our Work? On experimental music now, in: Ders., Cues, S. 210-231, hier S. 213. 


\title{
1.2 MusiK - WOZU? ANgesichts
}

\author{
WARUM AUCH? \\ Als nun ein solcher klarer \\ Tag hastig wieder kam, \\ sprach er voll ruhiger, wahrer \\ Entschlossenheit langsam: \\ Nun soll es anders sein, \\ ich stürze mich in den Kampf hinein; \\ ich will gleich so vielen andern \\ aus der Welt tragen helfen das Leid, \\ will leiden und wandern, \\ bis das Volk befreit. \\ Will nie mehr müde mich niederlegen; \\ es soll etwas \\ geschehen; da überkam inn ein Erwägen, \\ ein Schlummer: ach, laß doch das.
}

Musik - wozu? Warum auch? Diese Frage bestimmt den Ausgangspunkt aller nachfolgenden Überlegungen. »Warum auch?« Dieses Gedicht von Robert Walser ${ }^{5}$ berührt das Umfeld, in dem sich eine Beschäftigung mit der Frage nach dem Stellenwert und dem Charakter musikalischer Praxis lohnt. Mit der Offenheit des Schlusses ist eine Verlängerung des letzten Satzes angedeutet: »ach, lass doch das (werden) $\ll^{6}$, »ach, lass doch das (geschehen)«. Nicht umsonst wurde das Wort »geschehen« isoliert und als erstes Wort für sich in die vorletzte Zeile gestellt. Es gibt immer Grund genug, einzugreifen, etwas zu tun, »voll Entschlossenheit« - und es gibt immer wieder das Lassen, das Vertrauen auch ins (Geschehen-)Lassen. Das Gedicht bewegt sich zwischen Veränderung-Bewirken und »(Geschehen-)Lassen«. Ein Sich-Bescheiden ist herauszuhören, ein Sich-Gemeinsam-Bescheiden. Das Gedicht ist kein Aufruf zum Nichts-Tun, es sagt keinesfalls: Lass davon ab, irgendetwas zu tun. Es laviert vielmehr zwischen einem Veränderungswillen und einem Lassen, das nicht nur passivisch auftritt, sondern ein Sehnen und Hoffen weiterträgt: Hoffnung darauf, dass eine Praxis Veränderung bewirkt.

Das Gedicht steht dazwischen: zwischen dem Willen zur Veränderung aus dem Verlangen heraus, dass etwas passiert (angesichts des Leides, des Unrechts in der Welt), und der Hoffnung auf Wandel. So beschreitet das Gedicht den schmalen Grat zwischen Tun und Geschehen-Lassen: Ach, lass doch das (geschehen/werden).

5 | R. Walser: Gedichte und Dramolette, S. 9.

6 | Vgl. E.-M. Houben/I. Zelenka: und/oder - 1 Sammlung, S. 118. 
Immer angesichts dessen, was ist, treibt es die Tätigen zum Handeln. Sie sagen: Wir tun dies angesichts existentieller Grundsituationen, angesichts des Zustands der Welt, angesichts der Kriege und Hungersnöte, angesichts konkreter Ängste. Was war? Ein Feld von Katastrophen. Walter Benjamin hat, angeregt durch ein Bild von Paul Klee (Angelus Novus), den »Engel der Geschichte beschrieben, einen Engel, der mit dem Rücken zur Zukunft hin geht, also rückwärts, und, das Gesicht der Vergangenheit zugewandt, auf eine Geschichte von Katastrophen blickt. Er kann die Trümmer nicht kitten, die Wunden nicht heilen, auf die er blickt, ein Sturm weht vom Paradiese her und treibt ihn unerbittlich voran:

"Es gibt ein Bild von Klee, das Angelus Novus heißt. Ein Engel ist darauf dargestellt, der aussieht als wäre er im Begriff, sich von etwas zu entfernen, worauf er starrt. Seine Augen sind aufgerissen, sein Mund steht offen und seine Flügel sind ausgespannt. Der Engel der Geschichte muß so aussehen. Er hat das Antlitz der Vergangenheit zugewen-

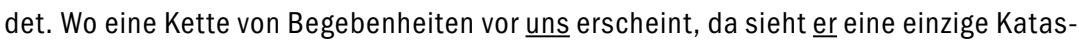
trophe, die unablässig Trümmer auf Trümmer häuft und sie inm vor die Füße schleudert. Er möchte wohl verweilen, die Toten wecken und das Zerschlagne zusammenfügen. Aber ein Sturm weht vom Paradiese her, der sich in seinen Flügeln verfangen hat und so stark ist, daß der Engel sie nicht mehr schließen kann. Dieser Sturm treibt inn unaufhaltsam in die Zukunft, der er den Rücken kehrt, während der Trümmerhaufe vor inm zu Himmel wächst. Das, was wir den Fortschritt nennen, ist dieser Sturm. " ${ }^{7}$

\section{Musik? Warum auch?}

Das Gedicht regt denjenigen, der von hier aus auf die musikalische Praxis blickt, zum Weiterfragen an. Denn Fragen nach dem Wie oder Was einer Komposition, nach der Art und Qualität einer Interpretation, nach einem wie auch immer gearteten Verstehen gehen nicht weit genug, wenn es um musikalische Praxis geht.

Wer »Musik als existentielle Erfahrung« (Lachenmann) betrachten möchte, fragt immer auch nach der musikalischen Praxis, die empfänglich machen könnte für Sehnsüchte und Hoffnungen, für all die kostbaren Augenblicke auch, in denen der Blick hinaus auf Wirklichkeiten und Möglichkeiten gelingt, die auch Teil unseres Lebens sind: So sind wir auch; so könnte es auch zugehen. Helmut Lachenmann macht den Sinn von Musik an der Kraft zur Hinausweisung fest: »Musik hat Sinn doch nur, insofern sie über die eigene Struktur hinausweist auf Strukturen, Zusammenhänge, das heißt: auf Wirklichkeiten und Möglichkeiten um uns und in uns selbst. « ${ }^{8}$ »Ich sehe keinen anderen Sinn der Musik als den, übers klingende Erlebnis, über die eigene

7 | W. Benjamin: Über den Begriff der Geschichte, S. 9, 19-20; Herv. i.0.

8 | H. Lachenmann: Vier Grundbestimmungen des Musikhörens, S. 62. 
Struktur hinauszuweisen auf Strukturen, das heißt auf Wirklichkeiten, und das heißt: auf Möglichkeiten um uns und in uns selbst.«?

Doch: Aufstände gegen Diktaturen, Revolutionen, weltweiter Klimaschutz, Eindämmung des Hungers in der Welt, Sensibilisierung gegenüber Unrecht - über musikalische Praxis? »Dass Komponisten sich so etwas zutrauen, ist ein Relikt des unbewältigten neunzehnten Jahrhunderts, wo dem Künstler als Propheten im Sinne des Wagnerschen Genie- und Ausdruckskults so etwas zugesprochen wurde. $\ll^{10}$ Lachenmann findet hier klare Worte. »Karl Kraus, der etwas davon verstand, nannte derlei Unternehmungen in Bezug auf Hitlers Machtergreifung >in den Krater spucken<.« So schrieb Karl Kraus in »Die Dritte Walpurgisnacht«, entstanden 1933:

"Wenn es das Element nun insbesondere auf die Offenbarung unfreundlichen Denkens abgesehen hätte, ja auf den Anschein des Denkens überhaupt, so wäre der nicht feigherzig, der sich der Mahnung fügte, nicht in den Krater zu spucken, um sich andere Pläne vorzubehalten. "11

Vielleicht lässt sich die Frage anders stellen: Welchen Sinn ergibt eine musikalische Praxis für uns angesichts einer bestimmten Weltsituation? Für was will sie (uns) begeistern? - wofür eintreten? - was bejahen? - an was erinnern? - auf was hoffen?

In seiner Auseinandersetzung mit John Cage schreibt Hans Heinrich Eggebrecht: »[B]leibt Kunst als Utopie einer Gleichsetzung von Leben und Kunst nicht gerade deshalb vom Leben getrennt, weil das Leben so noch nicht ist? «12 Die Frage nach dem Wozu impliziert die Frage nach einer näheren Bestimmung des Verhältnisses von Lebens- bzw. Alltagswelt (auch Weltgeschehen) und Welt der musikalischen Praxis. Lässt auch die Frage nach Macht und Machtlosigkeit musikalischer Praxis nicht aus. Trennung der Welten? Gleichsetzung? - Hinausweisung (aus der einen auf die andere)? - also doch Möglichkeiten der Bezugnahme? Diese Fragen werden die Beschäftigung mit musikalischer Praxis begleiten. Deutlich wird aber an dieser Stelle schon: Die Frage nach dem Wozu einer musikalischen Praxis kann nicht die Frage nach ihrer Zweckdienlichkeit sein. Die Praxis ist kein Tun auf etwas hinaus, sondern eines, das ohne definitiven Abschluss bleibt, von daher immer neu auf Zukünftiges aus ist.

9 | H. Lachenmann: Nono, Webern, Mozart, Boulez, S. 278.

10 | H. Lachenmann: Komponieren am Krater, S. 3; das folgende Zitat ebd.

11 | K. Kraus: Die Dritte Walpurgisnacht, S. 10.

12 | H. H. Eggebrecht: Musik verstehen, S. 208. 


\section{3 (Er-)Finden von Praktiken}

\section{Cornelius Cardew: Sextet - The Tiger's Mind (1967)}

Cornelius Cardew ist an sozialen Situationen interessiert, verfolgt die Fragen: Was passiert unter Menschen? Was wird getan, ist zu tun? Er erzählt eine Geschichte, die unterschiedliche Rollen aufgreift; diese können in bestimmten sozialen Strukturen eingenommen werden. Cardew gibt mit dieser Komposition den Anstoß, die Vorlage in unterschiedliche mögliche Richtungen weiter zu entwickeln.

\section{"Daypiece}

The tiger fights the mind that loves the circle that traps the tiger. The circle is perfect and outside time. The wind blows dust in tiger's eyes. Amy reflects, relaxes with her mind, which puts out buds (emulates the tree). Amy jumps through the circle and comforts the tiger. The tiger sleeps in the tree. High wind. Amy climbs the tree, which groans in the wind and succumbs. The tiger burns.

\section{Nightpiece}

The tiger burns and sniffs the wind for news. He storms at the circle; if inside to get out, if outside to get in. Amy sleeps while the tiger hunts. She dreams of the wind, which then comes and wakes her. The tree trips Amy in the dark and in her fall she recognizes her mind. The mind, rocked by the wind tittering in the leaves of the tree, and strangled by the circle, goes on the nod. The circle is trying to teach its secrets to the tree. The tree laughs at the mind and at the tiger fighting it. " ${ }^{13}$

Die Partitur trägt die Hoffnung auf Ausführung als »kontinuierlichen Prozess « weiter: »Interpretation of this piece is to be viewed hopefully as a continuous process. ${ }^{14}$ Damit ist die Praxis der Ausführenden in den Mittelpunkt gerückt, die sich verschiedenen Situationen aussetzen. Auch eine Transparenz zwischen ästhetischer Welt und Alltagswelt ist in den Blick gekommen. Weitere Hinweise: Die beiden Teile »Daypiece« und »Nightpiece« sollten bei wechselnden Gelegenheiten aufgeführt werden, den Ausführenden wird empfohlen, sich den Text einzuprägen; neue, nicht ausdrücklich genannte Aktionen und Situationen können hinzukommen; sogar neue Texte könnten - nach einiger Erfahrung mit der Ausführung - entstehen; selbst die Anzahl der Mitmachenden (im Sextett sind es Amy als Person, The tiger als Tier, The tree, Wind, The circle und The mind) kann sich vergrößern oder verkleinern. Die Anmerkungen bezüglich der Charakteristik der Sechs sind laut Partitur lose zu ver-

13 | C. Cardew: Sextet - The Tiger's Mind, Partitur, S. 1, (C) Peters Edition Ltd, London. Abdruck mit freundlicher Genehmigung C.F. Peters Ltd \& Co. KG, Leipzig.

14 | Ebd., S. 2; das Folgende ebd. 
stehen: »The following notes on the six characters are not limiting or definitive. They are intended primarily to encourage and assist prospective performers in the assumption of their roles.« Eine Komposition also, die sich selbst als unabgeschlossen versteht und Prozesse in Gang setzen will; die dazu ermuntert, in einer Aufführung bestimmte Beziehungen zueinander zu leben. ${ }^{15}$

Die wohl bekannteste Komposition Cardews sind die sieben »Paragraphen« The Great Learning, die zwischen 1968 und 1970 entstanden. Jeder ist für eine spezifische Besetzung geschrieben, immer handelt es sich um eine relativ große Gruppe von Ausführenden, zum Teil von unausgebildeten Musikern. Musikstück und soziales Geschehen sind eins geworden.

\section{Istvàn Zelenka: "und an 5 frei gewählten aufeinander folgenden Tagen " - für 1 Pianistinten (2008)}

Istvàn Zelenka schlägt mit jeder neuen Komposition eine bestimme Praxis vor - für einen »per se« Agierenden, für zwei, drei usw. - für viele. Mit dieser Komposition - der Titel in voller Länge lautet: und an 5 frei gewählten aufeinander folgenden Tagen, zu 5 unterschiedlichen, eigenständig bestimmten Tageszeiten zwischen Frühmorgen und Spätabend, spielen Sie per se pro Tag je eine der 5 Sequenzen dieser Komposition mit beliebiger Reihenfolge der einzelnen Seiten «-wird die Beschäftigung ganz in den Lebensalltag des Ausführenden hereingeholt. ${ }^{16}$

Die fünf Sequenzen, die an fünf Tagen in freier Reihenfolge gespielt werden können, dauern jeweils 20 Minuten und 20 Sekunden und sind mit Stoppuhr zu spielen. Die Anzahl der zu spielenden Klänge schwankt erheblich: Eine Sequenz enthält sieben Klänge, eine fünf, eine enthält drei Klänge, eine zwei, und eine enthält nur einen einzigen Klang (vgl. Abb. o1).

Wer dies praktiziert, widmet sich einem Tun, bezweckt nicht die Einstudierung einer zum Vortrag bestimmten Komposition. Die Wiederholung ist der Ausführungsanweisung, die hier bereits in den Titel eingeflossen ist, eingeschrieben: Man pflegt diese Praxis »an 5 frei gewählten aufeinander folgenden Tagen, zu 5 unterschiedlichen, eigenständig bestimmten Tageszeiten zwischen Frühmorgen und Spätabend«. Durch die Wiederholung entsteht Kontinuität. Die »Beschäftigung « ${ }^{17}$ mit dieser Komposition wird durch allerhand (Alltags-) Geschäfte unterbrochen, aber nicht empfindlich gestört oder gar beendet. Der Lebensalltag öffnet sich für die musikalische Praxis. Und: Man spielt ein jedes

15 | Wie offen die Partitur sich verstehen lässt, zeigt auch ein Filmprojekt von Beatrice Gibson.

16 | Vgl. E.-M. Houben/I. Zelenka: 1 Milieu, S. 225-230; Herv. i.0.

17 | I. Zelenka: "Beschäftigung mit: JA»; "Produktion von: NEIN«; E.-M. Houben/I. Zelenka: und/oder, S. 128, 133. 
Mal für sich allein und widmet sich in diesen Minuten der ausgewählten Sequenz, gibt sich ganz dieser Beschäftigung hin.

Abbildung o1: Istvàn Zelenka: »und an 5 frei gewählten aufeinander folgenden Tagen ... « für 1 Pianistinten (2008) (Ausschnitt)

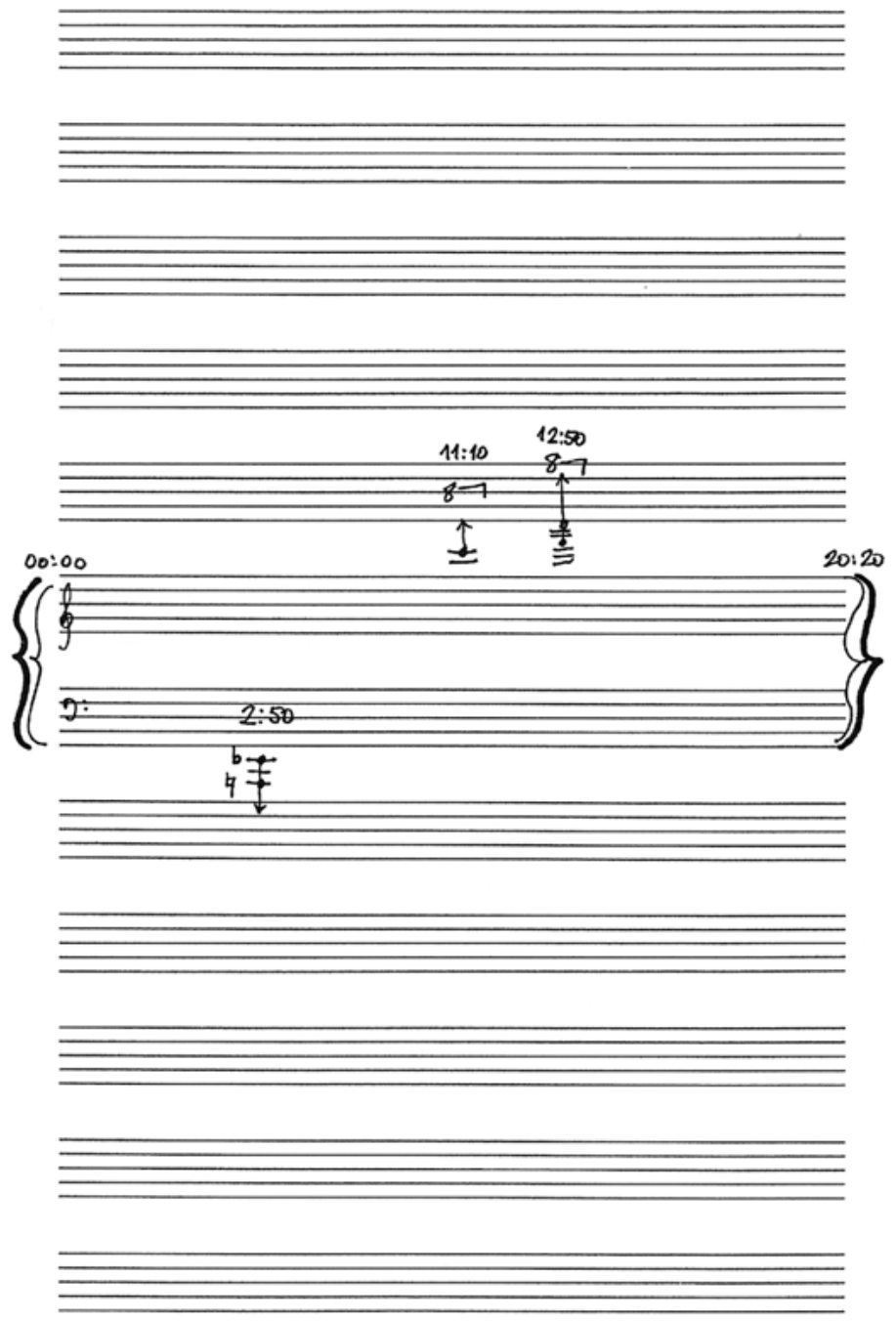

Manuskript; mit freundlicher Genehmigung des Komponisten 


\section{Antoine Beuger: gentle traces of transient being for 10 players (2016)}

Antoine Beuger hat bislang vier Kompositionen geschrieben, die von einem Text begleitet werden, der eine bestimmte Praxis beschreibt; Autor dieser Texte ist eine fiktive Person namens RN. Diese Texte sind für die Ausführenden bestimmt, ein Publikum wird nicht notwendigerweise mit ihnen bekannt gemacht. Die vier Stücke in chronologischer Reihenfolge: desert into dwelling place for seven players (2014); modes of dispossession, levels of affinity for string quartet (2014); ... of being numerous for a number of players (2015); gentle traces of transient being for 10 players (2016). Auch die Partitur von gentle traces of transient being verweist auf die fiktive Quelle: »this piece is strongly inspired by (if not an attempt to reconstruct) a musical practice called GENTLE TRACES OF TRANSIENT BEING, hitherto unknown, but documented in >The memories of $R N<. \ll^{18}$

»The memories of $\mathrm{RN} \ll$ : ein Text, der zur Partitur gehört und den Ausführenden Hinweise zur Aufführungspraxis gibt, die sich in einer herkömmlichen Ausführungsanweisung kaum unterbringen lassen, werden doch mehr Haltungen des Spielens und Hörens, Situationen, Interaktionen beschrieben. In gentle traces of transient being wird die Praxis verfolgt, kleine, unscheinbare Phrasen zu singen, zu spielen. Zu Beginn waren es - dem fiktiven Text aus »The memories « of $\mathrm{RN}$ « folgend - nur wenige, die mitmachten (von dreien ist die Rede), im Laufe der Zeit beteiligten sich immer mehr (bis zu zehn).

"Our phrases were nothing special, not at all meant to be surprising or impressive.

Just a few tones, just occurring, just little moments, disappearing as gently as they appeared.

Humble phrases, nothing grand or deliberately novel.

The charm, the beauty, the grace of these ephemeral moments, of these modest phrases, was only in their transient being, in their passing.

Their beauty was in their humility: the less they would insist on permanence, the more their passing would be touching.

A non-insisting, short-lived existence, diffusing grace, bestowing beauty, only by passing through our garden."

Die Ausführenden, in einem stillen und ruhigen Raum sitzend, sind die meiste Zeit über still und werden zu Hörern: »Each of us would most of the time just be silent and listen.« Die Partitur enthält mehrere Seiten, die in freier Anzahl gespielt werden können. Eine Seite besteht jeweils aus fünf Phrasen, jede Phrase gibt entweder einem oder zwei oder drei Spielern Gelegenheit, einen

18 | A. Beuger: gentle traces, Partitur; die folgenden Zitate ebd.; Herv. i.0. 
oder zwei oder drei oder vier Töne (nicht mehr) zu singen oder zu spielen. Die Tonhöhen, Tondauern und Einsätze der Töne sind frei. Bei zehn Ausführenden, die singen oder ein Instrument spielen, bleiben demnach pro Phrase sieben, acht oder neun still.

Die Abbildung zeigt, dass hier die erste Phrase Spieler 5 Gelegenheit gibt, einen Ton zu spielen; in der zweiten Phrase übernehmen Spieler 1 drei Töne, Spieler 2 einen Ton, Spieler 3 vier Töne; in der dritten Phrase treten Spieler 6, 9 und 10 mit einem Ton, wiederum mit einem Ton, mit drei Tönen auf - und so fort (vgl. Abb. 02).

Abbildung 02: Antoine Beuger: gentle traces of transient being for 10 players (2016), S. 5

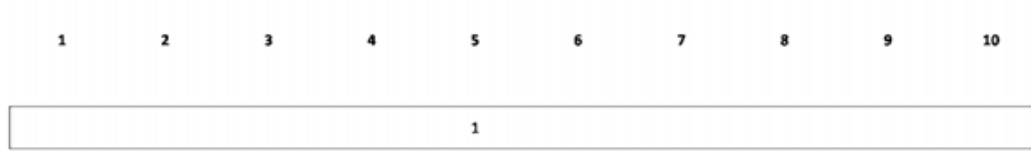

ew01.177; mit freundlicher Genehmigung der Edition Wandelweiser, Haan 2016

Diese Komposition ist eine Einübung in Aufmerksamkeit für Vergängliches und Unscheinbares - eine Friedenspraxis, wie sie Gisela Nauck beschreibt:

"Eine Musik an den Rändern der Wahrnehmung zeigt den Wert solcher kleinen, unscheinbaren demütigen Dinge [...]. Durch solche grundsätzlich anderen kompositorischen Herangehens- und Handlungsweisen verändert sich entscheidend das, was Musik sein - und bewirken kann. Gesten von Aggression, Bedrohung, Gewalt oder Herrschaft sind überhaupt nicht erst möglich. “19

19 | G. Nauck: "Es darf keine Siege mehr geben ...", S. 118. 
Eine Ausführung von gentle traces of transient being ist für die Zeit der Aufführungsdauer eine Wirklichkeit, in der »kleine, unscheinbare demütige Dinge« ihren Platz haben dürfen (»just a few tones, just occurring, just little moments « - wie es in den »memories of $\mathrm{RN} \ll$ heißt). Diese musikalische Wirklichkeit kann immer wieder neu entstehen - denn Praxis heißt ja: etwas immer wieder tun. Die Wiederholung entwickelt eine Praxis.

\section{Brian Ferneyhough: Time and Motion Study II for Solo 'Cello and Electronics (1973-1976)}

Die Entscheidung, diese Komposition zu spielen, ist die Entscheidung für eine ganz bestimmte Praxis. Der Ausführende weiß, dass er sich selbst in eine Ecke treiben lassen will, in der ein Gewinn, ein Überschuss erzielt werden soll. Er setzt sich diesem Prozess aus - mit Lust daran, eine Subjektivität aufzubauen, die sich den Zumutungen des Stückes stellt, diesen standhält.

Ferneyhough weist darauf hin, wie wichtig ihm der Titel einer Komposition ist. ${ }^{20}$ Hier bezieht sich der Titel auf Forschungen zur Effizienz von Fabrikarbeit. Untersucht wurden Arbeitsprozesse und Bewegungen, um die Effizienz zu steigern und Arbeitsabläufe zu optimieren. Detaillierte Studien von Produktionsabläufen zwecks Optimierung der Produktion gehen auf Frederick Winslow Taylor (1856-1915) zurück (Taylorismus).

»Electric chair music«: Der inoffizielle Untertitel der Komposition ist ein erster Hinweis auf den außerordentlichen Druck, dem sich der Ausführende aussetzt. Der Spieler ist von Mikrofonen umgeben, eines ist sogar an einem Band um den Hals befestigt. Es gibt einen genauen Plan für die Aufstellung der elektronischen Geräte (»Electric Circuit Plan«): »At least two assistants are required for the electronics, preferably in the direct field of vision of soloist. A third assistant could be useful for the regulation of overall balance. $\ll^{21}$

Absichtlich ist die Partitur mit Anweisungen überladen, denen nie gänzlich gerecht zu werden ist; verbale Hinweise machen ein zusätzliches Angebot: »schizophrenic: L. H. [left hand - linke Hand] hysterical. R. H. [right hand - rechte Hand] as though sleepwalking «; »suddenly withdrawn, childlike: becoming increasingly reflective«; »like exploding fireworks«; »suddenly extremely aggressive «, »like machine-gun fire ${ }^{22}$ Gegen Schluss (vgl. Abb. 03) heißt es: »with the utmost imaginable degree of violence«.

20 | Optic Nerve_Music_Ferneyhough_2 Electric Chair Music. A documentary on Brian Ferneyhough's avant-garde composition ,Time \& Motion Study Ilı for cello \& electronics. https://www.youtube.com/watch?v=sykB4znEk2Q vom 21.11.2016. Der Untertitel und die folgende Beschreibung nach dieser Aufnahme.

21 | B. Ferneyhough, Time and Motion Study II, Partitur.

22 | Ebd., S. 4, 7, 8, 9; das folgende Zitat ebd., S. 19. 
Abbildung 03: Brian Ferneyhough: Time and Motion Study II for Solo 'Cello and Electronics (1973-1976), S. 19

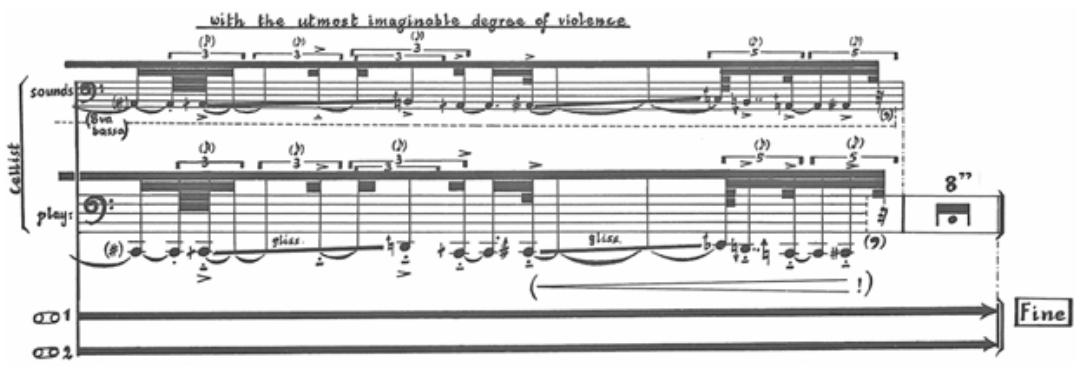

(C) C.F. Peters Edition Ltd, London. Abdruck mit freundlicher Genehmigung C.F. Peters Ltd \& Co. KG, Leipzig

Am Ende kollabiert der Spieler:

"After suddenly ceasing his frenetic playing activity the cellist should freeze - completely motionless - in his final playing position. This is held for the entire length of the pause. In a live performance the electronic equipment is turned off at the end of the pause with an audible ,click in the loudspeakers. This is the signal for the cellist to 'collapse , from his rigid posture, as though also 'switched off،. In a recorded performance the 8 "'-pause is retained, but the click omitted. ${ }^{23}$

Der Ausführende soll nach dem hörbaren Ausschalten der elektronischen Geräte in sich zusammenfallen - »als ob er auch >ausgeschaltet< worden wäre«. Eine »Etude d'exécution transcendante ${ }^{24}$ also als Exekution? Ein Als-Ob-Kollaps? - oder ein wirklicher? Nach der Ausführung wird der Spieler ohne Schaden das Podium verlassen. Was also ist geschehen?

Und warum? Im letzten Viertel etwa gibt es ein weit gespanntes Adagio: » Gran Adagio<: with passionate dedication and self-transcendence $« .{ }^{25}$ Dieser Hinweis auf »Selbst-Überschreitung « steht für viele Handlungen ein und gibt deren Zielrichtung an. Nahezu alle Kompositionen Ferneyhoughs schlagen Praktiken vor, die zur Überschreitung (der je eigenen Grenzen, der bislang bekannten Möglichkeiten) führen können, sie sind Einladungen zum Überschreiten (transcendere). ${ }^{26}$

23 | Ebd., S. 19.

24 | Etudes d'exécution transcendante: Titel eines Klavierwerks von Franz Liszt.

25 | B. Ferneyhough, Time and Motion Study II, Partitur, S. 16.

26 | Ferneyhoughs Komposition Etudes Transcendantales for soprano and chamber ensemble (1982-1985) führt den Hinweis auf eine solche Praxis im Titel. 
Die Notation ist ein »Labyrinth«, ein »Kampfplatz« (»area of struggle«), will eine Herausforderung sein (»enormous challenge«); der Ausführende wird aufgefordert, immer noch härter zu arbeiten (»to work harder«). ${ }^{27}$ Ferneyhough spricht in der Dokumentation sogar von »einer Art von berauschender Versenkung in totale Negation, welche eine Art von Erhabenheit« hervorrufe (»a sort of exhilarating emersion in total negation which produces a sort of sublimity«).

Wenn diese »totale Negation« nicht wirklich, sondern, offenbar weniger ernst zu nehmen, nur in der Musik stattfindet, wenn die Aufforderung zu fast unvorstellbarer »Gewalt« (»with the utmost imaginable degree of violence«) nicht wirklich, sondern (unernst und eher ironisch) lediglich musikalisch gemeint ist, wenn dieser Tod auf der Bühne (»as though also >switched off««) nicht wirklich geschieht, sondern gemimt wird: Ist dann eine Überschreitung, so sie denn zufiele, auch nicht wirklich - bloß musikalisch?

\section{4 ÜBEN: EXERCISES}

Um die Erfahrung von »Sinn« geht es Helmut Lachenmann - und um ein »Hinausweisen« der Musik von eigenen, musikimmanenten Strukturen »auf Wirklichkeiten und Möglichkeiten um uns und in uns selbst. « ${ }^{28}$ Ein Schlüsselbegriff für eine Beschreibung dessen, was »Musik als existentielle Erfahrung« bedeuten und verheißen könnte, ist der Begriff der »Struktur«, der »Klangstruktur«, des »Strukturklangs«. Im »Hinausweisen« liegt die verändernde Kraft.

Lachenmann erläutert anhand unterschiedlicher musikalischer Beispiele aus verschiedenen kulturhistorischen Zusammenhängen, was er unter »Struktur«, »Strukturklang« versteht. Der »Strukturklang« entfaltet sich als Klangprozess im Laufe einer gewissen Zeit, wobei sogar eine ganze Komposition oder ein ganzer Satz als ein großer Strukturklang wahrgenommen werden kann, der vom Hörer mit den Ohren »abgetastet« wird; Lachenmann greift auf diese Metapher des »Abtastens « mit dem Ohr zurück, wodurch deutlich wird, wie bei dieser Art von Hören Klang und Form vermittelt sind:

Wener Terminus Strukturklang [...] geht von einer Klangvorstellung aus, die - eben als mehrdimensionales Gefüge von Anordnungen - sich nicht als platter akustischer Reiz schnell mitteilt, sondern sich vielmehr erst allmählich erschließt in einem vielschichti-

27 | Optic Nerve_Music_Ferneyhough_2 Electric Chair Music, a.a.0.; das folgende Zitat ebd.

28 | H. Lachenmann: Vier Grundbestimmungen des Musikhörens, S. 62. 
gen, vieldeutigen Abtastprozess an der vorüberziehenden Konstruktion mit ihren charakteristisch aufeinander bezogenen Klangkomponenten. “29

In diesem Zusammenhang geht er auch auf den ersten Satz aus Beethovens Streichquartett Nr. 10 Es-Dur op. 74, das sogenannte »Harfenquartett« ein, wobei seine Analyse nicht mit der langsamen Einleitung, sondern mit dem Allegro (Takt 25ff.) beginnt. ${ }^{30}$ Lachenmann rückt an dieser Stelle eine ihm vertraute Perspektive in den Vordergrund, wodurch der Quartettsatz neu beleuchtet wird: Klänge bestimmen sich selbst neu in der Wahrnehmung durch den Zusammenhang, in den sie gestellt wurden. Mit den Worten Lachenmanns:

"Als strukturelle Erfahrung aber orientiert sich Hören nicht allein positivistisch an der Beschaffenheit des klingenden Objekts, sondern präzisiert sich an der Zuordnung dieses Objekts in seiner Umgebung. Die Wahrnehmung des Klingenden verengt und erweitert sich zugleich durch die Beziehungen, die sich zwischen inm und seiner näheren und ferneren Umgebung in Zeit und Raum entfalten, anders gesagt: Hören nimmt - bewußt und unbewußt - anhand des Klingenden zugleich Zusammenhänge wahr«. ${ }^{31}$

»Zusammenhänge« und »Beziehungen«: Lachenmann zeichnet die Strukturen der Musik nach, wie sie sich in einer Partitur niederschlagen und vom Hörer »abgetastet« werden.

Eine andere Perspektive auf dasselbe Stück eröffnet sich, wenn man das Tun der Ausführenden in den Blick nimmt. Die Ausführenden sind es schließlich, die Beziehungen stiften, musikalischen Zusammenhang in etwas Klingendes verwandeln. Zusammenhang entsteht - vergänglich zwar, doch von großer Resonanz. Musik wird »existentielle Erfahrung« (Lachenmann) zuerst für die Spieler.

In Beethovens Quartettsatz sind viele Orte der Interaktion und Tätigkeiten zu entdecken. Unterschiedliche Orte im Quartett könnten spezielle Übungen aus den »Exercises for String Quartet« von Mogens Heimann zugeordnet werden. Heimann konzentriert sich in diesem Übungsbuch auf das Streichquartett, die Akzente in seinen Übungsvorschlägen liegen auf Intonation (im Zusammenspiel bei Akkorden, bei Leittönen und Modulation), rhythmischer Präzision/Zusammenspiel, dynamischen Abstufungen, Rhythmus in Bezug auf die Notation der Tondauern (bei Kontrasten etwa), Phrasierung, Tonbildung und Tempo.

29 | H. Lachenmann: Klangtypen der Neuen Musik, S. 123.

30 | Vgl. H. Lachenmann: Hören ist wehrlos - ohne Hören, S. 118-121; hier auch Analysen zum vierten aus Anton Weberns Fünf Stücken für Orchester op. 10 und zu eigenen Werken: Air, Fassade, Tanzsuite mit Deutschlandlied.

31 | Ebd., S. 118. 
Aus diesem Blickwinkel kann der Übergang zur Reprise in Beethovens »Harfenquartett« (vgl. Abb. o4a), isoliert für sich betrachtet, für Violine 1, Viola und Violoncello eine Übung im Zusammenspiel werden - als spiele ein einziges Instrument (vgl. Abb. o4b) (»Unity of Execution«): »no break, should be played as one instrument $\ll^{32}$, Continuity $\ll^{33}$.

Abbildung 04a: Ludwig van Beethoven: Streichquartett Nr. 10 Es-Dur op. 74, 1. Satz, Takte $125-138$
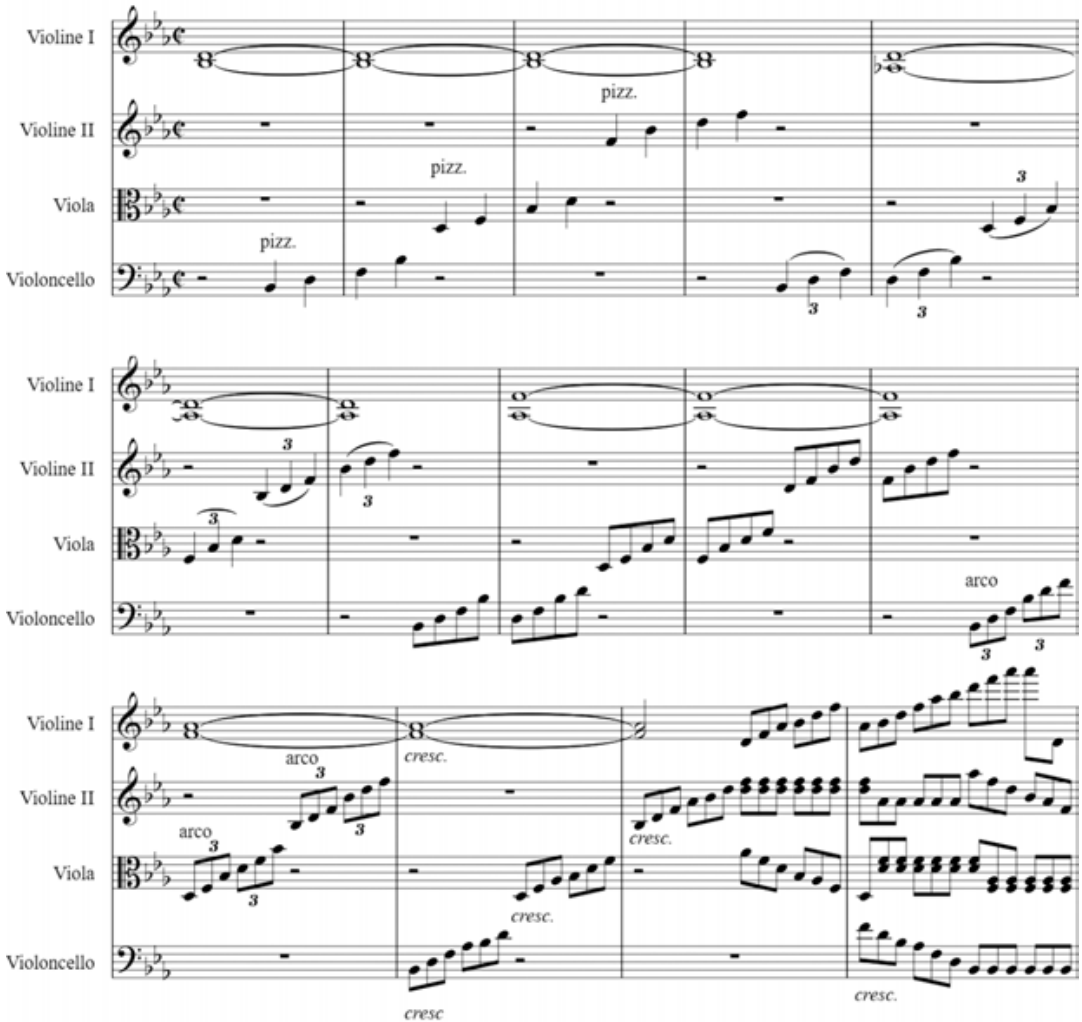

32 M. Heimann: Exercises for String Quartet, S. 16-17.

33 | Ebd., S. 18. 
Abbildung o4b: Mogens Heimann: Exercises for String Quartet, S. 16
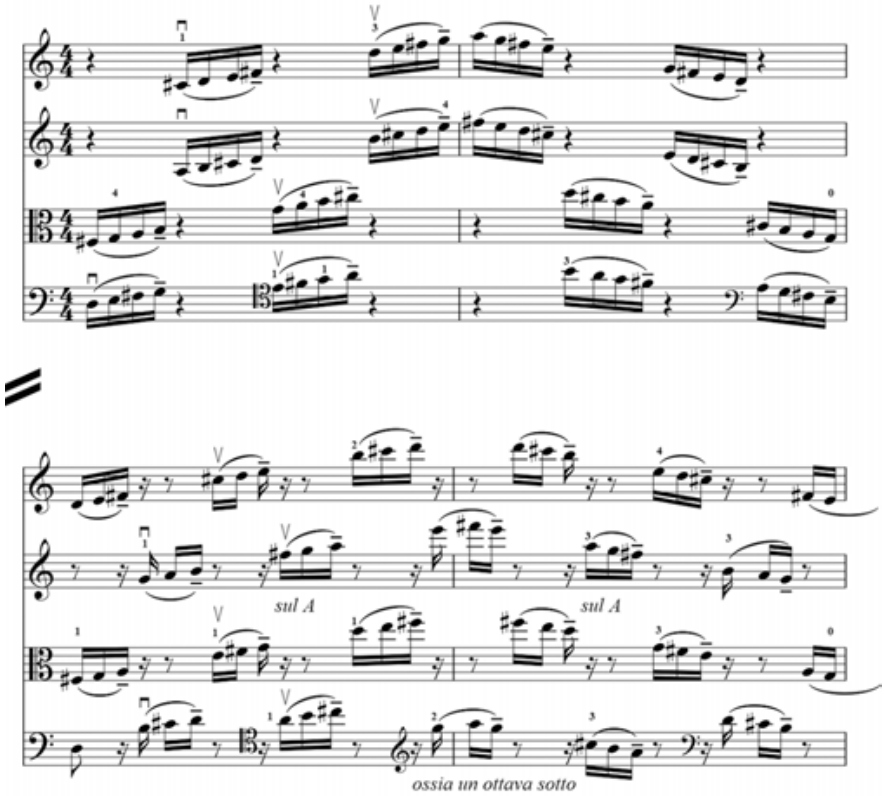

Ein anderer Ort: Die Sforzato-Akzente in der Durchführung, welche die in Sechzehnteln vibrierende Bewegung (2. Violine, Viola) zusammen mit den Akzenten im Violoncello anders gliedern als die Sforzato-Akzente in der 1. Violine (vgl. Abb. 05a). Eine entsprechende Übung aus Heimanns »Exercises«: Einzelne Klänge treten dynamisch hervor (vgl. Abb. o5b).

Abbildung 05a: Ludwig van Beethoven: Streichquartett Nr. 10 Es-Dur op. 74, 1. Satz, Takte 94-95

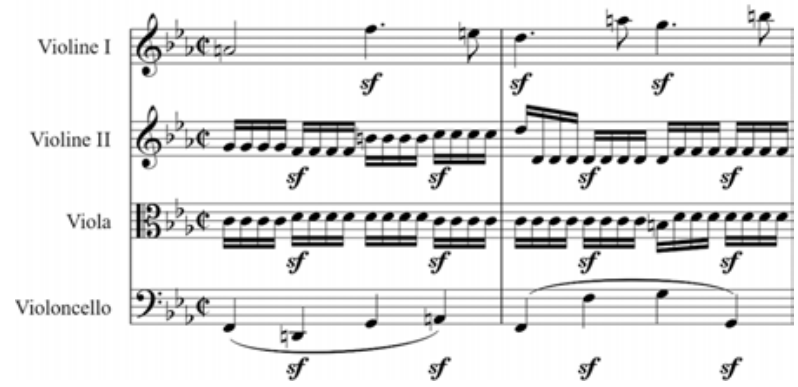


Abbildung 05b: Mogens Heimann: Exercises for String Quartet, S. 23

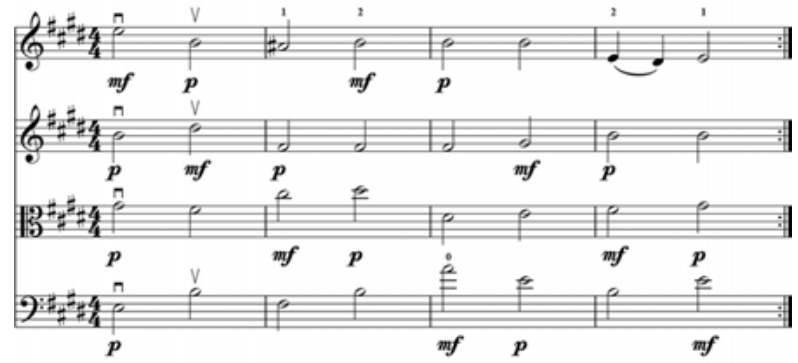

Ein wiederum anderer Ort: Die Tonrepetition mit augmentierten Dauern am Schluss der Exposition (vgl. Abb. o6a). Viertel-Puls gab es auch schon gleich zu Beginn im Hauptsatz: hier nun die Verlangsamung der Repetitionsfigur in den Halbe- und Ganze-Puls. Auch für solche und ähnliche Formen der Koordination bietet Heimann Übungen an: zum Beispiel eine Repetitionskette, die zuerst mit Metronom, dann ohne zu üben ist (vgl. Abb. o6b):

Abbildung o6a: Ludwig van Beethoven: Streichquartett Nr. 10 Es-Dur op. 74, 1. Satz, Takte 74-77

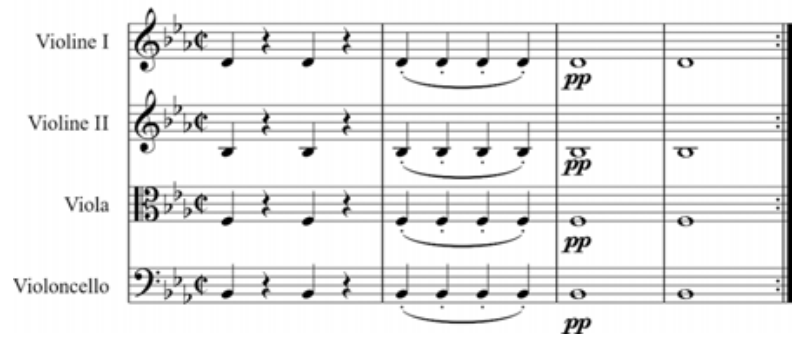

Abbildung o6b: Mogens Heimann: Exercises for String Quartet, S. 24

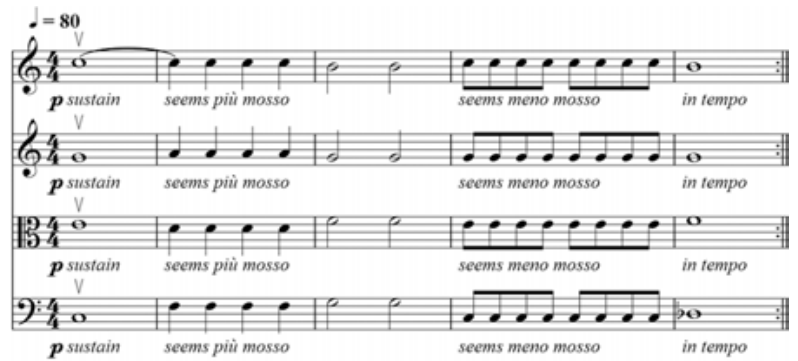


Könnte jede Übung eine Komposition sein? Umgekehrt: Es ist vielleicht eine Überlegung wert, Beethovens Streichquartettsatz als eine Zusammenstellung subtilster Übungen zu betrachten.

Mogens Heimanns Übungsbuch wurde von Hans Erik Deckert herausgegeben, der sich, selbst Cellist, speziell für die Ausübung von Kammermusik einsetzt und entsprechend Seminare zur Erarbeitung kammermusikalischer Literatur (vom Duo bis zum größeren Ensemble) anbietet. Diese Seminare wenden sich nicht nur an professionelle Musiker, sondern auch an Laien und Studierende; Zuhörer sind willkommen. Deckerts Publikation »Mensch und Musik« enthält Aufsätze und Vorträge aus den Jahren 1981 bis 2015 und gibt einen Einblick darin, wie der Autor Kammermusik als »Teamwork auf musikalischer Grundlage ${ }^{34}$ vermittelt und auch Musikworkshops in Wirtschaftsunternehmen durchführt - für interessierte musikalische Laien, die ihre musikalisch gewonnenen Erfahrungen in den Berufsalltag tragen wollen. Am Beispiel des Oktetts in F D 803 op. posthum 166 (1824) von Franz Schubert zeigt er, wie bei der Einstudierung und Aufführung verschiedene Weisen des »Zusammenwirkens« geübt werden. »Mir ging es diesmal [bei der Einstudierung des Oktetts] darum, die gemeinschaftsbildende Kraft der Musik [...] an einem Meisterwerk der Kammermusik zur Erfahrung werden zu lassen. ${ }^{35} \mathrm{Zu}$ einer Stelle zu Beginn des Allegro-Satzes (Takte 19-31) heißt es: »Ein Geben und Nehmen in einem kontinuierlichen Strom - ein >Pingpong ‘ auf musikalischer Ebene! Wiederum ein charakteristisches Spiegelbild menschlichen Zusammenwirkens.«Deckert ist daran interessiert, dass Ausführende wie Teilnehmer im Vollzug des Probens die Entstehung sozialer Beziehungen erfahren können; auch die Zuhörer sind als Teilnehmende einbezogen, sie können ebenfalls, wie Deckert es formuliert, »erleben, dass [und wie] an der sozialen Dimension der Musik gearbeitet« wird. Gemeinschaften entstehen nicht trotz, sondern gerade durch die Unterschiedlichkeit aller Einzelnen: »Erlebte Differenzierung in der Bildung menschlicher Gemeinschaften!«

Vor diesem Ansatz Deckerts rückblickend auf Heimanns Übungsbuch noch einmal und etwas zugespitzt die Frage: Könnte Beethovens Quartettsatz als Sammlung verschiedenster Übungen Gelegenheiten zu einer verheißungsvollen Praxis geben?

34 | H. E. Deckert: Mensch und Musik, S. 109-117; die folgenden Zitate ebd.

35 | Ebd., S. 109; die folgenden Zitate ebd., S. 114, 116. 


\subsection{Brauchbar? Notation UNd WIRKLIChKeIt Der Ausführung}

$\mathrm{Zu}$ welcher Praxis gibt eine Komposition Anlass oder Gelegenheit? Musik kann, wie zum Beispiel die Arie Sei stille dem Herrn aus Felix Mendelssohns Oratorium Elias, weniger Konzertdarbietung, sondern eher Teil einer Glaubenspraxis, einer Glaubensübung werden - ein nachdenkliches, demütiges, singendes Beten. Hier wie dort tun die Ausführenden etwas anderes, ein Vergleich unterschiedlicher Ausführungen zeigt dies sogleich. Das Tun der Ausführenden teilt sich visuell, aber auch über das Klanggeschehen mit. Praxis und Übung sind eng aufeinander bezogen: Praxis ist dabei keine Einübung, sondern eine Ausübung.

Ein Vergleich der musikalischen Praxis mit der Interpretation: $\mathrm{Zu}$ hören ist der Satz Dona nobis pacem (aus der Missa pro Pace) von Wojciech Kilar. Es singt der Chor OMNIA \& Žilina Mixed Choir unter der Leitung von Monika Bažíková. ${ }^{36}$ Die Aufführung erschafft eine besondere Situation; die Art der Aufmerksamkeit und Zuwendung seitens der Hörer verändert sich. Das, was jetzt bei der Bitte um Frieden geschieht, betrifft alle, unabhängig von persönlichen Einstellungen zu Fragen des Glaubens. Die werden hier nicht verhandelt. Auch Qualität oder Komplexität oder Modernität der Komposition nicht, ebenso wenig Art oder Qualität der Interpretation. Was zählt?

Bei der Bitte um Frieden zeigt sich hier die Sehnsucht einer »ganz gleich bedürftigen Gemeinsamkeit«. ${ }^{37}$ Im Prozess der Aufführung verändern sich die beteiligten Menschen, Ausführende wie Hörer. Sie werden nachdenklicher, stiller. Ein Wandel ist zu beobachten. Dieser Veränderungsprozess ist nicht Ergebnis einer besonderen Interpretation der Komposition, sondern Teil der musikalischen Praxis. Die Notation ist nicht die Musik: Dieser Satz lässt sich oft hören. Doch: Auch die Aufführung allein ist vielleicht (noch) nicht die Musik. Möglicherweise ist erst die Praxis, zu der dieses oder jenes Musikstück einlädt, die Musik. Eine Aufführung wird dann ein Eintreten für diese Praxis.

36 | Doctorate Concert of Monika Bažíková. 3th March 2011, Bytča - Wedding Palace. Choir: OMNIA \& Žilina Mixed Choir. Conductor: Monika Bažíková. Camera: Pavol Sestrenek, Branislav Valko. Sound: Miroslav Valovič. https://www.youtube.com/ watch?v=tCD5xalfEvQ vom 03.11.2016.

37 | Formulierung nach R. Wagner: Oper und Drama. Dritter Theil, S. 103. "Die christlich religiöse Lyrik erfand diese [polyphonische] Symphonie: in ihr erschien die Vielmenschlichkeit zu einem Gefühlsausdrucke geeinigt, dessen Gegenstand nicht das individuelle Verlangen als Kundgebung einer Persönlichkeit, sondern das individuelle Verlangen der Persönlichkeit als unendlich verstärkt durch die Kundgebung genau desselben Verlangens von einer ganz gleich bedürftigen Gemeinsamkeit war." Herv. i.0. 
Wie steht es um das Publikum, wenn der Akzent bei solcher Betrachtungsweise so entschieden auf die Ausführenden verlagert wird? Publikum kann bei der Praxis mit dabei sein, ist aber nicht der Adressat. Praxis hat keinen Adressaten, sondern Teilnehmer, Mitmachende. Die Perspektive von der Praxis her entwickelt eine ganz andere Einschätzung der (Zu-)Hörerschaft. Nicht ein Publikum wird angesprochen, sondern eine Teilnehmerschaft; diese Gemeinschaft ist auch mit dabei, wenn diese oder jene Komposition ausgeführt wird. Es ist deutlich zu hören und zu spüren, ob und wie ein Ausführender bzw. mehrere Ausführende sich an ein Publikum wenden. Die musikalische Verhandlung ohne Hinwendung an ein Publikum klingt ganz anders, als wenn ein Publikum zum Adressaten gemacht wird.

Hörer können durch Empathie Teilnehmer werden: Sie nehmen teil an den Fragestellungen: Was bestätigen wir durch diese Praxis? Wofür treten wir durch diese Praxis ein? Warum ist uns diese Praxis wichtig? Es sind Fragen wie diese, wodurch Komponisten, Ausführende und Hörer zur verschworenen Gemeinschaft werden, wodurch sich auch die »Brauchbarkeit « ${ }^{38}$ einer Komposition bestimmt. Diese »Brauchbarkeit« erweist sich so als Potential einer Komposition. Im Sinne der musikalischen Praxis wird dieses Potential bei der Ausführung aktiviert, eine Komposition wird also nicht eingeübt, sondern ausgeübt.

Heinrich Besseler bezeichnet in seinem Vortrag »Grundfragen des musikalischen Hörens « Musik, die fest im Leben ihren Platz hatte und zu verschiedenen Anlässen gespielt wurde, als »Gebrauchsmusik «. ${ }^{39}$ Dieser Musik, eingebettet in (alltägliche) Lebensvollzüge, stellt er die etwa mit der Renaissance aufkommende Konzertmusik gegenüber, die ein »Publikum《 einfordere, das eher in »Passivität« verharre..$^{40}$ Konzertmusik, so Besseler hier, halte am »Vollkommenheitsideal der Aufführung « und am Autonomieanspruch fest.

Mit der Verlagerung des Akzents von der Einübung auf die Ausübung und mit der Frage nach der Brauchbarkeit einer Komposition, ein bestimmtes Potential zu entfalten, wird die von Besseler gezogene Grenze zwischen »Gebrauchsmusik« und »Konzertmusik« relativiert. Die Unterscheidung mag musikgeschichtlich, musiksoziologisch, kulturhistorisch relevant bleiben: Für Fragen aus der musikalischen Praxis heraus verliert die Trennung ihre Bedeutung. Hier kann eine jede Komposition jeder Gattung, jeder Besetzung und jeder musikhistorischen Epoche ihre Brauchbarkeit erweisen, indem das ihr innewohnende Praxispotential aktualisiert wird.

38 | Der Begriff der "Brauchbarkeit" nach einem Gespräch mit Jürg Frey, Krefeld, 10.10.2001.

39 | H. Besseler: Grundfragen des musikalischen Hörens, S. 52; Herv. i.0.

40 | Ebd., S. 50; das folgende Zitat ebd.; Herv. i.0. 
Hier ein Beispiel: Jürg Freys klavierstück 2 (2001). Diese Komposition für Klavier ist eine Übung darin, etwas zu tun, ohne genau zu wissen, was dabei herauskommt. Notation und Klangwirklichkeit sind nicht so ohne Weiteres in Einklang zu bringen. Wie langsam geht es zu Beginn vorwärts? Die Terzen im zweiten Tempo-Abschnitt sind in dieser Tiefe kaum als solche zu erkennen. Diese tiefen Töne brauchen sehr lange, um zu verklingen. Für den Ausführenden stellt sich die Frage, wie zart bzw. kräftig der Anschlag sein darf, um den Klang (noch) so lange zu halten, bis der nächste zu spielen ist. Es ist äußerst schwierig, die genaue Anschlagsstärke zu treffen; fraglich ist, ob es diese Genauigkeit überhaupt gibt (vgl. Abb. 07).

Abbildung 07: Jürg Frey: klavierstück 2, Beginn
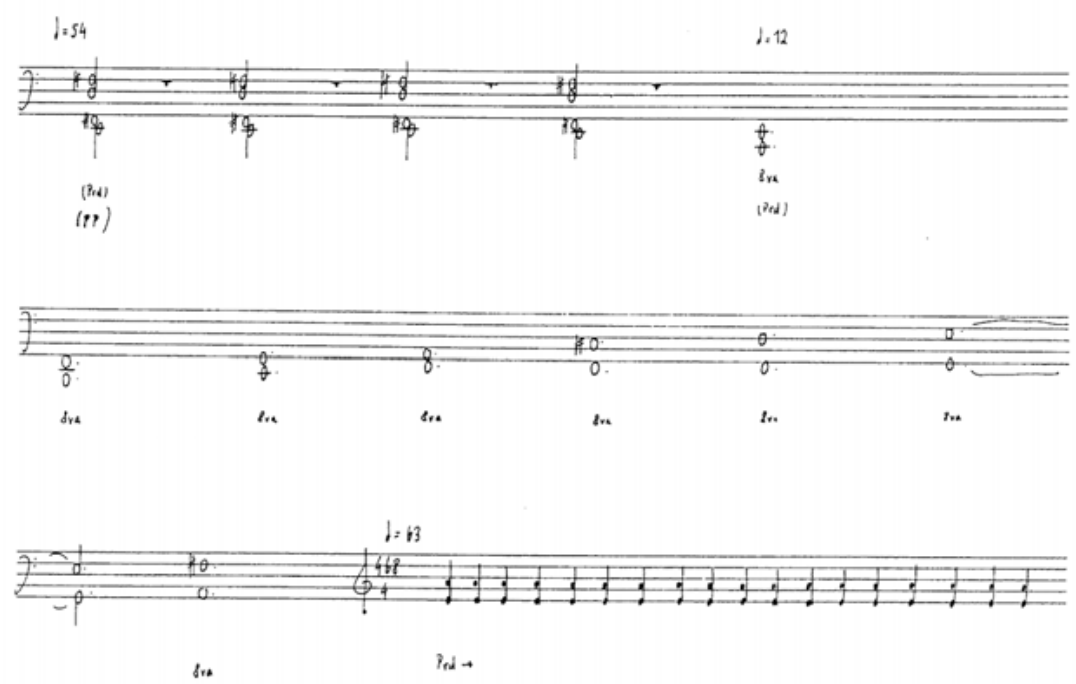

ew02.069; mit freundlicher Genehmigung der Edition Wandelweiser, Haan 2001

Für den Ausführenden ist das, was er hört, anders als das Notierte. Er übt eine Praxis des Fragens aus. Er setzt sich dem Entrinnen der Klänge aus. Die Ausführung von Musik wird ein Zelebrieren von Vergänglichkeit.

Eine paradoxe Situation: Ich beabsichtige, einen bestimmten Klang zu spielen, kann aber nicht entscheiden, ob der sich ergebende Klang derjenige ist, den ich zu spielen beabsichtige. Diese existentielle Situation zu ermöglichen, macht die Brauchbarkeit dieses Klavierstücks aus.

Auch eine Klaviersonate Beethovens oder Schuberts kann Anlass zur Ausübung einer bestimmten Praxis, vielleicht sogar speziell dieser Praxis des Fragens werden, kann ebenfalls ihre Brauchbarkeit in dem hier entfalteten Sinn erweisen. Epochengrenzen, kulturelle Differenzen verlieren bei dieser Fra- 
gestellung an Bedeutung. Es geht um Angebote für eine Praxis jeweils jetzt. Eine Komposition wird dann nicht (nur) daraufhin untersucht, welches Beziehungsgefüge die Klänge bilden, welcher kulturhistorische Kontext zugrunde gelegt werden kann, welche Rezeption ihr zugefallen ist, welche Interpretation angemessen zu sein scheint, sondern sie wird daraufhin befragt, in welche Situationen die Ausführenden gestellt sind, welchen Prozessen sie ausgesetzt sind, welche Beziehungen sie zueinander entwickeln. Ausführende und Hörer geben sich einer Praxis hin, der sie vertrauen und die ihrem Leben Sinn gibt. Kern der Musik wird das, was mit und zwischen den Ausführenden geschieht. Das wiederum kann Empathie bei den Hörern wecken, die sich berühren, in das Geschehen hereinziehen lassen. 


\section{Musikalische Praxis}

\subsection{Annäherung an den Begriff. BRENNPUNKTE, SCHNitTMENGEN}

\section{"Magische» Momente! (Vladimir Jankélévitch)}

Vladimir Jankélévitch stellt dem »Sagen« das »Tun« gegenüber. Und »Tun« kann vieles umfassen: Komponieren, Interpretieren/Ausführen/Aufführen/ Spielen/Singen wie auch Hören, Zuhören. Wenn Jankélévitch von »Sagen« spricht, meint er: Sprechen der Musik selbst, aber auch Sprechen über Musik. In Sprachlosigkeit entfaltet sich der Zauber des Musizierens und Hörens. Wichtig ist ihm die Prozesshaftigkeit des Musikalischen: Musik entsteht immer erst im Vollzug des Musikmachens. Flüchtigkeit macht das Wesen der Musik aus, begründet ihre ephemere Existenz im »magischen Vorgang« jeweils neu jetzt:

"Die Zauberwirkung, die von dem ausdruckslosen Espressivo ausgeht, ist kein Sagen, sondern ein Tun [...]. Das Tun gehört zu einer ganz anderen Ordnung als das Sagen! Wenn man Musik komponiert, wenn man sie spielt und dabei interpretiert, wenn man sie singt, oder selbst wenn man inr zuhört und sie dabei neu schafft - sind das nicht drei Wirkungsweisen, drei weitaus eher drastische als gnostische Haltungen? Der Schöpfer, der Ausführende, der ein aktiver Neuschöpfer ist, und der Hörer, der ein fiktiver Neuschöpfer ist, alle drei beteiligen sich gewissermaßen an einem magischen Vorgang: Der Ausführende wirkt mit dem ersten Schöpfer zusammen, weil er das Werk während eines bestimmten Zeitraums tatsächlich in der vibrierenden Luft existieren lässt, und der Hörer, der dritte Neuschöpfer, wirkt mit den beiden ersten durch seine Phantasie oder allmähliche Gesten zusammen. . ${ }^{1}$

Jankélévitch lässt hier mit der Nennung von Komponisten, Ausführenden und Hörern, die am »magischen Vorgang« Musik beteiligt sind, vor dem Auge des

1 | V. Jankélévitch: Die Musik und das Unaussprechliche, S. 112. 
Lesers das Bild einer verschworenen Gemeinschaft entstehen. Die am Prozess Beteiligten werden als »Schöpfer« bezeichnet, alle erschaffen »neu«.

Kein Sagen, vielmehr ein Tun: »[Die Musik] ist nicht dafür geschaffen, dass man über sie spricht, sie ist dafür geschaffen, dass man sie ausführt; sie ist nicht dafür geschaffen, dass man etwas von ihr sagt, sondern dass man sie >spielt $\ll^{2}{ }^{2}$

\section{"Musicking"? (Christopher Small)}

Was ist Musik? Folgt man Christopher Small auf dem Weg durch sein inspirierendes Buch Musicking, lässt sich diese Frage so beantworten: »There is no such thing as music. Music is not a thing at all but an activity, something that people do. ${ }^{3}$ Auch nach Small ist Musik nur als Tätigkeit existent.

Small erklärt, eine einseitige Betrachtung westlicher Kunstmusik habe -im Verein mit der Etablierung des Werkbegriffs - dazu geführt, die Komposition mit Musik gleichzusetzen und nach deren Bedeutung zu fragen. ${ }^{4}$ Die Aufführung sei, vor allem im Umkreis von Historikern und Musikwissenschaftlern der 8oer Jahre (hier bezieht sich Small dezidiert auf Carl Dahlhaus ${ }^{5}$ ), lediglich »Medium« geworden, durch welches das Werk zu den Hörern vordringe: je unaufdringlicher und durchsichtiger das Medium, desto besser (»the more tranparent the medium the better $\ll) .{ }^{6}$ Einige hielten sogar die Notation für das eigentlich Kostbare, da jede Aufführung ohnehin nur Annäherungswerte erreichen könne. Die Zuschreibung einer bestimmten Funktion verändere den Charakter von Ausführung; an dieser Stelle wird die Unterscheidung von Interpretation und Praxis deutlich: »[P]erformance does not exist in order to present musical works, but rather, musical works exist in order to give performers something to perform.«

Die Frage nach der Bedeutung von Musik verknüpft Small mit dem Werkbegriff und der damit verbundenen Verschriftlichung von Musik: Im musikalischen Tun erübrige sich diese Frage, da hier kein bestimmtes Objekt (Werk) zur Diskussion stehe, sondern eine sinnerfüllte Tätigkeit ausgeübt werde:

"The fundamental nature and meaning of music lie not in objects, not in musical works at all, but in action, in what people do. It is only by understanding what people do as they

2 | Ebd., S. 114; Herv. i.0.

3 | Chr. Small: Musicking, S. 2.

4 | Ebd., S. 3.

5 | C. Dahlhaus: Grundlagen der Musikgeschichte; hier in der Übersetzung von J. B. Robinson, J. B.: Foundations of Music History, Cambridge and London: Cambridge University Press 1983.

6 | Chr. Small: Musicking, S. 4f.; das folgende Zitat ebd., S. 8. 
take part in a musical act that we can hope to understand its nature and the function it fulfills in human life. Whatever that function may be, I am certain, first, that to take part in a music act is of central importance to our very humaneness, as important as taking part in the act of speech, which it so resembles (but from which it also differs in important ways), and second, that everyone, every normally endowed human being, is born with the gift of music no less than with the gift of speech." ${ }^{7}$

Zum Teilnehmenden zu werden: Das ist nach Small (über-)lebenswichtig, ist ganz eng mit dem menschlichen Leben verknüpft, ja Teil unserer Menschlichkeit - wie das Sprechen, von dem das Musikmachen aber deutlich zu unterscheiden ist.

Small geht nun so weit, vom Substantiv »music« herkommend das im Englischen mögliche Verbum »to music« zu präferieren, welches ihm aber im Allgemeinen zu schwach ist, um dann zur Partizip- oder Gerundium-Form zu kommen: »musicking«. Auch das Verb »to music« drückt für ihn mehr als Musik-Machen, Musizieren aus; es stellt, so wie er es verstehen will, einen umfassenden Zusammenhang in Aussicht: »To music is to take part, in any capacity, in a musical performance, whether by performing, by listening, by rehearsing or practicing, by providing material for performance (what is called composing), or by dancing. ${ }^{8}$ Small erweitert die Gemeinschaft der am »Musicking « beteiligten Personen vom Kreis Komponisten - Ausführende - Hörer auf viele weitere Menschen, die an einer Aufführung beteiligt sind, bezieht Kartenverkäufer, Türöffner, Putzkolonnen ein. In diesem Sinne wird »Musicking « ein Politikum als öffentliches Ereignis, ${ }^{9}$ werden Ort, Zeit, Umstände der Aufführung wichtig für die Tätigkeiten der Menschen: »What does it mean when this performance (of this work) takes place at this time, in this place, with these participants? Or to put it more simply, we can ask of the performance, any performance anywhere and at any time: What's really going on here? «10

Mit diesen Hinweisen auf Ausführung an einem bestimmten Ort, zu einer bestimmten Zeit, mit diesen und keinen anderen Teilnehmenden spricht Small implizit auch die besondere Art von Körperlichkeit an, die mit der Praxis verbunden ist. »What's really going on here?« Was passiert hier eigentlich? - was geschieht hier überhaupt? Ein weiterer wichtiger Aspekt: Jeder Teilnehmende ist nicht nur tätig, er ist auch in ein Geschehen involviert, selbst dann, wenn er bloß anwesend ist und (fast) nichts (äußerlich Sichtbares oder Hörbares) beisteuert. Tun und Da-Sein, Tun und Geschehen-Lassen durchdringen einander,

7 | Ebd.

8 | Ebd., S. 9.

9 | Vgl. P. Uhden: Musik als Praxis, S. 94.

10 | Chr. Small: Musicking, S. 10; Herv. i.0. 
können nur unzureichend über ein dualistisch aufgefasstes Begriffspaar (Aktivität - Passivität) umschrieben werden.

\section{"Wirklichkeitscharakter" (Erika Fischer-Lichte, Judith Butler)}

Erika Fischer-Lichte hebt den Wirklichkeitsbezug hervor, den performative Akte herstellen:

"Nun traten die bisher weitgehend übersehenen performativen Züge von Kultur in den Blick, die eine eigenständige Weise der (praktischen) Bezugnahme auf bereits existierende oder für möglich gehaltene Wirklichkeiten begründen und den erzeugten kulturellen Handlungen und Ereignissen einen spezifischen, vom traditionellen Text-Modell nicht erfaßten Wirklichkeitscharakter verleihen. ${ }^{11}$

»Bezugnahme« auf Wirklichkeiten? »Wirklichkeitscharakter« performativer Akte selbst?

Anders als Fischer-Lichte, die sich deutlich auf ästhetische performative Prozesse bezieht, konzentriert sich Judith Butler auf eher allägliches Geschehen in der Lebenswelt. Fischer-Lichtes Einschätzung, Butler »[beziehe] sich kaum je auf im engeren Sinne ästhetische Vorgänge, sondern auf Alltagshandeln«, wird durch Studien Butlers wie »Anmerkungen zu einer performativen Theorie der Versammlung« bestätigt. Durch einen Vergleich beider Ansätze kommt auf neue Weise eine Transparenz zwischen Kunst und Leben, zwischen musikalischer Aufführung und performativem Akt im Alltag in den Blick.

Jennifer Gebske hat Berührungspunkte der »Performativitätskonzepte« von Erika Fischer-Lichte und Judith Butler herausgearbeitet, aber auch deren deutliche Differenzen dargestellt. Butler setze, so Gebske, einen Akzent auf den »soziale[n] Prozess der gender performance «, ${ }^{12}$ den sie außerhalb ästhetischer Akte ansiedelt. Sie nutze allerdings wie Fischer-Lichte auch die »Begriffe der Ausführung, Performance, Herstellung und Handlung in Verbindung mit Performativität. « ${ }^{13}$ Weitere Parallelen der Konzepte nach Gebske: »Beide gehen von gemeinschaftlich produzierten Prozessen aus. Sie betrachten keine Zustände, sondern Entwicklungen. Ihnen geht es nicht um ein >Sein<, sondern um ein >Werden<.« Ergänzend sei hinzugefügt, dass Fischer-Lichte durchaus auch Prozesse einzelner Performer beispielhaft aufführt, während Butler sich vielleicht entschiedener noch an gemeinschaftlichen Handlungen im Lebensalltag orientiert. Am stärksten differenzierend: »Fischer-Lichte geht es im Gegensatz zu Butler nicht um alltägliche, soziale Vorgänge [...], sondern

11 | E. Fischer-Lichte: Ästhetik des Performativen, S. 36; das folgende Zitat ebd.

12 | J. Gebske: Performativität zwischen Zitation und Ereignis, S. 48.

13 | Ebd., S. 49; die folgenden Zitate ebd. 
um Aufführungen, die als ästhetische und kreative Vorgänge gekennzeichnet werden können. [...] Hier liegt ein Reibungspunkt zu Butlers Theorie«. Gerade dieser »Reibungspunkt« aber könnte die Diskussion einer Grenze zwischen Theater, Kunst, Aufführung, Musik einerseits und Lebensalltag andererseits beleben.

\section{Körperlichkeit? (Wolfgang Rüdiger)}

Die Besonderheit von Zeit und Ort, die Bezogenheit auf spezifische Prozesse und Situationen sowie die enge Beziehung von Tun und Geschehen(-Lassen) verweisen auf eine Art von Körperlichkeit, wie sie auch in Cages Komposition 4'33" durchlebt und erlebt werden kann. ${ }^{14}$ Wolfgang Rüdiger beschreibt 4'33" als »ein Stück intensivster Körpermusik«:

„Was erfährt der Spieler - und mit inm der Hörer - beim Exerzitium des stillen Stücks? Zunächst einmal ist er völlig auf sich selbst zurückgeworfen. Das bloße Dasein, der eigene Körper in all seiner Schwere und Wärme, die innere Musikı seiner vegetativen Funktionen (Atem, Herzschlag, Blutkreislauf etc.) und die ,äußere Musikı seiner Haltung und Bewegung treten ins Zentrum der Aufmerksamkeit - ein Durchflutetwerden des gesamten Körpers mit Bewusstheit, gesteigerter Kinästhesie. [...] Denn dies ist es, was aus dem Quellgrund der Stille aufsteigt: zu sich selbst gekommener Körperklang, sich selbst begegnende, ihrer selbst bewusst werdende musikalische Körperlichkeit im erfüllten Augenblick«. ${ }^{15}$

Dieser Augenblick (dieser einen Ausführung an diesem Ort zu dieser Zeit) ist singulär und zugleich auf Wiederholung ausgerichtet. Die Intensität des körperlichen Da-Seins, sogar die mögliche Abwesenheit eines Teilnehmenden, bestimmt die Praxis mit. ${ }^{16}$ Eine Ausführung von Cages 4'33" modifiziert auch den Charakter von Beziehungen: Beziehung muss sich nicht in einer Handlung niederschlagen, lässt sich auch im Stillen, ohne sichtbares oder hörbares Tun, durchleben und erleben: in der Gemeinsamkeit der Teilnehmenden, die Nehmende und Gebende ${ }^{17}$ zugleich werden. Kommunikation? Eine mögliche Antwort darauf, was Kommunikation in musikalischer Praxis sein kann, gibt an dieser Stelle ebenfalls Cages stilles Stück: Über den eigenen Körper ist jeder Einzelne, allein oder in der Gemeinschaft der Ausführenden, mit der Welt und mit allen verbunden.

14 | Vgl. M. Zenck/T. Fichte/K.-U. Kirchert: Gestisches Tempo, S. $353 f f$.

15 | W. Rüdiger: organische identität?, S. 30.

16 | Vgl. E. Fischer-Lichte: Ästhetik des Performativen, S. $58 \mathrm{ff}$.

17 | Vgl. H. E. Deckert: Mensch und Musik, S. 93ff. 


\section{"Lebensformen «? \\ (John Cage, Karlheinz Stockhausen, Istvàn Zelenka)}

Wiederholungsstrukturen entwickeln Zeithorizonte mit differenzierten Wirklichkeits- und Möglichkeitsfeldern - im alltäglichen Leben, aber auch in musikalischer Praxis. Kann musikalische Praxis durch ihre Wiederholungsstruktur Lebensform werden? ${ }^{18}$

Mit John Cage, Karlheinz Stockhausen und Istvàn Zelenka kommen Komponisten zu Wort, die musikalische Praxis als »Lebensform « kennen, wobei Cage und Stockhausen ausdrücklich auch diesen Begriff verwenden. Cage meint:

"Kunst ist eine Lebensform. Sie ist durchaus mit dergleichen wie einen Bus nehmen, Blumen pflücken, lieben, den Boden fegen, von einem Affen gebissen werden, ein Buch lesen usw. ad infinitum vergleichbar [...]. Kunst, wenn sie Kunst ist, wie Satie sie gelebt und gemacht hat, ist nicht vom Leben isoliert (ebensowenig das Tellerwaschen, so es in diesem Geiste ausgeübt wird).."19

Die Möglichkeit »künstlerischer Lebensform« spricht Karlheinz Stockhausen mit Blick auf die Aufführungspraxis von Spiral für einen Solisten (1968) an:

„Wäre es nicht für jeden eine künstlerische Lebensform, das Unvorhergesehene, das man aus einem Kurzwellenradio empfangen kann, in neue Musik zu verwandeln, das heißt, in einen bewußt gestalteten Klangprozeß, der alle intuitiven, denkerischen, sensiblen und gestalterischen Fähigkeiten wachruft und schöpferisch werden läßt, auf daß sich dieses Bewußtsein und diese Fähigkeiten spiralförmig steigern?! « ${ }^{20}$

Stockhausen lässt mit dieser Frage Lebenswelt und künstlerische Praxis verschwimmen. Wiederholte Aufführungen, mehrmals täglich im Kugelauditorium Osaka, integrieren diese Praxis in den Lebensalltag der Ausführenden: werden Lebensform. Deutlich werden deren Prozesscharakter und Unabgeschlossenheit.

18 | Georg W. Bertram kennt den Begriff der "Lebensform" innerhalb philosophischästhetischer Auseinandersetzung. Er bezieht sich angesichts des Pluralismus in der zeitgenössischen Kunst nicht speziell auf Musik, sondern eher auf Kunst allgemein und sucht die Diskussion von Kunst als "reflexive" und "kritische Praxis". In diesen Diskurs einbezogen sind alle Teilnehmenden: Kunst kann in diesem Sinne "menschliche Lebensform " werden; vgl. G. W. Bertram: Kunst als menschliche Praxis.

19 | J. Cage: Noch mehr über Satie, S. 122f.

20 | K. Stockhausen: SPIRAL, S. 136. 
Istvàn Zelenka zieht sich nicht explizit auf den Begriff »Lebensform « zurück. Sämtliche seiner Kompositionen sind aber Praktiken, die in den Alltag zu integrieren sind. Sie laden Musiker und Laien gleichermaßen zur Teilhabe, zur Begegnung, zum friedlichen Tun ein. Sie werden bei ihrer Einbindung in den Lebensalltag Lebensform. Nicht selten kann sich die Ausführungstätigkeit über mehrere Tage, sogar Wochen erstrecken, ohne ein Ergebnis anzustreben:

"Die Perfektion, Wunschbild einer klassischen Tradition, entspricht einer 'Handlung, die als eine unvergleichbare, allerbeste, eigentlich einzige bezeichnet wird. Daran kann nichts verändert werden, ohne die Perfektion zu verletzen, sie zum primus inter pares zu verwandeln, sie zu degradieren. ${ }^{21}$

Praxis, wie sie hier verstanden wird, bewahrt den offenen Zeithorizont des Zukünftigen, während bei der Perfektion das Perfekte als abgeschlossen ad acta gelegt wird. Ein Ideal angestrebter Vollkommenheit würde diese befreiende Offenheit zerstören.

\section{"Grenzen", "Schwellen«? (Erika Fischer-Lichte)}

Eine »Ästhetik des Performativen« (Fischer-Lichte) wird - je nach Fragestellung - nicht auf Aktionen, Performances, Happenings beschränkt bleiben. Sie findet immer dann Eingang in die musikalische Praxis, wenn danach gefragt wird, zu welchem Tun eine Komposition Anlass, Gelegenheit gibt; zu welcher Gelegenheit (an welchem Ort, zu welcher Zeit, mit welchen Teilnehmern) die Ausführung stattfindet. Diese Überlegungen betreffen durchaus nicht nur Kompositionen der zeitgenössischen Musik, klammern Werke nicht aus. Die Fragen, die von der Praxisperspektive ausgehen, richten sich an die Komposition selbst: Was tut man beim Einstudieren, beim Üben, beim Ausführen? Wie tut man es - und vor allem wozu? Nicht die Partitur ist Gegenstand der Betrachtung, sondern das Tun derjenigen, die sich mit diesem Angebot einer Partitur beschäftigen, auseinandersetzen.

Überlegungen zu einer Ästhetik des Performativen können Eingang finden in solche Auseinandersetzung, das Tun der Ausführenden trägt performative Züge, kann als performativ angesehen werden. Eine Ästhetik des Performativen hat ihre Geburtsstunde im 20. Jahrhundert. Musikalische Praxis kann jede Komposition jeder historischen Epoche auf die ihr innewohnende Gelegenheit zum Tun der beteiligten Ausführenden heute befragen, kann auf diese Weise jede Komposition in die unmittelbare Zeitgenossenschaft holen - mit Fragen wie: Warum wollen wir diese Praxis (der Ausführung dieses Stücks) pflegen? Welchen Sinn ergibt es für uns, dieses Stück in unser Leben herein-

21 | I. Zelenka, in: E.-M. Houben/I. Zelenka: und/oder, S. 283. 
zuholen und uns wiederholt zu treffen, dieser Praxis willen? Die Fragen nach musikalischer Praxis berühren eine »Ästhetik des Performativen«.

Die musikalische Praxis hat mit performativen Akten die Transparenz zwischen Kunst und Leben gemeinsam. Fischer-Lichte zieht es vor, statt von »Grenzen « von »Schwellen « zu sprechen ${ }^{22}$ : »Die Grenze wird zur Schwelle, die nicht voneinander trennt, sondern miteinander verbindet.« Mit der Rede von einer »Wiederverzauberung der Welt, die sich in dieser Verknüpfung von Kunst und Leben vollzieht und auf die eine Ästhetik des Performativen abzielt « ${ }^{23}$, rührt Fischer-Lichte an eben dies Charakteristikum musikalischer Praxis, das mit Hilfe von Metaphern im Umkreis des Stichworts »Magie« eingekreist werden könnte. Mit diesem Bild schweifen die Gedanken zum (musikalischen) Ritual, mit dem die musikalische Praxis sich wohl auch eine Schnittmenge teilt.

\section{Noch einmal: Magie. - Ritual? (Helmut Lachenmann, Christopher Small)}

»Irgendwo in Adornos >Minima Moralia< steht die Definition: >Kunst ist Magie, befreit von der Lüge, Wahrheit zu sein. $<$ Was ist der Sinn von Kunst heute?«Auf diese Frage Heinz-Klaus Metzgers antwortet Helmut Lachenmann: »Der ist vielleicht der, den Menschen an sich zu erinnern, an Kräfte in ihm, die ungenutzt sind, während er verschlissen wird. ${ }^{24}$ Besser lässt sich der Sinn musikalischer Praxis kaum umschreiben: Erinnerung an unsere Kräfte. Mit anderen Worten: Beschwörung von Wirklichkeiten und Möglichkeiten; Vergegenwärtigung dessen, was ist und geschieht; Ausgriff, Übergriff auf Zukünftiges - über ein Tun, das durch seine Wiederholungsstruktur an ein magisches Ritual erinnern mag. Lachenmann nennt mehrere Beispiele für Augenblicke des Stillstands und Innehaltens aus unterschiedlichen Kompositionen, Augenblicke, die er auch als »magischen Zustand « beschreibt. $^{25}$

Erinnerung an unsere Kräfte - etwas andere, aber ebenso treffende Worte findet Small, wenn er das Ritual als soziales Geschehen und Verhalten darstellt:

"Ritual is a form of organized behavior in which humans use the language of gesture, or paralanguage, to affirm, to explore and to celebrate their ideas of how the relationships of the cosmos (or of a part of it), operate, and thus of how they themselves should relate to it and to one another. Through their gestures, those taking part in the ritual act ar-

22 | E. Fischer-Lichte: Ästhetik des Performativen, S. 356ff.; das folgende Zitat ebd., S. 356.

23 | Ebd., S. 360.

24 | H. Lachenmann: Fragen - Antworten, S. 201.

25 | Ebd., S. 199. 
ticulate relationships among themselves that model the relationships of their world as they imagine them to be and as they think (or feel) that they ought to be. As the anthropologist Clifford Geerts (1973) puts it in a resounding formulation, when we take part in a ritual act the lived-in order merges with the dreamed-of order. " ${ }^{26}$

Im Ritual zeigt sich utopische Kraft, sobald die Grenze zwischen den Beziehungen, wie sie sind und wie sie (erfühlt) sein könnten, zwischen der erlebten und der erträumten Ordnung zur »Schwelle« (Fischer-Lichte) wird. Die Beziehungen - Small spricht von »relationships « - zwischen Menschen erfassen alle Dimensionen: Mit der Zweierbeziehung die Liebe, mit den zwischenmenschlichen Beziehungen innerhalb einer größeren Gruppe Politik und Öffentlichkeit.

"[Those relationships] may involve only one or two people, as in the rituals of courtship and lovemaking; a small and possibly exclusive group, as in rituals of family and of clubs and associations; or entire nations and even empires and major religious and secular faiths spanning or claiming to span the whole globe. ${ }^{27}$

Musik kann auf musikalische Weise und ohne Worte politisch wirksam werden. Für Small ist die körperliche Erfahrung entscheidend: Die besondere Art von Körperlichkeit, bei der gelernt und erfahren wird, enthebt die Teilnehmenden der Notwendigkeit von Versprachlichung. Im Ritual werden Beziehungen bestätigt, erforscht und gefeiert - auf eine Weise, die nicht verbalisiert werden muss. Es geht um Lernen und Erfahren über den Körper:

"In this way the participants not only learn about those relationships but actually experience them in their bodies. They explore the relationships, they affirm and they celebrate them, without having to articulate them in words; indeed, no words can adequately express the relationships as they are felt at that time. ${ }^{28}$

In ihrem Aufsatz »Ritualität und Grenze« kommt Erika Fischer-Lichte auf eine denkwürdige »Darstellung der Elektra« durch Gertrud Eysoldt (Hugo von Hofmannsthal, Elektra, Inszenierung von Max Reinhardt, Kleines Theater Berlin, 30. Oktober 1903) zu sprechen: Gänzlich irritierend sei die »[Überschreitung der] Grenze zwischen dem semiotischen und dem phänomenalen Körper« gewesen. ${ }^{29}{ }$ Überschreitung « meint hier in Fischer-Lichtes Text nicht Aufhebung. Die »Grenze« bleibe - doch lasse sich wohl sagen, dass »Eysoldts Kör-

26 | Chr. Small: Musicking, S. 95.

27 | Ebd.

28 | Ebd., S. 96; Herv. i.0.

29 | E. Fischer-Lichte: Ritualität und Grenze, S. 14; die folgenden Zitate ebd. 
perverwendung oszillierend zwischen dem semiotischen Körper und ihrem phänomenalen Leib hin- und herglitt, so daß sich der eine nicht vom anderen abgrenzen und unterscheiden ließ.« Konsequenz dieser Art von Darstellung war ein Verlust von Distanz, sodass »sich bei den Zuschauern keine Illusion mehr einstellen mochte«. Fischer-Lichte stellt drei »Phasen« dar, in denen es zu Grenzüberschreitungen kommt: die »Trennungsphase« (Ablösung vom Alltag, von gewohnten Mustern), die »Schwellen- oder Transformationsphase« (Ermöglichung neuer Erfahrungen), »Inkorporationsphase « (Rückkehr in die erste »Gesellschaft«, aber verwandelt): »In allen drei Phasen kommt offensichtlich Grenzen - dem Überschreiten bestehender Grenzen und dem Ziehen neuer Grenzen - eine große Bedeutung zu. ${ }^{30}$

Diese Ausführungen zum Ritual sind auf die musikalische Praxis übertragbar. Cornelius Cardews Komposition The Great Learning lässt sich zum Beispiel als ein komponiertes Ritual, eine ritualisierte Komposition betrachten. Bei der Erarbeitung wird gelernt und erfahren, auch gefeiert - aber nicht notwendigerweise gesprochen. Es geht nicht (nur) um eine Aufführung als Abschluss einer Phase der Arbeit und Auseinandersetzung mit dem Stück, sondern diese Phase der Auseinandersetzung selbst ist »Learning«, auch und gerade dann, wenn sie nicht auf ein mehr oder weniger perfektes Resultat ausgerichtet ist. Bei der Beschäftigung mit dem Stück verlassen wir als Musiker die gewohnte Welt, wir tauchen in eine andere ein, die vielfältige Erfahrungen und Überraschungen ermöglicht. Irgendwann erscheinen wir wieder im Alltag - verwandelt?

Die Rede von Ritual hinsichtlich musikalischer Praxis ist eine Metapher. Ein Bild allerdings, mit dem sich arbeiten lässt: Bei der Ausführung des Solostücks, der Komposition für Duo, Trio, Quartett, dann für kleinere und größere Ensembles, schließlich für Orchester usw. sind verschiedene Beziehungen zur Welt und zu anderen zu erleben und zu erfahren, sind politische Kräfte zu entdecken und zu erproben - auf musikalische Weise.

Erhalten bleibt in musikalischer Praxis die gemeinsame Erinnerung an das, was wir immer auch sind. Diese Erinnerung teilen wir; sie wiederholt zu beschwören, ist sicherlich eine Antwort auf die Frage: Was ist der Sinn von Musik heute?

Mit träumerischer Sicherheit berührt Dieter Schnebel diese Frage. Er erfasst gleich jede Art von Musik als Ritual: »Ritual [...] ist beschwörend. Tatsächlich ist Musik ihrem Wesen nach Ritual, freilich ein abstraktes. $\aleph^{31}$

30 Ebd., S. 17.

31 | D. Schnebel: Ritual - Musik, S. 17. 


\subsection{Sinn und Bedeutung}

\section{Synonyme? Komplementäre Begriffe? (Vladimir Karbusicky)}

Sinn und Bedeutung: Synonyme? Vladimir Karbusicky weist auf das »kaum noch durchschaubare terminologische Chaos « hin, das in der Nachfolge der Definition des Unterschiedes zwischen Sinn und Bedeutung durch Gottlob Frege (»Über Sinn und Bedeutung «, 1892) entstanden ist. ${ }^{32}$ In der Nachfolge Freges sei eine »verbindliche Übereinstimmung« darüber, wie die Termini voneinander abzugrenzen seien, in Vergessenheit geraten. Zudem: Bringe man zusätzlich den englischen Begriff »meaning « in die Diskussion ein, werde eine terminologische Klärung nicht eben erleichtert; »meaning« entspräche dem Frege'schen »Sinn«, werde aber »ins Deutsche als >Bedeutung< übersetzt«. »Dagegen werden im musikästhetischen Sprachgebrauch gerade die Termini >Sinn<, >Sinngehalt< und >Sinnzusammenhang < bevorzugt«.

Karbusickys Vorschlag, die Begriffe in ihrer »Komplementarität $\ll^{33}$ zueinander in Beziehung zu setzen, tritt der Verwirrung entgegen. Der Terminus »Sinn« wäre dann auf die Strukturebene eines Musikstücks zu beziehen; diesem käme dann Sinn durch formale Prozesse, Beziehungsebenen, thematischmotivische Querverweise, harmonische Entwicklungen und Bezüge zu. Der Terminus »Bedeutung « hingegen bliebe an ein »auf etwas verweisendes Zeichensystem« gebunden:

w. S. Bachs Präludium C-Dur Nr. 1 aus dem ,Wohltemperierten Klavier hat vornehmlich einen 'Sinn r als Struktur, als Fortspinnung harmonischer Spannungen, Modulationen und Lösungen, aber kaum eine 'Bedeutung، im Sinne eines auf etwas verweisenden Zeichensystems. Charles Gounod hat zu dieser Konstruktion nachträglich eine überaus gefühlvolle Melodie komponiert. Das Ganze unter dem Titel 'Meditation، hat jetzt eine vorher vermißte 'Bedeutung, aber der originelle 'Sinn ‘ wurde - dies ist der Effekt der Komplementarität - in einen geringeren Anteil zusammengedrängt: das Bachsche Gewebe wird zur 'Begleitung، der Melodie, ihres 'Ausdrucksı." ${ }^{34}$

In komplementärer Beziehung könnten also die Gewichtungen von »Sinn« und »Bedeutung« wechseln. Auch könnten demnach unterschiedlichen Kompositionen verschieden große Anteile beider Elemente der komplementären Beziehung zugesprochen werden.

32 | V. Karbusicky, zitiert in: P. Faltin: Musikalische Syntax, S. 152, Anm. 1 (Erg. durch den Hg.); die folgenden Zitate ebd.

33 | V. Karbusicky: Einleitung: Sinn und Bedeutung in der Musik, S. 13; das Folgende ebd.

34 | Ebd. 


\section{Sinnzusammenhänge (Carl Dahlhaus, Hans Heinrich Eggebrecht)}

Für eine Analyse als Nachvollzug von Denkvorgängen ${ }^{35}$ und für die Begründung der Qualität einer Komposition aus der »Notwendigkeit« der gelungenen Verknüpfungen heraus steht als einer der prominentesten Musikwissenschaftler Carl Dahlhaus ein, der 1969 zur Verteidigung des »Kunstwerks in der neuesten Musik« schreibt:

"Analyse ist der niemals ganz gelingende Versuch zu begreifen und zu demonstrieren, daß sämtliche Teile eines Werkes sinnvoll aufeinander und auf das Ganze bezogen sind und daß jeder von innen in der Funktion aufgeht, die er erfüllt. Der Triumph der Analyse besteht in dem Nachweis, daß ein Werk, mindestens ein geglücktes, nicht anders sein kann, als es ist. Wo ein Komponist Möglichkeiten sieht, realisierte neben unterdrückten, sucht der Analysierende nach Notwendigkeit. Von Zufall oder Überschuß spricht er nur widerstrebend. " 36

»Sinn« ist hier durch den Strukturzusammenhang einer Komposition gegeben. Die Aufdeckung dieser strukturellen Beziehungen ist Aufgabe der musikalischen Analyse. In »Analyse und Werturteil« zieht Dahlhaus sich dementsprechend vornehmlich auf die Partituranalyse zurück; in mehreren kritischen Analysen dienen die Zuschreibungen von »Zwiespältigkeit« und »Widersprüchlichkeit« der Diskussionsbewegung, der Argumentationslogik. Die »Gattungs- und Formtradition « ${ }^{37}$ einer Komposition sind wesentliche Grundlage einer kritischen Annäherung. Vollendetheit, Einheit und »Ausgleich « sind in der kritischen Partituranalyse wichtige Denkkategorien ${ }^{38}$ : »Der erste Satz der c-moll-Sonate [Franz Schubert, Klaviersonate c-moll, D 958] ist in sich zwiespältig. Züge, die an Beethoven erinnern, sind mit Eigenem verschränkt, ohne daß der Ausgleich restlos gelänge. « ${ }^{39}$ Die Diskussion besteht darauf, dass »Ausgleich« zu »gelingen« habe. Eine ähnliche Denkkategorie ist die der Einheit oder des Ganzen. Dahlhaus' Analysen sind dem Ideal der äs-

35 | Dieser Begriff geht auf Wolfgang Rihm zurück, der den "Ort" eines Klanges als diesem unmittelbar zugehörig beschreibt: "Für das Handwerk hat das die Konsequenz, daß Klänge nicht mehr als hingenommene Folge von Denkvorgängen stehen können, worin man ja lange das besonders Intelligente an einer Musik ausmachen zu können glaubte. Die Klänge müssen 'wie für sich، entstanden sein, unverwechselbar, unauswechselbar." W. Rihm: Spur, Faden, S. 74; Herv. i.0.

36 | C. Dahlhaus: Plädoyer für eine romantische Kategorie, S. 277; Untertitel: „Der Begriff des Kunstwerks in der neuesten Musik".

37 | C. Dahlhaus: Analyse und Werturteil, S. 92; vgl. ebd., S. 70.

38 | Ebd., S. 92, 82.

39 | Ebd., S. $81 f$. 
thetischen Autonomie, verbunden mit dem Werkbegriff, verpflichtet. Die Aufschlüsselung einer »sinnvollen Bezogenheit« der einzelnen »Teile« »aufeinander und auf das Ganze ${ }^{40}$ bezieht sich auf einen Denkvorgang, festgehalten in der Partitur, und stellt ihrerseits wieder einen Denkvorgang dar. Beide Denkvorgänge sind nicht kongruent, können sich aber einander annähern:

"Begreift man das Komponieren, das 'Arbeiten des Geistes in geistfähigem Materialı [Hanslick, 6, 35], als musikalisches 'Denken`, so erscheint das Verstehen von Musik, der hörende und lesend-hörende Nachvollzug, als 'Denken des Gedachten`. " ${ }^{41}$

Analyse, sofern sie gelungen ist, folgt den Denkvorgängen des Komponisten und deckt die durch Denkvorgänge hergestellten Beziehungsgefüge auf. Sprache muss nicht problematisiert werden, da die Analyse einerseits zwar dem hohen Anspruch eines sachgerechten (hier reflexiven) »Nachvollzugs« unterliegt, andererseits aber auch sich damit bescheidet: Sinn erfüllt sich als Beziehungsnetz, in dem die Teile einander zugeordnet sind und sich dabei an der übergeordneten Ganzheit ausrichten.

Der Partitur als zu entschlüsselndes »Sinngefüge« versucht auch Hans Heinrich Eggebrecht Sinn zu entnehmen:

"Zum Beispiel: Wir hören eine Musik von Bach. Daß diese Musik einen Sinn hat, ist vollkommen klar; es ist analytisch nachweisbar, zu erkennen und zu benennen, daß sie in ihren Bestandteilen, ihren Konstituenten, ein Sinngefüge ist, das sich als solches dem sinnlichen Wahrnehmen zu verstehen geben will. Und wir als Hörer sind hierfür prädisponiert: Wir haben - vornehmlich in Prozessen der ästhetischen Erfahrung - die Fähigkeit erworben und tragen sie in uns, Bachs Musik zu verstehen, das heißt sie als Sinngefüge zu erfassen, auch wenn der Sinn unbenannt und der Prozeß des Erfassens uns unbewußt bleibt. " ${ }^{42}$

Das Verstehen des Hörers geschieht durchaus auch ohne Fachtermini, auch ohne verbale Be- und Umschreibungen des Gehörten, es gründet sich auf Erfahrung mit einer bestimmten Art von Musik. »Wie aber, so sei nun weiterhin gefragt, kommt der Sinn in die Musik hinein? « ${ }^{43}$ Wenig später die Antwort:

40 | C. Dahlhaus: Plädoyer, S. 277.

41 | C. Dahlhaus: Das "Verstehen" von Musik, S. 46; Dahlhaus bezieht sich hier auf Hanslick, Eduard: Vom Musikalisch-Schönen. Reprographischer Nachdruck der 1. Auflage (Leipzig 1854), Darmstadt 1965, S. 6, 35.

42 | H. H. Eggebrecht: Musik verstehen, S. 26.

43 | Ebd., S. 27. 
"Der Sinn einer Musik liegt in ihrer Formung beschlossen. Unter Formung verstehe ich das Formsein der Musik insgesamt, das Gefüge aus den die Musik konstituierenden Substanzen, angefangen von der ersten Ton- und Klangfolge bis hin zur Form des Ganzen. [...] Das Sinngefüge einer Musik ist ihr Formgefüge und umgekehrt. " ${ }^{44}$

Das »Sinngefüge« ist die Bezogenheit der einzelnen Klangverbindungen aufeinander und auf das Ganze hin. Der Musikwissenschaftler kann dieses Gefüge beschreiben, dem (mehr oder weniger erfahrenen) Hörer erschließt es sich auch ohne Worte: »unbewußt«.

Sinn ist eher an einer nachvollziehbaren Formung festzumachen, während Bedeutung innerhalb eines subjektiven Spielraums die Brücke zum Außermusikalischen schlägt. Der Nachvollzug des »Formgefüges« ist der erste Schritt, von hier aus kann sich dann die Deutung vollziehen: »[W]eiträumig sind die Möglichkeiten des von dem Formsinn ausgelösten Bedeutungsverstehens, bei dem die subjektive Disposition des Hörers mitspielt. ${ }^{45}$ Die verbale Beschreibung der Komposition nimmt vom »Formgefüge« ihren Ausgang: »Zugleich bringt unser analytisches Beschreiben des Formsinns auch das ihm innewohnende Bedeuten der Musik zur Sprache (ihren Gehalt)«. Der »Sinn« ist angebunden an das »Formgefüge«, das »Bedeuten« geht darüber hinaus. So lautet eine Empfehlung zur Analyse: »Unterscheide Sinn und Gehalt: Analyse des Formsinns und Interpretation der Aussage einer Musik.«

In der gemeinsam verfassten Publikation »Was ist Musik?« behandeln Dahlhaus und Eggebrecht verschiedene Themen zum Teil in abwechselnden Beiträgen, zum Teil im verschriftlichten Dialog. Im Dialog »Musikalischer Gehalt« kommt Eggebrechts Standpunkt zur Trennung der Form, welche er mit dem musikalischen »Sinn« verknüpft, vom musikalischen »Gehalt« zur Sprache:

"Wann immer ich Musik betrachte, versuche ich, indem ich ihre Form erkunde, zugleich ihren Gehalt zu erkennen und anzusprechen. In der Form, der Formung im weitesten Sinn, liegt der musikalische Sinn beschlossen, und ohne inn ist musikalisch nichts. Der musikalische Sinn ist das spezifisch Musikalische; es gibt inn nur als Musik, sonst nirgends. Der Gehalt indessen ist etwas, das stets auch außerhalb der Musik existiert. Er erscheint als Musik, indem er dem musikalischen Sinn innewohnt, ohne mit inm identisch zu sein. " ${ }^{46}$

Dahlhaus folgt ihm nicht in dieser Entschiedenheit, er weicht einer Gegenüberstellung von Form und »Gehalt« aus, will sich eher vom »Denkzwang«

44 | Ebd., S. 28.

45 | Ebd., S. 131; die folgenden Zitate ebd., S. 131, 135.

46 | C. Dahlhaus/H. H. Eggebrecht: Was ist Musik?, S. 139. 
lösen, »der von Dichotomien wie >Form und Gehalt « ausgeht «. ${ }^{47}$ Er vertritt den Anspruch des Werks, im Hinblick sowohl auf »Form« als auch auf »Gehalt« ästhetische Autonomie zu behaupten:

"Die 'musikalische Logikı, die ein Streichquartett von Brahms realisiert, bildet ebenso eine Legitimation des Autonomiepostulats wie Liszts Ehrgeiz, in Symphonischen Dichtungen an der Weltliteratur musikalisch interpretierend gleichsam , weiterzudichten ‘. " ${ }^{48}$

Diese Debatte in den 6oer, 7oer und 8oer Jahren des vergangenen Jahrhunderts geschah vor dem Hintergrund einer ganz bestimmten ästhetischen und kunsttheoretischen Ausrichtung: der Orientierung am autonomen Kunstwerk. »Die Idee der absoluten Musik« - selbst Titel einer grundlegenden Schrift von Dahlhaus - bestimmte mit und seit der romantischen Musikästhetik musikphilosophisches und -ästhetisches Denken. Diese spezielle Ausrichtung muss keinen Mangel bedeuten, kann aber leicht die Ausblendung anderer Perspektiven mit sich führen.

\section{Lebensvollzüge - (Über-)Lebensformen (John Blacking)}

Etwa zeitgleich zu Dahlhaus' Publikation »Analyse und Werturteil« oder zu dessen Aufsatz »Plädoyer für eine romantische Kategorie« erschienen anthropologische und ethnowissenschaftliche Untersuchungen wie Allan P. Merriams »The Anthropology of Music« oder John Blackings »How musical is man?«.

»How musical is man?« In dieser 1973 veröffentlichten Studie setzt Blacking sich auch mit westlicher »Konzertmusik« (Besseler), so mit Werken von Gustav Mahler und Benjamin Britten (War Requiem), auseinander. Weil er keine distinkte Trennungslinie zwischen »Art Music« und »Folk Music« zieht, gewinnt er eine eigene Sicht auch auf Werke der europäischen Kunstmusik und widmet seine Forschung der Entstehung sozialer Kräfte beim Musizieren. Worin sieht Blacking Sinn oder Bedeutung? Vor dem Hintergrund einer eigenen klassischen musikalischen Ausbildung brachte ihn die Beschäftigung mit der Musik der Venda in Südafrika zu einer neuen Einschätzung der Musik Afrikas. ${ }^{49}$ Für ihn löste sich die Entgegensetzung von » folk< and >art< music« auf, alle Arten von Musik wurde für ihn »folk music, in the sense that music cannot be transmitted or have meaning without associations between people.« Diese Einsicht brachte für ihn auch eine ganz neue Einschätzung der eigenen

47 | Ebd., S. $145 f$.

48 | Ebd., S. 150; vgl. C. Dahlhaus: Die Idee der absoluten Musik, S. 105ff.

49 | J. Blacking: How musical is man?, S. IX; das folgende Zitat ebd., S. X. 
westlichen Musik mit sich. Sinn (»meaning«) bleibt für ihn an die Begegnung zwischen Menschen gebunden.

Blacking spricht über Musik als »Humanly Organized Sound « (so der Titel des ersten der vier Kapitel). Was ist Musik? Diese Frage beantworten unterschiedliche Kulturen und unterschiedliche soziale Gruppen unterschiedlich: »More important than any arbitrary, ethnocentric divisions between Music and Ethnic Music, or between Art Music and Folk Music, are the distinctions that different cultures and social groups make between music and nonmusic. $\aleph^{50}$ Nicht eine Gegenüberstellung von Kunst- und Volksmusik ist also für ihn entscheidend; er setzt vielmehr auf Unterscheidungen, die verschiedene Kulturen und soziale Gruppen zwischen Musik und Nicht-Musik (»between music and nonmusic«) treffen. Ihm kommt es auf das Tun, auf die musikalische Aktivität der Musiker an: »[I]t is the activities of Man the Music Maker that are of more interest and consequence to humanity than the particular musical achievements of Western man. $\aleph^{51}$ Diese Aktivitäten sind bezogen auf eine musikalische »Situation« bzw. auf eine musikalische »Gelegenheit«:

"[ []f we take a world view of music, and if we consider social situations in musical traditions that have no notation, it is clear that the creation and performance of most music is generated first and foremost by the human capacity to discover patterns of sound and to identify them on subsequent occasions. "“2

Wiederholt kommt Blacking auf diese musikalische »Gelegenheit« (»occasion«) zu sprechen, durch die das Tun in direkte Lebensvollzüge eingebunden wird: »Much Venda music is occasional, and its performance is a sign of the activity of social groups. $\ll^{53} »$ (Musikalische) Situation « und »(Musikalische) Gelegenheit« sind Termini, die sich in die Diskussion der musikalischen Praxis transferieren lassen; grundlegend für die Praxis ist schließlich auch die von Blacking im vierten und letzten Kapitel aufgeworfene Frage nach dem Wozu musikalischer Tätigkeit. Im zweiten Kapitel »Music in Society and Culture« geht Blacking auf verschiedene Funktionen des Musizierens in unterschiedlichen Situationen, zu unterschiedlichen Anlässen ein, während er im dritten (»Culture and Society in Music«) über musikalische Analysen den umgekehrten Weg von der Musik zur Praxis einschlägt. Das letzte Kapitel trifft die Essenz des Denkens über Musik als musikalische Praxis:

$\mathbf{5 0}$ | Ebd., S. 3f.; das folgende Zitat ebd., S. 4.

$51 \mid$ Ebd., S. 9.

$\mathbf{5 2} \mid$ Ebd.

53 | Ebd., S. 38. 
"In a world in which authoritarian power is maintained by means of superior technology, and the superior technology is supposed to indicate a monopoly of intellect, it is necessary to show that the real sources of technology, of all culture, are to be found in the human body and in cooperative interaction between human bodies. “ 54

In einer Welt der überlegenen, dominierenden Technik sei es nötig, die wahren Quellen für Technik und Kultur in der Körperlichkeit und im Beziehungsgeschehen zwischen Menschen aufzudecken. Musikalische Praxis wird vor diesem Hintergrund Über-Lebensform:

"In a world such as ours, in this world of cruelty and exploitation in which the tawdry and the mediocre are proliferated endlessly for the sake of financial profit, it is necessary to understand why a madrigal by Gesualdo or a Bach Passion, a sitar melody from India or a song from Africa, Berg's Wozzeck or Britten's War Requiem, a Balinese gamelan or a Cantonese opera, or a symphony by Mozart, Beethoven, or Mahler, may be profoundly necessary for human survival, quite apart from any merit they may have as examples of creativity and technical progress. " 55

Menschen überleben mit Musik. Der Sinn von Musik? Musik ist notwendig für menschliches Überleben (»necessary for human survival«). Eine ganz andere Perspektive öffnet sich hier. Musik zum Überleben, um Verbindungen mit anderen einzugehen, zu Begegnungen zu finden. In musikalischer Praxis agieren wir als Körper - und wir tun es gemeinsam; auch bei der Ausführung eines Solostücks per se sind wir mit anderen verbunden. Angesichts einer Welt wie der unseren (»In a world such as ours«, wie Blacking sagt) möchten wir etwas tun, wobei dieses Tun in musikalischer Praxis uns in ein Geschehen zieht, das auf Zukünftiges aus ist, Hoffnung macht. Blacking spricht dieses Potential an (aus anthropologischer, ethnowissenschaftlicher Perspektive) und ermöglicht so den Einstieg in einen neu und anders gefassten Sinnbegriff, der sich gleichwohl auch für Werke der europäischen Tradition geltend machen lässt.

Im Folgenden werden die Ansätze von Lawrence Kramer und Nicholas Cook vorgestellt. Beide Wissenschaftler widmen sich den Aktivitäten und der Körperlichkeit der Ausführenden, beide untersuchen das Spannungsverhältnis zwischen Partitur und Ausführung, beide arbeiten mit ihren Forschungen der Auseinandersetzung mit musikalischer Praxis zu. Der sich anschließende Exkurs zum »Sichzeigen« (Dieter Mersch) lässt sich als Anstoß zur Sprachfindung lesen.

54 | Ebd., S. 116.

55 | Ebd., Herv. i.0. 


\section{"Text" und "Kontext" (Lawrence Kramer)}

»Meaning, whether in music, image, or text, is a product of action rather than of structure. ${ }^{56}$ Bedeutung ist nicht gegeben, sondern entsteht in den $»$ Kontexten « einer bestimmten Interpretation, ist Ergebnis einer »Verhandlung« (»negotiation«) zwischen »Text« und »Kontext« der Interpretation. In »Interpreting Music« geht Lawrence Kramer der Frage nach, inwiefern die Ausführung von Musik deren Bedeutungsebene mitbestimmt - über die Partitur hinaus. Bedeutung (»meaning«) ist nicht von vornherein gegeben, ist nicht in der Partitur verschlüsselt, die dann entsprechend zu dechiffrieren wäre, sondern entsteht; erscheint mit der Interpretation, mit deren »Kontext«: »It thrives, or not, on what might be termed the contexture of interpretation. « Die Anbindung an die Praxis und die Berücksichtigung der Fragen, inwiefern Situation, Umgebung, Publikum zur Interpretation von Musik beitragen, machen Kramers Ausführungen offen; Bedeutung ist nicht festgelegt: »The best justification for the critical interpretation of music is that music simply does make sense in this way as a practical fact. It is widely felt to be integrated with, not remote from, the general atmosphere of meaning in daily life.« Sinn der musikalischen Praxis und Sinn des alläglichen Lebensvollzugs gehen ineinander über. Kramer besteht auf einer großen Vielfalt musikalischer Erfahrungen, die einer Komposition und deren Aufführungen anhängen. ${ }^{57}$ Er geht darum von einer engen Bezogenheit von »musical meaning « und »musical performance « aufeinander aus, wobei die Aufführung mit Lebenssituationen, mit lebensweltlichen Zusammenhängen verbunden ist.

Dies wird auch in »Why Classical Music Still Matters « angesprochen, vor allem im dritten Kapitel »Score and Performance«: Kramer berichtet über ein grundlegendes Erlebnis anlässlich einer Aufführung von Beethovens Streichquartett Nr. 12 Es-Dur op. 127 durch das Juilliard String Quartet. Er gesteht, dass er all das, was er bei dieser Aufführung in der Musik hörte, nicht eigentlich in der Musik hörte, sondern in der einen einzigen Aufführung an jenem Tag: »So what touched me more, the music or the performance? $\aleph^{58}$ Angesprochen werden hier situationsbedingte, persönlich-individuelle Kontexte, welche die Bedeutung einer Komposition für den Einzelnen grundlegend prägen, beeinflussen, verändern.

In »Musical Meaning. Toward a Critical History« behandelt Kramer »meaning« in kulturhistorischen Kontexten, er bewegt sich dabei zwischen theoretischen Ausführungen und Fallstudien. In der Beispielsammlung werden vorwiegend Kompositionen des 19. Jahrhunderts berücksichtigt, ferner Mu-

56 | L. Kramer: Interpreting Music, S. 68; die folgenden Zitate ebd.; Herv. i.0.

57 | Ebd., S. 260; die folgenden Termini ebd., S. 261.

58 | L. Kramer: Why Classical Music Still Matters, S. 73. 
sik der Marx Brothers, »Jazz and the Blues in Modern Concert Music« und Kompositionen von Weill und Schostakowitsch, schließlich Musik bis ins 20. Jahrhundert hinein (John Coltrane). Das Kapitel »Hands On, Lights Off. The >Moonlight Sonata and the Birth of Sex at the Piano « zeigt exemplarisch, wie Kramer auch den Ausführenden in die Betrachtung einbezieht. Zum ersten Satz der Sonate cis-moll op. 27, 2 (Sonata quasi una fantasia) Beethovens (1801) gibt es den Ausführungshinweis: »delicatissimamente e senza sordino«, sehr zart und ohne Dämpfer, mit Pedal also. Kramer bringt diesen Hinweis mit der Körperlichkeit des Ausführenden in Verbindung:

"He [Beethoven] adds a headnote stating that the Adagio must be played throughout with the greatest delicacy and 'without dampers', that is, with the pedal in continuous use. (Performers on modern pianos cannot take this instruction literally, but the spirit is clear: sustain with the pedal.) The result is to foreground the sensibility of the performer's body, its receptiveness to the slightest sensation. The instruction combines delicacy, which must be produced by touch, with the continuity of sound produced by piano technology. The player's body becomes perceptible as the medium, a kind of rising channel from foot (or, with a fortepiano, knee) to hand, in which mechanically produced sound becomes feeling. To give this process both a tactile and a visual focal point, Beethoven sets the upper and middle voices within the compass of a ninth in the right hand, so that they emerge continuously from a kind of intimate, delicate touch. The hand moves in fluid, rhythmic strokes as if it were caressing the keys. It is at least possible that this way of engaging the body links the Adagio with the expressivity of the lover's serenade, and more generally with the sensitivity of the romantic body. The pianistic effects involved would have been reasonably apparent in an era that knew the music as much, if not more, by playing as by hearing it. " 59

Bezeichnenderweise schreibt Kramer diese Art von Körperlichkeit, die sich im Tasten und Berühren niederschlägt, einer Epoche zu, deren Zeitgenossen mit Musik eher über die Praxis als über das Hören Bekanntschaft machten. Solche Fallstudien, wie sie hier vorgelegt werden, fragen danach, was Ausführende tun und warum sie es tun. Kramer beschreibt nicht strukturelle Aspekte der Partitur, sondern antwortet mit seiner Beschreibung auf das, was sich ihm durch Beobachtung einer Ausführung (oder durch eigenes Spiel) gezeigt hat.

Kein Wunder, dass in Kramers Vorstellung Sinn (»sense«) und Bedeutung (»meaning«) in der Musik ohne Umweg an Sinn und Bedeutung im Leben angebunden werden: Die Schwelle zwischen Musik und Leben ist leichtfüßig zu überschreiten. Mit Bezug auf »mixed media« fragt er, was über musikalische Bedeutung zu lernen sei, und kommt zu dem Ergebnis:

59 | L. Kramer: Musical Meaning, S. 48. 
"First of all that musical meaning is continuous with meaning in general [...]. We make sense of music as we make sense of life. And since we make sense of life only amid a dense network of social, cultural, and historical forces, musical meaning inevitably bears the traces, and sometimes the blazons, of those forces." ${ }^{60}$

Wir finden demnach musikalischen Sinn, wie wir auch Sinn in Lebensvollzügen finden. Und da alle Lebensvollzüge in sozialen, kulturellen und historischen Kontexten eingebunden sind, trägt das, was wir als musikalische Bedeutung erfahren, diese Spuren. Musik und Lebensform(en) sind ganz nah beieinander angesiedelt. Sinn in der Musik und Sinn im Leben: Beide Welten sind aufeinander bezogen, miteinander verknüpft.

\section{"Beyond the score" (Nicholas Cook)}

Mit der Betrachtung von Musik als Ausführung selbst kommt wiederum eine neue Bewegung in die Debatte. Nicholas Cook wählt den Titel eines seiner Beiträge »Music as Performance « mit Bedacht: Wenn man von Ausführung rede, so meine man in der Regel »etwas ausführen«; dies impliziere, mehr oder weniger gewollt oder nicht, die Vorstellung von zwei Bestandteilen, der Ausführung auf der einen Seite, der Musik auf der anderen Seite.

"You can 'just play،, but it's odd to speak of 'just performing،, because the basic grammar of performance is that you perform something, you give a performance rof something. In other words, language - and especially musicological language - leads us to construct the process of performance as supplementary to the product that occasions it, and it is this that leads us to talk quite naturally about music rand its performance ". ${ }^{61}$

Nicht der Musik und ihrer Ausführung also gilt Cooks Forschungsinteresse, sondern der Musik als Ausführung. Er akzentuiert die Frage nach den sozialen Beziehungen der Ausführenden und fasst Musik als »soziales Phänomen«: »To understand music as performance, then, means to see it as an irreducibly social phenomenon, even when only a single individual is involved. ${ }^{62} \mathrm{In}$ diesem Zusammenhang verweist er auf die Nähe zum Ritual. Wichtig wird dann eine begriffliche Differenzierung: Die Rede von der Partitur als »text« führt, so Cook, immer noch die strukturelle Dimension der Komposition mit sich, die auf Realisierung wartet, während die Rede von »script« (als einer Art Choreographie) die Interaktionen der Ausführenden bereits anklingen lässt: »Thinking of music as >script< rather than stext< implies a reorientation of the

60 | Ebd., S. 163.

61 | N. Cook: Music as Performance, S. 204; Herv. i.0.

62 | Ebd., S. 206. 
relationship between notation and performance. ${ }^{63}$ Eine der zentralen Fragen bleibt die nach der Möglichkeit, soziale Interaktion (= soziale Bedeutung) analytisch zu dekodieren. »Music [...] becomes a resource for understanding society. ${ }^{64}$ Aber wie darüber reden?

"[T]he problem disappears if instead of seeing musical works as texts within which social structures are encoded, we see them as scripts in response to which social relationships are enacted: The object of analysis is now present and self-evident in the interactions between performers, and in the acoustic trace that they leave. To call music a performing art, then, is not just to say that we perform it; it is to say that through it we perform social meaning. " ${ }^{65}$

An die Stelle von Versuchen, Partituren als Texte zu dekodieren, tritt die Entschlüsselung der Interaktionen der Ausführenden, welche »akustische Spuren« (»acoustic traces«) hinterlassen. Bedeutung (»meaning«) erschließt sich als »soziale Bedeutung« über eine Analyse der Interaktion.

»Beyond the Score. Music as Performance« (2013) ist die wohl umfangreichste inmitten einer Reihe von Veröffentlichungen, die Cooks Anliegen vertreten: Abkehr von textzentrierter Forschung, Hinwendung zur Analyse der Auf- und Ausführung. Bedeutung (»meaning«) wird im Vollzug der Ausführung geschaffen, sie entsteht im Prozess, wird hervorgebracht, ist also nicht a priori gegeben. Cook will beschreiben, »how performances afford the production of meaning « ${ }^{66}$ »Beyond the Score« widmet sich in den ersten Kapiteln der Analyse von Tonaufnahmen (zu einem größeren Teil von Klaviermusik); anschließend werden Ausführungen verglichen und einer kulturhistorischen Untersuchung unterzogen (anhand einer breit gestreuten Beispielsammlung); sodann wird die bereits angesprochene Frage nach den sozialen Interaktionen der Musiker in den Vordergrund gerückt. Die Frage lautet, wie Partituren dazu dienen, diese aufzuzeichnen (»how scores serve to script them « ${ }^{67}$ ). Die nächsten Kapitel behandeln die Rolle des Körpers, konzentrieren sich auf Körpergeste, Körperbewegung beim Spiel. Cook gibt die Anbindung an die Partitur nicht auf, er definiert deren Rolle aber neu und sucht Bedeutung nicht in der Partitur als Text, sondern in der »real-time activity«. Aufführung: »a real-time activity through which meanings emerge that are not already deposited in the score ${ }^{68}{ }^{6}$ Bedeutungen (Sinnhaftigkeiten auch) sind also nicht (in einer Parti-

63 | Ebd.

$64 \mid$ Ebd., S. 213.

65 | Ebd.

66 | N. Cook: Beyond the Score, S. 1.

67 | Ebd., S. 6.

$68 \mid$ Ebd., S. 23. 
tur verschlüsselt) gegeben, um als solche aufgespürt und sprachlich gefasst zu werden, sondern sie treten im Ausführungsprozess (live) zutage: Sie tauchen auf, entstehen, treten hervor, stellen sich heraus. Beobachtet wird ein prozesshaftes Geschehen.

In seinem Beitrag »Musikalische Bedeutung und Theorie« äußert Cook sich explizit zum Prozess der Bedeutungsgenese und zieht das Bild einer Reihe von »Spuren« heran, um seine Rede anschaulicher zu machen: »Was wir als rein Musikstück betrachten, sollte daher als eine unendliche Reihe von Spuren aufgefaßt werden. ${ }^{69}$ Wichtig wird in diesem Zusammenhang Cooks Terminus der Emergenz: im Deutschen als Substantiv gefasst für diesen Zusammenhang vielleicht weniger zutreffend. Im Englischen heißt es: »meanings emerge«, Bedeutungen erscheinen, scheinen auf. »[Bedeutung] wird nicht produziert, sondern durch den Akt der Aufführung hervorgebracht. « ${ }^{70}$ Bedeutung ist nicht festgeschrieben, sie verändert sich, schillert je nach historischem Kontext, unterschiedlichen Traditionslinien oder Aufführungsbedingungen: »Es ist demnach falsch zu sagen, daß Musik bestimmte Bedeutung hat; vielmehr hat sie das Potential dafür, daß bestimmte Bedeutungen unter bestimmten Umständen emergieren.« Diese Erweiterung um ein der musikalischen Ausführung (und auch der Partitur als »Skript«) innewohnendes »Potential« befreit von festen Zuschreibungen von Bedeutung.

Aufschlussreich ist Cooks Unterscheidung zwischen »potentieller« und »aktualisierter« Bedeutung: »[M]usikalische Werke sind, betrachtet man sie als Urheber von Bedeutung, instabile Aggregate potentieller Bedeutung. ${ }^{71}-$ »Interpretieren heißt, potentielle Bedeutung in aktualisierte Bedeutung zu überführen.« - »Musik ist von musikkritischer Interpretation abhängig, um Bedeutung zu haben, und gleichzeitig unaussprechlich «. »Potentielle« Bedeutung soll als ein Strang, als utopischer Ausblick, erhalten bleiben; in diesem Sinne gelingt es Cook, den romantischen Topos des Unaussprechlichen zu retten. ${ }^{72}$ »Aktualisierte « Bedeutung ist weniger stark, dafür variabel, abhängig von Kontexten und lässt sich, als Provisorium gedacht, auch verbalisieren. Ein Kompromiss? Wie dem auch sei: Sinn und Bedeutung sind nicht gegeben, sondern erscheinen, werden gegeben im Erscheinen (»meanings emerge ${ }^{73}$ ).

69 | N. Cook: Musikalische Bedeutung und Theorie, S. 98.

70 | Ebd., S. 99; das folgende Zitat ebd., S. 101; Herv. i.0.

71 | Ebd., S. 114; die folgenden Zitate ebd., S. 101, 113.

72 | Vgl. ebd., S. 108ff.: "Die Rehabilitierung des Unaussprechlichen ".

73 | N. Cook: Beyond the score, S. 23. 


\section{"Sichzeigen" (Dieter Mersch)}

»Überall regiert so ein Primat des Hermeneutischen, dominiert das Bedeutungsproblem, die Frage nach dem Sinn, nicht aber nach etwas, was sich selbst ausstellen oder präsentieren muß, um erscheinen zu können oder vernehmbar zu werden. ${ }^{74}$ Die Befreiung, die hier anklingt, betrifft musikalische Praxis unmittelbar: Nicht einmal mehr muss noch etwas gezeigt werden, Dieter Mersch geht es direkt um ein »Sichzeigen«. Er konzentriert die Rede über das, »was sich zeigt«, indem das Zeigen nicht länger als ein Zeigen auf etwas verstanden wird, sondern als ein »Sichzeigen «. ${ }^{75}$ Damit ist eine Dichotomie zwischen Sagen und Zeigen überwunden, denn das »Sichzeigen« tritt nicht in Konkurrenz zum Sagen; ihm kommt ein Mehrwert zu, der sich nicht sagen lässt:

"Das Sichzeigen geht dem Sagen voraus, überformt es, lenkt es in ein anderes um. Kein Zeichen vermag sich zu artikulieren oder vor dem Hintergrund anderer Zeichen abzuzeichnen, ohne selbst etwas zu 'sein'; ein 'Ereignis', das unbeherrschbar bleibt und beharrlich die Bedeutungsprozesse irritiert. Man könnte sagen: Jedes Zeichen ist stets mehr als es sagt, zeigend birgt es einen Überschuß, der nicht bedeutet und darum auch nicht wieder signifizierbar wäre." ${ }^{76}$

»Was sich zeigt«: Im ersten Teil geht Mersch auf Körpersprache, Kunst, Performativität der Stimme ein. Der zweite Teil setzt sich mit dem Zeichen in unterschiedlichen Zeichentheorien auseinander. Kernbegriffe sind Ereignis, Materialität, Präsenz. Als eine Grundlage wird Wittgensteins Sprachphilosophie genannt, wie sie im »Tractatus logico-philosophicus « dargelegt ist; sie »begründe«, so Mersch, die von ihm weiter ausgeführte »Duplizität von Sagen und Zeigen«: »Ihre spezifische Radikalität bildet die >Mystik des Sichzeigens, deren einzige Korrespondenz im Schweigen liegt «. ${ }^{77} \mathrm{Im}$ Weiteren wird das Ereignishafte entfaltet, dessen Begriff die gesamte Schrift prägt. »Wie aber davon überhaupt sprechen?« Mersch sieht einen Weg im »Antworten«, im Antworten auf das, was »widerfährt«: »Denken heißt weder bezeichnen noch unterscheiden oder bestimmen, sondern >antworten<. Das Antworten sucht dem Ereignis als Widerfahrnis zu entsprechen. Denken, oder auch Schreiben, Sprechen und Be-deuten, wird dann in die >Aufgabe $<$ einer Responsivität gestellt « ${ }^{78}$

74 | D. Mersch: Was sich zeigt, S. 16; Herv. i.0.

75 | Vgl. D. Mersch: Körper zeigen, S. $85 f$.

76 | D. Mersch: Was sich zeigt, S. 24; Herv. i.0.

77 | Ebd., das folgende Zitat ebd.; Herv. i.0.

78 | Ebd., S. 38; das folgende Zitat ebd.; Herv. i.0. 
Reden wird ein Antworten auf die Ansprache, die von dem, was sich zeigt, ausgeht. In metaphorischer Rede kann das Sich-Zeigende im Redevollzug umkreist werden:

"Metaphern sind Wege, sie beschreiben Annäherungen ans Ungesagte. Darum verbleiben sie stets im Vorläufigen. An innen stellt sich weder die Frage nach ihrer Richtigkeit noch nach ihrem Zutreffen, ihrer Adäquanz: Ihre Redeform ist das Weisen, die 'Zeige،. Dann handelt es sich um ein Sprechen, das nicht im strikten Sinne begrifflich verfährt, das vielmehr seine Analogien oder Übertragungen (meta-phorá) erzeugt, um anderes, Unbegriffliches anzudeuten. ${ }^{79}$

\subsection{WirklichKeiten? - Welten?}

\section{"Zwei-Welten-Modell" (Hans Heinrich Eggebrecht)}

Musikalisches Handeln, Da-Sein in einer musikalischen Situation, Tun und Geschehen-Lassen als Lebensform? - als Über-Lebensform sogar? Ist die musikalische Praxis leider (oder glücklicherweise?) lediglich Musik? Wird auf existentielle Fragen verwiesen, auf Wirklichkeiten und Möglichkeiten hinausgewiesen? - oder finden wir uns inmitten aller erdenklichen Möglichkeiten und Wirklichkeiten wieder?

»)...das Leben mit der Kunst gleichzusetzen...< John Cage«: In dem so betitelten und als »Intermezzo III« ausgewiesenen Kapitel aus »Musik verstehen $\ll^{80}$ bezieht sich Hans Heinrich Eggebrecht auf ein Gespräch zwischen John Cage und Richard Kostelanetz. Cage erklärt hier: »Der Begriff der Flucht erscheint mir witzlos, wie mir auch der Begriff einer Kunst als Flucht vor dem Leben witzlos erscheinen würde. « ${ }^{81}$ Mit Bezug auf das »I Ging « führt er weiter aus, die Kunst könne die wirklich »wichtigen Fragen « nicht beantworten, »weil diese wichtigen Fragen in jenem Dunkel gestellt werden, in das die Kunst nicht mehr vordringt.« An dieser Stelle wirft Kostelanetz ein: »Heißt das, daß Sie von der Kunst wegzukommen suchen? «22 Und Cage antwortet: »Nein, das heißt, daß wir das Leben mit der Kunst gleichzusetzen suchen, und damit beginnen wir in der Dunkelheit.«83

An eben dieser Stelle hakt Eggebrecht ein:

79 | Ebd., S. 40; Herv. i.0.

80 | H. H. Eggebrecht: Musik verstehen, S. 183-208.

81 | J. Cage: Gespräch mit John Cage. Richard Kostelanetz, S. 36; die folgenden Zitate ebd.

82 | Ebd.

83 | Ebd., S. 37. 
"Diese Maxime [von John Cage] trifft dasjenige ins Herz, was ich an anderer Stelle das ZZwei-Welten-Modell genannt habe. Mit diesem Modell-Begriff ist gemeint, daß die wirkliche Welt, die Welt als Lebenswirklichkeit einerseits, und die Kunst, insbesondere die Musik andererseits, antithetisch sich gegenüberstehen: Die Welt als Wirklichkeit ist negativ gesetzt und erzeugt als Zuflucht, Ventil, Überlebenschance, Erlösung die Gegenwelt der Kunst - ein Fungieren der Kunst, das in der deutschen Romantik seit Wilhelm Heinrich Wackenroder dominierend in Erscheinung trat, das aber weit über jeden historischen Rahmen hinaus eine für das Verhältnis von Kunst und Leben fundamentale Bedeutung hat. " ${ }^{84}$

Eggebrecht tritt eindringlich für Trennschärfe der »Welten« ein: Auf der einen Seite die »Lebenswirklichkeit«, auf der anderen Seite die »Gegenwelt« Kunst, speziell Musik, die zum Überleben verhelfen, »Überlebenschancen« bieten kann. Er verweist auf Cages Replik, in Cages »Silence« heißt es nämlich:

"Er [der Komponist] muß es besser tun, eindrucksvoller, schöner usw. als irgendwer sonst Und was hat, genaugenommen, dies, dieses schöne tiefe Objekt, dieses Meisterwerk, mit dem Leben zu tun? Es hat dies mit dem Leben zu tun: daß es davon getrennt ist. Jetzt sehn wir es und jetzt nicht. Wenn wir es sehn fühlen wir uns besser, und wenn wir fern davon sind, fühlen wir uns nicht so gut Das Leben scheint schäbig und chaotisch, in Unordnung, häßlich im Gegensatz dazu. ${ }^{85}$

Eggebrecht stellt in »Musik verstehen« die »Welt als Lebenswirklichkeit« neben die »Gegenwelt« der Kunst: ein antithetisches Verhältnis. Cage misstraut dem »Meisterwerk« und beruft sich mit einem Zitat aus dem »I Ging« auf Gedanken des Buddhismus.

Irritierend ist Eggebrechts Plädoyer für ein »Zwei-Welten-Modell«, dem er, es verabsolutierend, »weit über jeden historischen Rahmen hinaus eine für das Verhältnis von Kunst und Leben fundamentale Bedeutung « zuweist. ${ }^{86}$ In »Die Musik und das Schöne« beschreibt er, ausgehend von Liedern Schuberts und Mahlers, die romantische Ästhetik als eine Ästhetik der Antithese. Lebenswirklichkeit und schöne Welt der Kunst, des Traums, der Phantasie treten einander unversöhnlich gegenüber: »Die Lebenssicht der deutschen Romantik ist gekennzeichnet durch eine Auffassung der Welt als Weltendualität. « ${ }^{87}$ Diese »Zwei-Welten-Sicht«, die hier als genuin »romantische« Sicht klassifiziert wird, kann christlich orientiert sein, muss es aber nicht. Sie findet ihren Nie-

$84 \mid$ H. H. Eggebrecht: Musik verstehen, S. 203.

85 | J. Cage: Silence, S. 40; vgl. H. H. Eggebrecht: Musik verstehen, S. 204.

86 | H. H. Eggebrecht: Musik verstehen, S. 203.

87 | H. H. Eggebrecht: Die Musik und das Schöne, S. 162; das folgende Zitat ebd., S. 168. 
derschlag in Dualität, Spaltung, Trennung der Welten. Dem stellt Eggebrecht die christliche Sichtweise gegenüber: Auch hier gebe es zwei Welten, die irdische und die himmlische, aber sie seien nicht unversöhnlich nebeneinander gestellt, sondern, wie es Johann Sebastian Bachs Kantate Weinen, Klagen, Sorgen, Zagen zeige, in Christus miteinander versöhnt. ${ }^{88}$

Die Einbindung des »Zwei-Welten-Modells « in einen musikhistorischen Zusammenhang macht es als Erklärungsmodell für eine bestimmte ästhetische Orientierung in einer bestimmten historischen Epoche plausibel. Umso unverständlicher tritt indes zunächst die Verabsolutierung des Modells auf. Sobald jedoch die Ausführenden mit ins Spiel kommen, erfährt die Grenze zwischen den Welten eine neue Deutung, die den Transfer des »Zwei-Welten-Modells« in die Gegenwart wiederum erklärlich macht. Eggebrecht führt nämlich die für ihn entschiedene Trennung der Welten auf den Spielcharakter der Musik zurück; Komponisten, Spieler und Hörer können es »genießen, in dieses Spiel, indem sie es spielen und mitspielen, hineingezogen und das heißt ihrer Wirklichkeitswelt enthoben zu werden. ${ }^{89}$ Das Festhalten an der Grenze zwischen den Welten, die Eggebrecht ausdrücklich thematisiert, indem er die Notwendigkeit eines »Rahmens« für die Ausführung, nämlich »Raum, Garderobe und Programmheft, das Hingehen und wieder Weggehen und so weiter«, anspricht, wird vor dem Hintergrund des notwendigen Übergangs von der einen Welt in die andere und wieder zurück verständlich. Unausgesprochen bleibt allerdings, ob der »Gegenwelt« der Musik in diesem Modell auch Wirklichkeitscharakter zukommt; unausgesprochen bleibt ferner, ob und inwieweit beide Welten in Kontakt zueinander treten, welcher Art das Miteinander-zutun-Haben (Cage) sein könnte, das über bloße Trennung hinausgehen könnte.

\section{Performativität (Erika Fischer-Lichte)}

Vom »Performativen« ist die Rede, wenn zu beschreiben ist, dass und wie Handlungen Wirklichkeit(en) entstehen lassen, hervorbringen, erschaffen können. Erika Fischer-Lichte bestimmt den »Begriff des Performativen« dementsprechend so:

"Der Begriff bezeichnet bestimmte symbolische Handlungen, die nicht etwas Vorgegebenes ausdrücken oder repräsentieren, sondern diejenige Wirklichkeit, auf die sie verweisen, erst hervorbringen. Sie entsteht, indem die Handlung vollzogen wird. Ein performativer Akt ist ausschließlich als ein verkörperter zu denken." "

88 | Ebd., S. 168ff.

89 | Ebd., S. 205; das folgende Zitat ebd., S. 207.

$90 \mid$ E. Fischer-Lichte: Performativität, S. 44. 
Der Begriff der Performance, abgeleitet aus dem englischen Verb »to perform « (aufführen, ausführen, erfüllen, leisten, verrichten, ausüben, spielen, vollziehen, vollbringen, vorführen, vollführen, darbieten, wiedergeben), lässt sich differenziert auffassen: als »Aufführung « oder als »Ausführung/Leistung «. ${ }^{11}$ Fischer-Lichte unterscheidet zwischen »Aufführung « und »Ausführung«, indem sie »Ausführung« an »Leistung « bindet, »Aufführung « ist stärker als »Ausführung«. Dies wird daran deutlich, dass, so Fischer-Lichte, »sowohl Austin als auch Butler davon ausgehen, dass Sprechakte und performative körperliche Handlungen nicht nur ausgeführt, sondern auch aufgeführt werden.« Das »Performative« wäre ein Oberbegriff: »Aufführungen sind immer performativ, während nicht alles, was wir als performativ begreifen, in einer Aufführung in Erscheinung treten muss.«

Fischer-Lichte beschreibt Aspekte des Performativen vor dem Hintergrund der Entwicklungen, die seit etwa 1900 von der »Ritualforschung « und der »Theaterwissenschaft« ausgingen; im Übergang vom 19. zum 20. Jahrhundert vollzogen sich, so Fischer-Lichte, in den Kulturwissenschaften eine Abkehr vom »Text« und eine Hinwendung zu Körper, Verkörperung, Wirklichkeit auf der Bühne selbst (anstelle einer Als-ob-Wirklichkeit, in die sich die Zuschauer über eine Phantasieleistung hineinzuversetzen hatten)..$^{22}$

Die im Folgenden von Fischer-Lichte beschriebenen für Performativität wichtigen Aspekte sind gerade auch für musikalische Praxis konstitutiv: a) »Leibliche Ko-Präsenz«: Aufführung entspringt einer »Begegnung oder Konfrontation der Beteiligten «93; wesentlich ist der Prozesscharakter. b) »Räumlichkeit«: Damit ist weniger der architektonische Raum gemeint, sondern eine ephemere Räumlichkeit, die erst »durch die Aufführung hervorgebracht«, »performativ erzeugt« wird..$^{94}$ c) »Körperlichkeit«: Hier betont Fischer-Lichte das Werden, akzentuiert das Werden viel stärker als das Sein, denn der menschliche Körper »[befinde] sich beständig im Werden befindet, im Prozess einer permanenten Transformation «. ${ }^{95}$ Das Werden widersetze sich »vehement jeglicher Vorstellung von einem Werk«. d) »Lautlichkeit«: »paradigmatisch für die Flüchtigkeit von Aufführungen « - $\gg$ Raumgefühl« erzeugend. ${ }^{96}$ e) »Rhythmus«: nicht als Takt oder Metrum verstanden, sondern als »dynamisches Prinzip, das >unterwegs ist und bleib $\left.\ll .{ }^{97} \mathrm{f}\right) »$ Wahrnehmung/Erzeugung von Bedeutung«: Bedeutung entsteht prozesshaft; Wahrnehmung »erscheint [...] selbst

91 | Ebd., S. 53; die folgenden Zitate ebd.

92 | Ebd., S. 13.

93 | Ebd., S. 54.

94 | Ebd., S. 58.

95 | Ebd., S. 60; das folgende Zitat ebd.

96 | Ebd., S. 62.

97 | Ebd., S. 64; Herv. i.0.; Fischer-Lichte bezieht sich hier auf James J. Sheehan: Ge- 
als ein performativer Prozess «. $\left.{ }^{98} \mathrm{~g}\right) \gg$ Ereignishaftigkeit von Aufführungen«: Der Aufführung wesentlich sind Singularität und Unwiederholbarkeit. Die Aufführung ist durch ein »Zusammenfallen von Gegensätzen « gekennzeichnet, »dichotomische Begriffspaare« werden außer Kraft gesetzt; »Sowohl-alsauch « tritt an die Stelle eines »Entweder-oder «. ${ }^{99}$

Der zuletzt genannte Hinweis lässt sich geradezu als Charakterisierung einer Situation musikalischer Praxis lesen, in der sich Ausführende zwischen Tun und Geschehen-Lassen wiederfinden, in einer Situation, in der sie selbst bestimmen, wie es weitergeht, in der ihnen aber auch etwas geschieht, etwas zufällt. Zum Aspekt der Unwiederholbarkeit sei ergänzt: Mit Blick auf die musikalische Praxis sind Ausführungen auf Wiederholung angelegt; unwiederholbar sind sie allerdings in ihrer jeweiligen singulären Ausprägung. An dieser Stelle bietet sich noch einmal ein Vergleich zwischen Fischer-Lichtes und Butlers Performativitätskonzept an. Butlers Konzept geht, so Gebske, von der »Zitation« aus, welche das Alltagsleben und alltägliche soziale Prozesse kennzeichnet. Über die Wiederholung von bestimmten »Normen« und »Konventionen $\aleph^{100}$ werden diese bestätigt oder auch destabilisiert; der Wiederholungsprozess ist unanfänglich und unendlich: »Der andauernde Prozess der Zitation, den Butler als performativ bezeichnet, hat keinen Anfang und wird nie abgeschlossen sein. «101 Fischer-Lichte hingegen bindet, wie Gebske es sieht, Performativität an »Transitorik und Augenblickhaftigkeit«, ihr geht es um »Aufführungen, die sie als Ereignisse auffasst und die sich durch Flüchtigkeit auszeichnen.«

Die musikalische Praxis bewahrt die Unabgeschlossenheit des wiederholten Tuns und liefert sich zugleich - und vielleicht gerade dadurch - dem ephemeren Charakter der Aktionen und Aktivitäten aus. Wiederholung zeigt dann immer wieder neu, dass und auf welch vielfältige Weise es keine Wiederholung geben kann. Erneut hervorzuheben und für eine Studie zur musikalischen Praxis zu gewinnen seien Fischer-Lichtes Gedanken an die Flüchtigkeit der Ausführung, an deren Prozesscharakter sowie an die Oszillation zwischen Tun und Geschehen (auch: Geschehen-Lassen). Des Weiteren soll ein Aspekt nicht unerwähnt bleiben, der in musikalischer Praxis eine Antwort (von mehreren) auf die Frage »Warum auch?« geben kann, nämlich die Ausrichtung auf Zukünftiges:

schichte der deutschen Kunstmuseen. von der fürstlichen Kunstkammer zur modernen Sammlung, München: C. H. Beck 2002.

98 | Ebd., S. 65-67.

99 | Ebd., S. 67-68.

100 | J. Gebske: Performativität, S. 52.

101 | Ebd., S. 53; das folgende Zitat ebd., S. 54. 
"[P]erformative Prozesse [sind] per definitionem auf die Zukunft bezogen: Ganz gleich, ob es sich um Sprechakte, andere symbolische Praktiken, Rituale, Feste, Sportwettkämpfe, Gerichtsverhandlungen, politische Veranstaltungen, künstlerische Aufführungen u.a. handelt, verweisen sie alle unüberhörbar auf eben die Zukunft, die durch ihren Vollzug hervorgebracht wird. Aus innen geht Zukünftiges hervor, das häufig weder so intendiert und geplant noch vollständig dem Zufall überlassen ist. " ${ }^{102}$

Skepsis an der »Minimaldefinition « ${ }^{103}$ des Performativen, dass nämlich »Handlungen, die nicht etwas Vorgegebenes ausdrücken oder repräsentieren, [...] diejenige Wirklichkeit, auf die sie verweisen, erst hervorbringen «104, äußert Jörg Volbers: »Was heißt hier >hervorbringen<? Was heißt hier >Wirklichkeit<? Und wie nehmen Akte >Bezug«? Drei Fragen, die Grundprobleme der Sprachphilosophie, der Ontologie und der Metaphysik aufwerfen. ${ }^{105}$ Volbers schreckt vor dem Begriff der Wirklichkeit zurück, sofern damit eine Art Neuschöpfung von Wirklichkeit bzw. die Entstehung einer parallelen Wirklichkeit gemeint wäre. Aufmerken lässt an dieser Stelle sein Hinweis auf den Charakter des Performativen als »Wandel«:

"Die durch [performative Vollzüge] geschaffenen Wirklichkeiten - oder schwächer formuliert: die durch sie hervorgebrachten neuen Verständnisse - sind demnach nicht vollständig durch bereits gegebene Strukturen, Prinzipien oder Akteure zu erklären. Die Vollzüge selbst, die konkreten Ereignisse und Handlungen, bleiben unverzichtbar zur Erklärung des gesuchten Phänomens. Das 'Performative، steht auf diese Weise für den Gedanken eines produktiven Wandels, der sich nicht einfach unter allgemeinen Prinzipien subsumieren lässt. Es bedarf immer auch des einzelnen, konkreten Vollzuges, der sich selbst die Wirklichkeit schafft, auf die er sich bezieht. “106

Lässt sich diese Perspektive auf die musikalische Praxis übertragen? Führt auch eine Violinsonate Beethovens, ein Klaviertrio Schuberts Hoffnung auf »Wandel« mit sich?

Die Vorstellung von »Wandel«, der zu erhoffen ist, weil das Tun der Ausführenden nach Volbers »sich selbst die Wirklichkeit schafft, auf die es sich bezieht«, könnte von dichotomen Denkstrukturen befreien, in die man sich leicht verstrickt.

Unterschiedliche Formulierungen sind nach Fischer-Lichtes und Volbers' Ausführungen denkbar:

102 | E. Fischer-Lichte: Performativität, S. 85; Herv. i.0.

103 | J. Volbers: Performative Kultur, S. 1.

104 | E. Fischer-Lichte: Performativität, S. 44.

105 | J. Volbers: Performative Kultur, S. 1; das folgende Zitat ebd.

106 | Ebd., S. 2f.; Herv. i.0. 
a. Eine Studie zur musikalischen Praxis begibt sich dazwischen: zwischen eine durch das Tun der Ausführenden erschaffene Wirklichkeit und eine »Hinausweisung auf Wirklichkeiten und Möglichkeiten « ${ }^{107}$.

b. Eine Studie zur musikalischen Praxis begibt sich mitten hinein in durch das Tun der Ausführenden erschaffene Wirklichkeiten und Möglichkeiten.

Muss eine Entscheidung getroffen werden?

\subsection{Sprechen, Rede, Redeweise}

\section{Leihnahmen}

Verzauberung hat mit Verwandlung zu tun. Auch mit Geheimnis, Unerklärlichkeit, Magie: Sprachlosigkeit. Was bedeutet es, wenn (in musikalischer Praxis) eine Begegnung stattfindet, die, wie die Liebe es tut, das persönliche Leben von heute auf morgen auf den Kopf stellt und umkrempelt: »Being so deeply touched by the other person, that it changes one's life forever «? 108 Was bedeutet es, wenn eine »Erinnerung an ungenutzte Kräfte in uns « ${ }^{109}$ auftaucht? Wenn also individuelle und politische Verwandlungen möglich werden? Wir gehen dann aus einer Praxis des »Lernens und Erfahrens « ${ }^{110}$ anders heraus, als wir hineingegangen sind; es gab Verwandlung, die alle Beteiligten, Ausführende wie auch Hörer, betrifft.

Ein Zauberer berührt - und etwas wird anders. Die Zauberwirkung entsteht durch die Berührung. Indem ich berührt werde, spüre ich, dass das, was ich gerade erlebe, etwas mit meinem Leben zu tun hat. Aber ich finde keine Worte, die Berührung lässt mich sprachlos zurück. Eben diese Überschreitung der »Schwelle« (Fischer-Lichte) zwischen Kunst und Leben und diese Sprachlosigkeit verführen Jankélévitch dazu, auf die »Zauberwirkung, die von dem ausdruckslosen Espressivo ausgeht ${ }^{111}$, hinzuweisen, ermutigen Erika FischerLichte, eine »Wiederverzauberung der Welt, die sich in [der] Verknüpfung von Kunst und Leben vollzieht « ${ }^{112}$, ins Gespräch zu bringen.

Wie aber zum Sprechen gelangen? Eine Möglichkeit, sich dieser Magie anzunähern, ist die metaphorische Rede. Der Weg zur Sprache über die Metapher führt über ein Sich-Fallen-Lassen mitten hinein in die Praxis, führt über

107 | Nach H. Lachenmann: Vier Grundbestimmungen des Musikhörens, S. 62.

108 | A. Beuger/S. Vriezen: Asking questions, trying answers, S. 37.

109 | Nach H. Lachenmann: Fragen - Antworten, S. 201.

110 | Nach Chr. Small: Musicking, S. 96.

111 | V. Jankélévitch: Die Musik und das Unaussprechliche, S. 112.

112 | E. Fischer-Lichte: Ästhetik des Performativen, S. 360. 
immer dieselben Fragen, die sich aber immer neu stellen: Was tun die Teilnehmenden jetzt? Wie tun sie es? Wozu tun sie es? Diese Fragen nach dem konkreten Tun führen weg von einem Denken in rein strukturellen Zusammenhängen. Notwendig wird dabei ein Fall: ein Sich-fallen-Lassen in Sprachlosigkeit. Erst dann geht es weiter: Versuche, wieder neu Sprache zu finden - vorsichtig und mutig über die Metapher. Und über die Sprache der anderen. »Warum auch?« Dieses Gedicht von Robert Walser macht Angebote, über »Geschehen« (auch über Werden) neu nachzudenken. Die Metapher »Arche des Augenblicks « ${ }^{113}$ (Nelly Sachs) ist dazu angetan, Abschiede und (immer wieder neu provisorische, d.h. auf Zukünftiges ausgerichtete) Rettungen an sich herankommen zu lassen. Ich finde kein schöneres Wort und leihe es aus.

Die Möglichkeiten zur Beschreibung einer Praxis werden häufig aus Publikationen abgeleitet, die mit dem betreffenden Werk in keinerlei Zusammenhang stehen, sich aber für das Sprechen und Schreiben als brauchbar erweisen. So ist der Begriff des »In-Erscheinung-Tretens « der Darstellung von Judith Butler »Anmerkungen zu einer performativen Theorie der Versammlung« entnommen, ebenso der Begriff des »Aufeinander-Angewiesen-Seins«. »Paradiese auf Zeit « ${ }^{114}$ : Mit diesem Bild beschreibt Helmut Lachenmann Situationen des Stillstands, der »Nicht-Musik «115 in seinen Werken. Ich versuche, dieses Bild aufzugreifen und damit umzugehen.

Ich leihe Wörter aus. Von Erika Fischer-Lichte das Wort »Schwelle «"16, von Mogens Heimann das Wort »Übung« - »Exercises«, von Alfred Schütz das ins Substantiv verwandelte Pronomen »Wir «117, von John Blacking das Substantiv »(musikalische) Gelegenheit « ${ }^{118}$, von Jürg Frey das Wort »Brauchbarkeit«, von Hans-Joachim Hespos die Wortkombinationen »SO IST« - »SO GESCHIEHT ${ }^{119}$ und andere Wörter mehr. Solche Leihnahmen helfen zu sprechen.

\section{Suche nach Orten}

Zusammenhänge meiden. Stattdessen an einzelne Orte einer Partitur gehen, sich dort aufhalten. Die Partitur wird als »Skript« (Cook) gelesen, nicht als Strukturzusammenhang, nicht als Niederschlag von »Denkvorgängen ${ }^{120}$.

113 | N. Sachs: Fahrt ins Staublose, S. 50-51.

114 | H. Lachenmann: Paradiese auf Zeit, S. 205ff.

115 | H. Lachenmann: Musik als existentielle Erfahrung, S. 219.

116 | E. Fischer-Lichte: Ästhetik des Performativen, S. 356.

117 | A. Schütz: Mozart und die Philosophen, S. 172.

118 | J. Blacking: How musical is man, S. 9.

119 | H.-J. Hespos: AUGEN DER WÖRTER, Partitur.

120 | W. Rinm: Offene Enden, S. 81. 
Der Vergleich von einzelnen Orten aus der Partitur des »Harfenquartetts « von Beethoven mit Übungen aus Heimanns »Exercises« zeigt diese Arbeitsweise.

Ein Ort in der Partitur lässt sich befragen: Was tut man hier, wenn man das spielt? An Orte im Ausführungsraum gehen: Es ist beim Spiel eines Streichtrios wichtig, wo der Cellist, die Cellistin sitzt, mit dem Ort verändern sich die Stabilitätsverhältnisse. Es ist für die Ausführung eines bestimmten Streichquartetts überlegenswert, wie die Ausführenden einander zugeordnet werden. Eine Anordnung, die an ein vierblättriges Kleeblatt erinnert, ermöglicht gänzlich andere Gesten, Spielhaltungen, Körperhaltungen, Positionen und Zuwendungen als eine Sitzordnung, die eine gekrümmte Linie nachzeichnet. Eine Ausführung der 5. Symphonie Beethovens im Stehen, wobei vielleicht auch das Publikum steht, ist eine andere Aktivität als eine in gewohnter Sitzordnung.

Christopher Smalls Darstellung »Musicking« eröffnet neue Sichtweisen auch auf musikalische Strukturzusammenhänge. Er schlägt die Brücke zwischen klanglichen Strukturen und den Beziehungen zwischen den Ausführenden. Von der Analyse einer Partitur führt dieser Gedanke hin zum Entdecken von Handlungszusammenhängen, von Praktiken, von Beziehungen zwischen Tätigen, die diese Klänge ins Leben rufen. $\mathrm{Zu}$ finden sind Orte einer gelebten Beziehung. Small traut dabei dem »Musicking« den Entwurf »idealer Beziehungen« und Ermöglichung von »Welterkenntnis« ${ }^{121} \mathrm{zu}$ - ein guter Grund auch für die Analyse der Partitur. Ausgangspunkt für ihn ist »a set of relationships«, also eine Reihe von Beziehungen, welche über die musikalische Tätigkeit durchlebt, ausgetestet und gefeiert werden, wobei Wirklichkeiten und auch Möglichkeiten erkannt werden. ${ }^{122}$ Musik als Erkenntnis also: als Erkenntnis, was ist, war, sein könnte.

Hilfreich dafür, Beziehungsgeschehen in Partituren aufzufinden und dann in der Praxis wiederzuentdecken, ist Smalls Unterscheidung von Beziehungen zwischen den Klängen, die von den Musikern gespielt werden, und solchen zwischen den Musikern selbst. Diese »Spirale« von Beziehungen sei zu komplex, als dass sie in Worte gefasst werden könne:

"The relationships that are created in a musical performance are of two kinds: first, those among the sounds that the musicians are making, whether on their own initiative or following directions, and second, those among the people who are taking part. As we shall see, these two sets of relationships themselves relate in an ever more complex spiral of relationships, which become too complex for words to articulate but which the musical performance itself is able to articulate clearly and precisely. "123

121 | P. Uhden: Musik als Praxis, S. 94.

122 | Chr. Small: Musicking, S. 50.

123 | Ebd., S. 184. 
Wenn die Sprache versagt, die Komplexität der Beziehungsgefüge zu erfassen - die Ausführung selbst kann nach Small diese Beziehungen klar und deutlich »artikulieren«, nämlich stattfinden lassen.

Die künstlerische Praxis als eine »künstlerische Lebensform « (Stockhausen) stiftet Sinn, baut auf Erfahrungen auf und ist auf Wiederholung angelegt. Klänge transportieren diese Praxis, transportieren damit bestimmte Lebensformen, Formen der Beschäftigung von Einzelnen, Formen des Zusammenwirkens, Zusammenlebens. Sie tragen die Art ihrer Hervorbringung, den Sinn, den die Ausführenden ihrer Praxis abgewonnen haben, die Situation der Ausführung, das besondere Miteinander der Ausführenden bei sich und geben Kunde davon - auf unbegriffliche Weise. Deshalb kann auch eine zugrundeliegende Praxis von einem Hörer, der sich berühren lässt, beim Hören einer CD (ohne Kenntnis der Partitur, ohne Kenntnis der Ausführungsmodalitäten) erlebt und erfahren werden. Die Betrachtung einer Partitur führt deshalb vorrangig zur Entdeckung von Orten der Interaktion, von Praktiken, Situationen, Handlungszusammenhängen, von Beziehungen zwischen den Teilnehmenden - und bleibt stets an der Frage orientiert: Wozu tun sie das? - tun wir das?

\section{Noch einmal: Brauchbarkeit}

Über eine »Schwelle, die nicht voneinander trennt, sondern miteinander verbindet « ${ }^{124}$, werden musikalische Praxis und Leben transparent. Könnte eine musikalische Praxis, die in den Lebensalltag integriert wird, so etwas wie eine durchlässige Membran zwischen musikalischer Aktivität und alltäglicher Handlung entstehen lassen?

Ist ein solcher Umgang mit Musik ausschließlich mit musikalischen Angeboten, die den Werkbegriff preisgegeben haben, oder ausschließlich mit musikalischen Angeboten, die zeitlich nach der Formulierung einer Ästhetik des Performativen im weitesten Sinne entstanden sind, möglich? Die vorliegende Studie verneint beide Fragen und fragt nach der Brauchbarkeit einer Partita von Froberger, nach der Brauchbarkeit einer Symphonie von Beethoven, eines Streichquartetts von Lachenmann, eines Flötenstücks von Debussy, eines Streichtrios von Schönberg und vieler anderer Kompositionen. Die herangezogenen Beispiele sind entweder als am traditionellen Werkbegriff orientierte Kompositionen zu bezeichnen oder als solche, die die Frage nach dem Werkbegriff gar nicht stellen. Auch Epochengrenzen hindern nicht: Ein Werk der Tradition lässt sich durch eine Befragung auf seine Brauchbarkeit hin in Zeitgenossenschaft hereinholen. Die hier aufgeworfenen Fragen lauten darum auch ganz anders. Wenn es sich lohnt, Mozarts »Gran Partita « auszuführen: Wozu tun wir das? Welche Angebote zu welcher Praxis entnehmen wir der

124 | E. Fischer-Lichte: Ästhetik des Performativen, S. 356. 
Partitur? Was können wir damit tun? Wie befinden wir uns im Aufführungsraum? $\mathrm{Zu}$ welcher Gelegenheit könnte man das tun? Warum ergibt das für uns Sinn? Warum möchten wir dieses Tun wiederholen? Könnte eine solche Komposition über die Schwelle in unser Leben gleiten? - die Praxis so in den Lebensalltag eingehen?

\section{"Geschlossene Sinnbereiche" (Alfred Schütz)}

Nach dem Hinübergleiten über die »Schwelle« vom Lebensalltag in die musikalische Praxis hinein: In welcher Wirklichkeit befinde ich mich dann? Die

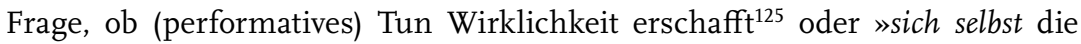
Wirklichkeit schafft, auf die [es] sich bezieht ${ }^{126}$, bleibt als offene im Raum.

Eine Perspektive entwickelt Alfred Schütz, der in engem Dialog mit Max Weber dessen Gedanken zur sozialen Handlung aufgreift und weiterführt und sich der Entstehung von Intersubjektivität im Alltagshandeln zuwendet. Er eröffnet mit seiner Vorstellung unterschiedlicher »Sinnbereiche« die Möglichkeit, sich von ontologischen Fragestellungen zu lösen. Der vorrangige Sinnbereich ist die Alltagswelt, daneben können weitere Sinnbereiche vorübergehend Priorität erlangen und verschiedene Welten erschließen. In Anlehnung an William James, der »Subuniversa « unterschied, spricht Schütz von »geschlossenen Sinnbereichen «. Vom »Sinn unserer Erfahrungen « ${ }^{127}$ ausgehend findet er unterschiedliche Wirklichkeitsbereiche; einer davon lässt sich als derjenige musikalischer Praxis betrachten. Es ist sicher kein Zufall, dass Schütz sich dem Thema des »Gemeinsamen Musizierens« widmet.

\section{Metapherntheoretischer Ansatz (Simone Mahrenholz)}

Die vorliegende Studie behandelt nicht die musikalische Praxis der Improvisation, klammert auch - abgesehen von der Komposition Cantar del Alma von Federico Mompou - Vokalmusik aus. Ebenfalls fehlen Beispiele aus der populären Musik (Jazz, Rock, Pop, Schlager). Die Konzentration auf Instrumentalmusik erlaubt die Ablösung von sprachlich vermittelten Bedeutungsfeldern und damit - bei breiter Streuung der Beispiele, die unterschiedlichen historischen Epochen, auch unterschiedlichen Gattungen entnommen sind die Probe aufs Exempel, ob und inwiefern ein Zugang von der musikalischen Praxis her Perspektiven auf Kompositionen verändern könnte.

Worauf nimmt ein Präludium oder eine Fuge von Johann Sebastian Bach oder eine Klaviersonate Mozarts Bezug? Die Frage nach einer möglichen Be-

125 | E. Fischer-Lichte: Ästhetik des Performativen, S. 49.

126 | J. Volbers: Performative Kultur, S. 2f.; Herv. i.0.

127 | A. Schütz: Über die mannigfaltigen Wirklichkeiten, S. 264. 
zugnahme einer Komposition auf Lebenswelt, auf (Alltags-)Wirklichkeit in der Praxis und durch die Praxis lässt sich durch den vorübergehenden Verzicht auf Text, Programmatik oder Zitat vielleicht zuspitzen. Simone Mahrenholz erweitert die Möglichkeiten der Bezugnahme (in Anlehnung an die Symboltheorie Nelson Goodmans) durch Bezugnahme über Exemplifikation, wodurch genau dieses Problem zur Diskussion gestellt wird: »Worauf und wie nimmt Beethovens Klaviersonate op. 111 Bezug [...]?« ${ }^{128} \mathrm{Ihr}$ metapherntheoretischer Ansatz und ihre Darstellung einer (möglichen) Bezugnahme von Musik auf (Lebens-) Wirklichkeit und umgekehrt zeigt Perspektiven für die metaphorische Rede auf.

Dass die Körperlichkeit der Ausführenden, ferner der Körper eines Trios, Quartetts, eines Ensemblekörpers allgemein für die Fragestellungen wichtig werden, verwundert nicht. Im Kapitel »Tasten« beispielsweise werden die Finger und Fingerspitzen, Hände und Arme als Verlängerungen des Körpers beim Klavierspiel betrachtet: unmittelbarer Kontakt des Ausführenden mit dem Instrument. Wenn ich das Trommeln auf dem Klavier in einer Klaviersonate Aurèle Stroës als »Hinken« eines »Geretteten« beschreibe, entleihe ich ein Bild aus der Literatur ${ }^{129}$, das, wie Mahrenholz sagen würde, »fragil« und »alternativehaltig « ${ }^{130}$ ist, das aber dem Sprechen auf die Sprünge hilft und sich als nützlich erweist, eine musikalische Praxis zu umschreiben. Bei solchem Reden geht es also darum, über die Metapher zu sprachlichen Wendungen zu kommen, die im jeweiligen Kontext brauchbar sind und dabei mehr oder weniger zutreffend sein mögen.

\section{Vorläufiges Fazit}

In dieser Studie versuche ich,

- den etablierten Sinn von Musik als »hingenommene Folge von Denkvorgängen « ${ }^{131}$ aufzugeben - und dabei doch und gerade an Sinn festzuhalten;

- Musik als »existentielle Erfahrung« (Lachenmann), als Begegnung und Teilhabe ernst zu nehmen - ohne notwendigerweise das Werk preiszugeben;

- die Sprachlosigkeit der Musik als Potential zu begreifen - und dabei der Musik zuzutrauen, auf musikalische Weise individuell und gesellschaftspolitisch wirksam zu werden;

128 | S. Mahrenholz: Musik und Erkenntnis, S. 48.

129 | U. Bail: "Die verzogene Sehnsucht hinkt an ihren Ort", S. 136.

130 | S. Mahrenholz: Musik-Verstehen jenseits der Sprache, S. 219.

131 | W. Rihm: Offene Enden, S. 81. 
- traditionelle und neue Musik als ein umfassendes Angebot zu musikalischer Praxis anzunehmen - dabei auf Zeitgenossenschaft zu bestehen: Zeitgenossenschaft verstanden als Teilhabe an einem sinnvollen Handeln, einer Praxis;

- mich darauf einzulassen, was sich uns in Musik zeigt - und dabei die Chance wahrzunehmen, so lange wie nur irgend möglich die Ablösung von der Wortsprache zu wagen. 


\section{Sprachfindungen}

\subsection{Intersubjektive Sinngebungen - Sinnzusammenhänge (Alfred Schütz)}

\section{Gemeinsam als "Wir»}

Das berühmte erste Finale am Ende des zweiten Akts aus Mozarts Oper Le nozze di Figaro. Opera buffa in vier Akten (KV 492), Nr. 16, beginnend mit der sechsten Szene: Der Graf und die Gräfin allein, zwei Personen. Nach dem Geständnis der Gräfin befiehlt der Graf dem Pagen Cherubino, aus dem Kabinett herauszutreten, damit die Wahrheit ans Licht komme. Als sich die Tür öffnet, tritt Susanna hervor, worüber die Gräfin ebenso erstaunt ist wie der Graf: drei Personen. Nun erscheint Figaro, berichtet, dass die Hochzeitsgäste versammelt seien. Er bedrängt den Grafen, die Einwilligung zur Hochzeit zu geben - vier Personen. Sogleich tritt der Gärtner Antonio auf, empört über die zertretenen Blumen vor dem Fenster: fünf Personen. Endlich eilen Marcellina, Bartolo und Basilio herbei, um den Einspruch gegen die Hochzeit zu erheben. Acht Personen auf der Bühne.

Wie Alfred Schütz es beschreibt, handeln diese unterschiedlichen Personen auf der Bühne »als ein Wir«: »[Mozart] verwendet dieses besondere Mittel der Opernform [die simultane Darstellung], um die intersubjektiven Beziehungen unmittelbar hervortreten zu lassen, in die seine Charaktere verwickelt sind.« ${ }^{1}$ Bei aller Verschiedenheit der »Reaktionen auf die gemeinsame Situation«, bei allen »individuellen Charakteristiken« der handelnden Personen »handeln sie gemeinsam, fühlen sie gemeinsam, wollen sie gemeinsam als Gemeinschaft, als ein Wir.« Schütz weiter:

"Das heißt natürlich nicht, daß sie dasselbe mit der gleichen Intensität tun, fühlen oder wollen. Im Gegenteil, Ensembles, wie das im bewunderten ersten Finale des Figaro, zeigen deutlich die vielfältigen Gruppierungen im Miteinander und Gegeneinander der

1 | A. Schütz: Mozart und die Philosophen, S. 172; das folgende Zitat ebd. 
Personae dramatis. Aber selbst im Gegeneinander sind sie in einer gemeinsamen intersubjektiven Situation, in einem Wir, einander verbunden. ${ }^{2}$

Alfred Schütz (geb. 1899 in Wien, gest. 1959 in New York) bewegte sich als Wissenschaftler »an der Grenze zwischen Philosophie und Soziologie «3; sein erstes großes Werk war »Der sinnhafte Aufbau der sozialen Welt« (1932). »Strukturen der Lebenswelt« (zwei Bände) konnte er nicht mehr vollenden; das Werk wurde von seinem Schüler Thomas Luckmann weitergeführt und vervollständigt. Nach der Veröffentlichung seines ersten Buches begegnete er Edmund Husserl, von dem er in seinem weiteren Leben stark geprägt werden sollte. 1939 emigrierte Schütz in die USA; dort begann er in New York zu lehren, und zwar an der Graduate Faculty der New School for Social Research, wo er ab 1952 eine Professur innehatte. Von großem Einfluss auf Schütz war neben der Forschung Husserls auch diejenige Max Webers.

Für die Diskussion der musikalischen Praxis sind vor allem Schütz' Ausführungen über »geschlossene Sinnbereiche« sowie seine Aufsätze »Gemeinsam musizieren« und »Mozart und die Philosophen« weiterführend. Zudem stehen die Begriffe Sinn, Erfahrung, Handlung, Wirklichkeit, die bei der Erörterung musikalischer Praxis wiederkehren, in Schütz' Schriften in einem Bedeutungskontext, der eine Übertragung auf Beschreibungen musikalischer Praxis erlaubt.

\section{Sinn und Erfahrung}

Schütz' Ausgangsfrage ist die Frage nach der »alltäglichen Lebenswelt«:

"Unter alltäglicher Lebenswelt soll jener Wirklichkeitsbereich verstanden werden, den der wache und normale Erwachsene in der Einstellung des gesunden Menschenverstandes als schlicht gegeben vorfindet. Mit schlicht gegeben bezeichnen wir alles, was wir als fraglos erleben, jeden Sachverhalt, der uns bis auf weiteres unproblematisch ist. " ${ }^{4}$

Er bestreitet nicht, dass das »Fraglose in Frage gestellt werden kann«; dennoch gilt für ihn: »In der natürlichen Einstellung finde ich mich immer in einer Welt, die für mich fraglos und selbstverständlich >wirklich< ist.« In dieser Welt gibt es Probleme, die zu lösen sind, hier leben andere Menschen - »mit einem Bewusstsein begabt, das im wesentlichen dem meinen gleich ist. So ist meine

2 | Ebd.; Herv. i.0.

3 | Die kurzen biografischen Notizen an dieser Stelle nach Th. Luckmann: Vorwort, in: A. Schütz/Th. Luckmann: Strukturen der Lebenswelt I, S. 11-22.

4 | A. Schütz/Th. Luckmann: Strukturen der Lebenswelt I, S. 25; die folgenden Zitate ebd., S. 26. 
Lebenswelt von Anfang an nicht meine Privatwelt, sondern intersubjektiv; die Grundstruktur ihrer Wirklichkeit ist uns gemeinsam.« Von hier aus gelangt Schütz zur Frage nach Intersubjektivität, die er nicht phänomenologisch begründet, sondern von der »natürlichen Einstellung des Alltags« her entwickelt; »Natur« wie auch »Sozial- bzw. Kulturwelt« sind in die »alltägliche Wirklichkeit der Lebenswelt« integriert ${ }^{5}$ :

"Da wir auf das phänomenologische Problem der Konstitution der Intersubjektivität hier nicht eingehen können, müssen wir uns mit der Feststellung begnügen, daß ich in der natürlichen Einstellung des Alltags folgendes als fraglos gegeben hinnehme: a) die körperliche Existenz von anderen Menschen; b) daß diese Körper mit einem Bewußtsein ausgestattet sind, das dem meinen prinzipiell ähnlich ist; c) daß die Außenweltdinge in meiner Umwelt und der meiner Mitmenschen für uns die gleichen sind und grundsätzlich die gleiche Bedeutung haben; d) daß ich mit meinen Mitmenschen in Wechselbeziehung und Wechselwirkung treten kann; e) daß ich mich - dies folgt aus den vorangegangenen Annahmen - mit innen verständigen kann; $f$ ) daß eine gegliederte Sozial- und Kulturwelt als Bezugsrahmen für mich und meinen Mitmenschen historisch vorgegeben ist, und zwar in einer ebenso fraglosen Weise wie die Naturwelt; g) daß also die Situation, in der ich mich jeweils befinde, nur zu einem geringen Teil eine rein von mir geschaffene ist." 6

Wichtig ist Schütz das »Tun« in der Alltagswelt, die von ihm als selbstverständlich und fraglos hingenommene »Lebenswelt« angenommen wird:

"Die Lebenswelt ist der Inbegriff einer Wirklichkeit, die erlebt, erfahren und erlitten wird. Sie ist aber auch eine Wirklichkeit, die im Tun bewältigt wird, und die Wirklichkeit, in welcher - und an welcher - unser Tun scheitert." ${ }^{7}$

Von hier aus, vom Tun in der Lebenswelt, kommt Schütz zu einer Unterscheidung zwischen Erlebnis, Erfahrung und Handlung, eine Unterscheidung, die eine genauere Bestimmung des Sinnbegriffs und des Begriffs der Wirklichkeit erlaubt. Erlebnisse, denen keine weitere »Aufmerksamkeit« geschenkt wird, »[treten] scheinbar schlicht im Erlebnisablauf [auf]«; aber es gibt andere Erlebnisse, »denen das Ich seine Aufmerksamkeit zuwendet«. »Solche Erlebnisse, in denen sich das Ich sozusagen fest engagiert, wollen wir Erfahrungen nennen. Kurz: Erlebnisse heben sich im Bewußtseinsstrom ab; Erfahrungen sind durch Aufmerksamkeit ausgezeichnete Erlebnisse.« Und von der Erfahrung

5 | Ebd., S. 27.

6 | Ebd.; vgl. A. Schütz: Symbol, Wirklichkeit und Gesellschaft, S. 361.

7 | A. Schütz/Th. Luckmann: Strukturen der Lebenswelt II, S. 11; die folgenden Zitate ebd., S. 12, 13; Herv. i.0. 
her findet Schütz einen Sinnbegriff, der auch musikalische Erfahrung fassen kann:

"Als aktuelle Bewußtseinsvorgänge haben Erfahrungen von sich aus noch keinen eigentlichen Sinn. Den erhalten sie erst in reflexiven, nachträglichen Bewußtseinsleistungen. [...] Erst wenn ich wohlumschriebene Erlebnisse, also Erfahrungen, über ihre Aktualität hinaus reflexiv erfasse, werden sie erinnerungsfähig, auf ihre Konstitution hin befragbar, sinnvoll. Wenn das Ich auf seine eigenen Erfahrungen hinblickt, genauer: zurückblickt, hebt es sie aus der schlichten Aktualität des ursprünglichen Erfahrungsablaufs heraus und setzt sie in einen über diesen Ablauf hinausgehenden Zusammenhang. Dieser weist notwendig über das schlichte Engagement des Ich in seinen Erfahrungen hinaus. Ein solcher Zusammenhang ist ein Sinnzusammenhang; Sinn ist eine im Bewußtsein gestiftete Bezugsgröße, nicht eine besondere Erfahrung oder eine der Erfahrung selbst zukommende Eigenschaft. Es geht vielmehr um die Beziehung zwischen einer Erfahrung und etwas anderem. Im einfachsten Fall ist dieses andere eine andere als die aktuelle, so z.B. eine erinnerte Erfahrung." 8

Schütz' Erfahrungsbegriff ist die Grundlage für seine Erschließung unterschiedlicher Wirklichkeitsbereiche, Schütz spricht auch von »Wirklichkeitsordnungen «" ${ }^{9}$ zu denen neben der für ihn vorrangigen der Alltagswelt auch die Wirklichkeit ästhetischer Erfahrung zählt.

\section{Die ausgezeichnete Wirklichkeit}

Schütz nennt die »alltägliche Lebenswelt« auch »ausgezeichnete Wirklichkeit«; es ist die Welt des »schlicht Gegebenen«, »fraglos « Hingenommenen. ${ }^{10}$ Was heißt »schlicht gegeben«? - »fraglos« hingenommen? Schütz führt diese zunächst fraglose Annahme der Lebenswelt des Alltags auf die allen gemeinsame Körperlichkeit, auf das allen gemeinsame, mit dieser Körperlichkeit verbundene »Bewußtsein«, auf die mit anderen geteilte »Bedeutung « der »Außendinge«, auf die möglichen »Wechselbeziehungen« zwischen den Menschen, auf die Möglichkeit von Verständigung, auf die Funktion einer für alle »gegliederte[n] Sozial- und Kulturwelt« als »Bezugsrahmen« (vergleichbar der Funktion der »Naturwelt« als Rahmen) sowie auf die Einlassung eines jeden auf die nicht persönlich herbeigeführte, sondern eher vorgefundene »Situation «, in der sich alle befinden, zurück. ${ }^{11}$

8 | Ebd., S. 13; Herv. i.0.

9 | A. Schütz/Th. Luckmann: Strukturen der Lebenswelt I, S. 49.

10 | Ebd., S. 25.

11 | Ebd., S. 27. 
"Die Außenwelt des Alltags ist eine ausgezeichnete Wirklichkeit: a) Weil wir immer durch unseren Leib, der selbst ein Gegenstand der Außenwelt ist, an ihr teilnehmen, sogar während wir träumen; b) Weil Gegenstände der Außenwelt die Möglichkeiten unseres freien Handelns einschränken, indem sie Widerstand leisten, der nur durch besondere Anstrengung oder gar nicht überwunden werden kann; c) Weil es der Bereich ist, in den wir uns durch unsere körperlichen Tätigkeiten einschalten können und den wir somit verändern oder umgestalten können; d) Weil wir uns mit unseren Mitmenschen innerhalb dieses Bereichs - und nur da - verständigen [...] können. “12

Wenn Schütz von »Gegeben[heiten]« spricht, so heißt das nicht, dass es kein Verstehen, kein Handeln, keine Modifikation des Handelns gibt:

"Die Lebenswelt ist [...] eine Wirklichkeit, die wir durch unsere Handlungen modifizieren und die andererseits unsere Handlungen modifiziert. [...] [Schon] in der natürlichen Einstellung ist mir die Welt zur Auslegung aufgegeben. Ich muss meine Lebenswelt zu jenem Grad verstehen, der nötig ist, um in ihr handeln und auf sie wirken zu können. ${ }^{13}$

\section{Mannigfaltige Wirklichkeiten}

Schütz’ Aufsatz »Über die mannigfaltigen Wirklichkeiten« zeigt nun auf Welten und Wirklichkeiten neben der alltäglichen Lebenswelt. Gleich zu Beginn schlägt er eine Brücke zur Philosophie von William James:

"Wirklichkeit, stellt [James] fest, bedeutet ganz einfach ein Verhältnis zu unserem emotionalen und tätigen Leben. Der Ursprung aller Wirklichkeit ist subjektiv; was immer unser Interesse erweckt und anregt, ist wirklich. Ein Ding als wirklich zu bezeichnen bedeutet, daß dieses Ding in einer bestimmten Beziehung zu uns steht. “14

Und er zitiert James: »Das Wort >wirklich< ist kurzum ein Sinnhorizont. « ${ }^{15}$ Ausgehend von einem solchen Sinn konstituierenden »Sinnhorizont« wird ein Gegenstand oder ein Sachverhalt wirklich durch das Interesse, das ihm entgegengebracht wird.

Schütz veranschaulicht die Fantasiewelt in seinem Aufsatz »Don Quixote und das Problem der Realität«, ausgehend von »verschiedenen Realitätsbereichen, jede [Realität] mit ihrem eigenen speziellen und besonderen Existenzstil, welche [William] James >Subuniversa< nennt «. ${ }^{16}$ Vor diesem Hintergrund

12 A. Schütz: Symbol, Wirklichkeit und Gesellschaft, S. 395.

13 | A. Schütz/Th. Luckmann: Strukturen der Lebenswelt I, S. 28.

14 | A. Schütz: Über die mannigfaltigen Wirklichkeiten, S. 238.

15 | Ebd.; vgl. W. James: The Principles of Psychology II, S. 320.

16 | A. Schütz: Don Quixote, S. 102; das folgende Zitat ebd., S. 103. 
untersucht er die Abenteuer des Don Quixote, der sich in eine Ritterwelt hineingeträumt hat: »ein Subuniversum der Wirklichkeit, das mit der ausgezeichneten Wirklichkeit des Alltagslebens unvereinbar ist«. In dieser Wirklichkeitsordnung gerät Don Quixote mit der Wirklichkeit des Alltags ständig in Konflikt. Don Quixote erteilt der Fantasiewelt (und eben nicht der Alltagswelt) den »Wirklichkeitsakzent ${ }^{17}$ oder $»$ Realitätsakzent ${ }^{18}$, sodass die Wirklichkeit der Fantasie die Oberhand gewinnt, was zu den bekannten Verwirrungen führt.

Schütz zieht es vor, statt von »Subuniversa« von »geschlossenen Sinnbereichen (finite provinces of meaning) « (auch: »Sinngebieten«) zu sprechen:

"Einem jeden dieser Bereiche können wir den Wirklichkeitsakzent erteilen. Wir sprechen von Sinnbereichen und nicht von sub-universa', weil nicht die ontologische Struktur der Gegenstände, sondern der Sinn unserer Erfahrungen die Wirklichkeit konstituiert. “19

Die Alltagswelt ist die ausgezeichnete Wirklichkeit. Andere »geschlossene Sinnbereiche«: die »verschiedenen Welten der Phantasievorstellungen«, die »Traumwelt«, die »Welt der wissenschaftlichen Theorie«, auch Kunst und Spiel, das Theater, viele Bereiche mehr. Jeder dieser »Sinnbereiche« hat einen eigenen »Erlebnis- bzw. Erkenntnisstil«, der für sich einheitlich ist, aber nicht so ohne Weiteres auf einen anderen Bereich übertragen werden kann:

"Die Geschlossenheit eines Sinngebietes - der alltäglichen Lebenswelt, der Traumwelt, der Welt der Wissenschaft, der Welt religiöser Erfahrung - beruht auf der Einheitlichkeit des inm eigenen Erlebnis- bzw. Erkenntnisstils. Einstimmigkeit und Verträglichkeit hinsichtlich dieses Stils sind demnach auf ein gegebenes Sinngebiet beschränkt. "20

Ein Wechsel zwischen einem und einem anderen »Sinnbereich« kann nur im »Sprung« geschehen, wird als »Schock« erfahren:

"[Die] Geschlossenheit bedeutet, daß es an Transformationsregeln fehlt, mit denen man die verschiedenen Sinnbereiche in wechselseitigen Bezug setzen könnte. Der Übergang von einem zum anderen kann nur durch einen 'Sprung', wie Kierkegaard es nennt, geleistet werden. Dieser offenbart sich in der subjektiven Erfahrung als ein Schock. " ${ }^{21}$

17 | A. Schütz: Über die mannigfaltigen Wirklichkeiten, S. 264.

18 A. Schütz/Th. Luckmann: Strukturen der Lebenswelt I, S. 48.

19 | A. Schütz: Über die mannigfaltigen Wirklichkeiten, S. 264; Herv. i.0.; die Ausführungen zu den genannten Sinnbereichen ebd., S. 169ff., $276 \mathrm{ff}$., $281 \mathrm{ff}$.

20 | A. Schütz/Th. Luckmann: Strukturen der Lebenswelt I, S. 49.

21 | A. Schütz: Über die mannigfaltigen Wirklichkeiten, S. 267. 
Ein solcher »Schock « kann sich beim Erwachen einstellen, wenn man aus dem Traum in die Alltagswelt zurückkehrt und dann, nach einem Albtraum etwa, mit Erleichterung feststellt, dass man geträumt hat. Auch der »Sinnbereich« des Witzes kann einladen, für eine gewisse Zeit aus der Alltagswelt in die Wirklichkeit des Witzes und des erlösten Lachens $\mathrm{zu}$ fallen, bis, schockhaft, der Alltag sich wieder geltend macht. Peter Berger macht am Beispiel des Witzes klar, wie Grenzen zwischen »Wirklichkeitsbereichen« überschritten werden können. Wenn ein Witz verletzend war und die Person getroffen hat, die dann empört reagiert, macht die Einlassung, es sei doch nur Spaß gewesen, gerade deutlich, dass hier eine Schwelle zur Alltagswelt überschritten wurde. »Der Witz, mit dem man >zu weit gegangen ist<, hat eine sehr empfindliche Realität berührt und ist deshalb weit mehr als >nur< ein Witz. ${ }^{22}$

Was sagt vor diesem Hintergrund die Rede aus, eine bestimmte musikalische Ausführung sei schließlich nur Musik?

\section{Exkurs: William James' "sub-universes"}

»Any object which remains uncontradicted is ipso facto believed and posited as absolute reality. ${ }^{23}$ Auch das geflügelte Pferd im Traum behauptet sich so lange in einer (Traum-)Wirklichkeit, bis ihm nicht widersprochen wird. William James geht von einer Unterscheidung von Räumen aus: Ein Objekt im selben Raum wie andere Realien muss sich der Prüfung stellen, ob es hier seinen Platz finden kann. ${ }^{24}$ Er unterscheidet Sub-Universen (»sub-universes«), die alle eigene Wirklichkeitsbereiche oder -räume ausmachen sowie eine je eigene Existenzform ermöglichen (»each with its own special and separate style of existence«): die Welt der Sinne, die physikalischen Dinge (mit bestimmten Qualitäten wie Hitze, Farbe etc.) und die Welt der Kräfte (Elektrizität); die Welt der Wissenschaften; die Welt der idealen Beziehungen oder abstrakten Wahrheiten (etwa Mathematik); die Welt der Götzen (»idols of the tribe«), Illusionen und Vorurteile; die verschiedenen übernatürlichen Welten (zu ihnen zählt er den christlichen Himmel und die Hölle, die Hindu-Mythologie, Swedenborgs Welt etc.); die Welt der individuellen Meinung (so vielfältig wie Menschen sind); die Welt der Verrückheit (»sheer madness«) - seiner Meinung nach in vielen Facetten vertreten. ${ }^{25}$

James selbst betrachtet diese Liste nicht als abgeschlossen und umfassend. All diese »Welten« sind die vielen Welten (»The Many Worlds«). Davon zu unterscheiden ist die Welt praktischer Belange, James spricht von »the world

22 | P. L. Berger: Erlösendes Lachen, S. 8.

23 | W. James: The Principles of Psychology II, S. 918; Herv. i.0.

24 | Ebd., S. 919.

25 | Ebd., S. 921-922; die folgenden Zitate ebd., S. 924; Herv. i.0. 
of >practical< realities«. In dieser Welt erwirbt sich ein Ding, ein Gegenstand Wirklichkeits-Qualität durch die Bedeutung für uns, durch das Interesse, das in uns geweckt wird: »[A]n object must not only appear, but it must appear both interesting and important. The worlds whose objects are neither interesting nor important we treat simply negatively, we brand them as unreal.« Was wirklich ist, bestimmen wir durch Interesse, Aufmerksamkeit und Zuwendung:

"[R]eality means simply relation to our emotional and active life. This is the only sense which the word ever has in the mouths of practical men. In this sense, whatever excites and stimulates our interest is real; whenever an object so appeals to us that we turn to it, accept it, fill our mind with it, or practically take account of it, so far it is real for us, and we believe it. ${ }^{26}$

\section{"Gemeinsam musizieren"}

Der Untertitel zu Schütz’ Aufsatz »Gemeinsam musizieren« lautet: »Die Studie einer sozialen Beziehung«. Schütz stellt mit diesen Gedanken eine direkte Verbindung zur Alltagswelt her:

"Das Hauptinteresse unserer Analyse richtet sich auf den besonderen Charakter aller sozialen Interaktionen, die sich mit dem Musikprozeß verbinden: Zweifellos sind sie für den HandeInden ebenso wie für den Adressaten sinnvoll, aber diese Sinnstruktur kann nicht in der Begriffssprache ausgedrückt werden; sie gründen sich auf Kommunikation, aber primär nicht auf ein semantisches System, das vom Kommunikator als Ausdrucksund von seinem Partner als Auslegungsschema verwendet wird." ${ }^{27}$

Mit Rekurs auf Max Weber: »Handlungen müssen sich in ihrem Verlauf durch Bezug aufeinander orientieren. $\aleph^{28}$ Über die (offen gelassene) Frage nach dem Stellenwert von »sozialer Interaktion« und »Kommunikation« kommt Schütz zu seiner Grundannahme, dass sich Kommunikation auf das »Sich-aufeinander-Einstimmen « gründet: »Es ist genau diese wechselseitige Beziehung des Sich-aufeinander-Einstimmens, durch die das $>$ Ich $<$ und das $>$ Du< von beiden, die an der Beziehung teilhaben, als ein >Wir werden. ${ }^{29}$ Mit der Erwähnung der sinnhaften Handlung, des »Sich-aufeinander-Einstimmens« an einem bestimmten Ort, mit der Verwirklichung einer Beziehung und dem Durchleben einer gemeinsamen Zeit charakterisiert Schütz musikalische Praxis. Etwas später kommt er darauf zu sprechen, dass

26 | Ebd., S. 924; Herv. i.0.

27 | A. Schütz: Gemeinsam musizieren, S. 129.

28 Ebd., S. 130.

29 | Ebd., S. 132; das folgende Zitat ebd., S. 146. 
alle, Ausführende wie Hörer, »miteinander älter« werden, »solange der Musikprozeß dauert«. Das gemeinsame Da-Sein an einem bestimmten Ort und das gemeinsame Durchleben dieser Zeit lassen aus den Beteiligten eine Gemeinschaft werden. Die Verbindung zur Alltagswelt ist nicht die Sprache, sondern die »Wir-Beziehung«, die sowohl die Alltagswelt als auch die musikalische Situation prägt:

"Wir müssen jetzt in Betracht ziehen, daß jenes Phänomen in der Außenwelt, nämlich die Rede des Mitteilenden, während ihres Ablaufs ein gemeinsames Element seiner und meiner lebendigen Gegenwart ist, die somit miteinander gleichzeitig sind. Gleichzeitig nehme ich am Ablauf der Mitteilung des Anderen teil und so wird eine neue Zeitdimension konstituiert. Er und ich, wir teilen während der Dauer des Kommunikationsprozesses eine gemeinsame lebendige Gegenwart, nämlich unsere lebendige Gegenwart, die uns gestattet zu sagen: 'Wir haben diesen Vorgang gemeinsam erlebt. In der Wir-Beziehung, die hiermit konstituiert wurde, leben wir beide in unserer gegenseitigen lebendigen Gegenwart - er, indem er mich anspricht, und ich, indem ich inm zuhöre. Wir sind dabei auf jenen Gedanken ausgerichtet, der in und durch den Kommunikationsprozess verwirklicht werden soll. Wir altern zusammen." 30

Ein solches »gemeinsames Erleben« verbindet die »Alltagswelt« und die Welt der musikalischen Praxis. Dort, in der Alltagswelt, entsteht die »Wir-Beziehung« vorrangig über die gemeinsam »erlebte« oder durchlebte Rede (oder durch die erlebten Gesten), beim Musizieren durch Klänge, Gesten, Körperhaltungen, Positionen im Raum, Ortsbestimmungen, Beziehungen der einzelnen Beteiligten zueinander.

»Gemeinsam musizieren«: In einem ersten Schritt erörtert Schütz das »Gewebe sozialer Beziehungen«, in dem sich selbst ein einsamer Musiker bewegt, der für sich eine ihm fremde Komposition studiert: Dass dieser überhaupt in der Lage ist, sich mit diesem bestimmten Musikstück zu befassen, verdankt er unzähligen »Erfahrungen«, die er in seinem individuellen Leben sowie in seiner eigenen singulären »Musikkultur machen konnte. Musikalisches »Wissen«, so Schütz, ist wie ein jedes »sozial abgeleitet«. ${ }^{31}$ Mit einem Hinweis auf Edmund Husserls Untersuchungen zur »Struktur unserer Erfahrungen« im Allgemeinen verknüpft Schütz an dieser Stelle seine Darlegung zur Situation des ausübenden Musikers fast wie von selbst mit der alltäglichen Lebenswelt.

30 | A. Schütz: Über die mannigfaltigen Wirklichkeiten, S. 252; Herv. i.0.; vgl. A. Schütz: Mozart und die Philosophen, S. 172.

31 A. Schütz: Gemeinsam musizieren, S. 139; die folgenden Zitate ebd., S. 144, 145, 148. 
Eine weitere Analyse widmet Schütz der Beziehung zwischen Ausführenden, Hörern und Komponisten. Eine Brücke sucht er über die »innere Zeit«, bei Henri Bergson »temps durée«, zu finden. Alle Beteiligten durchleben, so Schütz, beim Verfolgen »gegliederter Schritt-für-Schritt-Ereignisse in der inneren Zeit «² eine »gemeinsame lebendige Gegenwart«.

Hinzu kommt ein Ausgreifen jedes Einzelnen in den äußeren Raum, eine Orientierung an den nicht nur hörbaren, sondern auch sichtbaren Handlungen der anderen Mitspieler, eine, wie Schütz es nennt, »Gesichtsfeldbeziehung « ${ }^{33}$.

An dieser Stelle lässt sich erneut ein direkter Bezug zum Handeln in der Alltagswelt herstellen: Auch hier sind nach außen hin sichtbar werdende Körperbewegungen sowohl Ereignisse, die sich, wie ein Steinwurf, chronometrisch messen lassen und der sogenannten objektiven Zeit unterliegen, als auch spontane Äußerungen, die sich auf den Fluss der »inneren Zeit« zurückführen lassen. ${ }^{34}$

"Den Übergang von unserer durée [inneren Zeit] zur räumlichen oder kosmischen Zeit vollziehen wir in und durch unsere Körperbewegungen. Unser Wirken vollzieht sich in beiden Zeitdimensionen. Wir erfahren unser Wirken gleichzeitig als eine Reihe von Ereignissen in der äußeren und in der inneren Zeit: beide Dimensionen werden so in einen einzigen Strom gefaßt, den wir lebendige Gegenwart (vivid present) nennen. « ${ }^{35}$

\section{Potentialität}

Über Schütz' Beitrag hinausgehend wäre eine weitere Verbindung zwischen der Alltagswelt und der Welt des »Gemeinsamen Musizierens« zu berücksichtigen, nämlich die Wiederholungsstruktur des Musikmachens. Musikalische Praxis ist auf Wiederholung ausgelegt, auch und gerade ohne eine wie auch immer geartete Perfektion zu erstreben. Die Sinnhaftigkeit der Praxis begründet ihren Ruf nach Wiederholung. Gerade die Wiederholungsstruktur macht Schütz für die Alltagswelt geltend: Er unterscheidet eine bestimmte »Schicht der Wirklichkeit, die das Individuum als Kern seiner Wirklichkeit erfährt«, nämlich »die Welt in seiner Reichweite«, eine Welt, die »wesentlich zur Zeitform der Gegenwart gehört « ${ }^{36}$, von anderen Welten mit anderen Zeithorizonten, nämlich Welten mit »Potentialität«. Die erste, »die Welt in wiederherstellbarer Reichweite«, blickt auf die Vergangenheit, die andere, »die Welt in erlangbarer

32 | Ebd., S. 144; das folgende Zitat ebd., S. 145.

33 | Ebd., S. 148.

34 | A. Schütz: Über die mannigfaltigen Wirklichkeiten, S. 247.

35 | Ebd., Herv. i.0.

36 | Ebd., S. 257; Herv. i.0. 
Reichweite«, auf die Zukunft. ${ }^{37}$ Durch die »Idealisierungen des >und so weiter und des $>$ Ich kann immer wieder « $^{38}$ werden diese Welten erreichbar. ${ }^{39}$

Solche »Idealisierungen « sind aber auch der musikalischen Praxis eingeschrieben, die damit lebensweltliche Züge gewinnt und sich ihrer Potentialität bewusstwird. Vor allem, wenn die musikalische Praxis die ausschließliche Bindung an den Musik-Kunst-Charakter lockert und sich einer Lebenspraxis annähert (eine »Lebensform« wird), wird ihre Wiederholungsstruktur ein Tun mit bestimmten Zeithorizonten.

"Das wichtigste Beispiel dieser zweiten Potentialitätszone [auf die Zukunft gerichtet, also der ,Welt in erlangbarer Reichweiter] ist die Welt in der gegenwärtigen Reichweite meines Zeitgenossen. So deckt sich z.B. sein Handhabungsbereich nicht - oder zumindest nicht ganz - mit dem meinigen, weil jener nur für inn ein Handhabungsbereich im Modus des hic, für mich aber ein Handhabungsbereich im Modus des illic ist. Trotzdem ist er aber mein erreichbarer Handhabungsbereich, der mein tatsächlicher Handhabungsbereich wäre, wenn ich mich an Stelle meines Mitmenschen befinden würde, was ja auch durch entsprechende Ortsveränderungen eintreten kann. “40

Eine Handlung, die für mich gegenwärtig nicht möglich ist, einem anderen Beteiligten aber schon, kann für mich dennoch möglich werden, wenn ich die Stelle des anderen einnehmen würde (oder der andere diese Handlung für mich ausführt). Ein wichtiger Aspekt für die musikalische Praxis.

\section{Appräsentation}

Appräsentation bedeutet »Mit-Vergegenwärtigung«:

"Anzeichen, Merkzeichen, Zeichen und Symbole ermitteln Nachrichten über die Grenzen der unmittelbaren Erfahrung hinweg, indem sie alles, was für die jeweils gegenwärtige Erfahrung thematisch, interpretativ und motivationsmäßig relevant ist, jedoch den Kern der Erfahrung in irgendeiner Weise überschreitet, in der Erfahrung mit-vergegenwärtigen. [...] Zeichen, obwohl wesentlich 'Nachrichtenüberbringer', helfen - in der wechselseitigen Verständigung mit anderen Menschen - auch im Überschreiten der Grenze zu innen; Symbole, obwohl wesentlich Verkörperungen einer anderen Wirklichkeit in der alltäglichen, können in Verbindung mit bestimmten (nämlich ritualisierten) Handlun-

37 | Ebd., S. 257f.; Herv. i.0.; vgl. A. Schütz/Th. Luckmann: Strukturen der Lebenswelt I, S. $63 \mathrm{ff}$.

38 | Ebd., S. 258.

39 | A. Schütz/Th. Luckmann: Strukturen der Lebenswelt I, S. 63-69.

40 | A. Schütz: Über die mannigfaltigen Wirklichkeiten, S. 258f.; Herv. i.0. 
gen im Überschreiten der Grenzen zu anderen Wirklichkeiten, einschließlich der letzten Grenze, in Anspruch genommen werden. ${ }^{41}$

»Grenzen der Erfahrung « können überschritten werden: durch Mit-Vergegenwärtigung, Appräsentation. Überschreitungen von Grenzen nennt Schütz »Transzendenzen« - und unterscheidet »kleine«, »mittlere« und »große« Transzendenzen. »Die >kleinen< Transzendenzen der Alltagswirklichkeit werden typisch als ein Außer-Reichweite-Sein von Erfahrungsgegenständen erlebt, die einmal in Reichweite gewesen sind. ${ }^{42}$ Die »kleine « Transzendenz gehört der Alltagswirklichkeit an. Ein Beispiel, das Schütz anführt: ein vergessenes Buch, das zu Hause auf dem Tisch liegengeblieben ist. Man weiß, dass man es jederzeit wieder in Reichweite bringen kann, dass die Erfahrung sich neu aktivieren lässt. Mit dem Ort, an dem das Buch vergessen liegenblieb, verändern sich die »Chancen der Wiederherstellbarkeit « ${ }^{43}$ »Mittlere « Transzendenzen ergeben sich in der Begegnung: Mit dem »Körper« eines anderen Mitmenschen ist zugleich auch »ein Innen« dieses anderen »mit-gegenwärtig«, das sich aber meiner unmittelbaren Erfahrung entzieht: »In dem Wahrnehmungskern der Erfahrung ist mir der Andere von außen gegeben, aber eben nicht als ein bloßes Außen; in der vollen Erfahrung ist mir sein Innen mit-gegeben. Das andere, dessen Körper ich wahrnehme, ist in der Erfahrung von vornherein meinesgleichen. ${ }^{44}$ Die Mit-Vergegenwärtigung beruht auf der Erfahrung »Meinesgleichen«, es geschieht, so Schütz, eine »Sinnübertragung«: »[E]inem Außen wird ein Innen zugesprochen. ${ }^{45}$ Diese Gegenwart des Mitmenschen, des Mitspielers auf derselben Bühne, rückt den Aspekt der Appräsentation mit ins Zentrum der Diskussion über musikalische Praxis:

"Es ist [der] Körper [des anderen] in lebendiger Gegenwart, der mir sein Fühlen, Wollen und Denken runmittelbar vermittelt. Der Mitmensch verkörpert sich in meiner Gegenwart. Dieser Umstand, seine Gegenwart für mich und meine Gegenwart für inn, die ich an meiner Erfahrung von inm ablese, gibt uns die Berechtigung, von unmittelbaren Erfahrungen eines Mitmenschen in der Wir-Beziehung zu sprechen." ${ }^{46}$

Die »großen« Transzendenzen sind Überschreitungen der Grenzen der Alltagswelt in »andere Wirklichkeiten« hinein: durch »Abkehr vom Alltag in Schlaf und Traum«, in »Halbwachheit und Tagtraum«, in »Ekstasen«, in »Kri-

41 A. Schütz/Th. Luckmann: Strukturen der Lebenswelt II, S. 178f.; Herv. i.0.

42 | Ebd., S. 149.

43 | Ebd., S. 151.

44 | Ebd., S. 153.

45 | Ebd., S. 155.

46 | Ebd., S. 156. 
sen und Tod «. ${ }^{47}$ Die Appräsentation, die Mit-Vergegenwärtigung also, ermöglicht es, Grenzen innerhalb eines Sinnbereichs zu transzendieren oder auch Sinnbereiche miteinander in Beziehung zu bringen.

\section{Lebenswelt und musikalische Praxis: eine erste Diskussion der Schwelle}

Schütz besteht demnach auf Trennung der Sinnbereiche. Seiner Darstellung ist der Rat zu entnehmen, bei allen Arten von Verweisungen die Grenzen der »geschlossenen Sinnbereiche« zu respektieren. Es gibt zwar Brückenschläge zwischen Sinnbereichen sowie schockhaften oder sprunghaften Wechsel ${ }^{48}$ beim Übergang von einem Wirklichkeitsbereich in einen anderen - etwa durch einen Knall, der einen aus der Betrachtung eines Bildes herausreißt. Dennoch bleibt die »Geschlossenheit« der Sinnbereiche erhalten; vor dem Hintergrund dieser Geschlossenheit lassen sich Brückenschläge, Wechsel und Transparenzen überhaupt erst denken und darstellen.

Aufschlussreich sind die Parallelen zwischen dem geschlossenen Sinnbereich musikalischer Praxis und der Alltagswelt. Hier ein kurzer Rückblick auf Schütz' Mozart-Studie und seinen Aufsatz »Gemeinsam musizieren. Die Studie einer sozialen Beziehung«. Als verbindende Elemente zwischen der hier geschilderten musikalischen Praxis und der »ausgezeichneten Wirklichkeit« des Alltags sind zu nennen:

- die Orientierung am Tun der Beteiligten;

- die Sinngebung;

- das Werden eines »Wir«;

- das gemeinsame Durchlaufen eines (Alterungs-)Prozesses;

- die soziale Struktur von Erfahrungen;

- die soziale Ableitung von (musikalischem) »Wissen«;

- die Teilhabe an einer gemeinsamen Gegenwart;

- die Orientierung an Handlungen des Anderen (»Gesichtsfeldbeziehung«);

- Intersubjektivität.

Über diese Studien hinaus sind weitere Parallelen auszumachen, die musikalische Praxis und Alltagswelt miteinander verbinden.

a. Wiederholungsstrukturen sind sowohl für den Alltag als auch in musikalischer Praxis bestimmend - wie auch die mit der Wiederholungsstruktur verbundene »Potentialität«. Durch die »Idealisierungen des >und so weiter

47 | Ebd., S. $161 \mathrm{ff}$.

48 | A. Schütz: Über die mannigfaltigen Wirklichkeiten, S. 267. 
und des $>$ Ich kann immer wieder $«^{49}$ werden die Welt in »erlangbarer Reichweite « und diejenige in »wiederherstellbarer Reichweite « erreichbar. ${ }^{50}$

b. Weiterführend auch die Bestimmung des »Sinnhorizonts«: Ausgehend von einem solchen »Sinnhorizont«, der Wirklichkeit - oder besser gesagt: eine ganz bestimmte Wirklichkeit unter mehreren - konstituiert, wird es deutlich, warum beispielsweise die Ausführung einer Sonate Wirklichkeit werden kann. Die Sonate wird wirklich, sobald sie Aufmerksamkeit auf sich zieht: Wenn man sich mit ihr beschäftigt, wenn sie geübt, gespielt, vorgetragen, also ausgeführt wird.

c. Schließlich greift die Alltagswelt auf den Sinnbereich musikalischer Praxis über, sobald der Leib in Erscheinung tritt: Über den Leib sind wir immer mit der »Außenwelt des Alltags « verbunden, selbst, so Schütz, wenn wir »träumen $\ll .{ }^{51}$ Über die Leiblichkeit der Beteiligten wird zugleich eine »Appräsentation«, eine Mit-Vergegenwärtigung des »Inneren«, möglich.

\subsection{Verkörperungen (Simone Mahrenholz)}

\section{Musik und Welt: Bezugnahmen "via Hören“}

Wir finden eine ganze Reihe von Wörtern für das, was da jetzt passiert: Das semantische Feld kann groß sein. Und schon treten Zweifel an der Tragfähigkeit solcher und ähnlicher Sprachfindungen auf. Erst recht, wenn es darum gehen soll, Erfahrungen von Sinn oder von Beziehungen in Worte zu fassen.

"Musik mit Worten beschreiben heißt immer, so etwas wie eine Wunde schlagen, eine Kluft bilden. Dies rührt her aus einem Verlust, einem Verletzen: aus jenem Riß, der mit dem Über-Setzen zwischen einem vorweisenden und einem verweisenden Symbolsystem einhergeht, zwischen einem, das zeigt, und einem, das spricht. Jede Verbindung zwischen dieser Klangstruktur und diesem beschreibenden Wort ist fragil, alternativehaltig [...]. In dem Moment, wo wir in musikalischen Strukturen auch einen Welt- und Selbstbezug ausmachen - so abstrakt der im Fall der rabsoluten، Musik auch sein mag - entstehen Fragen, die sich um das Verhältnis von Musik und Wort drehen bzw. um das Phänomen des metaphorisch-übertragenden Denkens." ${ }^{52}$

49 | Ebd., S. 258.

50 | Vgl. A. Schütz/Th. Luckmann: Strukturen der Lebenswelt I, S. 63-69.

51 | A. Schütz: Symbol, Wirklichkeit und Gesellschaft, S. 395.

52 | S. Mahrenholz: Musik-Verstehen jenseits der Sprache, S. 219; Herv. i.0. 
Simone Mahrenholz setzt an diesem Punkt ihrer Sprachfindung an, versucht, sich dem Anspruch zu stellen, das »Hinausweisen ${ }^{53}$ (Lachenmann) von Musik auf Welt und Wirklichkeit und, umgekehrt, die Auswirkung der Lebenswelt auf Musik über Sprache, aber nicht nur über Sprache, einzukreisen - mittels der Metapher. Sie beschreibt in Anknüpfung an die Symboltheorie Nelson Goodmans $^{54}$ das »Phänomen des metaphorisch-übertragenden Denkens «. ${ }^{55}$ »[Ein] Verstehen von Musik [kann] gerade im Verstehen durch Musik bestehen, ohne involvierte Begriffe: ein Realisieren, Auffassen innerer oder äußerer Welt, Wirklichkeit, Möglichkeit.« So spricht sie eine Wechselwirkung zwischen musikalischer Wirklichkeit und Lebenswelt an:

"Damit ist Lachenmanns Position reformuliert, daß musikalische Strukturen hinausweisen: nicht nur auf potentiell andere musikalische Strukturen, sondern auf Außermusikalisches - auf Welt, auf Selbst, auf Wirklichkeit (im Werk und/oder der Welt) oder Möglichkeit (in der Welt oder im Selbst). [...] So kann ein neues Wahrnehmungsvokabular, das Musik bereitstellt, neue Erfahrungsweisen der Welt mit sich bringen." ${ }^{56}$

Dabei verweist sie auch auf George Steiner, der diesen Zugewinn an Erfahrung so beschrieben hat:

"Die Straßen unserer Städte sind nach Balzac und Dickens andere geworden. Sommernächte, vor allem gen Süden hin, haben sich mit van Gogh gewandelt. Es ist faszinierend, wie aleatorische und elektronische Musik vielen der städtischen, technischen 'Geräusche`, die uns umgeben, einen neuen formalen Charakter und neue 'Hörbarkeit verleiht. ${ }^{57}$

Mahrenholz widmet sich im Anschluss an Goodmans Symboltheorie, welche sich auf Malerei und musikalische Notationsformen konzentriert, vorrangig der Aufführung, der klanglichen Erscheinung von Musik. Sie kritisiert die einseitige Betrachtung der Notation und tritt für eine stärkere Berücksichtigung des Klingenden ein: Dem Prozesscharakter des musikalischen Geschehens sei durch eine Analyse der Partitur allein nicht gerecht zu werden. ${ }^{58}$ Dabei spricht

53 | H. Lachenmann: Vier Grundbestimmungen des Musikhörens, S. 62; H. Lachenmann: Nono, Webern, Mozart, Boulez, S. 278.

54 Goodman, Nelson: Languages of Art. An Approach to a Theory of Symbols, Indianapolis: The Bobbs-Merrill Company 1968.

55 | S. Mahrenholz: Musik-Verstehen, S. 219; das folgende Zitat ebd., S. 220; Herv. i.0.

56 | Ebd., S. 226; Herv. i.0.

57 | G. Steiner: Von realer Gegenwart, S. 217; Herv. i.0.; vgl. S. Mahrenholz: Musik-Verstehen, S. $226 f$.

58 | S. Mahrenholz, Musik und Erkenntnis, S. 5. 
sie allerdings, sieht man von Beiträgen zur Leiblichkeit des Komponierens ${ }^{59}$ (und Ausführens) ab, nicht explizit die musikalische Praxis des Ausführens an, sondern orientiert sich am Hören bzw. am Hörer: Das Berührt-Werden geschieht »via Hören « ${ }^{60}$. Hören von Musik ist auf die Ausführung angewiesen, auch ein auf Tonträger gebanntes Musikstück musste zuvor ausgeführt werden. So kommt Mahrenholz wiederholt auf die Notwendigkeit der Aufführung zu sprechen - nähert sich dabei aber nicht dem konkreten Tun der Ausführenden. Die Distanz von einer ausschließlichen Orientierung am musikalischen Schriftbild ist ihr wichtig: »Es geht [...] im musikalischen Ausdruck nicht um das, was die Partitur ausdrückt - ihre Funktion liegt nicht im Expressiven, sie ist zum Denotieren konstruiert - sondern um dasjenige, was die partiturkompatiblen Aufführungen ausdrücken «. ${ }^{61}$

Mahrenholz' Ansatz weitet den Blick auf die musikalische Praxis, obwohl eine solche Akzentuierung nicht vordergründig in ihrem Forschungsinteresse liegt. Er stellt ein Vokabular bereit und hilft bei der Sprachfindung, wenn es gilt, auch musikalische Praxis zu beschreiben. Er ermöglicht größere Genauigkeit der eigenen Rede, vor allem bei der Unterscheidung von metaphorischen und buchstäblichen Eigenschaften. Vor allem die Unterscheidung von »Sagen « und »Zeigen « ${ }^{62}$ (resp. Verkörpern) führt die Diskussion der Frage weiter, was musikalische Praxis sein kann.

\section{Exemplifikation}

Mahrenholz bringt das Dilemma zur Sprache, dass einerseits eine Beschreibung musikalischer Strukturen mit musikwissenschaftlich präzisen Termini in der bloßen (buchstäblichen) Beschreibung stecken bleibt, dass aber andererseits, beim »Übergang ${ }^{63}$ in eine an Metaphern reiche Sprache, die Frage nach dem »Sinn« der Analyse dem Vorwurf der Beliebigkeit und Subjektivität begegnet. Eine andere Rede als bloße »Beschreibung« struktureller Details sei »ebenso nötig wie schwierig«. Schwierig aufgrund des latenten Vorwurfs mangelnder Objektivität, nötig, »weil ohne eine solche sinnhafte Verbalisierung die phänomenologische (zuweilen auch >hermeneutisch des Gehörten nicht erfaßt scheint - nicht dasjenige, was wir als die musikalische Bedeutung, Bedeutsamkeit ansehen.«

59 | Vgl. S. Mahrenholz: Der Körper des Komponisten.

60 | S. Mahrenholz: Musik und Erkenntnis, S. 169; Herv. i.0.

61 | Ebd., S. 83f.; Herv. i.0.

62 | Vgl. S. Mahrenholz: Der Körper des Komponisten, S. 31.

63 | S. Mahrenholz: Musik-Verstehen, S. 221; die folgenden Zitate ebd.; Herv. i.0. 
Mahrenholz' Entwurf unterscheidet sich zunächst von demjenigen Goodmans, als sie sich auf Musik »als klangliches Phänomen « ${ }^{64}$ bezieht. Ein Grund für die Anknüpfung an Goodmans Theorie ist für sie dessen »Neuerung, die seine Erweiterung des Konzepts der Bezugnahme (reference) um die Exemplifikation bedeutet.« $\mathrm{Zu}$ unterscheiden seien zwei unterschiedliche Weisen der Bezugnahme: Denotation und Exemplifikation. Denotation: Eine Beziehung zwischen einem Zeichen und einem Bezugsobjekt wird hergestellt: »Denotation ist Bezugnahme im Sinne des Stehens-für, des Bezeichnens, auf etwas Zutreffens. Sie ist eine zweistellige semantische Relation zwischen einem Zeichen und demjenigen, worauf es sich bezieht «. ${ }^{65}$ Formen der Denotation

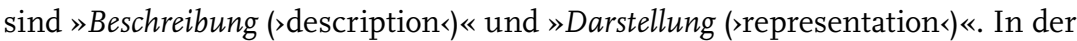
gegenständlichen Malerei sei Denotation die geläufige Art der Bezugnahme, in der Musik allerdings nur in Sonderfällen möglich: beim »musikalischen Zitat«, bei »Leitmotivik«, in der »Programmusik«. ${ }^{66}$

Im Hinblick auf die sogenannte absolute Musik komme man, so Mahrenholz, mit Denotation als alleiniger Form der Bezugnahme nicht aus. Eben an dieser Stelle hilft ihr Goodmans Erweiterung der Bezugnahme-Möglichkeiten um die Exemplifikation weiter, Mahrenholz bezeichnet Goodmans »Konzeption der Exemplifikation [als] eine weitreichende Lösung von auffallender Eleganz und Einfachheit« und führt aus:

"Ist die Denotation ein Verweis vom Symbolgefüge aus auf anderes - auf Menschen, Gegenstände, Ereignisse - so nimmt die Exemplifikation Bezug auf Züge des Symbolgefüges selber. Ein Kunstwerk (und potentiell jedes andere symbolisierende Objekt) zeigt vor, stellt aus, referiert buchstäblich auf Eigenschaften seiner selbst: auf interne Strukturen und Relationen, auf Farben, Formen, Klangeigenschaften - und metaphorisch zudem auf eine Fülle von Eigenschaften, die das eigene Medium transzendieren, einschließlich des Bereichs menschlicher Gefühle und Emotionen." ${ }^{67}$

Zur Bezeichnung dieser »Eigenschaften« übernimmt sie von Goodman den Begriff »Label ${ }^{68}{ }^{68}$ Es sind diese Labels (Eigenschaften), die exemplifiziert werden. Was genau kann in Musik ein Label sein?

"Eine Musikpassage kann ihren speziellen Rhythmus exemplifizieren, ihre Instrumentierung bzw. Klangfarbe, ihre Architektur, Aspekte von Harmoniegebung, Melodie und

64 | S. Mahrenholz: Musik und Erkenntnis, S. 5; das folgende Zitat ebd., S. 6; Herv. i.0.

65 | Ebd., S. 40; das folgende Zitat ebd., S. 41; Herv. i.0.

66 | Ebd., S. 41f.

67 | Ebd., S. 49; Herv. i.0.

68 | In der deutschen Übersetzung von "Languages of Art", "Sprachen der Kunst", ist von "Eigenschaften" die Rede. 
vieles mehr. Sie ist für diese Eigenschaften ein sample, ein Muster. Und diese exemplifizierten Eigenschaften heißen in Goodmans Terminologie label, übersetzbar mit Etiketten (unter die etwas ıfälltı). "69

Es ist ein Unterschied, ob ein Musikstück bestimmte Eigenschaften nur besitzt oder sie ausstellt. Mahrenholz greift auf Goodmans Beispiel der Stoffprobe zurück, die als »Probe«, »Muster«, »Exemplar« oder »sample« fungieren kann: Abhängig vom jeweiligen Kontext besitzt dieses Muster verschiedene Eigenschaften (beispielsweise einen Geruch, eine bestimmte Größe), die aber nicht exemplifiziert werden, wenn sie in diesem Kontext nicht gezeigt werden sollen. Die Eigenschaften, die gezeigt werden, könnten abhängig vom Kontext Farbe oder Stoffart sein. Was ein Label ist und was nicht, ist also nicht generell $\mathrm{zu}$ bestimmen, ist vielmehr abhängig von der Art der Bezugnahme und vom Kontext. ${ }^{70}$ Mit Bezug auf die Aufführungssituation von Musik formuliert: »Die musikalische Aufführung exemplifiziert buchstäblich diejenigen Eigenschaften, die sie a) als klangliches Symbol besitzt und auf die sie sich b) in einem ästhetischen Kontext bezieht. «11 Label sind nicht nur sprachlicher oder musikalischer Art (wie harmonische Wendungen, Rhythmen etc.): Der Charakter des »Unaussprechlichen ${ }^{72}$ hafte dem Exemplifizierten vielmehr deshalb an, weil Label »einer Fülle anderer dichter und voller Sphären, einschließlich dem [Bereich] der Gefühle« entstammen könnten und weil die »Dichte und Fülle« der Label niemals gänzlich erschlossen werden könnten. ${ }^{73}$

\title{
Exkurs: Der Sprung in die Metapher vor dem Hintergrund der Theorie Nelson Goodmans
}

\author{
Goodman veranschaulicht Exemplifikation so:
}

"Nehmen wir die Kollektion kleiner Stoffmuster eines Schneiders. Diese funktionieren als Proben, als Symbole, die bestimmte Eigenschaften exemplifizieren. Aber ein Stoffmuster exemplifiziert nicht alle seine Eigenschaften; es ist eine Probe der Farbe, der Webart, der Textur und des Musters, aber nicht der Größe, der Form, des absoluten Gewichts oder des Wertes. Es exemplifiziert nicht einmal alle die Eigenschaften - etwa die, an einem Dienstag fertiggestellt worden zu sein -, die es mit dem gegebenen Ballen oder der Bahn des Materials teilt. Exemplifikation ist Besitz plus Bezugnahme. [...]

69 | S. Mahrenholz: Musik-Verstehen, S. 224; Herv. i.0.

70 | S. Mahrenholz: Musik und Erkenntnis, S. 49.

71 | Ebd., S. 64.

72 | Mahrenholz, ebd., S. 53, spricht auch von der "tendenzielle[n] Ineffabilitätı des Exemplifizierten “.

73 | Ebd. 
Das Stoffmuster exemplifiziert nur die Eigenschaften, die es hat und auf die es zugleich Bezug nimmt. “74

Von der Exemplifikation her lässt sich verstehen, was »Ausdruck« ist, wie »Ausdruck« zustande kommt. Ausdruck ist, so Goodman, eine besondere Art der Exemplifikation, nämlich die »metaphorische« Exemplifikation, die sich von der »buchstäblichen « unterscheidet; diese »buchstäbliche« weist nämlich rein materiale Eigenschaften vor. Bei der »metaphorischen« Exemplifikation hingegen findet ein Sprung in eine andere Referenzebene statt, Goodman wählt als Beispiel ein graues, düsteres Bild: Ein Bild »in düsteren Grautönen [...] mit Bäumen und Klippen am Meer, das tiefe Traurigkeit ausdrückt« - so die Beschreibung - kann selbst nicht traurig sein, wohl aber die besagten Grauschattierungen aufweisen. ${ }^{75}$ Es ist im buchstäblichen Sinne grau, doch stellt sich die Frage:

"[I]st es auch in derselben Weise traurig, in der es grau ist? Ein bemerkenswerter Unterschied besteht darin: Da strenggenommen nur empfindende Wesen oder Ereignisse traurig sein können, ist ein Bild nur im übertragenen Sinne traurig. Ein Bild besitzt eine graue Farbe buchstäblich und gehört wirklich zur Klasse der grauen Dinge; aber nur metaphorisch besitzt es Traurigkeit oder gehört es zur Klasse der Dinge, die sich traurig fühlen." ${ }^{76}$

Analog zu Goodmans Beispiel der Stoffprobe wählt Mahrenholz eines aus der Musik: Chopins Etüde für Klavier op. 25, Nr. 7 - »eine Passage in cis-moll mit langsamen, gleichmäßigen Achtelnoten in der Mittelstimme, über und unter denen sich jeweils eine Melodie in engen, zunächst abfallenden Tonabständen entwickelt. «77 Wichtig ist Mahrenholz, dass die Expression von der Emotion getrennt wird: »Wir charakterisieren diese Musik als traurig - genauer: wir verleihen ihr ein nonverbales Label, das in etwa koextensiv ist mit >traurig < - und zwar unabhängig davon, ob die Musik das Gefühl in uns hervorruft [...] oder ob wir es gleichsam an der Musik wahrnehmen.« Die harmonischen, rhythmischen und melodischen Eigenschaften besitzt die Passage buchstäblich und sie verweist auch darauf; der Sprung in die Ebene der Metapher vollzieht sich mit der Zuschreibung des Labels »traurig«.

74 | N. Goodman: Sprachen der Kunst, S. $59 f$.

75 | Ebd., S. 57.

76 | Ebd., S. $57 f$.

77 | S. Mahrenholz: Musik und Erkenntnis, S. 85; das folgende Zitat ebd., S. 86. 


\section{Hinausweisung}

Diese Studie kann - und diesbezüglich führt sie die Diskussion auch der musikalischen Praxis weiter, wenngleich dies nicht ausdrücklich ihr Thema ist - die Schwelle zwischen Musik und Außermusikalischem transparent werden lassen. Um noch einmal auf Chopins Etüde cis-moll als Beispiel zurückzukommen:

„Wir erfahren in dem einen Akt der Denotierung einer Musikpassage durch das Label 'traurig، nicht nur etwas über diese Musik, sondern komplementär etwas über das Label 'traurig،. Wir erfahren, genauer, sogar weit mehr über straurig، (und potentiell über uns und die Welt) als über die Musik. Denn während das relativ unspezifische Label ,traurig، die Musik u.a. denotiert, weil es so unspezifisch ist, so ist es die im Gegensatz dazu äußerst nuancierte, differenziert symbolisierende Musik, die darin umgekehrt das Label 'traurig، charakterisiert und inm in diesem Passen höchst spezifische Konturen verleint. ${ }^{78}$

Musik und Außermusikalisches nehmen aufeinander Einfluss; diese Beeinflussungen ereignen sich nicht einseitig, sondern wechselseitig, es kommt zu einer Art Fluktuation. Unter Hinweis auf Lachenmann ist Mahrenholz der Begriff des »Hinausweisens« wichtig; Musik ist geeignet, »Wirklichkeiten und Möglichkeiten « außerhalb ihrer selbst zu »erschließen « und zugleich auf diese $\mathrm{zu} »$ verweisen«, auf diese »Bezug zu nehmen«:

mHinausweisen auf Strukturen, auf Wirklichkeiten und Möglichkeiten um uns und in uns selbst: Diese Sicht enthält für unseren Zusammenhang vor allem zweierlei: erstens etwas, das man die erkenntnistheoretische Dimension nennen könnte - Musik erschließt etwas an Wirklichkeiten und Möglichkeiten jener Seinsbereiche, denen wir selbst angehören; zweitens eine Präzisierung dessen: Musik verweist auf etwas jenseits inrer selbst, genauer, auf etwas um sie herum, etwas, dessen Bestandteil sie ist. Musik nimmt Bezug. ." ${ }^{79}$

Der Transfer zwischen Musik und Außermusikalischem gelingt Mahrenholz über das Hören. Die klingende Erscheinung steht im Mittelpunkt der Betrachtung, nicht das Notierte. Doch dabei erfährt das Hören eines Zuhörers die Akzentsetzung, nicht das Tun eines Ausführenden. Ihre Thesen umreißen den Prozess der »Hinausweisung « als eine Übertragungsleistung des Hörers.

Die erste These: »Musik weist beim Hören über ihre buchstäblich besessenen Strukturen hinaus, zugleich liegt dieses Hinausweisen in ihren Struk-

78 | Ebd., S. 88; Herv. i.0.

79 | S. Mahrenholz: Musik-Verstehen, S. 220f.; Herv. i.0. 
turen. Musik verstehen heißt unter anderem, ihre Strukturen anderswo wiederzuerkennen oder auf anderes zu übertragen. ${ }^{80}$ Dies meint erstens das »Wiedererkennen« von »Labels« im innermusikalischen Bereich (eines Werks beispielsweise), zweitens ein Wiedererkennen von einem Werk in einem anderen (beispielsweise einer anderen Epoche), drittens eine Bezugnahme von musikalischen Strukturen zu Außermusikalischem (Bewegung, Bild, Architektur etc.). Mit der zweiten These erläutert Mahrenholz die Möglichkeit non-verbaler metaphorischer Übertragung: Für die Übertragung generell mache es keinen Unterschied, ob ein bestimmter Ausdruck durch ein Wort oder etwa durch ein Bild mit einer bestimmten Farbtönung bestimmt werde: »Das Verstehen von Musik, sofern es auch im Erkennen und Wiederfinden musikalischer Strukturen in Außermusikalischem besteht, ist ein Akt metaphorischer Übertragung. Dieser muß nicht notwendig in Sprache stattfinden. ${ }^{81}$ Die dritte These schließlich verdeutlicht die Wechselseitigkeit des Übertragungsprozesses, zugleich auch das Verwandlungspotential, das der metaphorischen Übertragung innewohnen kann. Die metaphorische Übertragung von Musik auf Außermusikalisches verändert dieses Außermusikalische, was wiederum Auswirkungen auf die Musik hat:

"Der Akt metaphorischer Übertragung auf Anderes, der mit dem ästhetischen und verstehenden Erleben von Musik einhergeht, bedeutet eine Umstrukturierung dieses Anderen. Musikalische Strukturen werden analog zu nonverbalen Prädikaten auf anderes projiziert. Sie re-organisieren dieses andere - und dieses andere re-organisiert potentiell umgekehrt auch wieder die Musik. Das Verstehen/Erleben von Musik fällt damit partiell zusammen mit dem Verstehen/Erleben durch Musik." ${ }^{82}$

\section{Die Kraft der Sprache}

Mahrenholz lehnt den Verzicht auf Sprache, Rede, verbale Beschreibung ab: Wenngleich jedes Wort durch ein anderes, ebenso passendes zu ersetzen ist, so ist für sie doch über die Metapher die Möglichkeit einer Übertragung gegeben. Metaphorisches Sprechen bleibt für sie notwendig, damit die Rede über Musik sich nicht in einer bloßen Aufzählung von Strukturmerkmalen erschöpft. An dieser Stelle ein Beispiel der sprachlichen Annäherung an Franz Schuberts Sonate op. posth. c-moll, D 958 (1828), Takt 117-159 (Durchführung):

"Das allmähliche Verschwinden des Zeitmetrums, die Orientierung hin in eine nicht-artikulierte, entdifferenzierte Tiefe und zugleich entlegene Höhe läßt sich so etwa mit der

80 | Ebd., S. 221; Herv. i.0.

81 | Ebd., S. 223.

82 | Ebd.; Herv. i.0. 
Bedrohung und dem gleichzeitigen Sog des Todes in Verbindung bringen: der allmählichen Auflösung robjektiver Zeitlichkeit ineins mit der Zeitlichkeit des Selbst. Damit macht dieses Zeitlabel eine Erfahrung von Welt und Selbst zugänglich(er), die über das Innermusikalische hinausgehend kognitiv wirksam ist. Artikuliert wird die Empfindung einer Situation, die für Jeden jederzeit Realität hat und die zugleich kaum bewußtseinsfähig ist [Anmerkung Mahrenholz: "'Der Tod ist kein Ereignis des Lebens. Den Tod erlebt man nicht. Ludwig Wittgenstein: Tractatus logico-philosophicus, 6.4311"]: der notwendig kommende Tod bzw. das kommende Sterben samt der Möglichkeit des Einnehmens einer Haltung dazu. Natürlich muß die Passage keineswegs mit 'Todı in Verbindung gebracht werden, ganz andere Sinnbereiche sind mit demselben musikalischen Material zu erschließen möglich." 83

Wäre eine Beschreibung musikalischer Praxis über die Metapher eine prozesshafte »Annäherung « ${ }^{84}$ an das, »was sich zeigt« - im Prozess der Ausführung? Anders gefragt: Lässt sich metaphorisch sagen, was jemand tut, der die besagte Stelle aus der Sonate Schuberts ausführt?

Ich erfahre beim Spielen, dass und wie das Thema in weite Ferne rückt, ich spiele einige Töne des Themas gar nicht mehr; sie fehlen, Phrasen werden zusammengezogen. Ich spüre, dass und wie ich in verschiedenen Registern des Klaviers (mit beiden Händen an unterschiedlichen Stellen) spiele, ein Zusammenhang geht mir verloren. Ich mache mit der linken Hand etwas anderes als mit der rechten, habe verschiedene Schichten gleichzeitig zu bewältigen. Es entsteht in meinem Körper eine Art »floating ${ }^{85}$, das Almut Rößler mit Blick auf Olivier Messiaens »valeurs irrationelles« folgendermaßen beschreibt: »Man begibt sich [...] als Spieler in ein stark dialektisches Spannungsfeld: selbst die aufeinander geschichteten Zeitabfolgen, die ich genau wiederzugeben vermag, produzieren in ihrer Komplexheit den Eindruck einer irrationalen Zeitaufgliederung, eines Schwebens im Zeitraum «. ${ }^{86}$ Die besagte Stelle aus der Schubert-Sonate versetzt mich als Spieler in Orientierungslosigkeit, mir rutscht der Boden unter den Füßen weg. Wie kann man das spielen? Man wird es vielleicht zunächst fast mechanisch, vielleicht auch beide Hände einzeln, üben, bis die Bewegungsabläufe im Kopf und im Körper sind, sodass das Spiel losgelassen werden kann. Spielen wird ein Lassen, ein Loslassen, Verlust von Kontrolle. Ich begebe mich als Spieler auf schwankenden Boden, in ein nebliges Feld, in Dämmerung und Zwielicht.

Dies eben verheißt die wechselseitige Bezogenheit der Welten aufeinander: Die an Metaphern reiche Sprache hilft mir zu sagen, wie es mir beim Spielen

83 | S. Mahrenholz: Musik und Erkenntnis, S. 146; Herv. i.0.

84 | D. Mersch: Was sich zeigt, S. 40.

85 | A. Rößler: Zur rhythmischen Freiheit, S. 158.

86 | Ebd., S. 159. 
ergeht. Dabei finde ich nicht nur zum Sprechen über die Musik, sondern die Musik selbst präzisiert auf ihre Weise zugleich das Loslassen, lässt mich am eigenen Leib spüren, wie es wirklich ist, wenn ich alles dahingebe, mich verliere und in Orientierungslosigkeit falle.

\section{Verkörperungen:}

\section{Auseinandersetzung mit dem Schaffen Wolfgang Rihms}

"Musik - indem sie vor-begrifflich, d.h. (auch) physisch-sinnlich rezipiert [...] wird - führt in eine Form der Berührung mit [...] nicht 'wiß-baren Inhalten, die das Subjekt über die Sinne und deren komplexe physisch-intellektuelle Einheit im musikalischen Geschehen gleichsam leiblich-existentiell verankert. In dem Moment, wo man etwa die Zyklizität der balinesischen Musik und ihre interne Erfülltheit wahrhaft sinnlich zugänglich bekommt, sie im Hören selber ver-körpert und perpetuiert, ist sie zugleich nicht nur erfaßt und verstanden, sondern für diesen Moment auch bejaht. Die Musik samt dieses Inhalts bejaht sich im Akt der umfassenden sinnlichen Aufnahme selbst (wohlgemerkt: nicht schon im Akt des Hörens, die Musik kann einen auch uninteressiert lassen oder abstoßen). Auch hier [...] ermöglicht Musik den kognitiv aufschließenden Zugang zu einer Wahrheit der Realität und der Existenz, die mittels anderer Symbolisationsformen, wie der im gegenwärtigen Akt des Schreibens und Lesens verwendeten sprachlichen, nicht zugänglich gemacht werden kann." 87

Mahrenholz beschreibt hier ein Hören mit allen Sinnen, das Zugänge zu existentiellen Erfahrungen ermöglicht. Solche Erfahrungen aber sind potentiell nicht nur Hörern zugänglich, sondern auch (vielleicht mehr noch) den Ausführenden.

Aus der Praxis des Komponierens heraus hat sich Wolfgang Rihm mehrfach zur Körperlichkeit des Komponierens geäußert: »Handwerk ist >Körperwerk<, Sich-Eindrücken des Körpers in eine andere plastische Dimension, Negativform, aus Druck. Handwerk gelangt als Artikulationsform nach außen, und dort setzt es den Körper, dem es entstammt, wieder zusammen. ${ }^{88}$ In seinem Aufsatz »Musikalische Freiheit« geht er auf die Situation um 1910 ein, als Schönberg noch nicht eigenen »Gesetzen« gefolgt sei, sondern »im chromatischen Total ohne Tonartbindung« gearbeitet habe:

"Freie Prosar meint hier: Musik, die sich in jedem Augenblick selbst erneuert, eigentlich Debussys Ideal, Musik, deren Verlauf in ihrer eigenen Verlaufsenergie begründet liegt, die der Komponist in den Klangobjekten aufspürt und freisetzt. 'Triebleben der Klänge،

87 | S. Mahrenholz: Musik und Erkenntnis, S. 149f.; Herv. i.0.

88 | W. Rinm: Spur, Faden, S. 71. 
wurde dies einmal genannt. Vegetatives Komponieren kann man es auch nennen, muß es aber nicht. ${ }^{89}$

Debussy: Mit diesem Namen weckt Rihm nicht nur Assoziationen an Naturund Körperhaftes oder an Vegetationsprozesse, sondern auch solche an gesprochene Rede. Für ihn ist Debussy ein »Erforscher« des musikalischen Redens, des musikalischen Sprechens im Vollzug: »Für Debussy war Komponieren stets das Erforschen der musikalischen Sprache selbst. Debussy war ganz Musiker: In der puren Entsprechung syntaktischer Konstellationen sah er keine Musik. Für ihn war Sprache untrennbar vom Sprechen, vom Gesprochenwerden, vom Tonfall. ${ }^{90}$ Wichtig wird an dieser Stelle die Unterscheidung von Syntax und »Ton«. Hier, auf der Suche nach dem »Ton« und bei dessen Auffinden beginnt das Tun des Ausführenden:

"Der Interpret erfährt über die Art, wie die Klangsprache gesetzt ist, wie sie inn durch ihren Text zum Nachsprechen auffordert, also schon auf haptischer Ebene, Grundsätzliches über diese Sprache. Er sspricht، bereits im Ton der Musik, wenn er deren Griff an sich selbst verspürt, indem er diesen Griff , in seine Hand nimmt, die Hand dem Griff nachbildet, anbildet, um durch das Greifen dem Instrument die Sprache erst zu entlocken. [...] [B]ei Debussy ist spürbar, wie sehr diese qualitativen Spracheinheiten beim Komponieren schon mitgedacht, bei der Sprachfindung berücksichtigt sind, wie sehr das Sprechen selbst eine eigene Sprache ist. " ${ }^{91}$

Von der Betrachtung des »Tons« aus geht es weiter zum musikalischen Einzelereignis, zum einzelnen Ort, der das Tun des Komponisten und des Ausführenden auf eine ganz eigene Weise herausfordert:

"Der Versuch, diese Sprachfindung genauer zu verstehen, könnte uns auf unserer Suche nach dem musikalischen Einzelereignis und dessen Freiheitspotential auf neue Wege bringen. Für Debussy scheinen Abgeschlossenheit und Definition des Einzelereignisses gleich wichtig wie das Wachstum der Ereignisse. Das erlaubt uns, das Einzelereignis als Zelle zu verstehen. Durchaus in der doppelten Bedeutung: als abgeschlossene, entwicklungsfremde Einheit und als Wachstumskern, als Keim. Stellen wir uns eine andere doppelbedeutende Aktion vor: das Freisetzen! Etwas frei, unverbunden in den Raum setzen; oder etwas entfesseln, freisetzen. Versuchen wir die gedankliche Verbindung zum doppeldeutigen Zellbegriff. So ist das musikalische Einzelereignis von zwei Seiten her beleuchtet: erstens ein unverbundenes, nicht auf Entwicklung hin Gesetztes, das

89 | W. Rihm: Musikalische Freiheit, S. 26.

90 | Ebd., S. 35.

91 Ebd. 
frei in den Zusammenhang - also ohne diesen - gesetzt ist; zweitens eine gerichtete Einheit, die Wachstum provoziert, Entwicklung freisetzt. ${ }^{92}$

Diese Worte beschreiben nicht nur die Perspektive des Komponierenden, sondern auch das Vorgehen aus der musikalischen Praxis heraus: sich an einzelne Orte begeben.

Eben hier liegt der Ansatzpunkt für Mahrenholz' Auseinandersetzung mit dem Schaffen Wolfgang Rihms:

"Ein Skandalon wie zugleich ein Faszinosum von Wolfgang Rihm als Komponist wie als Autor liegt darin, dass er in seinem Werk für einen anderen Logos plädiert, für andere Verlaufsformen bzw. eine andere Struktur des Künstlerischen. Eine, die hier vorläufig und zugespitzt als Logos des Körpers, des Materialen oder Ausgedehnten bezeichnet wird - im Unterschied zum Logos der Sprache, des Geistes, der Kausalität und Folgerichtigkeit. ${ }^{93}$

Ein Affront gegen das »an Logik und Widerspruchsfreiheit ausgerichtete diskursive und mathematisch-lineare Denken - das als wissenschaftliches nach wie vor die offizielle Domäne von Erkenntnissen bildet.« In diesem Sinne vergleicht sie ein »Modell«, das Musik als Sprache begreift und von daher an logisch nachvollziehbaren Zusammenhängen interessiert ist, und ein »Modell«, das sich eher an »Natur-Metaphern « ausrichtet. ${ }^{94}$ Rihms Werk »sei gerade nicht an der Idee von Musik als Sprache orientiert«. Diese Abkehr von der Vorstellung von Musik als Sprache sucht Mahrenholz »positiv« zu bestimmen, indem sie, ausgehend von schriftlichen Äußerungen des Komponisten, die einzigartige Bindung eines Klanges an einen bestimmten Ort der Komposition (seine Unverwechselbarkeit, seine, so Rihm, »Unauswechselbarkeit «"5) und Rihms Rückgriff auf Metaphern des Vegetativen und Körperlichen geltend macht. Sie knüpft dabei an Dahlhaus' Konzept des Verstehens an, das hier unterlaufen werde. Dahlhaus habe das »Verstehen« von Musik (als einer Sprache) auf die »Einsicht in einen Zusammenhang zwischen Tönen « zurückgeführt: »Verhandelt wird dieses Thema unter der Unterüberschrift >Sinnzusammenhang ${ }{ }^{96}$ Quer zu eben diesem »Sinnzusammenhang « stehe aber eine Körperlichkeit des »Materials« mit eigenen Ansprüchen, wobei Verstehen nicht ab-,

92 | Ebd.

93 | S. Mahrenholz: Der Körper des Komponisten, S. 24; das folgende Zitat ebd.; Herv. i.0.

$94 \mid$ Ebd., S. 28; das folgende Zitat ebd., S. 26.

95 | Vgl. W. Rihm: Spur, Faden, S. 74f.; Herv. i.0.

96 | S. Mahrenholz: Der Körper des Komponisten, S. 29f.; das folgende Zitat ebd., S. 30 . 
sondern umgewertet werde. Aus einem Brief der Komponistin Isabel Mundry: Die Frage nach dem Verstehen in der Musik habe Mundry dahingehend beantwortet, sie schreibe nicht Musik, »um verstanden werden zu wollen, sondern um zu verstehen. ${ }^{97}$ So bringt Mahrenholz die metaphorische Übertragung ins Gespräch. Doch: Wie steht es um die Gefahr, in eine, wie sie sagt, »Privatsprachenfalle«, in ein »privatistische[s] Abseits « zu geraten? ${ }^{98}$ Ihre Antwort: durch Hinwendung zu Musik, »die für sich selber steht«; hierbei werde Musik nicht »Bild für eine Wirklichkeit«, sondern »selbst Wirklichkeit«. ${ }^{99}$ Mahrenholz: »Was ist dieses >Selbst<? Rihm bindet es an den Körper.« Rihm: »Das Verhältnis zur Bewegung ist für mich dadurch gegeben, daß ich die Musik als Körper sehe, dessen Bewegungen und Bewegtheiten sie selbst sind, also die Musik selbst ist. «100 Es geht Rihm offensichtlich um ein Selbst-Sein der Körperbewegungen, um ein Selbst-Sein der »Musik als Körper« auch.

Musik wird sie selbst - durch die Anbindung an den Körper. In diesem Zusammenhang erinnert Schütz daran, dass »in der natürlichen Einstellung des Alltags« die »körperliche Existenz von anderen Menschen« und eine Ausstattung der anderen Körper mit einem »Bewußtsein [...], das dem meinen prinzipiell ähnlich ist«, gegeben sind. ${ }^{101} »$ Musik selbst« (Rihm) - diese Formulierung wirft einmal mehr Fragen auf wie diese: Hinausweisung auf Wirklichkeiten und Möglichkeiten und/oder Selbst-Sein? Musik: Als-ob-Geschehen oder Wirklichkeit sui generis? Grenzen/Schwellen zwischen Musikwelt und Lebenswelt? - und Übergänge?

\subsection{Grenzen, Schwellen - Und Übergänge}

\section{Lebenswelt und Musikwelt: Trennung - Verbindung}

Schütz' Ausführungen lassen deutlich werden, dass er die verschiedenen »Sinnbereiche« als »Welten ${ }^{102}$ betrachtet, die jeweils durch einen eigenen »Erlebnis- bzw. Erkenntnisstil ${ }^{103}$ geprägt sind. Zu diesen Sinnbereichen zählt er auch das »Gemeinsame Musizieren«. Er betrachtet die Sinnbereiche als »geschlossen«, weil aus seiner Sicht »Transformationsregeln « ${ }^{104}$ für eine wechsel-

97 | I. Mundry, zitiert ebd., S. 30; Herv. i.0.

98 | Ebd., S. 32.

99 | Ebd., S. 33; das folgende Zitat ebd.

100 | W. Rihm: ... zu wissen, S. 147.

101 | A. Schütz/Th. Luckmann: Strukturen der Lebenswelt I, S. 27.

102 A. Schütz: Über die mannigfaltigen Wirklichkeiten, S. 269f., 276f., 281.

103 | A. Schütz/Th. Luckmann: Strukturen der Lebenswelt I, S. 49.

104 | A. Schütz: Über die mannigfaltigen Wirklichkeiten, S. 267; das folgende Zitat ebd. 
seitige Bezugnahme fehlen; so wird für ihn ein Wechsel von einem Bereich zu einem anderen nur im »Sprung « möglich.

Von Schütz' Darstellung unterschiedlicher »Sinnbereiche« ausgehend und diese weiterführend ließe sich mit Blick auf eine musikalische Situation wohl auch bildhaft von einer Art Schleier zwischen musikalischer Welt und Lebensbzw. Alltagswelt sprechen, auch von einer (durchsichtigen) Membran, die zugleich trennt und verbindet.

Performative Akte verleihen Grenzen zwischen Alltagswelt und performativem Geschehen Transparenz. Erika Fischer-Lichte spricht von daher eher von »Schwellen« als von »Grenzen« zwischen den Welten. ${ }^{105}$

»An der Garderobe bringt das Publikum die Ohren in Ordnung und gibt das Gehör ab. « ${ }^{106}$ An der Garderobe scheiden sich die Welten? Auf der einen Seite eröffnet die Musikwelt im Konzerthaus oder in der Oper beispielsweise die Möglichkeit, Alltagswelt eine Zeitlang zu verlassen; auf der anderen Seite gibt die Alltagswelt das Publikum für eine gewisse Zeit frei. Das Publikum begibt sich aus der einen in die andere Welt, richtet sich dort zeitweise ein und begibt sich wieder zurück. ${ }^{107}$ Diese Vorstellung entspricht wiederum eher einer Geschlossenheit der Bereiche.

Wie die Musikwelt eine Art Refugium oder Zeitinsel werden kann, zeigen Frobergers Lamentations und Méditations. Der Spieler begibt sich hinein in diese verschlungene Welt der Klänge, die Schritt für Schritt ertastet werden, und kann sich vergessen, verlieren im Spiel. Jeder Ton könnte der letzte sein: So geht es (eine Zeitlang) immer weiter. Am Ende begibt man sich wieder zurück in den Lebensalltag, der vom Ticken der Uhr bestimmt wird, der man sich nun wieder unterwirft. Die Zeitinsel wird aufgesucht, man begibt sich hinein, wohl wissend, dass das Verweilen dort begrenzt ist. Der Übergang von der einen in die andere Welt wird vollzogen: Ein Spieler betritt (bewusst) die Musikwelt - und verlässt diese wieder.

Transparenz zwischen Musik- und Alltagswelt zeigt sich in vielfältiger Weise mit Blick auf Kompositionen des 20. und 21. Jahrhunderts: Karlheinz Stockhausen wünscht sich die wiederholte Ausführung von Spiral für einen Solisten als »künstlerische Lebensform « ${ }^{108}$; Istvàn Zelenka entwirft Praktiken, die vollkommen in den Lebensalltag integriert werden können und sollten (beispielsweise mit der Komposition Und an 5 frei gewählten Tagen...); HansJoachim Hespos formuliert als Ideal für eine Ausführung seiner Kompositionen »Fast-Identifikationen « der Ausführenden und »Distanzverringerung «. ${ }^{109}$

105 | E. Fischer-Lichte: Ästhetik des Performativen, S. 356ff.

106 | I. Bachmann: Die wunderliche Musik, S. 46.

107 | Vgl. E.-M. Houben: Wie wunderlich ist die neue Musik?, S. 299.

108 | K. Stockhausen: SPIRAL, S. 136.

109 | H.-J. Hespos: ..redezeichen.., S. 130. 
Musik- und Alltagswelt können, so zeigt es sich, mehr oder weniger eng aufeinander bezogen werden.

Einige Kompositionen sind für eine selbstverständliche Integration in den Lebensalltag bestimmt. Dazu gehören auch The Tiger's Mind oder The Great Learning von Cornelius Cardew oder Kompositionen von Istvàn Zelenka. Letztere sind zum Teil ausdrücklich auch für musikalische Laien konzipiert, verstehen sich als Einladungen zu bestimmten »Beschäftigungen «110, die den Lebensalltag unterbrechen. Die Unterbrechung des Alltagsgeschäfts durch die »Beschäftigung« mit der Komposition und, umgekehrt, das Verlassen dieses Raumes, verbunden mit erneuter Zuwendung zum Lebensalltag, markieren wiederum Schwellen.

Erst durch die Übergänge, d.h. durch die Überschreitungen der Schwellen hin und wieder zurück, wird die musikalische Situation in den Lebensalltag integriert. Die trennende Schwelle scheint notwendig zu sein, damit die Überschreitung möglich wird.

\section{Aufkündigung eines Als-ob-Geschehens}

Dort, wo uns die Schwellen zwischen Sinnbereichen berühren, wo wir uns als Musiker Übergängen von einer Welt in die andere aussetzen, begegnen wir einander in der musikalischen Situation. Wir simulieren diese Begegnung nicht. Sie ereignet sich tatsächlich im Sinnbereich »gemeinsamen Musizierens« (Schütz), wobei gar nicht einmal ununterbrochen deutlich sein muss, in welchem Sinnbereich wir uns gerade aufhalten, ob in der Welt der Musik oder in der Welt des Alltags. Durch den zeitweiligen (bewussten) Übergang in den Sinnbereich der Musik, in dem wir alle in unserer Verschiedenheit und bei aller Geschiedenheit voneinander zusammentreffen dürfen, finden wir uns (zwar) in einer anderen Welt, aber nicht in einem Als-ob-Geschehen wieder. Wir betreten als Ausführende einen anderen Bereich als den der alltäglichen Lebenswelt mit eigenem wirklichem Geschehen selbst. Diese Gedanken bestätigt Schütz in seiner »Studie« (»Gemeinsam musizieren«). Eine Schlüsselstellung in Schütz' Ausführungen nimmt die Idee des »Sich-aufeinander-Einstimmens « ein, wodurch eine lebendige »Beziehung« während dieser Zeit des gemeinsamen Musizierens entsteht. ${ }^{111}$ Dieses »Sich-Einstimmen « geschieht an einem bestimmten Ort. Alle am Geschehen Beteiligten durchleben gemeinsam eine bestimmte Zeit, sie werden gemeinsam älter. ${ }^{112}$ Dies ist und geschieht wirklich so - in der Welt des Musizierens. In dieser Welt mit eigener

110 | E.-M. Houben/I. Zelenka: und/oder, S. 20, 21, 22, 27, 314.

111 | A. Schütz: Gemeinsam musizieren, S. 132.

112 | Ebd., S. 146. 
Wirklichkeit, eigenen Dingen, Orten und Lebenszeiten, zeigt sich dann kein Als-ob-Geschehen, sondern tatsächliches »SO IST«, »SO GESCHIEHT« ${ }^{113}$.

Beim Spielen der Méditation »sur ma mort future« von Johann Jacob Froberger tue ich nicht so, als ob ich meditieren würde, sondern ich falle in echte Meditation; beim Spielen des Klavierstücks pour être seul(e) sans réserve von Antoine Beuger tue ich nicht so, als ob ich mich verlieren würde, sondern ich gehe tatsächlich verloren: erfahre, dass und wie ich mich vertrauensvoll verloren geben darf. Dabei kann beim Aufenthalt im Sinnbereich des Musizierens durchaus die andere Welt des Alltags einbrechen, sodass ich mir beim Spielen selbst nicht immer sicher sein kann, in welcher Welt ich mich gerade befinde.

Der Umgang mit einer Vielfalt von »Sinnbereichen« kann in musikalischer Praxis verhandelt werden, weil sie zwar sinnhaft, aber nicht zweckgebunden ist. In musikalischer Praxis ist man frei, die »Schwelle« (Fischer-Lichte) bzw. die Membran zwischen Musikwelt und Alltagswelt zu thematisieren. Das ist die grundsätzliche Orientierungsfrage im Alltagsleben und in musikalischer Praxis: Welches Spiel wird hier eigentlich gespielt? In welchem Sinnbereich halte ich mich jetzt auf? In musikalischer Praxis lässt sich diese Frage zugespitzt formulieren, denn hier geht es um die Entstehung von Sinn und nicht um das Erreichen eines bestimmten Zwecks.

\section{Don Quixote}

Was geschieht beim Springen zwischen den Sinnbereichen des Musizierens und der Welt des Alltags (Schütz)? Gerade der »Schock« beim Wechsel von der einen in die andere Welt und zurück (und wieder neu in die andere Welt usf.) birgt konfliktreiches Spannungspotential. Hier, beim Wechsel, tut sich die Möglichkeit auf, nicht genau zu wissen, wo man jetzt eigentlich ist. Beim Übergang über Schwellen können diese Schwellen auch unscharf werden. Was jetzt? Wo bin ich? Wie geht es jetzt weiter? Solche Fragen wachsen aus Konflikten von Sinnbereichen: Was ist Traum? Was ist Alltagswelt? Was ist Fantasiewelt? Wo ist die Welt des Musizierens? Bin ich schon da angelangt? - oder noch nicht (ganz)?

In seinem Aufsatz »Don Quixote und das Problem der Realität« knüpft Schütz an William James' »Principles of Psychology« an: Jeder Realitätsbereich, James spricht von »Subuniversa«, hat seinen »eigenen speziellen und besonderen Existenzstil ${ }^{114}$ Neben der »Welt der Sinne oder der physischen Dinge« zählen ebenso die Wissenschaftswelt, die Welten der Träume und Fantasien, die Welten religiöser Überzeugungen und viele mehr zu den »Sub-

113 | H.-J. Hespos: AUGEN DER WÖRTER, Partitur.

114 | A. Schütz: Don Quixote, S. 102. 
universa« (James), die Schütz »mannigfaltige Wirklichkeiten«, »geschlossene Sinnbereiche« nennt. Und Schütz' Aufsatz »Don Quixote«?

"Die These, die wir aufstellen wollen, ist, daß sich Cervantes' Roman systematisch mit dem Problem der mannigfachen Wirklichkeiten befaßt, das von William James gestellt wurde, und daß die verschiedenen Phasen in Don Quixotes Abenteuern sorgfältig ausgearbeitete Variationen des Hauptthemas sind, nämlich wie wir Realität erfahren. «115

Des Protagonisten Kampf gegen die Windmühlen: für seinen beobachtenden Begleiter kein Streit gegen eine mächtige militärische Bedrohung, sondern ein ohnmächtiges Einschlagen auf lebloses Material; des Protagonisten Bewunderung für die Schönste aller Damen, deren Bildung alles bislang Erlebte übersteigt: für seinen verständnislosen Begleiter Bewunderung für eine alltäglich zu sehende Marktfrau, die ihrer gewohnten Tätigkeit nachgeht.

Was hat Don Quixotes Lebensform (denn eine solche ist seine fahrende Ritterschaft zweifellos) mit der Lebensform eines Musikers zu tun? Ich möchte in diesem Zusammenhang noch einmal auf die Magie, auf die Zauberkraft der Musik eingehen. Don Quixotes Subuniversum der fahrenden Ritterschaft, dem er, um mit Schütz zu sprechen, den »Realitätsakzent« verliehen hat, wird von Zauberern regiert, denen es sogar gelingt, Sinnbereiche miteinander zu versöhnen und Widersprüche oder Paradoxa aufzulösen. Sie übernehmen in Don Quixotes Welt die »Rolle der Kausalität und Motivation«.116 Ihnen, den Zauberern, wird die Aufgabe zugewiesen, »die Koexistenz und Kompatibilität von bestimmten Sinnbereichen zu gewährleisten [...] und sicherzustellen, daß der Wirklichkeitsakzent, der einem jener Subuniversa erteilt wurde, erhalten bleibt. ${ }^{117}$ Versöhnung der Sinnbereiche durch Zauberhand!

Der Konflikt zwischen Don Quixotes Fantasiewelt und der Lebenswelt seiner Umgebung spitzt sich zu, als die Wohlmeinenden unter seinen Mitmenschen ihm dadurch entgegenzukommen suchen, dass sie zeitweilig in eine Als-ob-Welt einziehen - im Spiel, im Witz -, der sie aber niemals den »Wirklichkeitsakzent« zu verleihen bereit sind. Damit, so Schütz, gelingt es ihnen aber nicht, in eine »echte soziale Beziehung« zu Don Quixote zu treten, was zu dessen »persönlicher Tragödie« beiträgt; ein weiterer die Situation verschärfender Punkt ist der, dass Don Quixote mit der Zeit selbst »immer weniger« an seine Welt »glaubt« und in Unsicherheit verfällt. ${ }^{118}$

Don Quixote: Inbegriff des Musikers, der Musikerin - aller Spieler! Wie wirklich ist das Spiel, das hier gespielt wird? Nur Musik? Nur ein Spiel? (Ge-

115 | Ebd., S. 103.

116 | Ebd., S. 107.

117 | Ebd.

118 | Ebd., S. $114 f$. 
meinsam) Musizieren! Wie ernst ist es uns mit dieser Praxis? Ist es eine Praxis, an die wir glauben (glauben möchten, glauben können)? So, wie es jetzt aussieht, ist die Beantwortung dieser Frage auch von einer Entscheidung des einzelnen Musikers abhängig. Die Frage lautet also auch: Will ich mich als Spieler so weit ins Spiel hineinbegeben, dass ich die Ausstrahlung der einen Welt (der Musizier- und Spielwelt) auf die andere gestatte, ja mehr noch: heraufbeschwöre?

Schütz zitiert einen Satz Don Quixotes, einen Satz, den er als »Kern« des Problems identifiziert: »[I]ch bilde mir ein, daß alles, was ich sage, wahr ist, weder mehr noch weniger. «119 Hier anknüpfend: Die Don Quixotes als Ausführende von Musik, die für eine bestimmte Praxis eintreten und von daher dieser Welt den »Wirklichkeitsakzent« verliehen haben, begeben sich mit ihren Handlungen und ihrem Mit-Dabei-Sein (ihrem In-Erscheinung-Treten) in eine »Wahrheitsprozedur « ${ }^{120}$ - ein hoher und bescheidener Anspruch zugleich. Für was treten wir ein? Wozu tun wir das?

Vom Ereignis berührt, begibt man sich, so Alain Badiou, in eine »Wahrheitsprozedur«: Nach dem »Ereignis« gibt es die Möglichkeit, dieses Ereignis anzuerkennen, dafür einzutreten; erst dann wird das Ereignis für diejenigen, die dafür eintreten, zum Ereignis; für sie hat sich die Welt geändert. Es sind nicht die Philosophen (und Musikwissenschaftler), die ein Ereignis an den Anfang einer »Wahrheitsprozedur« stellen, sondern die Künstler, die für das Ereignis eintreten und sich damit in die »Wahrheitsprozedur begeben - mit ihrem Schaffen, ihrem Tun. ${ }^{121}$

Für was engagieren wir uns mit der Praxis? Was affirmieren wir? Versuchen wir, die Welt des (gemeinsamen) Musizierens mit der Welt der alltäglichen Lebenswirklichkeit zu verbinden, wobei wir eine jede von ihnen als in sich »geschlossenen Sinnbereich« annehmen: Welche Chancen und Möglichkeiten ergeben sich aus den »Sprüngen«, aus den Schockerfahrungen, aus den »Transzendenzen« (Schütz) bei der Überschreitung der Schwellen zwischen den Welten? Keine der beiden Welten wird unbehelligt davonkommen: Die Spuren der Erfahrungen und Erinnerungen, der Hoffnungen und Sehnsüchte folgen den Spielern, die den Sprung gewagt haben bzw. denen der Fall in die ganz andere Welt passiert ist. Die Ausrichtung auf Zukünftiges, verbunden mit einem Sich-Einrichten in einem wie auch immer gearteten Provisorium hier wie dort (im Lebensalltag wie in der Musizierwelt), macht frei und lässt sich nicht nach einem Passieren der Schwelle hin und wieder zurück abschüt-

119 | Ebd., S. 115.

120 | A. Badiou, zitiert in: J. de Bloois/E. van den Hemel: Kunst creëert altijd, S. 50.

121 | Ebd.; vgl. A. Badiou: Das Sein und das Ereignis; A. Badiou: Paulus. Die Begründung des Universalismus. 
teln. Musikalische Praxis als Lebensform verheißt Wandel - gerade weil die Sinnbereiche in Bewegung geraten.

\section{Desorientiertheit im Sprung hinaus}

Was jetzt? Wo bin ich? Wie geht es jetzt weiter?

Ich frage, wenn ich nicht weiterweiß: wenn ich desorientiert bin. Was ist eigentlich Desorientiertheit in musikalischer Praxis? Wie gehen wir hier mit Desorientiertheit um? Desorientiertheit scheint einem Konflikt zwischen Sinnbereichen zu entspringen. Desorientiertheit prägt die Musizierwelt wie die Alltagswelt, in der Desorientiertheit treffen sich beide Welten. In beiden Welten kann man sich nicht sicher sein.

Der philosophischen Frage nach »Orientierung «122 geht die Erfahrung von Desorientiertheit voraus. Für die musikalische Situation ist es gerade die Desorientiertheit, die das spezifisch Musikalische dieser Situation ausmacht. Nicht die Erfahrung, zu wissen, wo man ist, sondern die Erfahrung, nicht oder nicht genau oder nicht mit Sicherheit zu wissen, wo man ist, charakterisiert musikalische Praxis wie alltägliche Lebenswelt. Eben der Umstand, dass wir als Musiker nicht immer wissen, in welchem Sinnbereich wir gerade sind, ermöglicht Hinausweisung als Geschehen. Von Orientierung zu sprechen, bietet sich hinsichtlich der Welt des (gemeinsamen) Musizierens erst von der musikalischen Situation der Desorientiertheit aus an. ${ }^{123}$ Die musikalische Situation lebt von der Desorientiertheit. Und die Desorientiertheit ist nur zu gewinnen, wenn ich als Musiker, als Musikerin zeitweise nicht weiß, in welchem Bereich ich jetzt bin. Dann kommt die Frage nach (musikalischer) Orientierung auf. Sobald wir die Situation der Desorientiertheit auflösen, finden wir Orientierung. Orientierung (immer wieder neu) zu finden: Dieser Prozess ist grundsätzlich verschieden von einem Prozess des Sich-Orientierens.

Nach Andreas Luckner beinhaltet Orientierung immer auch Desorientierung - und umgekehrt: »Um [von Orientiertheit] eine positive Bestimmung geben zu können, empfiehlt es sich, zunächst einmal danach zu fragen, was uns eigentlich fehlt, wenn wir desorientiert sind. ${ }^{124}$ Luckner unterscheidet zwischen »Desorientiertheit« und »Orientierungslosigkeit«:

"'Desorientiert ist dabei nicht einfach dasselbe wie sorientierungslos`. Denn während man entweder orientierungslos ist oder nicht, gibt es in der Desorientierung offensicht-

122 | Vgl. W. Stegmaier (Hg.): Orientierung.

123 | Anders Stefan Berg, der beim Entwurf einer "Hermeneutik musikalischer Orientierung", Spielwerk, entschieden von der "Orientierung" ausgeht; vgl. S. Berg: Was heißt: sich in Musik orientieren?; S. Berg: Orientierung in Klangräumen.

124 | A. Luckner: Drei Arten, nicht weiterzuwissen, S. 227; Herv. i.0. 
lich Grade. Terminologisch können wir hier so verfahren, daß ,Orientierungslosigkeit das Extrem größter Desorientiertheit ist. "125

Vielleicht lässt sich das Verhältnis von Orientierung und Desorientiertheit hinsichtlich der musikalischen Praxis noch stärker von der Desorientiertheit ausgehend beschreiben: Man kann nur Orientierung finden, wenn man von der Erfahrung der Desorientiertheit ausgeht. Desorientiertheit im Anschluss an Schütz und in der Weiterführung seiner Darstellung: In der musikalischen Situation wie auch in der Lebenswelt fehlt die Gewissheit, welchem Sinnbereich jetzt der »Wirklichkeitsakzent« (Alfred Schütz) zukommt. Wie Desorientiertheit sich auflöst, wenn man (als Spieler) wieder Orientierung findet? Diese Frage ließe sich mit Schütz dahingehend beantworten, dass für eine gewisse Zeit Orientierung neu durch eine klare Zuweisung des »Wirklichkeitsakzents « oder »Realitätsakzents« zu einem ganz bestimmten Sinnbereich gefunden wird.

\section{Überschreiten: im Sich-Hineinbegeben und im Sich-Wiederfinden}

Die »Grenze« resp. die »Schwelle« zwischen musikalischer Situation und Lebensalltag, zwischen Musikwelt und Alltagswelt kann überschritten werden. In dieser Beschreibung schwingt ein bewusster Vollzug mit: Ich begebe mich in eine musikalische Situation hinein. Ebenso entschieden verlasse ich sie wieder. Eine solche Akzentuierung von Aktivität oder Aktion sagt noch nichts aus über die Klarheit der Schwelle. Diese kann eine Zeitlang unscharf bleiben, aber schließlich besteht kein Zweifel mehr daran: Das Spiel hat begonnen.

Beim Wechsel (beim Sprung) von einem Sinnbereich in einen anderen, von der jeweiligen musikalischen Praxis in die Alltagswelt und zurück (und wieder hin und wieder her usf.) kann es aber auch geschehen, dass ich mich (eher unverhofft) in einer jeweils neuen Situation wiederfinde. Übergang wird nicht nur vollzogen, Übergang passiert mir auch, widerfährt mir. Beides ist möglich beim Wechsel: das bewusste Sich-Hineinbegeben in einen anderen Sinnbereich wie der schockhafte Wechsel, der einem widerfährt.

Immer wieder Übergänge: Ich begebe mich als Musiker in den anderen Bereich des (gemeinsamen) Musizierens. Und dieses Sich-Hineinbegeben ist ein notwendiger Schritt, der die Transparenz der Membran bewahrt. Ohne Scheidung ist der andere Bereich nicht zu haben. Auch wenn mir der Übergang passiert: Die Trennung der Bereiche bleibt bestehen. Beide Arten des Wechsels, der aktive wie der passive, ermöglichen das lebendige Konfliktpotential.

Die bereits angesprochene Nähe der musikalischen Praxis zum Ritual lässt an dieser Stelle an »Zwischenräume« denken, welche die unterschiedlichen 
Welten voneinander trennen und sie zugleich verbinden; notwendig wird Übergang als Geschehen. Klaus-Peter Köpping und Ursula Rao widmen sich eben dieser Erfahrung von »Zwischenraum« in der Praxis des Rituals:

"[Wir stellen fest], dass die Grenze, die durch das Ritual errichtet wird, nicht als Zeitpunkt zu verstehen ist und auch räumlich nicht klar abgegrenzt werden kann. Vielmehr handelt es sich bei dem Übergang zwischen den Sphären - von der Alltagswelt zur rituellen und zurück - um einen ausgedehnten Prozess, der die Regeln des gesellschaftlichen Ideals neu aushandelt. “126

Eben dies ließe sich auch für die Wanderungen zwischen Alltagswelt und musikalischer Situation (und wieder zurück) sagen: Zeitpunkte für den Wechsel sind kaum auszumachen; die (metaphorische) Rede von »Zwischenräumen« zwischen den Welten hebt die räumliche Unschärfe bei den Übergängen hervor.

Die Frage nach der Art der mehr oder weniger durchsichtigen Membran zwischen Lebenswelt und Musikwelt ist auch eine Frage nach Anfang und Ende eines Musikstücks. Stockhausen unterscheidet zwischen Anfang und Beginn sowie zwischen Ende und Schluss:

"Wenn ich sage Anfang, so denke ich an einen Vorgang, etwas hebt an, spielt sich ein; wenn ich sage Ende, so denke ich an etwas, das zu Ende geht, ausklingt, verlöscht. Hingegen verbinde ich mit den Worten Beginn und Schluß die Vorstellung von Zäsuren, die eine Dauer als Ausschnitt aus einem Kontinuum heraus begrenzen. “127

Nicht immer sind Beginn und Schluss, Anfang und Ende klar zu bestimmen. Zwar legt die Rede von »Beginn« und »Schluss « die Vorstellung eines scharfen Schnitts nahe, doch ein (gedachter) Punkt im Kontinuum der Zeit erweist sich beim tatsächlichen Wechsel als Über-Gang. ${ }^{128}$ Hinsichtlich der Komposition 4'33" von John Cage sprach Herbert Henck vom (zeitlichen) »Rahmen « ${ }^{129}$, den das Stück benötige: Der »Rahmen« trennt die Welt der Komposition von der alltäglichen Lebenswelt und ermöglicht so deren Verbindung; Übergang wird vollzogen oder geschieht (vielleicht wie im Traum). Die präzise Zeitangabe 4'33", die den »Rahmen « abbildet, ermöglicht einen Wechsel von der alltäglichen Lebenswelt in die Musikwelt und wieder zurück, einen Wechsel, der als Übergang immer unscharf bleibt. Es sind oftmals gerade die Prozesse des

126 | K.-P. Köpping/U. Rao: Zwischenräume, S. 248.

127 | K. Stockhausen: Momentform, S. 207.

128 | "Indem ich ,jetzt، sage, ist jetzt schon nicht mehr jetzt." B. A. Zimmermann: Die Notwendigkeit, eine Invektive zu verfassen, S. 130.

129 | Begriff hier nach H. Henck: Vom Klang der Stille, S. 83. 
Verschwindens, die den unscharfen Wechsel von der einen in die andere Welt als Übergang erfahren lassen:

"Musik ist verschwunden: in der fast zu langen Generalpause mitten im Stück, in der Zeit zwischen zwei Sätzen eines Werks von mehreren Sätzen, in der Zeit vor und nach einem Konzert. Musik ist nicht mehr und noch nicht wieder da. Die Situation, in der ich erlebe, dass Musik verschwunden ist, kann nicht ohne Musik wahrgenommen werden. “130

Eine klare Bestimmung dessen, was Musik, was, im Unterschied dazu, NichtMusik (innerhalb von Alltagswelt) sei, mag kulturellem Wandel unterworfen sein, muss hier aber kaum getroffen werden. In musikalischer Praxis geht es um ein Sich-Hinein-Begeben in eine musikalische Situation wie auch um ein Sich-Wiederfinden in einer bestimmten Situation. Diese Bewegung ist unscharfer Übergang in den je anderen (Sinn-)Bereich. Viele Hervorhebungen des »Rahmens « in Cages stillem Stück waren wohl übertrieben deutlich, allzu sehr pochend auf Einschnitt, Zäsur: »Schließlich geht es nicht darum, einen genauen Punkt zu markieren (>jetzt fängt es an<), sondern irgendwie aufscheinen zu lassen, dass >es angefangen hat<. Ein einfaches innerliches Stillwerden ist eigentlich schon genug. «131

Musik - wozu? Damit es still werden kann? Vielleicht reicht diese Antwort wirklich schon.

130 | E.-M. Houben: Hector Berlioz, S. 123.

131 | Antoine Beuger, zitiert nach einem der Autorin zur Verfügung gestellten Manuskript einer Email-Korrespondenz zwischen Antoine Beuger und Nikolaus Gerszewski vom 19.02.2017. 



\section{Zweiter Teil}





\section{Tasten}

»Ich mag die Worte >Taste und stasten< sehr. Genau ist da eingefangen, was Komponieren auch sein kann: versuchen. Zumindest in einem Stadium, wo es aufs Finden ankommt. Das Klavier scheint ebendies zu verkörpern. $\ll^{1} \mathrm{Am}$ hier von Rihm angesprochenen Doppelsinn Tasten - tasten knüpft Martin Zenck an und spricht von zwei »Körpern«, die einander begegnen, die sich »berühren «. ${ }^{2}$ Aus dieser Perspektive erscheint das Tasteninstrument wie ein Geliebter, eine Geliebte fast, die Zärtlichkeit des Berührens und Berührt-Werdens schwingt bei solcher Rede mit. Der Titel »L'art de toucher le claveçin« des Unterrichtswerks von François Couperin führe die Bedeutung »der erotischen Berührung « mit sich. ${ }^{3}$

Begegnung von zwei Körpern: Nicht nur das Tasteninstrument, bei dem eine oder mehrere Tasten auf einer Klaviatur niedergedrückt werden, ermöglicht diese »Berührung«, alle anderen Arten von Instrumenten natürlich auch. Der körperliche Kontakt des Spielers zum Instrument ist beim Spielen des Horns oder der Trompete vielleicht sogar direkter, unmittelbarer, wird ohne Umweg über Tastaturen möglich. Beispielhaft soll hier dennoch das Tasten betrachtet werden, gerade wegen der komplizierteren Übertragung der Energie vom Körper des Spielers auf den Körper des Instruments. Dabei werden Kompositionen für Klavier, Cembalo und Orgel berücksichtigt. Beim Klavier werden über die Tasten Saiten angeschlagen, beim Cembalo gezupft. Als Orgelspieler wird man nicht vergessen, dass die Orgel auch und vor allem ein Blasinstrument ist: Variabler Tastendruck und variable Schleifenstellung - ganz feine, nuancierte Bewegun-

1 | W. Rihm: Tasten, S. 422.

2 | M. Zenck: tasten - tasten, S. 47.

3 | Ebd.; vgl. M. Zenck: Vom Berühren der Klaviertasten und vom Berührtwerden von Musik. Zenck widmet sich hier vor allem drei Aspekten des Tastens: der "taktile[n] Übertragung der Bewegungsempfindung" (ebd., S. 120ff.), dem "Finger als Fortsetzung des Mundes" (ebd., S. 123ff.) und dem Finger, der Hand als "Expressionsorgan" (ebd., S. 126). Doch nicht das Tun des Ausführenden wird eigens beleuchtet, Zenck bleibt beim Klang, der die je spezifische Art der (körperhaften) Hervorbringung transportiert und übermittelt. Vgl. M. Zenck/T. Fichte/K.-U. Kirchert: Gestisches Tempo, S. 348ff. 
gen und Einstellungen also - können bei mechanischen Instrumenten eine Vielfalt von unterschiedlich gefärbten Luftströmen freisetzen. Über die Taste und die Registereinstellung wird der Weg frei für einströmende Luft.

Es geht im Folgenden um Suche, auch um »Finden « (Rihm); um zärtliches »Berühren« (Zenck), aber auch um Schlagen. Das Klavier kann sogar zur Trommel werden. Ganz empfänglich wird die Taste, wenn feinste Bebungen und Vibrationen des Körpers vom Instrumentenkörper aufgefangen, verstärkt und hörbar gemacht werden.

Tasten und Ertasten können auch zum Begreifen führen: Wiederum bietet sich ein doppelsinniger Begriff an, den Lachenmann nutzt. Die Körperlichkeit des »Greifens und Begreifens« zeigt er am Beispiel seines Zyklus' Ein Kinderspiel für Klavier (1980). Es ist eine Art körperlichen Begreifens nahe an den Tasten gemeint, ein »Abtastvorgang«, ein »Abtasten« diesmal nicht nur mit den Ohren, sondern auch mit den Händen, Fingern, Füßen (auch der Einsatz der Klavierpedale ist genau bezeichnet):

"Ich habe Hören immer wieder gern bezeichnet als Abtastvorgang, welcher Rückschlüsse auf die im Werk wirkenden Bauprinzipien und darüber hinaus auf die zugrunde liegende expressive und ästhetische Haltung ermöglicht [...]. Jener Gedanke des Abtastens von Bauprinzipien wurde in diesen Stücken einmal ganz wörtlich genommen." ${ }^{4}$

Lachenmann fasst Be-Greifen im wörtlichen Sinne auf, bezeichnet die Klavierstücke so als »leicht zu greifende und zu begreifende Modelle«.$^{5}$ Nicht nur der Hörer ist involviert, der die Struktur einer Komposition während des Hörens mit den Ohren »abtastet«, sondern auch und diesmal vor allem der Spieler, der mit Händen und Füßen tastet und ertastet, greift und begreift.

4 | H. Lachenmann: Vom Greifen und Begreifen, S. 164.

5 | Ebd., S. 163; vgl. E.-M. Houben: alte Musik mit neuen Ohren, S. 162-178; hier auch Hinweise zu Franz Liszts Klavierstücken R. W. - Venezia, La lugubre gondola No. 1, II penseroso, aus: Années de pèlerinage. Deuxième année - Italie. 


\subsection{LudWig van Beethoven: KLaViersonate NR. 32 C-MOLL OP. 111, 1. Satz (MaEstoso. Allegro con brio ed appassionato) $(1821 / 22)$}

\section{Einzelereignisse - Desorientierung. Neuorientierung?}

I

»Arietta. Adagio molto semplice e cantabile«: So ist der zweite Satz dieser zweisätzigen Sonate überschrieben. ${ }^{6}$ Beethoven stellt den zweiten Satz Arietta unter das Vorzeichen der Bescheidenheit: »molto semplice«. Eine Übung in Bescheidenheit: diesen Satz bescheiden anzufangen und bescheiden zu bleiben.

Ganz anders der erste Satz: »Maestoso« - so ist die Einleitung überschrieben; es folgt »Allegro con brio ed appassionato «. Aber ist das ein Maestoso, das einen würdevollen, majestätischen Auftritt präsentiert, vielleicht in der Art eines pompösen Marsches? Im Gegenteil finde ich mich beim Spielen immer wieder im Stillstand wieder. Unentwegt neue Ortlosigkeiten: Und jetzt? Was nun?

Narration wird durch Zäsuren gestört: Viele Interpreten überspielen die zahlreichen Zäsuren, wohl um vermeintlichen Zusammenhang zu wahren. Aber wer sich tatsächlich in diese Unterbrechungen fallen lässt, findet einen neuen Ton.

Ich begebe mich an einzelne Orte der Partitur. Gleich zu Beginn gibt es einen offenen Satz (Takte 1-2), der in Einzelteile zerfällt (vgl. Abb. o8). Der Spieler spielt hier Klänge, die - wie Wolfgang Rihm es in anderem Zusammenhang formuliert hat - »)wie für sich< entstanden « sind: »Ihr Ort gehört zu ihnen«. Sie sind »unverwechselbar, unauswechselbar«.?

Abbildung o8: Ludwig van Beethoven: Klaviersonate Nr. 32 c-moll op. 111, 1. Satz, Takte 1-2

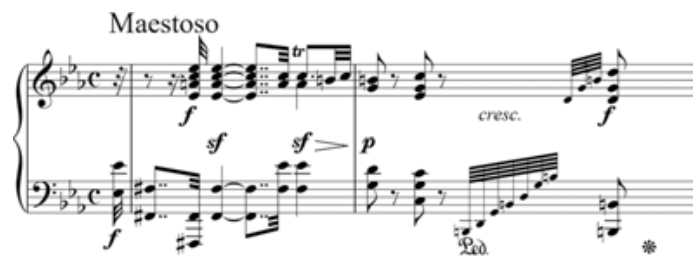

Ich gebe nicht eine »hingenommene Folge von Denkvorgängen ${ }^{8}$ wieder, sondern begebe mich beim Spielen in einen Prozess der Desorientierung hinein.

6 | Zur Besonderheit der Zweisätzigkeit dieser und anderer Sonaten Beethovens vgl. L. Kramer: Music as Cultural Practice, S. 21ff.

7 | W. Rihm: Spur, Faden, S. 74; Herv. i.0.

8 | Ebd. 
Für mich als Spieler besteht die Übung darin, mich in der Ortlosigkeit zurechtzufinden.

Der Stillstand zu Beginn des zweiten Taktes ist nicht der erste, es ist der erste größere: Der gegriffene Halbschluss (Takt 2, auf der ersten Zählzeit) ist vorläufig. Wie beiläufig taucht die Tonika auf unbetonter Zählzeit auf, um gleich darauf wieder durch ein Arpeggio in Frage gestellt zu werden: erneutes Stehen-Bleiben. Aber auch vorher schon, bis ich als Spieler überhaupt so weit gekommen bin, zerfällt mir die Struktur unter den Händen: Es erscheinen Akzente mit Zweiunddreißigstel-Vorschlägen, Klangverbindungen von jeweils zwei Klängen, die für sich stehen.

Ich wiederhole diesen Vorgang, variiert, mit anderen Klängen (Takte 3-4). Und dies könnte schon eine ganze Komposition sein. Eine Reihe von Vorschlagsakzenten mit abschließendem Arpeggio - nur diese Folge von Suchvorgängen: Musik, die einen Weg sucht. Eine erneute Wiederholung kündigt sich an; so könnte es immer weitergehen. Beim dritten Mal schließt sich ein weiterer Suchprozess an, ein Vorantasten auf engem Raum. Doppelpunktierung und Vorschlagscharakter der Zweiunddreißigstel sind erhalten geblieben, aber jetzt verändern sich allmählich die harmonischen Farben beim Spiel dieser Kette. In dieser Bewegung könnte man die ganze Klaviatur abtasten und immer neue Farben entdecken (vgl. Abb. o9).

Abbildung o9: Ludwig van Beethoven: Klaviersonate Nr. 32 c-moll op. 111, 1. Satz, Takte 6-11

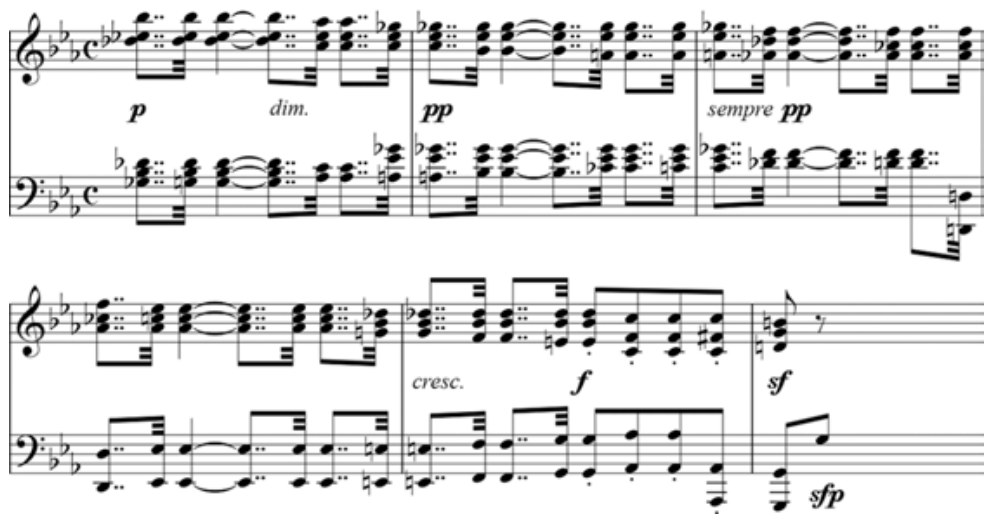

Ich nehme beim Spielen teil an einem Entstehungsprozess, an einem Werden: ein Handeln, nicht ein Herstellen. Wohin das führt? Wenn ich spiele, was die Musik hier anbietet, nehme ich teil an einem Werden auf ein Unbekanntes hin. Ich muss immer wieder stehenbleiben und mich den Fragen aussetzen: Und jetzt? Was jetzt? Wie weiter? Genau das macht das Spielen dieses Stücks aus; das ist die Chance, welche die Musik mir gibt. 
Was jetzt kommt (Takte 11-18), bis zum Beginn des Allegros, ist ein einziges Stehenbleiben. Es gibt Variationen über eine Tonrepetition auf g - eine verkörperte Fermate. Wenn es dann endlich weitergehen soll, spiele ich einen einzigen Ton (Takt 19). Ein erneuter Anlauf: Und wieder Stehenbleiben unter einer Fermate (Takt 20). Ein dritter Anlauf: Es geht weiter (vgl. Abb. 10).

Abbildung 10: Ludwig van Beethoven: Klaviersonate Nr. 32 c-moll op. 111, 1. Satz, Takte 19-21

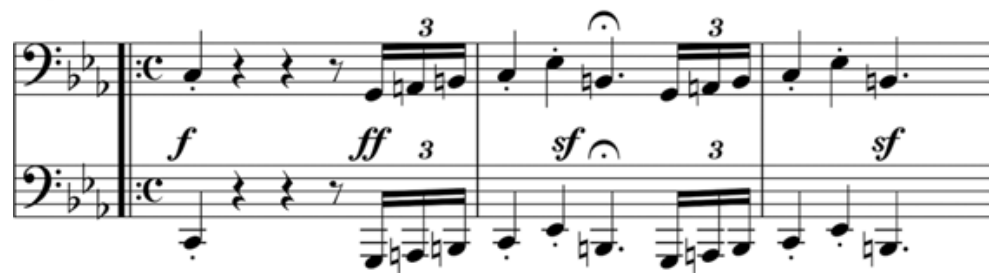

Wolfgang Rihm spricht das »musikalische Einzelereignis« an, das bei solcher Suche sein »Freiheitspotential« zeige. Verstehe ich das Einzelereignis als »Zelle«, dann ist es einerseits in sich abgeschlossen, steht es an seinem Ort für sich, dann ist es aber auch fähig, etwas anzustoßen, »Entwicklungen freizusetzen «. ${ }^{9}$ Eben solche Zellen spiele ich hier bei der Ausführung von Beethovens Sonate. Formungen ergeben sich, entstehen unter den Händen. Man begibt sich von Ort zu Ort, in einem Prozess des Werdens, der nicht zielgerichtet ist (vgl. Abb. 11).

Abbildung 11: Ludwig van Beethoven: Klaviersonate Nr. 32 c-moll op. 111, 1. Satz, Takte 50-55

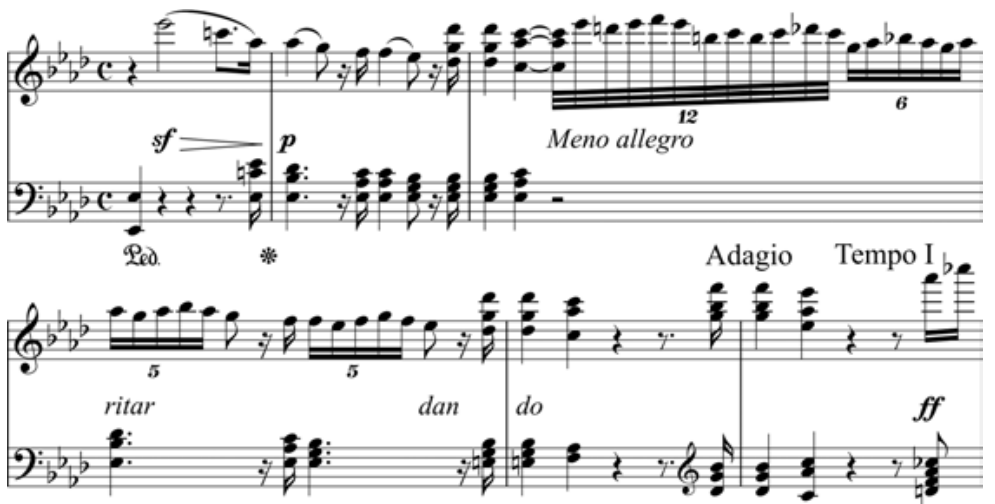

Hier spielt man schon gleich nach den Vorhaltsauflösungen Pausen (Takt 51); Sechzehntelpausen zwar nur, aber die genügen vollauf, um immer neu Klang-

9 | W. Rihm: Musikalische Freiheit, S. 35. 
verbindungen zu isolieren, »Zellen« zu bilden. Der Vorgang wiederholt sich - und nun vollziehe ich als Spieler diese kleinen Stillstände im großen AdagioStillstand (Takt 55) nach: eine Art Zurückdenken. Das kann doch noch nicht alles gewesen sein?

\section{II}

Und jetzt? Was jetzt? Wie weiter? Dies sind Fragen, die ich in Desorientierung stelle. Beim Spielen dieses Satzes wird es möglich, Desorientierung wirklich zu durchleben. Desorientierung stellt sich beim Spielen als befreiende Essenz der musikalischen Praxis heraus. Es entsteht ein offener Raum von Möglichkeiten.

Diesen Satz zu spielen, verheißt Verlust von Orientierung, Orientierungssuche. Wenn in musikalischer Praxis »Wirklichkeiten und Möglichkeiten« (Helmut Lachenmann) verhandelt werden, kann Konzeptlosigkeit eine Chance, Desorientiertheit eine Öffnung hin auf Unbekanntes werden.

Der Prozess des ersten Satzes der angesprochenen Sonate Beethovens lässt den Musiker Desorientiertheit erfahren. Diese Desorientierung wird nicht abgeschwächt durch schnelle Angebote von Neuorientierung oder Umorientierung. Man begegnet beim Spielen überraschend einsetzender Neuorientierung. Aber die Desorientiertheit (bis hin zur Orientierungslosigkeit) hat eine eigene Kraft, will ganz durchlebt werden. Sie ist nicht nur Chance zur Umoder Neuorientierung, sondern behauptet sich als eigener Wert.

Walter Brueggemann zeigt den Klagepsalm als Sprache von Desorientiertheit (»Lament as Speeches of Disorientation «). ${ }^{10} »$ The Psalter knows that life is dislocated.«»Psalms of lament are powerful expressions of the experience of disorientation.« Die Klage hat hier ihren Platz; Desorientiertheit wird anhaltend als dauerhafter Prozess durchlebt. Dass Desorientiertheit als eigener Sinn erfahren wird: Dies haben Sonatensatz und Klagepsalm vielleicht gemeinsam.

Beim Spielen dieses Sonatensatzes tue ich nicht so, als wäre ich desorientiert, sondern ich begebe mich mitten hinein in ein musikalisches wirkliches Geschehen, wechsle in den Sinnbereich der musikalischen Praxis und erfahre hier etwas darüber, wie Desorientiertheit wirklich sein kann, lasse mich in einen solchen Zustand fallen.

Der Sonatensatz lässt mich als Ausführenden teilhaben an einem Werden. Dies gelingt, wenn ich darauf vertraue, dass ich mich in immer neue Desorientierung hineinbegeben kann.

Was Adorno in seiner Beethoven-Studie zur Musik Beethovens allgemein sagt, gilt sicherlich auch für diesen Sonatensatz, in dem sich zeigt: »Das ein-

10 | W. Brueggemann: Praying the Psalms, S. 20ff.; die folgenden Zitate ebd., S. 21, 29. 
zigartige Wesen der Musik, nicht Bild, nicht für eine andere Wirklichkeit, sondern eine Wirklichkeit sui generis zu sein. $\ll^{11}$

\subsection{Johann Sebastian Bach: Fantasia in G FÜR ORGEL BWV 542 (UM 1720)}

\section{Historische Positionierung: handgreiflich}

\section{I}

Üben - Exercises: Die Clavier-Uebung Johann Sebastian Bachs ist eine Sammlung von Werken für Tasteninstrumente. Der erste Teil umfasst die Sechs Partiten (BWV 825-830); der zweite Teil besteht aus der Ouvertüre h-moll (BWV 831) und dem Italienischen Konzert F-Dur (BWV 971); den dritten Teil machen 21 Choralbearbeitungen (BWV 669-689) und Vier Duette (BWV 802-805) aus, umrahmt von Präludium und Fuge Es-Dur für Orgel (BWV 552); und der vierte Teil schließlich: Das sind die berühmten Goldberg-Variationen für Cembalo (BWV 988), ein Zyklus von 30 Variationen. »Übung«: ein Bestandteil des Titels für das gesamte mehrteilige Werk. Übung wird hier verstanden als Einübung in Spieltechniken, in Variations- und Bearbeitungstechniken, als Reflexion über Traditionen des Musizierens, als theologische Reflexion, als meditative Haltung beim Spielen.

Eine solche Übung im umfassenden Sinne ist auch Bachs Orgelbüchlein, eine Sammlung von Choralvorspielen (BWV 599-644). Auf der Titelseite des Autographs heißt es entsprechend:

"Worinnen einem anfahenden Organisten Anleitung gegeben wird, auff allerhand Arth einen Choral durchzuführen, anbei auch sich im Pedal studio zu habilitiren, indem in solchen darinnen befindlichen Choralen das Pedal gantz obligat tractiret wird. Dem höchsten Gott allein zu Ehren, dem Nächsten, draus sich zu belehren. “12

Übungen, Exercises sind fast alle Kompositionen Bachs, die dem Spieler etwas zum Be-Greifen geben. Gleich das erste Stück, Praeludium 1 C-Dur (BWV 846) aus dem Wohltemperierten Klavier I, zeichnet mit seinen Figurationen wechselnder Akkorde Handgriffe, Handstellungen nach, scheint fast ein Ergebnis solchen Greifens zu sein. Der Ausführende übt sich auch im musiktheoretischen Wissen, welches er sich über die Bewegungen der tastenden Hände aneignet (vgl. Abb. 12).

11 | Th. W. Adorno: Beethoven, S. 235; Herv. i.0.

12 | J. S. Bach: Orgelbüchlein, S. XXV. 
Abbildung 12: Johann Sebastian Bach: Praeludium 1 C-Dur WK I, Takte 1-4
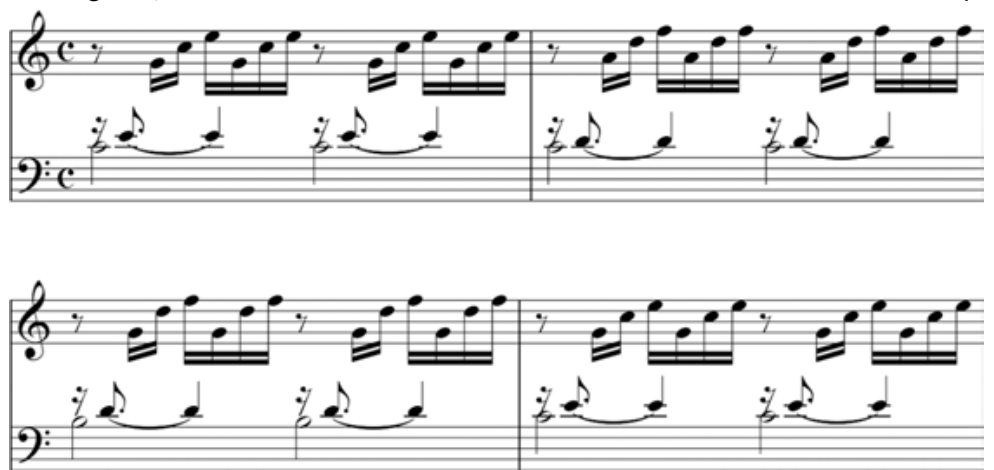

Ganz anders erfolgt körperlicher Zugriff auf das Instrument im Preludio 12 f-moll (BWV 881) aus dem Wohltemperierten Klavier II: Durch die Entfernung der beiden Hände voneinander, dann aber auch durch das Ineinander-Greifen der Hände wird der jeweils entstehende Akkord als ein zusammengesetzter körperlich erfahren. Die Brechung des Dreiklangs erscheint in einem besonderen Licht: Welcher Akkordton wird isoliert? Man übt Griffe, zugleich begreift man mit der Hand den speziellen Akkord (vgl. Abb. 13).

Abbildung 13: Johann Sebastian Bach: Preludio 12 f-moll WK II, Takte 1-8

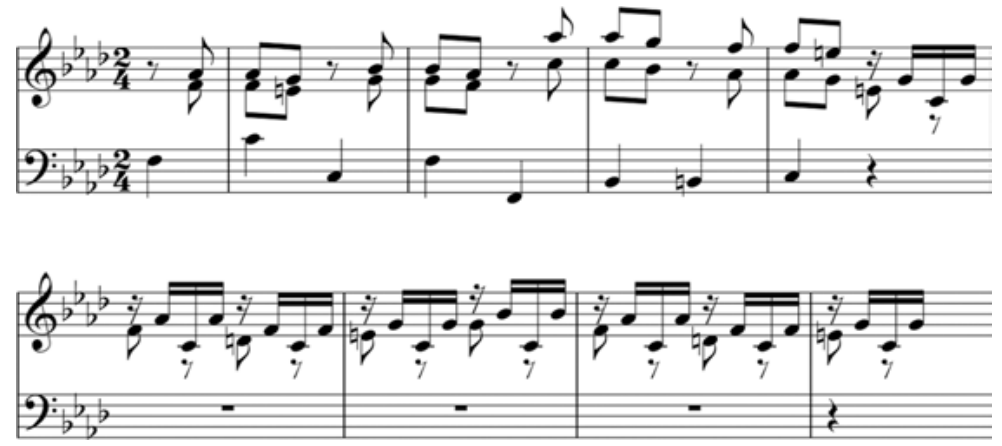

Aber nicht nur mit den Händen wird getastet. Der Orgelspieler tastet auch mit den Füßen. Wer, wenn nicht Bach, hätte diese Gelegenheit wahrgenommen. Bach hat als herausragender Orgelspieler diese Praxis, harmonische Sachverhalte mit Händen und Füßen zu greifen, zu begreifen und an andere weiterzugeben, ausgiebig gepflegt. Der zweite Teil der Toccata F-Dur für Orgel (BWV 540), der Teil nach den Orgelpunkten und den ausgiebigen Pedalsoli, ist, nachdem zuerst das Spiel mit Hand und Fuß getrennt geübt wurde, ein gutes Beispiel für deren Zusammenwirken. Man findet sich beim Spielen mit wechselnden harmonischen Ergebnissen konfrontiert. Für den Spieler buchstäblich zu 
ertasten ist, wie unterschiedliche harmonische Wendungen möglich werden. Bach ertastet sich als Spieler das Klangangebot seiner Zeit (vgl. Abb. 14, 15).

Abbildung 14: Johann Sebastian Bach: Toccata F-Dur, Takte 188-192

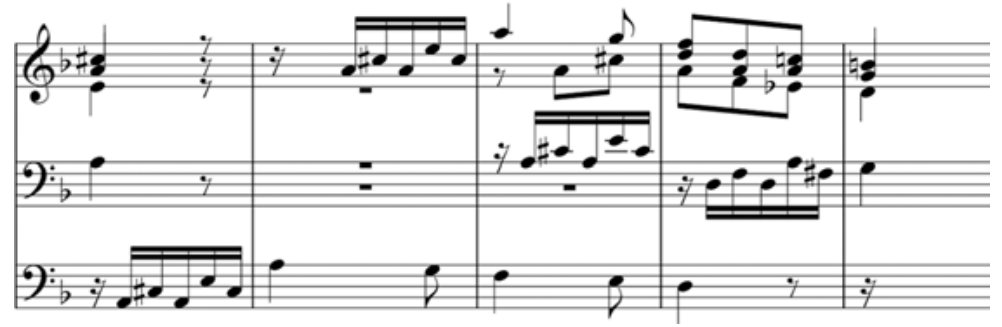

Abbildung 15: Johann Sebastian Bach: Toccata F-Dur, Takte 238-242

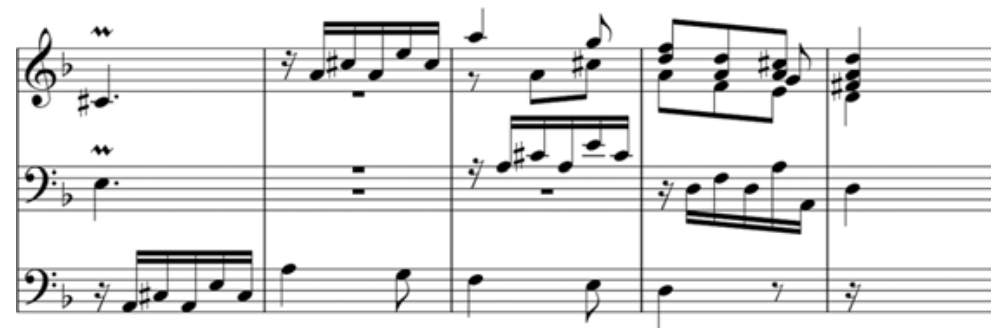

Auch die »Dorische Toccata« (Toccata et Fuga in d) (BWV 538) kann - neben vielen anderen Orgelwerken - als Beispiel herangezogen werden, wie es über körperliche Aktivität mit Händen und Füßen zu einem Be-Greifen musikalischer (hier vornehmlich harmonischer) Zusammenhänge kommt (vgl. Abb. 16). Abbildung 16: Johann Sebastian Bach: Toccata in d, Takte 7-10
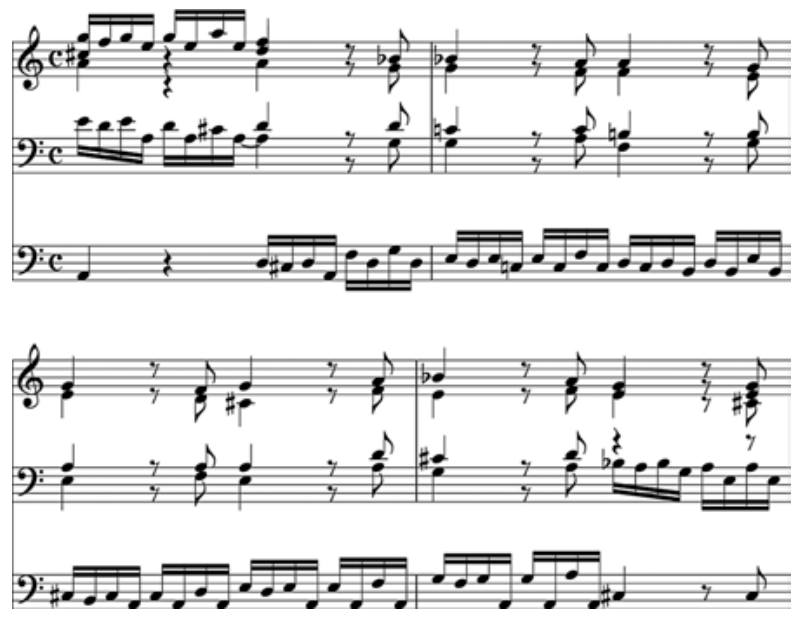
II

Ein spezieller Ort in der Fantasia in g für Orgel (BWV 542): Der lange Tonleiter-Abstieg, der gar kein Ende nehmen will. Als Spieler hat man das Gefühl: Es geht immer weiter abwärts - »Schritt für Schritt « ${ }^{13}$. Die Tastatur des Pedals ist zu kurz für diesen Abstieg, wird eigentlich überschritten. Denn die Oktavversetzungen immer wieder nach oben haben den Zweck, einen Ausgleich für die zu kurze Pedaltastatur und für die zu kurzen Beine des Spielers zu schaffen (vgl. Abb. 17).

Abbildung 17: Johann Sebastian Bach: Fantasia in g, Takte 31-36

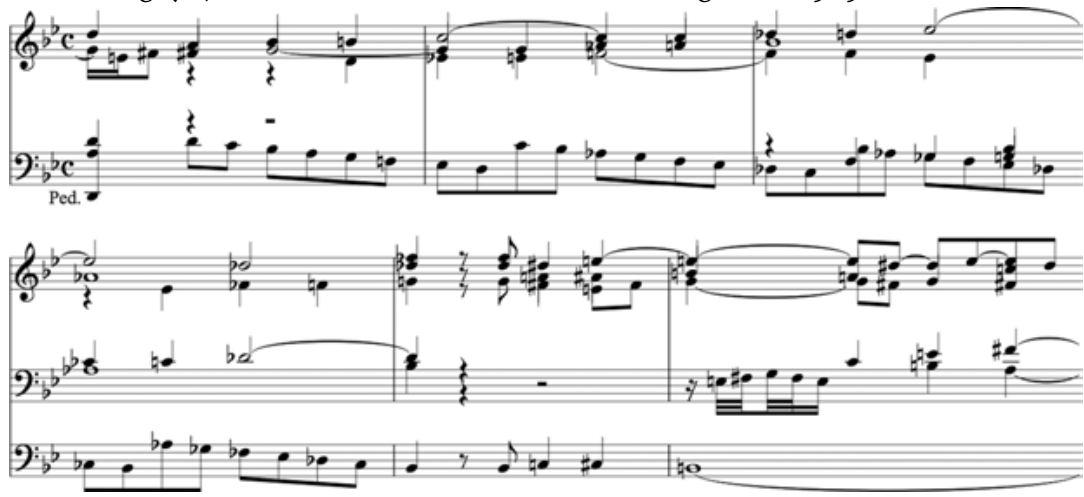

Gesetzt den Fall, der Spieler würde den ersten Abstieg nicht auf 16'-Basis, wie es üblich wäre, sondern eine Oktave höher auf 8'-Basis registrieren: Dann könnte nach der ersten Oktavversetzung auf 16'-Basis, nach der zweiten Versetzung auf 32'-Basis, nach der dritten auf 64'-Basis weitergespielt werden. Doch utopisch, denn eine Orgel mit so tiefen Registern gibt es nicht. Schon 32'-Bässe sind selten. ${ }^{14}$ Ein Abstieg, der es in sich hat - und der vom Ausführenden »Schritt für Schritt« (Stäbler) durchwandert wird. Ohne Oktavversetzungen würde die Hörgrenze unterschritten: Man würde als Spieler ohne die Versetzungen auf dem Sub-Subkontra B landen. ${ }^{15}$ Hände und Füße exerzieren gemeinsam durch, was Quintfall bedeuten kann: $D^{7}-g-G^{7}-c-C^{7}-f-F^{7}-b$ $-\mathrm{B}^{7}-\mathrm{es}-\mathrm{Es}^{7}-\mathrm{as}-\mathrm{As}^{7}-\mathrm{des}-\mathrm{Des}^{7}$. Jetzt müsste ges-moll erscheinen, mit den Tönen heses (im Pedal) und ges - heses - des im Manual. Mit ges-moll wären neun $b$-Vorzeichen erreicht. Der Spieler greift stattdessen den verminderten

13 | G. Stäbler: "Um verlorene Schlüssel zu suchen...", S. 1.

14 | Gerd Zacher schlägt vor, die letzte Oktave dann auf 32'-Basis (Takt 34) "eine Oktave tiefer als notiert" zu spielen, falls man die Tiefe hörbar machen wolle; vgl. G. Zacher: Die Form der g-moll-Fantasie, S. 27.

15 | = 14,6 Hz; vgl. G. Stäbler: "Um verlorene Schlüssel zu suchen...", S. 1. 
Septakkord - und fällt in eine »Schreckpause ${ }^{16}$. In dieser Schreckpause wird die Notbremse gezogen.

Der Ton fes ist vor der Pause Mollterz des Akkords des-moll; nach der Pause ist e zuerst die Septime im Fis ${ }^{7}$-Akkord, dann der Quartvorhalt im Vorhaltsquartsextakkord. Man ertastet beim Spielen verschiedene Töne mit derselben Taste und hört sie auch als verschiedene.

»Bach mit seinem Wohltemperierten Klavier kann geradezu als der Totengräber der Vieltönigkeit gesehen werden. ${ }^{17}$ Und: »Bach kannte meines Wissens keine vieltönigen Orgeln. ${ }^{18}$ Gleichwohl gab es im 16. und 17. Jahrhundert vieltönige Instrumente. ${ }^{19}$ Die Orgeln, auf der die Fantasia in der Folgezeit nach ihrer Entstehung geübt und ausgeführt wurde, waren nicht vieltönig, davon ist wohl auszugehen. Doch in der »Schreckpause« (Takt 35) ist Vieltönigkeit zu ertasten und auch zu hören.

Ein solches Tasten ist zugleich »historische Positionsbestimmung « ${ }^{20}$. Was gab es? Was gibt es jetzt? Solchen und ähnlichen Fragen wird nachgespürt beim Durchspielen der Wirklichkeiten und Möglichkeiten. Tasten, Er-Tasten wird ein Fühlen und Begreifen der eigenen musikalischen »Erfahrungskategorien ${ }^{21}$, bindet die Zeitgenossenschaft in einen historischen Erfahrungshorizont ein.

Hinsichtlich Bachs denkwürdigen zweistündigen Bewerbungskonzerts an der Orgel in der Hamburger Katharinenkirche, an dem wohl auch Johann Adam Reincken teilnahm, vermutet Christoph Wolff, dass es am 16.11.1720 stattfand und »daß Bach [u.a.] die Fantasie und Fuge in g-Moll BWV 542 [...] spielte, nicht als improvisiertes Werk, sondern [...] als eine sorgfältig aufgezeichnete Komposition«, wobei »die Fuge von BWV 542 bereits vor 1720 komponiert wurde ${ }^{22}$

II

Es ist eine Zeit heftiger musiktheoretischer Diskussion und Auseinandersetzung mit Worten und auch mit Kompositionen. Im zeitlichen Umfeld entstehen zum Beispiel der erste Teil des Wohltemperierten Klaviers (BWV 846-869), die Chromatische Fantasie und Fuge d-Moll (BWV 903). Werke wie diese treten wie eine kompositorische Antwort auf Johann Matthesons Beschwerde auf,

16 | G. Zacher: Die Form der g-moll-Fantasie, S. 27.

17 | B. Haas: Über Mikrotonalität und Vieltönigkeit, S. 138; Herv. i.0.

18 | Ebd., S. 140.

19 | Vgl. M. Kirnbauer: Vieltönigkeit statt Mikrotonalität.

20 | E.-M. Houben: Das Alte ist vergangen, S. 60.

21 H. Lachenmann: Zum Verhältnis Kompositionstechnik - Gesellschaftlicher Standort, S. 95.

22 | Chr. Wolff: Johann Sebastian Bach, S. 234. 
dass, obwohl »alle Claves nunmehr per Temperaturam so eingerichtet werden können, daß man sie diatonicè, chromaticè \& enharmonicè sehr wohl gebrau-

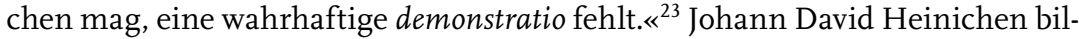
det in seiner 1711 veröffentlichen Schrift »Neu erfundene und gründliche Anweisung...« in der »Zweiten Abtheilung « (»Capitel IV: Von der vollkommenen Wissenschafft des General-Basses«) einen Quintenzirkel ab: „Von einem Musicalischen Circul, vermittelst welchen aller Tone Eigenschafft/Verwandtschaft/ Ausschweiffung und Veränderung gar leicht zu erkennen/und sonderlich in Clavier und Composition nützlich zu gebrauchen. $\aleph^{24}$ In der Praxis erweist sich dessen Brauchbarkeit. Man ertastet sich auch musiktheoretisches Wissen, das dann in der Praxis (all-)täglichen Musizierens auf den Prüfstein gehoben wird.

Wolff würdigt die Fantasie: »[E]ine Fantasie von ungewöhnlicher rhetorischer Kraft und einmaliger harmonischer Spannweite, deren chromatische Akkorde sich auftürmen über einer absteigenden Pedaltonleiter und die Illusion eines endlosen Raums wecken ${ }^{25}$ Der Ausführende allerdings gibt sich hier nicht einer »Illusion« hin, sondern macht handgreiflich Bekanntschaft mit Überfülle. Der Raum, den es zu erfahren gibt, ist tatsächlich grenzenlos, man tut nicht so, als ob es so sei. Die konkrete Erfahrung beim Tasten mit Händen und Füßen wird durch die Begegnung mit Grenzen geprägt: Die Hörschwelle wird tatsächlich unterschritten, die Pedaltastatur ist wirklich zu kurz, die Beine reichen einfach nicht weit genug - würden die Schritte nicht immer wieder eine Septime höher neu ansetzen; die Tasten des Manuals sind eigentlich nicht differenziert genug eingeteilt. Konkret zu ertasten sind all diese Begrenzungen - und dadurch tritt die Überfülle ans Licht. Dem Ausführenden zeigt sich: Es ist immer noch mehr da, immer noch mehr, als du denkst, als du ertasten kannst. Die Grenzen zeigen die Grenzenlosigkeit. Hier, bei solchem Fall in die Tiefe, gerate ich beim Spielen ins Fliegen.

Dies wirklich zu tun, ist erhebend und führt uns über uns hinaus. Notwendig wird es jetzt, diese Fantasia Bachs hereinzuholen in Zeitgenossenschaft. Wozu? Sind wir doch alle längst an diatonische, chromatische, enharmonische »Verwandtschaften«, »Veränderungen« und »Ausschweifungen« (Heinichen) gewöhnt, kennen wir doch Vierteltönigkeit, Vieltönigkeit, Mikrotonalitäten, Spektralkompositionen und vieles mehr. Wozu also?

Im Tun des Ausführenden erwacht aktuell auch heute wieder neu die Auseinandersetzung mit den Bedingungen und Möglichkeiten, die zu dieser Art von Komposition damals geführt haben. Der Körper ist involviert. Teilnehmende hören die Verkörperungen des Klangs, hören den begrenzten Körper des

23 | Johann Mattheson: Das beschützte Orchestre, Hamburg 1717, S. 437; zitiert in: Chr. Wolff: Johann Sebastian Bach, S. 250; Herv. i.0.

24 | J. D. Heinichen: Neu erfundene und gründliche Anweisung, S. 261.

25 | Chr. Wolff: Johann Sebastian Bach, S. 234. 
Instruments Orgel, hören den begrenzten Körper des Ausführenden, wenn er fällt, wenn er sich fallen lässt - können nachvollziehen, mitempfinden. Im Tun des Spielers zeigt sich Fülle: dem Spieler, aber auch denjenigen, die mit dabei sind.

\subsection{Frédéric Chopin: Prélude Nr. 2 a-moll, AUS: 24 PRÉLUdES OP. 28 (PUBl. 1839)}

\section{Zärtliche Verbindungen in verstörendem Kontext: der zweihändige Pianist}

Was macht man als Spieler hier? Man spielt einen Ton - und einen weiteren dazu. Zwei Töne, die nicht weit auseinander liegen, hier und dort eine Nebennote (vgl. Abb. 18).

Abbildung 18: Frédéric Chopin: Prélude Nr. 2 a-moll, Takte 1-7

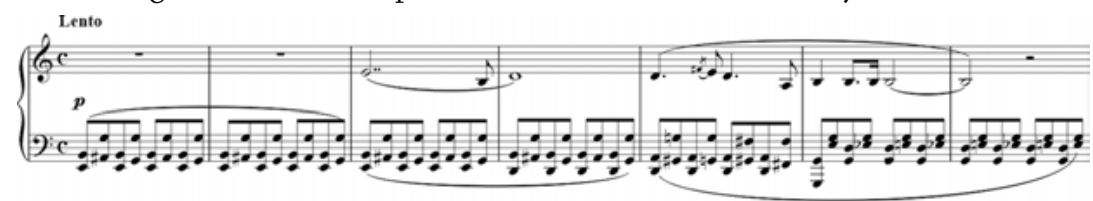

Welche innere Haltung könnte damit verbunden sein? - welche Art von Körperlichkeit? Warum könnte man es als sinnvoll empfinden, dies zwei oder drei Mal am Tag allein, ohne Publikum, zu tun?

Man spielt einen ersten Ton, und dann geht es behutsam weiter zum anderen hin. Zwei Töne werden zueinander in Beziehung gebracht. Die Behutsamkeit, mit der ich hier als Spieler von Ton zu Ton gehe, innehalte, um wiederum von Ton zu Ton zu gehen, wird womöglich noch durch die Hinzufügung der Achtelnote gesteigert.

Das gesamte Prélude könnte als wiederholte Bewegung zwischen zwei Tönen aufgefasst werden, die nicht weiter als eine Sekunde oder eine Terz voneinander entfernt sind (vgl. Abb. 19).

Abbildung 19: von Ton zu Ton - ein Überblick über das gesamte Prélude

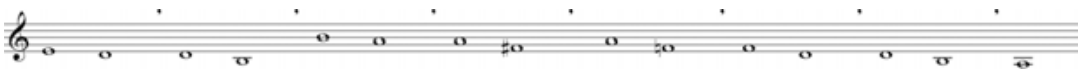

Man könnte dieses Spiel als eine Übung in Zärtlichkeit auffassen: Zwei Töne miteinander in Berührung zu bringen. Die Tonrepetition am Ende einer Phrase gibt auch dem Ankommen etwas Behutsames. Die Punktierung hat nichts Marschmäßiges, eher bewirkt sie eine Verzögerung. Auch die Einfärbung des 
Tones fis ${ }^{1}$ in den Ton $\mathrm{f}^{1}$ (Takt ${ }^{16}$ ) wirkt wie ein Angebot zu zarter Annäherung. Das Spiel in der rechten Hand ermöglicht Verbindung, Annäherung, Begegnung zweier Körper. ${ }^{26}$

Mit der Bewegung in der linken Hand wird dieses Tun in einen verstörenden Kontext gestellt. »Die Kargheit der Melodie korrespondiert mit der sparsamen Begleitung oder konkreter gesagt: mit dem Part der linken Hand, denn von Begleitung kann man hier schwerlich sprechen. ${ }^{27}$ Diese Bewegung ruft einen Puls hervor, welcher der Melodie in der rechten Hand gänzlich fremd ist. Hinzu kommt, dass diese Bewegung auch kaum harmonische Rücksichten auf die liedhaften Phrasen der rechten Hand nimmt.

Chopins Prélude setzt den Spieler dieser zerrissenen Situation aus. Die Bewegung in der linken Hand fordert in langen Phrasen ein Legato, das mit einer Hand allein stellenweise schwer zu bewerkstelligen ist. Wie ist es möglich, gleichzeitig das eine und das andere zu tun? Die Komposition hilft dem Spieler, indem die rechte Hand unsystematisch einsetzt, mal auf der ersten Zählzeit, mal auf der dritten, dann auf der zweiten. So kann sie sich der Unerbittlichkeit des Pulses einigermaßen entziehen. Während der Puls zwei Takte früher als die Melodie anfängt, geht am Schluss die Melodie alleine weiter, während der Puls zuerst unterbrochen wird (Takte 17-18), dann ganz aufhört. Die Kadenz am Schluss wirkt daraufhin fast wie ein Zitieren.

Die Bewegung in der linken Hand bietet keinerlei Schutz - im Gegenteil. Die Praxis: den Fortgang der liedhaften Melodie weiterhin zu ermöglichen, trotz der Beeinträchtigung; die Behutsamkeit zu wahren, trotz der Behinderung. Da geht ein Riss durch den Körper, und diesen Riss gilt es auszuhalten.

Die Melodie ist überaus verletzlich: Die Klänge der ganzen Note sind über einen Takt hinweg gerade noch zu hören; die Überbindung von einer punktierten Halben zu einer doppelt punktierten Halben (Takte 14-15) ist kaum möglich, der Klang in Takt 15 ist eigentlich verklungen, bevor die rettende Achtelnote als Brücke zum nächsten Ton ergriffen werden kann (vgl. Abb. 20).

Abbildung 20: Frédéric Chopin: Prélude Nr. 2 a-moll, Takte 13-16

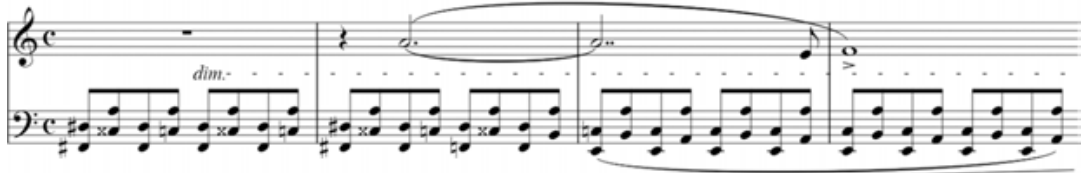

Die Figurationen mildern diese Verletzlichkeiten ab. Hier aber entsteht eine Unterbrechung, die sich kaum vermeiden lässt, will man beim Spielen nicht entscheidend lauter oder schneller werden, was ja nicht vorgesehen ist. Der

26 | Vgl. M. Zenck: tasten - tasten, S. 47.

27 | T. A. Zielinski: Chopin, S. 586. 
mutige Spieler lässt es darauf ankommen und begibt sich in einen Bereich zwischen Tun und Geschehen-Lassen.

Die der Komposition innewohnende Dialektik wird von Lawrence Kramer angesprochen, der bereits den Rahmen des Klavierstücks (Beginn mit der schweren Bewegung in der linken Hand, Schluss mit der Melodie in der rechten) als eine Form von »dialektischer Umkehrung« (»dialectical reversal«) beschreibt:

"Taking this framework as a hermeneutic window, we might try to understand the prelude itself as a study in reversal or, more precisely, as a study in dialectic, conceived of in nineteenth-century terms as a series of dynamic oppositions that lead to reversals of meaning or value. ${ }^{28}$

Die Beziehung zwischen Melodie und Begleitung sei mehr als bloße Unstimmigkeit (»incongruity«), es handele sich hierbei vielmehr um einen vielschichtigen Prozess von Dissoziation (»a many-sided process of dissociation«).

»Is pure songfulness a consolation or a lie? « ${ }^{29}$ Diese Frage Kramers ließe sich von der Praxis her auch so stellen: Ist das zärtliche, Beziehung stiftende Tun der rechten Hand angesichts der Bedrohung in sich selbst schon legitim? - oder müsste ihm in der Reflexion etwas entgegengesetzt werden? Das Stück bietet dem Spieler die Möglichkeit, ein Tun angesichts einer Bedrohung durchzustehen, ohne diese zu negieren.

Es gilt, das Verschwinden der langen Melodietöne, deren Schweben wie über einem Abgrund, deren Verletzlichkeit und Bedrohtheit wie auch die immer neu gefährdete Verbindung zwischen den Tönen auszuhalten.

\subsection{Aurèle Stroë: $3_{\text {im }}$ Sonate pour Piano (EN PALIMPSESTE) (1947/1957/1990-1991)}

\section{Brüche - das Klavier als Trommel. Raumgreifende Bewegungen}

\section{I}

Es ist gerade die Unterbrechung, die Aurèle Stroë kompositorisch fasziniert. $\mathrm{Zu}$ seiner ersten Klaviersonate führt er aus:

"Der erste Teil der Sonate ist auf einem bestimmten Niveau, dann war er plötzlich zerbrochen, und ich habe versucht, die unterschiedlichen Einflüsse zusammenzubringen. Plötzlich gibt es einen Bruch - und es fängt neu an, auf einem ganz anderen Niveau.

28 | L. Kramer: Music as Cultural Practice, S. 73; das folgende Zitat ebd., S. 77.

29 | Ebd., S. 76. 
Eine Grammatik wird durch eine neue ersetzt. Man komponiert, kommt zu einem neuen, anderen Element - und findet ein drittes, das beide verbindet. “ ${ }^{30}$

Ausdrücklich zieht Stroë den Begriff des »Bruchs« heran, um über seine Musik zu sprechen: »Welche Art von Bruch ereignet sich? Wie groß soll der Kontrast sein zwischen den Elementen rechts vom Bruch und links vom Bruch? Dies sind die Fragen, die mich interessieren. ${ }^{31}$ Gustav Mahler ist für ihn ein Komponist der Brüche:

"Ich denke jetzt auch an die lange Pause zwischen dem ersten und dem zweiten Satz in der 2. Symphonie c-Moll: Der Schock ist so groß, dass wirklich eine Tragödie stattfindet, zu hören ist nicht nur ein Symbol für eine Tragödie. Nicht nur verschiedene Stile, auch verschiedene Arten von Werten und von Wertungen kommen zusammen. Was Wert hat im ersten Teil, hat keinen Wert im zweiten - und umgekehrt. Was sich ereignet, das ist die Tragödie der Form selbst. Die Form stirbt. Die Symphonie existiert, sie hat eine eigene Ontologie. Ihre Tragödie wird nicht dargestellt, sondern die Tragödie ereignet sich wirklich als Tragödie der Form selbst. « ${ }^{32}$

Aurèle Stroë wurde 1932 in Bukarest geboren, wo er neben Komposition auch Mathematik studierte. Nach dem Kompositionsstudium unterrichtete er an der Musikhochschule Bukarest zuerst Orchestration und Instrumentenkunde, später auch Komposition (1974-1985). In den Goer Jahren war er häufig Gast bei den Darmstädter Ferienkursen für neue Musik, auch arbeitete er in den USA längere Zeit an verschiedenen Zentren für Elektronische Musik; als Gastprofessor lehrte er von 1985 bis 1986 in Illinois. Von 1986 an lebte er als freischaffender Komponist und Musikwissenschaftler in Mannheim, wo er 2008 starb. ${ }^{33}$

\section{II}

Da es sich bei der dritten Klaviersonate, der $3^{\text {ème }}$ Sonate pour Piano (en palimpseste), um ein eher unbekanntes Stück handelt, hier ein Überblick.

Gleich beim ersten Hören fallen die Pausen auf, die von Stroë exakt ausnotiert wurden: differenzierte Pausen und genaue Zeitangaben (in Sekunden) für den Übergang von einem Satzteil zum nächsten in jeweils einem Satz, genaue Zeitangaben auch für den Übergang von einem Satz zum nächsten. Die Sonate gliedert sich in drei Sätze:

30 | A. Stroë, zitiert in: E.-M. Houben (Hg.): immer wieder anders, S. 31.

31 | Ebd.

32 | Ebd., S. 32f.

33 | Die biografische Notiz ebd., S. 70. 
- Scherzando, »Schattenhaft« - Colinda (1947): Andantino narrante

- Tranquillo (doppio canone) (... hommage à Pierre de la Rue) - Quasi Colinda (1957): Contemplativo ma rigorosamente in tempo

- Vivace brillante - Allegro - Colinda (1947, rev. 1991): Lo stesso tempo - Développement sur deux accords et un cluster: Allegro con gioia - Coda (lo stesso tempo)

Die von Stroë eingetragenen Jahreszahlen weisen darauf hin, dass diese Sonate ihn über 44 Jahre hin beschäftigte. Die Sonate ist, so Stroë in der Anmerkung zur Partitur, ein »Palimpsest in drei Schichten«, wobei jede »Schicht« »ein oder mehrere Fragmente « unterschiedlicher zeitlicher Entstehung enthält. ${ }^{34}$ Die »Schichten « datieren aus verschiedenen Jahren. Die älteste ist aus dem Jahr 1947; es handelt sich um die beiden »Colinda « betitelten Segmente (1. und 3. Satz), die Stroë »aus dem Gedächtnis« niedergeschrieben hat (»réecrites de mémoires«):

"Das Manuskript war längere Zeit verschollen, ich war gezwungen, eine neue Niederschrift nach vierzig Jahren zu unternehmen. Der Erfolg war nur ein teilweiser: Während die erste dieser Miniaturen fast gänzlich wiederhergestellt werden konnte (1. Satz, S. 7), so konnte, im Unterschied dazu, die zweite (S. 17) nur zu $50 \%$ vervollständigt werden. ${ }^{35}$

Colinda: ein Weihnachtslied alter Tradition, das in mehreren Varianten überliefert sein kann. Die zweite Schicht: Die Quasi Colinda aus dem Jahre 1957 (2. Satz, S. 14-15), die unter Verwendung des Materials der alten Lieder komponiert wurde. Die dritte und jüngste Schicht wird durch Scherzando (1. Satz), Hommage à Pierre de la Rue (Canon) (2. Satz) und Allegro con gioia (3. Satz) gebildet und stammt aus den Jahren 1990-1991. Diese Schicht ist die umfangreichste und beansprucht bei einer Aufführung etwa drei Viertel der gesamten Aufführungszeit.

Wegweisend für eine Untersuchung dessen, was in dieser dritten Sonate mit Brüchen gemeint sein könnte, ist wohl Stroës Hinweis: »Une écoute nonlinéaire est indispensable! ${ }^{36}{ } »$ Ein nicht-lineares Hören ist unverzichtbar! « An welchen Stellen sind im Hinblick auf die gesamte Komposition (die Klaviersonate mit allen drei Sätzen und Formteilen) und innerhalb eines Satzes Brüche auszumachen?

Im ersten Satz Scherzando, »Schattenhaft«, der letzten »Schicht« von 1990/1991 zugehörig, fallen die zahlreichen Pausen auf, aber auch völlig unver-

34 | A. Stroë: $3^{\text {ème }}$ Sonate pour Piano (en palimpseste), Partitur, Note (Übersetzung aus dem Französischen: E.-M. Houben).

35 | Ebd.

36 | Ebd. 
mittelte Übergänge. Pause und plötzlicher Kontrast können gleichermaßen abbrechen, unterbrechen. Von großer Heftigkeit ist zum Beispiel ein plötzlicher Ausbruch (»explosion«), dem gleich eine äußerst zarte, häufig wiederkehrende Phrase (»en résonance«) folgt (vgl. Abb. 21).

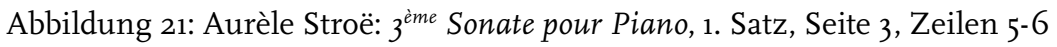
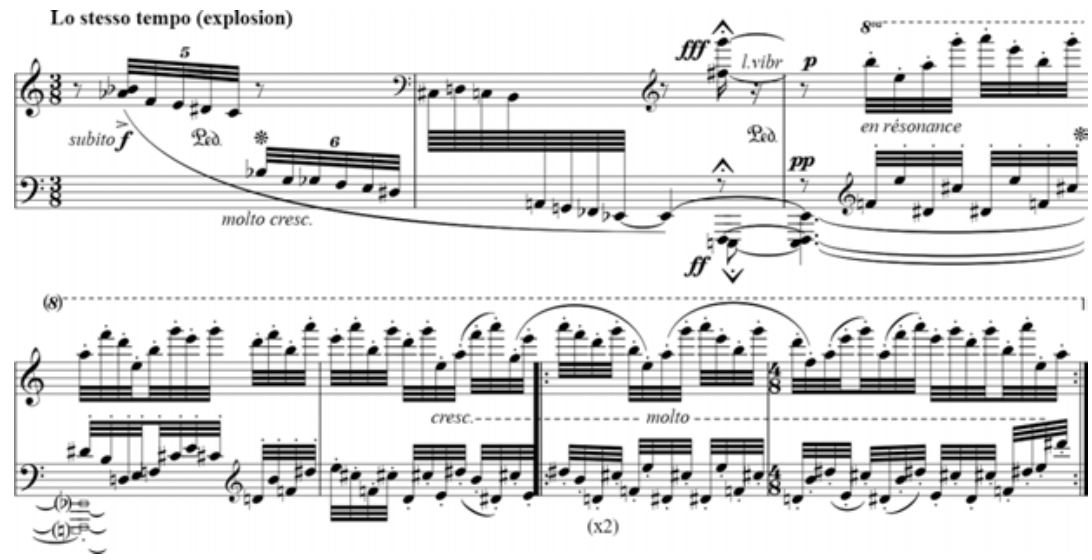

Manuskript; mit freundlicher Genehmigung der Tochter, Raluca Brumariu

Diesem Satzabschnitt folgt die erste Colinda (1947), ein Bestandteil der tiefsten, ältesten »Schicht«. Als »Andantino narrante«, so im Untertitel bezeichnet und mit den Vortragsanweisungen »cantabile«, »un poco marcato«, »espressivo« versehen, fällt ihr die Aufgabe zu, zu berichten, zu erzählen, ein Geheimnis weiterzugeben. Die Tonrepetition unterstreicht dies (Anklänge an ein Rezitieren, Psalmodieren), zugleich weist sie zurück auf den vorhergegangenen Abschnitt Scherzando, »Schattenhaft«, der ebenfalls stark von Tonrepetitionen geprägt war; die Cluster könnten als ungenaue, klanglich und farblich variierte Repetitionen gehört werden.

Der erste Teil des zweiten Satzes, Tranquillo (doppio canone), soll als »...hommage à Pierre de la Rue« verstanden werden (1957). Der zweite Satz tritt als langsamer inmitten zweier schneller Sätze auf, verweist dabei zugleich durch die kompositorische Auseinandersetzung mit der alten Colinda - auf die ältere Schicht der Lieder. Gleichsam auf den Spuren Pierre de la Rues werden auf komplexe Weise mehrere »Schichten« vereint: Dem anfänglichen Kanon, wiederum sehr gesanglich, »cantabile« gehalten, gesellen sich weitere Räume hinzu, zunächst in Gestalt einer entfernten Trompetenstimme (»quasi una tromba lontana«, »un poco nervoso « $)^{37}$, die an den Erzählton der ersten Colinda im ersten Satz anknüpft, dann in Gestalt eines Scherzando-Motivs (»f un

37 | A. Stroë: $3^{\text {ème }}$ Sonate pour Piano (en palimpseste), Partitur, S. 9. 
poco scherzando, moqueur« $)^{38}$, das auf den ersten Teil des ersten Satzes Scherzando, »Schattenhaft« zurückweist. Nach einer Pausenzäsur schließt sich die Quasi Colinda an, aus der mittleren »Schicht« (1957) stammend. Die tiefe und sehr tiefe Lage der Liegeklänge in der linken Hand mag auf Pierre de la Rue verweisen, der tiefe Stimmlagen bevorzugte. Deren Aufbau als Cluster und deren Klangbild in der sehr tiefen Lage erinnern an den ersten Abschnitt des ersten Satzes Scherzando.

Der erste Teil des dritten und letzten Satzes knüpft deutlich durch die Motivik (Clusterbildung, Art der Bewegung der Cluster, Quintolen- bzw. Sextolenbewegung abwärts, Thema »résonance«) an den ersten Teil des ersten Satzes an. Unmittelbar schließt sich die Colinda an (älteste Schicht; 1947, allerdings revidiert 1990/91); es folgt sogleich der letzte Abschnitt des Satzes Allegro con gioia, näher spezifiziert als » Développement sur deux accords et un cluster » (Entwicklung über zwei Akkorde und einen Cluster). Hier eine abschließende Übersicht über die Art der Übergänge mit Pausen zwischen Satzteilen und Sätzen:

\section{Satz}

Scherzando, "Schattenhaft"

10 Sek. Pause

Colinda (1947): Andantino narrante

10 Sek. Pause - attacca

\section{Satz}

Tranquillo (doppio canone) (...hommage à Pierre de la Rue)

5 Sek. Pause

Quasi Colinda (1957): Contemplativo, ma rigorosamente in tempo

5 Sek. Pause

3. Satz

Vivace brillante

Allegro

attacca

Colinda (1947, rev. 1991): Lo stesso tempo

Pause lunga - attacca

Développement sur deux accords et un cluster: Allegro con gioia

Pause - attacca Coda

Pause

Die ausdrückliche Einbeziehung der Übergangs-Pausen in die Komposition durch entsprechende Vermerke sind nicht nur in der von Stroë erwähnten 2. Symphonie Mahlers, sondern auch in anderen Werken, etwa in Arnold Schönbergs Pierrot lunaire oder in Alban Bergs 4 Stücken für Klarinette und Klavier op. 5 zu finden. Neben explizit bestimmter Dauer gewinnt die unbestimmte Pause zwischen zwei Sätzen eine spezifische Charakteristik, eine eigene Färbung: In ihr hallt das Vergangene nach, sie öffnet zugleich den Raum für das Kommende. Stroë stellt die Vorschriften »ca. 10 Sek. Pause« und »attacca« nebeneinander: Die Pause gehört demnach noch zum Ende des vergangenen Abschnitts (erst nach der Pause gilt die Anweisung »attacca«, so sie denn angegeben wird); die Pause ist der Nachschwing-, Nachhall-, Nachhör-Raum,

38 | Ebd., S. 10. 
zugleich Raum der Zuwendung zum Kommenden. Beides, der unvermittelte Übergang ohne Pause (attacca) und der Übergang im Pausen-Raum, durch den Pausen-Raum hindurch, zeigt einen ganz bewussten Umgang mit Übergang.

Alle Elemente sind zugleich da: Sowohl durch den Bruch als auch durch die Schichtung, bei der Fragmente aus unterschiedlichen Formteilen einander überlagert werden (wie in Hommage à Pierre de la Rue), entstehen Verbindungen. Ein Palimpsest ist eine antike oder mittelalterliche Manuskriptseite aus Pergament, die nach dem Beschreiben durch Abschaben oder Waschen gereinigt wird, um frei für eine neue Schrift zu werden. Der Untertitel »en palimpseste« meint: Wie ein Palimpsest nach mehrfachem Gebrauch oft unterschiedliche Schichten aus unterschiedlichen Zeiten bergen kann, die alle gleichzeitig da, nur mehr oder weniger leserlich sind, so tritt diese Sonate auf, die nicht nur heterogenes musikalisches Material, sondern auch unterschiedliche individuelle Lebensalter der Zuwendung, der Beschäftigung, des Komponierens, aber auch unterschiedliche Traditionslinien, damit Zeiträume/Epochen (Colinda, Pierre de la Rue) mit sich führt.

Stroës Klaviersonate zeigt ein Alles-auf-einmal, ein Zugleich-da-Sein heterogener Materialien, die unterschiedlichen Zusammenhängen entstammen. Während die Störung eines kontinuierlichen Ablaufs eher als ein Eingriff in den horizontalen Verlauf der Sonate in der Zeit gelten kann, zeigt die Schichtung unterschiedlicher Materialien eine »Verräumlichung « ${ }^{39}$ in der vertikalen Dimension.

II

Wie zeigen sich »Bruch« und »Katastrophe« in der körperlich zu erlebenden Praxis des Spiels - hier am Beispiel des dritten und letzten Satzes (Schluss)? Wo könnte die Nahtstelle zwischen der (alltäglichen) Lebenswirklichkeit und der Wirklichkeit, die von Stroë als eigene Wirklichkeit der Komposition beschworen wird, zu finden sein?

Der Schlussteil im dritten und letzten Satz nach dem Rückblick auf den Beginn der Sonate und nach der letzten Colinda trägt die Überschrift: »Développement sur deux accords et un cluster« (Entwicklung über zwei Akkorde und einen Cluster) - Allegro con gioia. Die Rhythmik ist nicht das Problem beim Üben, das kann man »mit Freude« (»con gioia«) schaffen. Man übt ein pulsierendes Sich-Bewegen, wie man sich sonst im Alltag nicht bewegt. »sempre martellato« (eine Spielanweisung im weiteren Verlauf): Hämmern, Klopfen, Trommeln. Das Klavier wird ein Schlagwerk. Hier geschieht das Trommeln, Hämmern mit Freude, frei von Druck: »con gioia«. Die Akkorde sind so weit voneinander entfernt, dass die Spielbewegungen sehr groß werden. Mit beiden

39 | Zum Begriff der Verräumlichung vgl. Chr. M. Schmidt: Brennpunkte der Neuen Musik, S. 69-114. 
Händen wird getrommelt, der Spieler ist körperlich ganz involviert - intensiv, nahezu tänzerisch (vgl. Abb. 22).

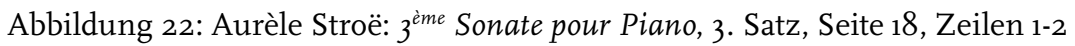

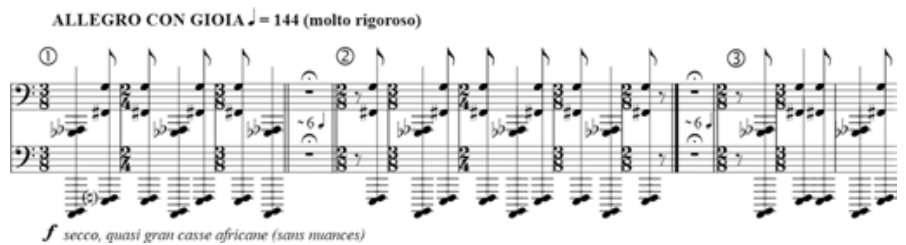

Manuskript; mit freundlicher Genehmigung der Tochter, Raluca Brumariu

Der Tanz der beiden Akkorde wird immer wieder von Pausen unterbrochen. Ein Schlagen: »f secco, quasi gran casse africane (sans nuances) $\ll^{40}$ Ein Trommeln auf dem Klavier also, wie auf einer afrikanischen Trommel. Ohne Nuancen her und hin, hin und her. In diesen Tanz mischt sich mehr und mehr der Cluster an der unteren Tongrenze des Klaviers ein; der Tanz wird immer wilder, immer vertrackter, bis er am Schluss abreißt. Einer Generalpause folgt attacca die Coda, die mit einer Pause schließt.

Die Abschnitte werden von Mal zu Mal immer länger. Es fängt mit kürzeren Phasen an; nach einer Pause (Atemholen) folgt ein längerer Trommelabschnitt; nach erneuter Pause ein wiederum längerer Trommelabschnitt - so geht es weiter. Immer mehr rhythmische Elemente treten hinzu (Viertel, Achtel, Achtel in Tongruppen, Triolen etc.). Das Trommeln wird immer differenzierter, die Bewegungen immer intensiver. Nach und nach häufen sich auch die Cluster. Unsystematisch treten Elemente hinzu: Pausen, Cluster, Wiederholungen (vgl. Abb. 23).

Abbildung 23: Aurèle Stroë: $3^{\text {ème }}$ Sonate pour Piano, 3. Satz, Seite 22, Zeilen 2-3

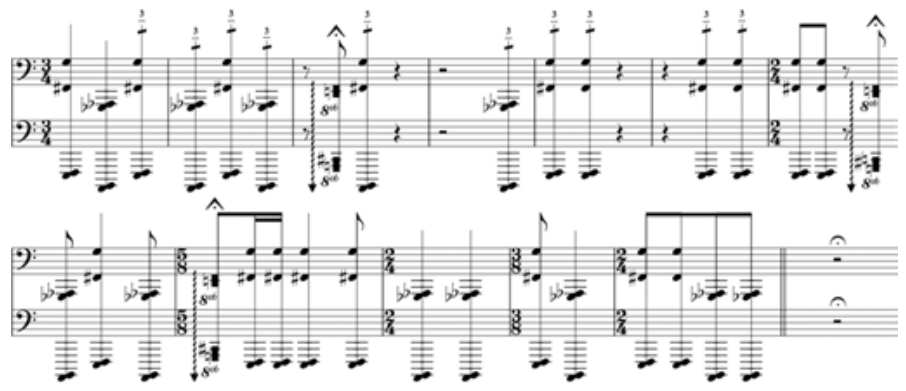

Manuskript; mit freundlicher Genehmigung der Tochter, Raluca Brumariu

40 | A. Stroë: $3^{\mathrm{èm}}$ Sonate pour Piano (en palimpseste), Partitur, S. 18. 
Die Musik ist hier zunächst ein rein körperliches Tun. Der Spieler trommelt sich in eine Lebensenergie hinein. Neben die körperliche Aktion tritt eine geistige Aktivität, die sich auf die Zerrupftheit der rhythmischen Bewegung gründet: Nicht in bloßer Motorik, sondern in der immer wieder stockenden Motorik vergewissert sich der Spieler seiner selbst. Brüche sind allerorts zu finden, man begibt sich beim Spielen in eine Welt der Brüche hinein. Nicht nur die Pausen sind die Brüche, sondern auch innerhalb einer Trommelpartie gibt es unentwegt Brüche. Die längeren Abschnitte werden ja nicht gleichförmig gespielt, sondern sie werden in sich ständig variativ umgeformt. Der Ausführende kann an keiner Stelle die Bewegung abspulen lassen, er ist in einem Prozess ständigen Agierens und Reagierens (vgl. Abb. 24).

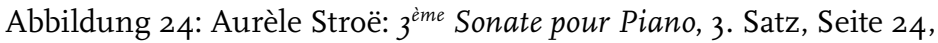
Zeilen 4-5

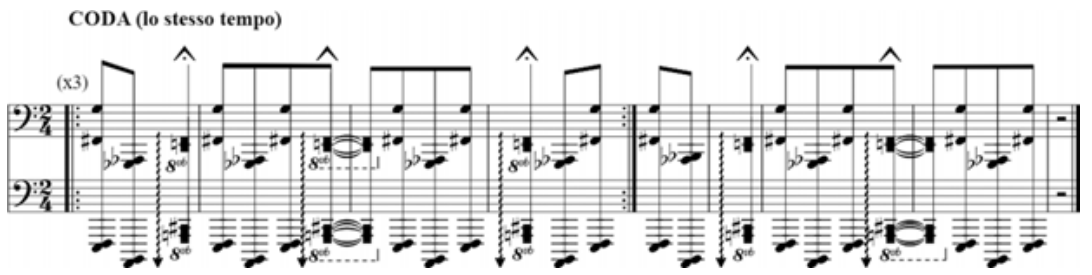

Manuskript; mit freundlicher Genehmigung der Tochter, Raluca Brumariu

Warum hat man das Gefühl, dass hier nicht nur ein ausgelassener Tanz getanzt wird? Hat das mit den Brüchen zu tun? Die Kontinuität wird ständig gestört. Bei aller kraft- und lustvollen Motorik finden wir hier eine Art hinkender Bewegung.

Ein Versuch, dieser Körperlichkeit über die Metapher beizukommen: Wenn man dieses Stück übt und spielt, erlernt man das Hinken. Ein selbstbewusstes Hinken. »Wer hinkt, kann nicht im militärischen Gleichschritt gehen. ${ }^{41}$ So hinkt man als Geretteter, als Überlebender, der die Katastrophe noch in sich trägt; so hinkt man, wenn man die ganze Sonate hinter sich hat. »con gioia«: Da ist die Katastrophe noch präsent in der Diskontinuität. Das ist eine Fröhlichkeit der Überlebenden.

»Développement sur deux accords et un cluster«: Hier entwickelt sich etwas im Vollzug der Ausführung »wie ein Stück Natur, das sich entwickelt« - um mit Stroës Worten zu sprechen. ${ }^{42}$ Diese Entwicklung gewinnt ein Eigenleben, parallel zur Alltagswelt.

41 | U. Bail: "Die verzogene Sehnsucht hinkt an ihren Ortı, S. 136.

42 | Aurèle Stroë, film de Bernard Cavanna et Laurence Pietrzak. Production des Films d'ici. Version allemande sous-titrée. Aurèle Stroë 5e partie (dernière partie). 12:14 12:40. https://www.youtube.com/watch?v=4k5S0f6Y7cM vom 27.10.2016. 


\subsection{Robert Schumann: Kreisleriana. Fantasien für Piano-Forte OP. 16 (1838; ReV. 1850)}

\section{Praxis körperlichen Sich-Zeigens: Alles auf einmal}

\section{I}

Als Fantasien kommen diese Klavierstücke daher - und reihen sich so in eine große Zahl von Fantasie-Stücken ein, die Schumann im Laufe seines Lebens geschrieben hat, nicht nur für Klavier. Tatsächlich wirken gerade diese FantasieStücke wie eine aufs Papier hingeworfene Improvisation. Die Überfülle an Einfällen, an Gedanken und Bildern, Erinnerungen und Visionen sind hier leicht und flüssig aufs Notenblatt geflossen. Ein Alles-Auf-Einmal fügt sich in einen Verlauf von einem Anfang bis an ein Ende. Kreisleriana: Diese Komposition wird im Prozess der Ausführung eine Welt für sich. Musik aus dem Bauch heraus?

"In den Kreisleriana von Schumann höre ich eigentlich keine einzige Note, kein Motiv, kein Thema, keine Grammatik, keinen Sinn, nichts, was eine irgendwie geartete intelligible Struktur des Werks wiederherzustellen erlauben würde. Nein, was ich höre, sind Schläge: ich höre das, was im Körper schlägt, was den Körper schlägt, oder besser: Diesen Körper, der schlägt. « ${ }^{43}$

Barthes weiß, wie er spricht, hier hat herkömmliche Wissenschaft ein Ende:

"Wenn das Schreiben triumphiert, löst es die Wissenschaft ab, die unfähig ist, den Körper wiedereinzusetzen: allein die Metapher ist genau; und es würde ausreichen, Schriftsteller zu sein, um von diesen musikalischen Wesen, diesen körperlichen Schimären auf eine vollkommen wissenschaftliche Weise berichten zu können. “44

Der »Sinn« (Barthes) erschließt sich durch eine Einlassung auf diese Art von Körperlichkeit, durch die die Klaviertaste eine Verlängerung der Extremitäten des Spielers wird. ${ }^{45}$ Die Taste ist verlängerter Arm, verlängerter Finger. Die wiederum gehorchen den Zuckungen des Gehirns, folgen dem brain-storming

43 | R. Barthes: Rasch, S. 264.

44 | Ebd., S. 271; Herv. i.0.; vgl. M. Heinemann: Chopins Fragilität, S. 94. Heinemann schlägt, ebd., ausgehend von Barthes' Beitrag eine "Textpragmatik im Sinne einer historischen Semantik“ vor: "[D]enn der Text selbst vermag als Instanz hinlängliche Information auch über das biographische Subjekt zu eröffnen. Dies bedeutete den Versuch, Barthes' Beobachtungen und Erfahrungen zu kontextualisieren, zu objektivieren, mithin nichts anderes als hermeneutisch zu integrieren."

45 | Vgl. E.-M. Houben: gelb, S. 66: "Das Instrument wird Verlängerung, Erweiterung des Atems, der Stimme, des Körpers." 
im Kopf (oder folgt dieses den Zuckungen der Gliedmaßen?). Alles tritt simultan in Erscheinung: nicht zu bändigen.

II

Dissoziation: »Schläge«, von denen Barthes spricht, in der einen Hand, Überbindungen, Verschleierungen gleichmäßiger metrischer Akzente in der anderen. Gleich im ersten Klavierstück tun beide Hände Verschiedenes, sie sind unabhängig voneinander (vgl. Abb. 25).

Abbildung 25: Robert Schumann: Kreisleriana 1, Takte 1-2

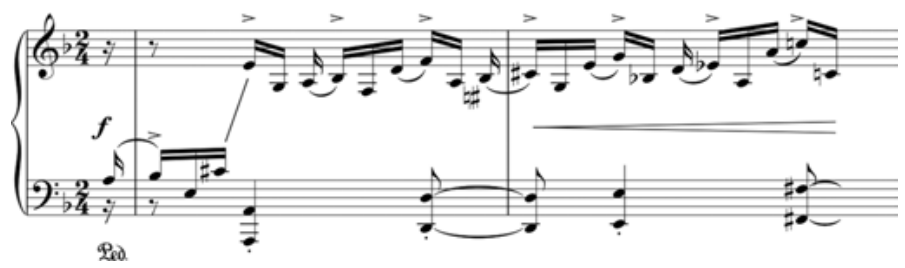

Höre ich im zweiten Klavierstück Stimmen, wenn ich spiele? Stimmen tauchen auf und verschwinden. Vorschläge und Arpeggien hüllen die Stimmen in einen Nebel. Eine Stimm-Führung gibt es nicht. Im dritten Stück (»Etwas langsamer«, Takt 33ff.) führen Tonleitern auf- und abwärts. Sie tauchen auf und enden irgendwo, erscheinen in der Höhe, in der Mittellage, in der Tiefe. Auch hier die Frage nach einer sogenannten Führung der Stimmen, die ein Eigenleben beanspruchen: Welche Stimme gerade beteiligt ist, bleibt im Unklaren. Tonleitern versanden irgendwo, oft übernimmt eine andere Stimme, eine andere Hand den Tonleiterverlauf, auch überschneiden sich Anfang der einen und Ende einer anderen Leiter.

Klänge werden von der Hand tastend so tief geführt, dass sie fast nur noch als Farbträger wirken. Dies ist zum Beispiel im vierten Klavierstück der Fall. Die Oktav- und Terzparallelen (Takt 3) in Verbindung mit dem Vorschlag, der zusätzlich chromatische Einfärbungen mit sich bringt, sind ganz dem Farbklang geweiht: farbige Tiefe (vgl. Abb. 26).

Abbildung 26: Robert Schumann: Kreisleriana 4, Takte 1-3

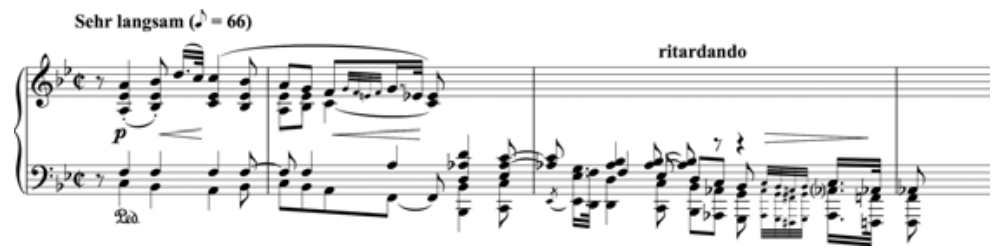


Pausen schlagen Löcher - wie im fünften Klavierstück. Linien werden immer wieder durch Pausen unterbrochen, Motivpartikel und einzelne Akkorde durch Pausen isoliert. Quere rhythmische Akzente, stellenweise auf jedem Viertel: Schläge wiederum, hier in zurückgenommener Dynamik. Im sechsten Stück wandert die schlichte Melodie aus dem Alt in den Tenor, in ein Unisono von Sopran und Tenor, um schließlich im Bass in Form einer Tonrepetition aufgegriffen zu werden (vgl. Abb. 27).

Abbildung 27: Robert Schumann: Kreisleriana 6, Takte 1-5
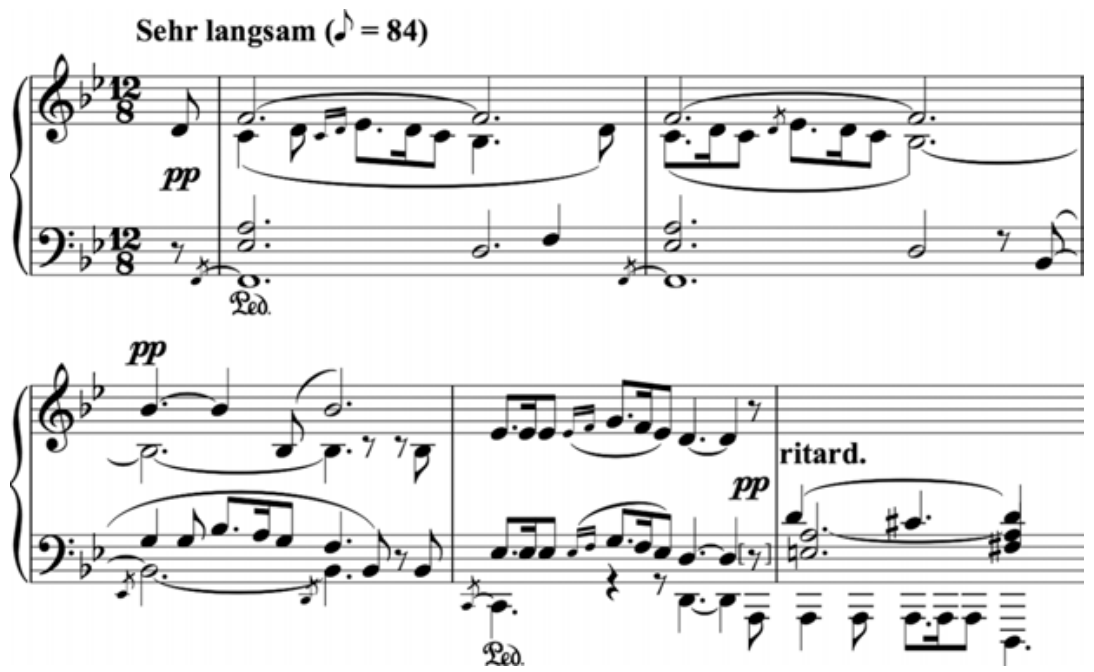

Verzicht auf Diastematik, Rückzug ins pure Klopfen. Äußerste Ent-Rückung einer Melodie. Ganz in die Ferne gerückt scheint die Melodie auf. Im weiteren Verlauf setzen sich die Wanderungen der Melodien durch die Stimmen fort. Imitationen sind Schumann als Erinnerung an Fugentechniken in die Finger geflossen. Das vorletzte, siebte Klavierstück ist eine Musik der Atemlosigkeit. »Sehr rasch« beginnt es - und diesmal setzen die Schläge tatsächlich auf den Hauptzählzeiten im Forte ein. Dann soll es noch schneller werden: fast nur noch Schläge. Das letzte Stück schließlich schwebt über lang ausgehaltenen Bässen, die immer mal wieder unvorhersehbar »ver-rückt « werden. ${ }^{46}$ Später treten Arpeggien an die Stelle der ausgehaltenen Bässe: Alles schwebt.

Einige Klavierstücke reißen am Schluss abrupt ab: Was nun? Wie geht es weiter?

Man könnte den gesamten Zyklus durchaus wie ein einziges großes Klavierstück spielen. Schumann hat hier viele kleinere Klavierstücke komponiert, die zusammen ein großes ergeben, welches dann, aus dieser Perspektive be-

46 | D. Schnebel: Rückungen - Ver-rückungen, S. 43-54. 
trachtet, eigener Verschachtelung folgt - nach den Bewegungen des Ausführenden, des Spielers, des Tasten-Schlagenden. Dieses Stück spielen, das bedeutet: Schumann zu werden. Dessen Körper wird lebendig im Körper des Spielers.

Hinzu kommen die Intermezzi. Das Intermezzo unterbricht. Warum? Damit es danach weitergehen kann. Womit? Mit etwas Neuem? Mit einem Alten, das verändert wurde? Der Unterbrechung haftet der Fortgang an: Das Intermezzo taucht auf - und die erste, hier unterbrochene Bewegung läuft weiter, wird nur eine Zeitlang unhörbar. Wer so hört und spielt, nähert sich dem Zugleich-Da-Sein der Schichten an. Hört und spielt: Wir sind zwar alle an die Sukzession gebunden beim Hören und Spielen, aber die hier unterbrochene andere Schicht klingt auch weiter. Es ist alles da. Aus dieser Perspektive erscheinen die aufblitzenden Wiederholungen in einem neuen Licht. Aus dem Strom der Fantasie taucht unvermittelt ein Vergangenes wieder (manchmal nur ganz kurz) auf, um erneut unterzugehen, aber unterschwellig weiterzulaufen.

Wenn ich Schumanns Kreisleriana spiele, zeigt sich Alles-auf-Einmal: Alles, was da ist.

\section{III}

Schumann pflegte in diesem Sinne eine Praxis, bei der alles Mögliche zutage treten durfte - durch den Körper. So entlastete er sich ${ }^{47}$, so machte er sich frei von Engen, Verfestigungen, Erstarrungen. Musik: eine Praxis zum Überleben. Praxis Kreisleriana: Warum, wozu auch? Vielleicht, um ganz Körper zu sein, die eigene Lebendigkeit zu spüren und zu leben, sich ins Menschliche und Verletzliche fallen zu lassen und diese Verletzlichkeit zu einer Lebensform zu machen.

47 | Vgl. Schnebel, ebd., S. 84: „Die Arbeit ist der Versuch einer vorsichtigen psychoanalytischen Deutung von Schumanns Leben und Werk, wobei die musikanalytischen Befunde einbezogen werden. Die analytische Interpretation insgesamt ergibt, wie Schumanns Bewältigung seines Innenlebens zu außerordentlichen Neuerungen in der Musik führte, und wie ihr Scheitern sich ebenfalls musikalisch auswirkte, so daß sich mannigfache Wechselwirkungen von Leben und Werk zeigen. Allerdings kann und will die Arbeit keine psychiatrische Beurteilung von Schumanns Lebenskrankheit geben." 


\subsection{LUIGI NONO: ......SOFFERTE ONDE SERENE... PER PIANOFORTE E NASTRO MAGNETICO (1976)}

\section{Pulsationen: Lebenszeichen. Tasten als Verlängerungen des Körpers, der Finger}

Die Partitur fordert zu einer Praxis kontinuierlicher Bewegung, kontinuierlicher Aufmerksamkeit heraus. Jede Berührung der Tasten, jedes Ertasten eingespielter Klänge mit den Ohren erfordert sogleich wieder ein Loslassen, ein Abschied-Nehmen. Es geht immer weiter. Der Klavierklang, der eingespielte wie der live ausgeführte, bebt und vibriert. Durch das Beben, durch die Bewegung und Vibration, wird er gehalten.

"What's about the sound of piano?

The sound of the piano decays.

It cannot be sustained. I let it loose time and again.

It appears by disappearing; starting to disappear just after the attack.

In disappearing it begins to live, to change.

The piano: an instrument, that allows me to hear how many ways sound can disappear.

There seems to be no end to disappearance.

The sound of piano!

I can hear, how listening becomes the awareness of fading sound. " 48

Klavierklang zerfällt, verschwindet, lässt sich nicht festhalten. Er erscheint im Verschwinden, verschwindet bereits wieder kurz nach dem Anschlag; färbt sich im Verklingen durch das Hervortreten bestimmter Partialtöne, gewinnt so im Verklingen neue Färbungen, neue Schattierungen.

Hier, beim Spielen von .....sofferte onde serene..., erfährt der Klavierklang immer wieder neue Fortsetzungen in den Tonrepetitionen: Bebungen, Vibrationen. Das Klavier wird hier weniger Körper, der sich berühren lassen will, im Sinne von »toucher « ${ }^{49}$, sondern eher Schlagwerk, das auch ganz zart und behutsam beklopft wird: »Die Finger/Die Hand als Expressionsorgan des Körpers $\ll^{50}$.

.....sofferte onde serene... ist Nonos einziges Werk für Klavier allein (mit Tonband-Einspielung allerdings). Der schwer ins Deutsche zu übersetzende Titel könnte in etwa heißen: ».....durchlittene Wellen heitere... «" ${ }^{51}$. Widmungsträger der Komposition sind Maurizio und Marilisa Pollini, Maurizio Pollini spielte

48 | E.-M. Houben: Presence - Silence - Disappearance, S. 1.

49 | M. Zenck: Vom Berühren der Klaviertasten, S. 130.

50 | Ebd., S. 126.

51 | J. Stenzl: Luigi Nono, S. 91; vgl. Doris Döpke: Booklet zur CD: "[D]ie ungewisse, 
die Uraufführung (17. April 1977, Mailand). Das Werk ist eng mit persönlichen Schicksalsschlägen in Nonos und Pollinis Familien verbunden (die Eltern Nonos und ein Kind in der Familie Pollini waren 1975/76 innerhalb kurzer Zeit verstorben $)^{52}$, was eine Erklärung für den Titel sein kann, der auf Nonos Heimat Venedig anspielt:

"In mein Heim auf der Giudecca in Venedig dringen fortwährend Klänge verschiedener Glocken, sie kommen mit unterschiedlicher Resonanz, unterschiedlichen Bedeutungen, Tag und Nacht, durch den Nebel und in der Sonne. Es sind Lebenszeichen über der Lagune, über dem Meer. Aufforderungen zur Arbeit, zum Nachdenken, Warnungen. Und das Leben geht dabei weiter in der durchlittenen und heiteren Notwendigkeit des 'Gleichgewichts im tiefen Inneren`, wie Kafka sagt. “ 53

Ein- und Ausschwingungen als »Lebenszeichen«? Praxis eines immer wieder neuen Loslassens und Fortsetzens als Über-Lebensform? Nono hat mit diesem Klavierstück ein Trauerstück für Pollini geschrieben, welches zu spielen der Trauer helfen kann, eine Form, ja, eine Fortsetzung zu finden. Das Stück zu spielen, kann helfen, weiter zu trauern: die Trauer und damit die Beziehung zum Verlorenen nicht aufzugeben. Das Zittern und Beben auf den Tasten wird zur Annahme und Anerkennung des inneren Bebens und Zitterns. Das Tonband, zugespielt von einem zweiten Aufführenden, trägt und unterstützt so die Aufrechterhaltung der Beziehung in der Trauer.

Wie kann man dieses Klavierstück nutzen? Dies ist wieder die Frage nach seiner Brauchbarkeit. Man übt dieses Stück nicht nur für einen Konzertauftritt, man übt vielmehr eine Praxis aus und nimmt die vom Klavierstück angebotene Gelegenheit wahr zu trauern, wenn man dies möchte.

schwebende Nuance, die die ungewöhnliche Wortstellung dem italienischen Originaltitel verleiht, ist nicht übersetzbar."

52 | Vgl. J. Stenzl: Luigi Nono, S. 91.

53 | D. Döpke: Booklet zur CD. 


\section{Viele}

Wenn Paul Bekker von der "gesellschaftbildende[n] Fähigkeit « ${ }^{1}$ der Symphonie Beethovens sprach, so hatte er die Ausführung der Vielen für Viele im Sinn. Der Raum der Symphonie ist der große Konzertsaal, ein Raum der Öffentlichkeit.

Viele: Das sind im Folgenden die vielen Ausführenden einer Symphonie, die solistisch auftretenden Ensemblemitglieder eines Kammerorchesters, das größere Bläserensemble, Einzelne im mehr oder weniger großen Gruppenverbund.

Es gibt immer eine "gemeinsame Situation $\aleph^{2}$ der Beteiligten, kraft der individuellen Unterschiede. Um mit Schütz weiter zu sprechen: Im Mit- und »selbst im Gegeneinander sind sie in einer gemeinsamen intersubjektiven Situation, in einem Wir, einander verbunden «. Zu beobachten sind Interaktion und Kommunikation, aber auch das Fehlen intendierter Bezugnahme aufeinander. Sinn entsteht in der gemeinsamen, miteinander geteilten Aufführungssituation, durch die Teilhabe am »Wir«. Die »Gesichtsfeldbeziehung « ${ }^{3}$ ermöglicht Teilhabe an den hörbaren und sichtbaren Handlungen der anderen Ensemblemitglieder.

1 | P. Bekker: Die Sinfonie von Beethoven bis Mahler, S. 11; Herv. i.0.

2 | A. Schütz: Mozart und die Philosophen, S. 172; das folgende Zitat ebd.

3 | A. Schütz: Gemeinsam musizieren, S. 129. 


\subsection{Anton Webern: Fünf Stücke für Orchester Op. 10, I (1911-1913) - Christian WOLFF: FOR 1, 2 OR 3 PEOPLE (1964)}

\section{Allein, zu zweit, zu mehreren im Gruppenverbund (1)}

I

Mit einer Untersuchung der Besetzung ist anzufangen, mit der Frage: Wie setzt sich die Gruppe zusammen, die diese fünf Orchesterstücke spielt? Walter Kolneder ging in seinen kurzen Einführungen zum Werk Anton Weberns, hervorgegangen aus diversen Vorträgen (1961), gleich zur Besonderheit der Besetzung über:

"Den Schlüssel zum Verständnis dieser Sätze [...] gewinnt man vielleicht von der Besetzung her, die deutlich in drei Gruppen gegliedert ist:

I Vier Streichinstrumente, d.i. Solo-Geige, Solo-Bratsche, Solo-Violoncello, SoloKontrabaß.

II Eine Bläsergruppe: Flöte (auch kleine Flöte), Oboe, Klarinette in B (auch Baßklarinette in B), Klarinette in Es, Horn in F, Trompete in B, Posaune.

III Eine Gruppe von ,Klangfarbeninstrumenten: Harmonium, Celesta, Mandoline, Gitarre, Harfe, Schlagwerk (Glockenspiel, Xylophon, Herdenglocken, tiefe Glocken, Triangel, Becken, kleine Trommel, große Trommel).

Es mag überraschen, die Schlaginstrumente in diese Gruppe einbezogen zu sehen, aber für Webern sind sie in diesem Werk kaum Rhythmusinstrumente, sondern [...] vorwiegend Klangfarbenträger. In gleicher Art sind auch die übrigen Instrumente dieser Gruppe verwendet. Der Einsatz dieser reichen Farbmittel erfolgt sehr sparsam: die sieben Bläser haben nur in Nr. II zu tun und auch da nie gleichzeitig, in Nr. I spielen vier Bläser, in Nr. III drei. Die Gitarre ist nur in Nr. III und V beschäftigt; das Harmonium schweigt in zwei Stücken und hat in Nr. III nur zwei Zweiklänge zu spielen; in Nr. IV ist das Schlagwerk ausgespart und nur die kleine Trommel beteiligt sich mit drei ppp-Schlägen." ${ }^{4}$

Jeder Ausführende spielt insgesamt wenige Klänge. Nicht-Spielen wird ebenso wichtig wie Spielen. In manchen Stücken schweigen einige Spieler gänzlich. Die Bezeichnungen »Solo-Geige«, »Solo-Bratsche«, »Solo-Violoncello« und »Solo-Kontrabaß« weisen darauf hin, dass je Einzelne in verschiedenen Konstellationen auftreten.

Im ersten Takt (mit Auftakt) des ersten Stückes gibt es ein fein strukturiertes Zusammenspiel von fünf Ausführenden. Die Harfe spielt die Töne $h^{1}$ $-\mathrm{c}^{1}-\mathrm{h}^{1}$, Trompete in B mit Dämpfer, Celesta, Bratsche und Flöte spielen mit - alle agieren auf unterschiedliche Weise. Wenn die Harfe mit dem letzten

4 | W. Kolneder: Anton Webern, S. $62 f$. 
Ton verklingt, fällt die Flöte mit Flatterzunge kurz ins Crescendo, fängt damit das Verklingen des Harfentons auf. Die Flöte übernimmt hier eine Aufgabe, welche die Harfe als verklingendes Instrument nicht erfüllen kann, nämlich ein Crescendo auf einem Ton zu spielen. Durch die Flatterzunge kommt unregelmäßige Energie ins Spiel, auch diese Akzentuierung bleibt der Harfe verschlossen. Die Trompete hilft der Harfe beim Einsatz. Harfe und Bratsche haben dann ein gemeinsames Flageolett. Die Ausführenden widmen sich nicht nur diesem speziellen Klang, sondern vor allem diesem Zusammenspiel (vgl. Abb. 28).

Abbildung 28: Anton Webern: Fünf Stücke für Orchester op. 10, I, Takt 1

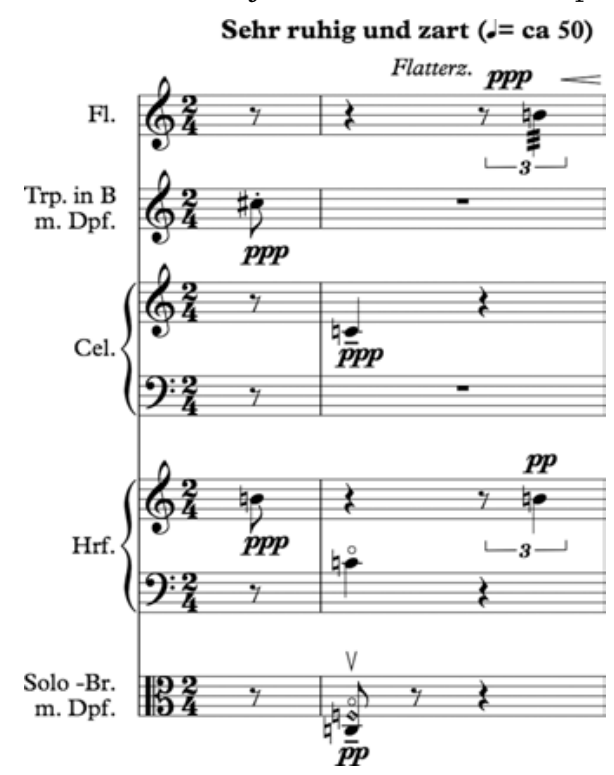

Anton Webern, 5 Stücke op. 10, für Orchester, op. 10/1

(c) Copyright 1923, 1951 by Universal Edition A.G., Wien/PH449

Im nächsten Takt ist das Glockenspiel allein - und fängt, »dolcissimo « und im Decrescendo, die Bewegung auf. In den Takten 5 bis 6 (mit Auftakt) spielen Geige und Bratsche, beide mit Dämpfer, zusammen mit der Harfe. Das Violoncello fängt diesmal die Bewegung auf wie vorher das Glockenspiel. Dazwischen sind andere tätig: Der Ton $b^{1}$ in der Flötentriole berührt kurz Geige, Bratsche und Harfe, die Flöte gehört aber zum Duo, das sie zusammen mit der Klarinette bildet. In den Takten 7 und 8 verbindet sich die Geige mit dem Violoncello zu einem Duo. Seinen vierten Ton in diesem ersten Stück spielt das Glockenspiel in Takt 9 im Oktavunisono mit der Geige. Das Glockenspiel kann 
den Ton nicht halten, es verklingt. Aber die Solo-Geige kann den Ton halten, kann das Verklingen hinauszögern und immer leiser werden (vgl. Abb. 29).

Abbildung 29: Anton Webern: Fünf Stücke für Orchester op. 10, I, Takte 9-10

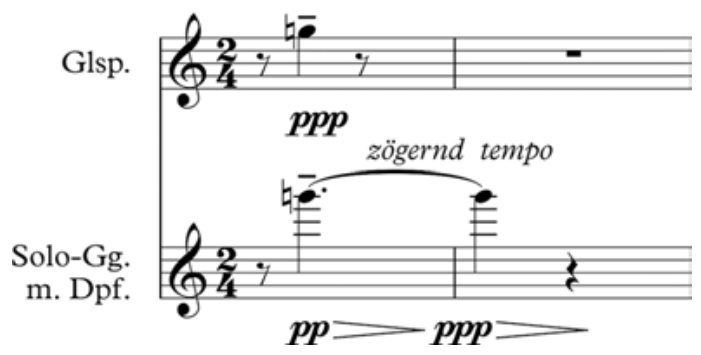

Anton Webern, 5 Stücke op. 10, für Orchester, op. 10/1

(C) Copyright 1923, 1951 by Universal Edition A.G., Wien/PH449

Dem Glockenspiel kommen demnach zwei unterschiedliche Tätigkeiten zu: einmal die ersten drei Töne zeitlich relativ frei allein, dann den vierten Ton genau mit der Geige zusammen zu spielen.

In Takt 9 sind Harfe und Trompete zusammen, am Schluss bilden Flöte, Trompete und Celesta ein Trio; derselbe Ton wandert von der Flöte zur Trompete, diese gibt weiter an die Celesta: ein gemeinsam erzeugtes Verklingen (vgl. Abb. 30).

Abbildung 30: Anton Webern: Fünf Stücke für Orchester op. 10, I, Takt 12

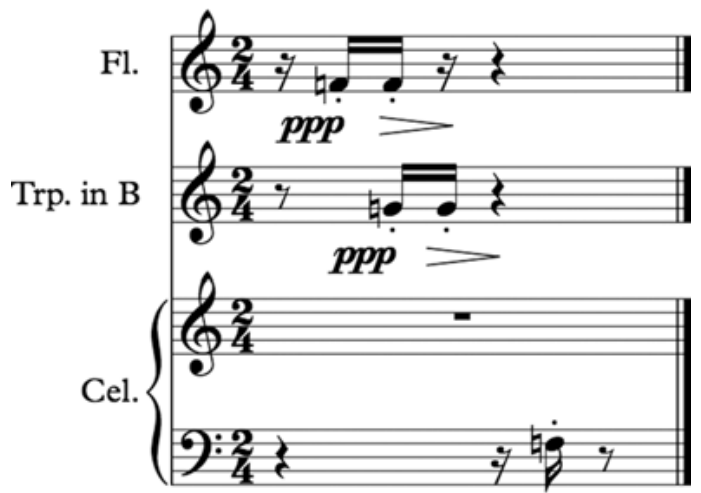

\section{ppp}

Anton Webern, 5 Stücke op. 10, für Orchester, op. 10/1

(c) Copyright 1923, 1951 by Universal Edition A.G., Wien/PH449 
Der Celesta kommt ab Takt 3 eine Aufgabe zu, die sonst nicht gefordert wird, nämlich eine Trillerbewegung auszuführen.

Dieses erste Orchesterstück kann, wie alle anderen aus diesem Zyklus, aus der Funktion eines einzigen Instruments, also aus der Perspektive eines Ausführenden gehört werden. Je nachdem, welches Instrument ich gerade übernehme, orientiere ich mich anders. Die Klarinette kommt hier nur zu Beginn vor, als Duo-Partner der Flöte. Ab dann ist sie hörend mit dabei. Die ganze Aufmerksamkeit des Glockenspiels richtet sich auf das Zusammenspiel mit der Geige, wenn beide gemeinsam den gleichen Ton spielen.

So hat Webern unterschiedliche Orte und unterschiedliche Weisen der Kommunikation zusammengefügt, dabei werden alle Mitspieler in diesem Stück gleichermaßen, aber verschiedenartig berücksichtigt.

Wie verhält sich diese Gesellschaft im Stück zu der Lebenswelt außerhalb der Komposition, jenseits der Schwelle zur alltäglichen Lebenswelt? Kann dieses Stück für unser Leben miteinander jetzt einen Ort anbieten und eine Perspektive eröffnen? - kann es mithin für uns heute brauchbar sein?

\section{II}

In einem Gespräch mit Gerald Gable (»I can't shake Webern's influence « - »Ich kann Weberns Einfluß nicht abschütteln«) berichtet Christian Wolff über die frühen 5oer Jahre: »Ich traf Cage 1950, als ich sechzehn Jahre alt war. Tatsächlich war er mein erster und eigentlich einziger richtiger Lehrer. [...] Wir analysierten Webern. $\aleph^{5}$ Auch die Bekanntschaft mit Morton Feldman, der bei Stefan Wolpe studiert hatte ${ }^{6}$, trug zur Webern-Begeisterung bei; später traten David Tudor und Earle Brown hinzu. Wolff: »Das Denken und die Musik von Cage übten einen sehr starken Einfluß auf mich aus. Die Webern-Erfahrung ging sehr tief. Ich fuhr mit dem Studium fast aller seiner Werke fort und schrieb auch darüber. Ich kann Weberns Einfluß nicht abschütteln. «7

Die Komposition For 1, 2 or 3 people ist zehnteilig, ein Teil ist auf je einer Seite notiert. Es ist eine Komposition nicht für bestimmte Instrumente, sondern ausdrücklich für Spieler. Das auf einer Seite angegebene Material ist in freier Reihenfolge zu spielen, nichts soll wiederholt werden (Ausnahme: Teil IX). Die Spieler sind frei hinsichtlich des Tempos und der Klangdauern, in der Partitur ist vermerkt, dass schwarze Noten kurze Klangdauern bedeuten (mit Hälsen und Sechzehntel-Fähnchen sogar sehr kurze), weiße Noten eher lange. Falls zwei oder drei spielen, teilen sie das Material jeweils einer Seite auf. Bei einem besonderen Zeichen ist ein Spieler zur Koordination mit dem

5 | Chr. Wolff: "I can't shake Webern's influence “. Interview by Gerald Gable, in: Ders., Cues, S. 156-175, hier S. 165.

6 | Ebd.

7 | Ebd., S. 167. 
Klang oder dem Geräusch eines anderen Spielers aufgerufen. Wird das Stück von einem Spieler allein aufgeführt, tritt er in Koordination zu einem Klang oder Geräusch in der Umgebung oder zu einem Klang, den er unabsichtlich selbst hervorgebracht hat. ${ }^{8}$ »Diese Musik entsteht aus den wechselseitigen Beziehungen der Musiker, die sie spielen. «" Eine Aufführung verlangt von den Musikern ein hohes Maß an Entscheidungsfähigkeit und Reaktionsvermögen.

Im folgenden Beispiel aus Teil II (vgl. Abb. 31) beginnt ein Spieler zu spielen, nachdem ein vorhergehender Klang begonnen hat, hält dann seinen Klang weiter über das Ende des vorherigen Klangs hinaus, so lange, bis ein anderer Klang beginnt, und endet, bevor dieser andere nachfolgende Klang endet. ${ }^{10}$

Abbildung 31: Christian Wolff: For 1, 2 or 3 people, Teil II (Ausschnitt)

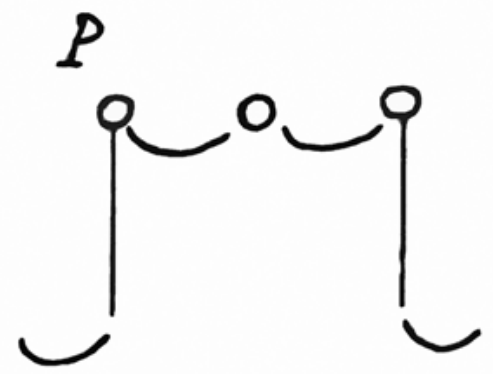

(C) C.F. Peters Corp, New York. Abdruck mit freundlicher Genehmigung C.F. Peters Ltd \& Co. KG, Leipzig

Ist dies eine Musik nur für die Ausführenden? Sicherlich bleiben Entscheidungsprozesse und Gedanken eines Ausführenden dem Hörer verborgen, dieser hört die entstehenden Klangverbindungen. Diese aber transportieren die Kommunikationsprozesse, führen diese implizit mit sich. Der Hörer mag so schnell keine sprachlichen Umschreibungen (etwa im Sinne von »demokratischer gegenseitiger Abhängigkeit « ${ }^{11}$ ) finden: Der Prozess, der zu dieser oder jener spezifischen Klangkonstellation geführt hat, bleibt ihm dennoch nicht verborgen.

8 | Chr. Wolff: For 1, 2 or 3 people, Partitur, Instructions.

9 | Chr. Wolff: For One, Two or Three People (1964), Werknotiz, in: Ders., Cues, S. 493.

10 | Vgl. Chr. Wolff: For 1, 2 or 3 people, Partitur, Instructions.

11 | Chr. Wolff: For One, Two or Three People (1964), Werknotiz, in: Ders., Cues, S. 493. 


\subsection{Wolfgang Amadeus Mozart: Serenade in B ("Gran Partita") (KV 361), Largo/Molto allegro - AdAGIO (VERMUTLICH 1783-84')}

\section{Allein, zu zweit, zu mehreren im Gruppenverbund (2)}

I

Mit oder ohne Dirigent?

»Gran Partita«, 3. Satz Adagio ${ }^{13}$ : Das Ensemble (University of Michigan Symphony Band Chamber Winds) wirkt sehr homogen, die dreizehn Ensemblemitglieder (zwei Oboen, zwei Klarinetten, zwei Bassetthörner, vier Hörner, zwei Fagotte und Kontrabass) sind insgesamt auf den Dirigenten (Michael Haithcock) ausgerichtet. Die Ausführenden sitzen.

»Gran Partita«, 1. Satz Largo/Molto allegro ${ }^{14}$ : Die Koordination kommt über den Dirigenten Ivan Meylemans zustande. Der Klang des Ensembles (Danmarks Radio Symfoni Orkestret) wird vereinheitlicht.

»Gran Partita«, 1. Satz Largo/Molto allegro, ausgeführt vom Ensemble Zefiro ${ }^{15}$ : Alle spielen stehend, ohne Dirigent. Der Kontrabass ist in der Mitte aufgestellt, rechts und links von ihm stehen die Bläserpaare: Oboen I und II ganz links, Bassetthörner I und II daneben; dann, auf der rechten Seite (vom Zuhörer aus) die Fagotte I und II, daneben, noch weiter rechts, die Klarinetten I und II. Die Hörner verteilen sich auf zwei Paare, stehen hinter den Bläserpaaren rechts und links vom Kontrabass. Sie spielen auf Originalinstrumenten.

Es fällt sofort auf, dass das Ensemble Zefiro eine andere Praxis als die beiden anderen verfolgt. Ohne zentrale Ausrichtung auf einen Dirigenten sind die Musiker aufeinander bezogen. Beim Spiel des Ensembles Zefiro gibt es körperliche Hinwendungen und Zuwendungen zueinander, Kommunikationsstrukturen; die Phrasen der Musik finden Entsprechungen in den Bewegungen der Körper.

12 | W. A. Mozart: Serenade in B, Partitur, S. 141.

13 | University of Michigan Symphony Band Chamber Winds. Conductor: Michael Haithcock. February 17, 2012. https://www.youtube.com/watch?v=LLpBkIhIO2c vom 15.11.2016.

14 | Danmarks Radio Symfoni Orkestret - Ivan Meylemans. https://www.youtube.com/ watch?v=3ES0Sc84RSw vom 15.11.2016.

15 | Zefiro Ensemble Mozart Gran Partita. W.A. Mozart Gran Partita KV 361/370a - 1: Largo, Molto allegro - Amsterdam - November 2011. https://www.youtube.com/watch ?v=HFf5W1VjJvQ\&list=PLDBB1EC5701C8FF7D vom 15.11.2016. 
II

Largo/Molto allegro: Der Einsatz in Takt 1 ist hier kein Dirigenteneinsatz, sondern Ergebnis eines Kommunikationsvorgangs. In den ausgehaltenen ersten Klang tritt die Klarinette I ein - und kommt dann solistisch hervor (Takt 1, dann wieder Takte 2-3). Die anderen Ensemblemitglieder haben die Aufgabe, dem Solisten die Tür zu öffnen. Zu hören (und zu sehen) ist eine Art Zurückweichen; auf diese Weise tritt der Solist in Erscheinung, ohne hervorzutreten (vgl. Abb. 32).

Abbildung 32: Wolfgang Amadeus Mozart, Serenade in B, 1. Satz, Takte 1-3

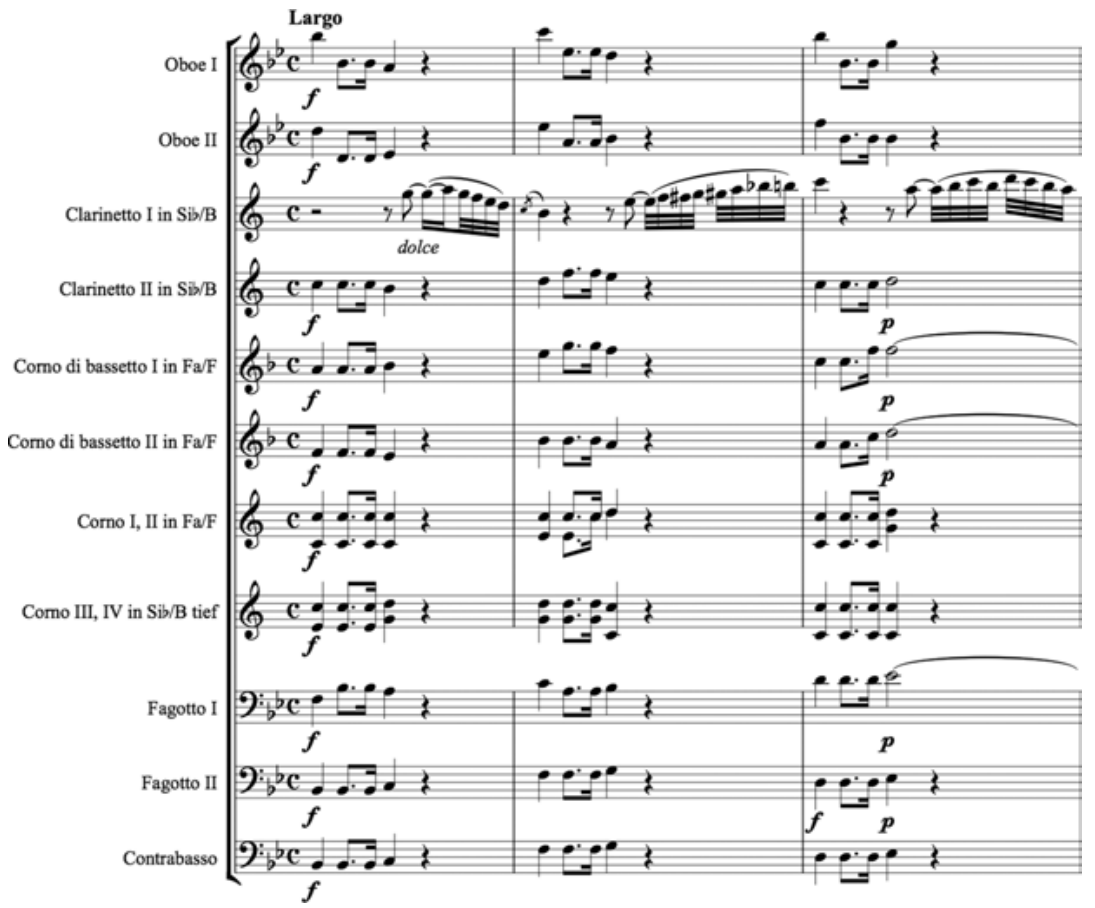

Die Gruppe schenkt dem Einzelnen Raum. Nach dem dritten Auftreten (Takt 3) folgen dem Solisten (Klarinette I) Klarinette II und Fagott I; jetzt zeigen sich weitere Beziehungen.

Bei der Synkopenbewegung zwischen Oboe I und Bassetthorn I (Takte 5-6) sind die beiden Musiker in der Ausführung des Ensembles Zefiro intensiv aufeinander bezogen (vgl. Abb. 33). 
Abbildung 33: Wolfgang Amadeus Mozart, Serenade in B, 1. Satz, Takte 5-6

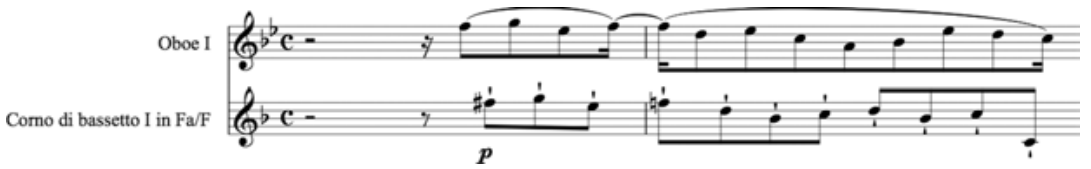

Sie bilden ein Duo, das auf eine bestimmte Weise in ein Kommunikationsgeschehen eingetreten ist. Die Partitur bietet viele ähnliche Gelegenheiten für Begegnungen, die sich beim Spielen tatsächlich ereignen und sich dann auch einem Zuhörenden mitteilen. Wir hören Ausführende spielen.

Dem ersten Duo folgen unterschiedliche Gruppen- und Paarbildungen (vgl. Abb. 34).

Abbildung 34: Wolfgang Amadeus Mozart, Serenade in B, 1. Satz, Takte 23-27

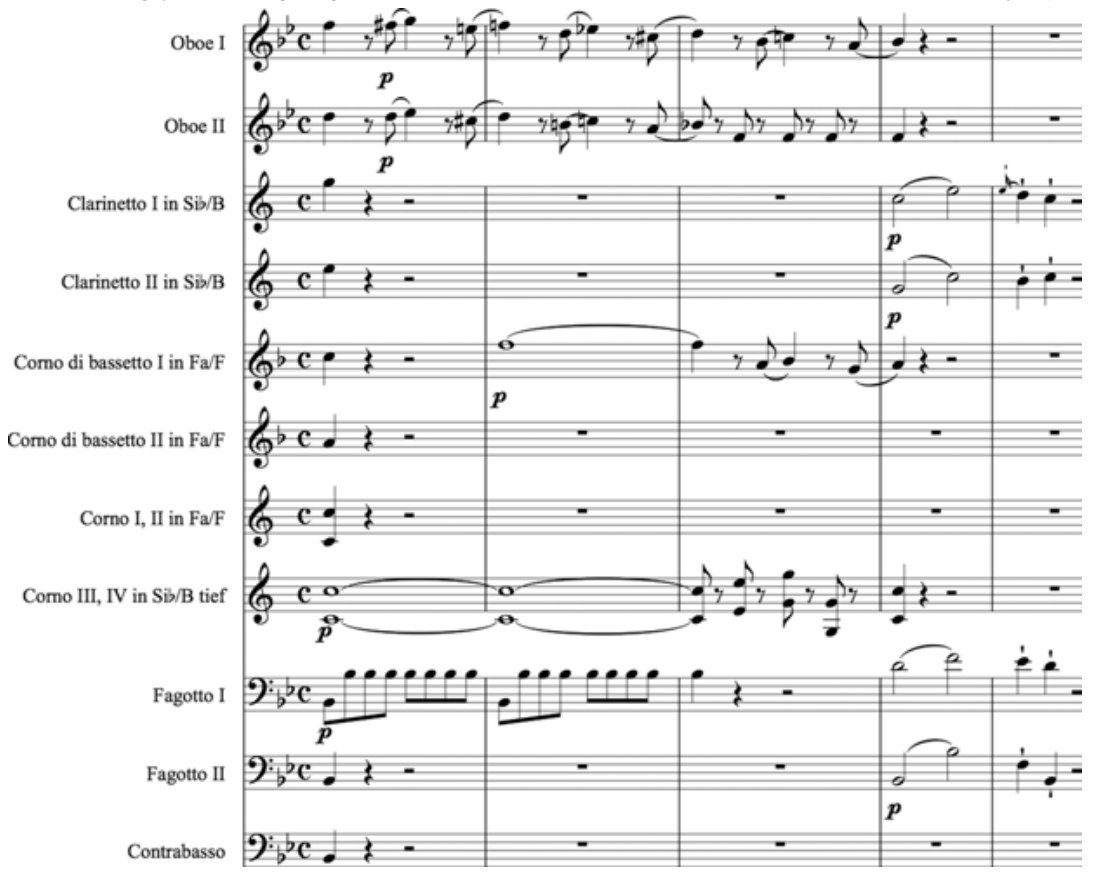

Die beiden Oboisten bilden ein Duo, währenddessen spielen die beiden Hornisten (III und IV) einen Liegeklang, Fagott I eine Tonrepetition (Takte 23-24). Sehr bald übernimmt Bassetthorn I die Figur der Oboe I, während Oboe II die Tonrepetition spielt. Der Rollenwechsel kündigt sich mit dem Liegeklang des Bassetthorns I für alle merkbar an.

Im weiteren Verlauf gibt es Varianten solcher Kommunikationen. Die Kommunikation der Spieler wird über Atemenergien möglich; alle sind ja Bläser, 
außer dem Kontrabass, dem eine ganz eigene Rolle in dieser Gemeinschaft zukommt. So entsteht ein differenziertes, dynamisches Netz von Beziehungen.

Die vier Hörner haben, anders als die Duos, stützende Funktion. Sie wirken als bindende Kraft, setzen Akzente. Der Kontrabass in der Mitte gibt der ganzen Gruppe in ihrer Dynamik Halt. Dieser reiche Beziehungsschatz dient also nicht nur der Entstehung eines klanglichen Geschehens, sondern lässt erleben, wie die Spieler dort einander begegnen. $\mathrm{Zu}$ hören ist, was zwischen (diesen) Menschen passiert, was zwischen Menschen möglich ist: Praxis.

II

Adagio (3. Satz, Es-Dur): Aus jedem der vier Paare (zwei Oboen, zwei Bassetthörner, zwei Fagotte, zwei Klarinetten) tritt einer im Solo auf, der andere ist an der Pulsation beteiligt (vgl. Abb. 35).

Abbildung 35: Wolfgang Amadeus Mozart, Serenade in B, 3. Satz (Es-Dur), Takte $1-5$

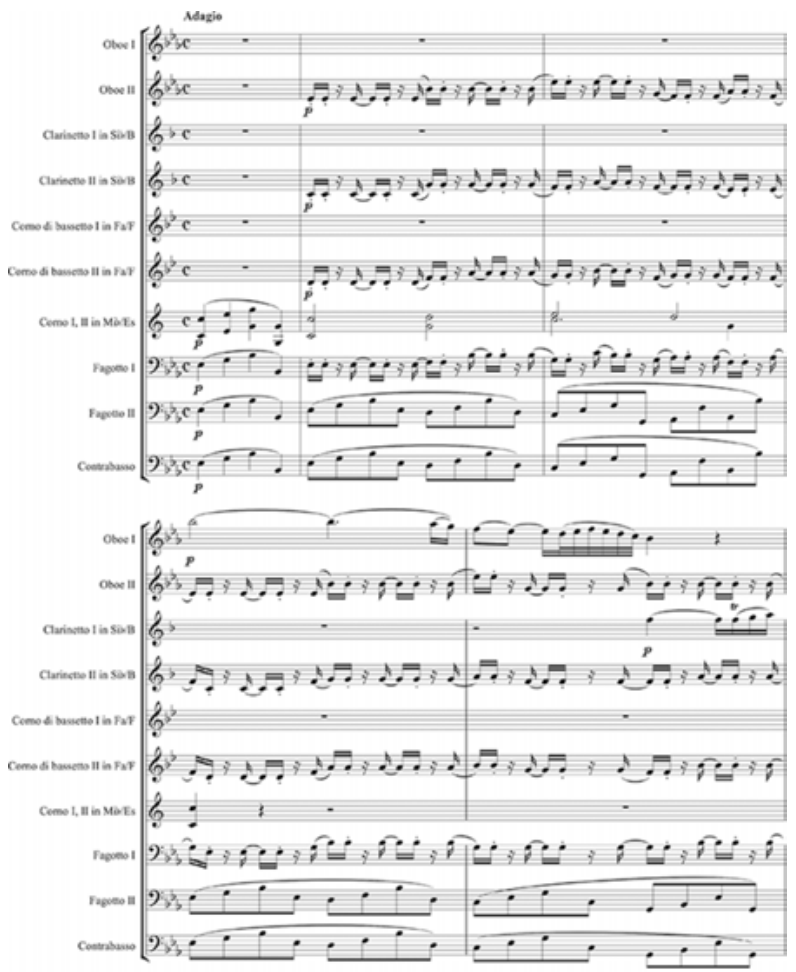

Diese Pulsation durchdringt den gesamten Satz, wird fortlaufend aufrechterhalten. Selbst gegen Schluss (Takt 42), wenn die Holzbläser die Pulsation unterbrechen, wird diese von den Hörnern aufgegriffen und weitergeführt. So 
gibt es zwei Zeitschichten, einmal die gemeinsame Pulsation, dann die solistischen Partien. Zuerst tritt Oboe I in Erscheinung, Oboe II beteiligt sich an der Pulsation. Dann übernimmt Klarinette I das Solo, ihr folgt Bassetthorn I; dann wieder tritt Klarinette I solo auf, ihr folgt Oboe I solo (Takte 4-11). Es folgt ein Trio zwischen Bassetthorn I, Klarinette I, Oboe I, grundiert von der Pulsation und der stützenden Achtelbewegung (Fagott II, Kontrabass). Die Hörner stehen dem Geschehen beobachtend und begleitend zur Seite, ihm Stabilität und Bindekraft verleihend.

$\mathrm{Zu}$ erleben ist bei dieser Praxis, wie man als Duo, als Paar in einer Gemeinschaft mitwirken kann. Ein Paar muss sich nicht erst von der Gruppe trennen, um ganz Paar zu sein. Im Gegenteil: Das Paar findet zu sich selbst gerade erst in dieser Gemeinschaft. Auch der Einzelne für sich findet Raum - alle hören zu. In Erscheinung tritt, wie sich Begegnungen ereignen.

\subsection{Ludwig van Beethoven: Symphonie NR. 5 C-moll op. 67 (UA 22.12.1808)}

\section{Einzelner und Gruppenverbund: das Recht, in Erscheinung zu treten - die Verheißung und die Herausforderung des Wir}

I

An der Ausführung durch das Orchestre Révolutionnaire et Romantique unter der Leitung von John Eliot Gardiner fällt zuerst auf: Sie stehen. ${ }^{16}$ Die meisten Musiker sind ungewohnt engagiert. Eine Art Atemlosigkeit begleitet das Spiel von Anfang bis Ende, bis es sich in überschäumendem Jubel im letzten Satz nahezu überschlägt. Den Musikern passiert etwas - und auch dem Publikum, das vielleicht ebenfalls stehen müsste. Es sind so viele da: Eine Orientierung wie im (mehr oder weniger großen) Ensemble gelingt hier nicht. Viele Streicher sind beteiligt, Bläser treten oft als Einzelne hervor: Wie kann hier Zusammenhalt zustande kommen? Die Funktion des Dirigenten? Dieser verschwindet fast, wenn alle stehen. Er findet einen Platz fast inmitten der Musiker, ist einer von ihnen. Wucht geht von der unüberschaubaren Gemeinschaft aus, die auf der Suche nach neuem Zusammenhalt ist. Diese Gruppe schafft eine Vermittlung zwischen dem Einzelnen und den Vielen. Hier und jetzt entsteht neue Wirklichkeit. Die Symphonie ist fast zu Ende, doch wachsen immer noch Paare und Einzelne aus dem Gruppenverbund heraus (4. Satz, ab Takt 318): Fagotte zu zweit, Hörner zu zweit, dann Flöte allein, Klarinette, Fagott allein; dann Flöte, Oboe, Klarinette, Fagott im Quartett mit den Streichern (und den

16 | John Eliot Gardiner conducts Orchestre Révolutionnaire et Romantique. https:// www.youtube.com/watch?v=zk01dTrEtRc vom 16.11.2016. 
Hörnern); schließlich die vier im Quintett mit der Piccoloflöte. Die Symphonie ist ein soziales Geschehen, eine gemeinsame Selbst-Vergewisserung. Diese Praxis schließt das Publikum mit ein: die Vielen.

\section{II}

Unüberhörbar die Anklänge an die Französische Revolution! Abgesehen von der Instrumentation des Finales (Verstärkung des Orchesters durch drei Posaunen, Piccoloflöte und Kontrafagott): Thematisch-motivische Verflechtungen mit Revolutionsthemen stellen Bezüge her. ${ }^{17}$ Aufschlussreicher als analytische Details scheint mit Blick auf Praxis der Hinweis Martin Gecks auf den Versammlungscharakter einer Symphonie-Aufführung zu sein:

„Paul Bekker vertritt die Auffassung, daß seit Beethoven , die Aufführung einer Sinfonie gleichbedeutend mit einer musikalischen Volksversammlung، sei - - einer Versammlung, in der ein durch die Musik zum Ausdruck gelangendes Gemeingefühl lebendig und tätig، werde." ${ }^{18}$

Theodor W. Adorno machte für die Symphonien Beethovens den jeweiligen Redecharakter geltend:

"Die Beethovenschen Symphonien waren, objektiv, Volksreden an die Menschheit, die, indem sie ihr das Gesetz ihres Lebens vorführten, sie zum unbewußten Bewußtsein jener Einheit bringen wollten, die den Individuen sonst in ihrer diffusen Existenz verborgen ist. ${ }^{19}$

Er war offensichtlich beeindruckt von Paul Bekkers Beschreibung der Symphonie Beethovens als »Rede $\ll .{ }^{20}$ In seinem Aufsatz »Was Symphonien vom Beethovenschen Typus im Lautsprecher widerfährt« setzte Adorno sich mit Bekkers These hinsichtlich der »'gesellschaftsbildenden Kraft«« der Symphonie auseinander, wenn er diese These auch angreift, weil aus seiner Sicht »Musik, seit sie irgend rationalisiert und geplant ward, kein unmittelbarer Laut mehr ist, sondern in gesellschaftliche Zustände eingepaßt sich findet und in ihnen fungiert. $\ll^{21}$

17 | Vgl. M. Geck: Von Beethoven bis Mahler, S. 38f.

18 | Ebd., S. 40; vgl. P. Bekker: Die Sinfonie von Beethoven bis Mahler, S. 15.

19 | Th. W. Adorno: Einleitung in die Musiksoziologie, S. 281.

20 | Vgl. P. Bekker: Beethoven, S. 201.

21 | Th. W. Adorno: Beethoven, S. 174-179, hier S. 175. Auszug aus: Ders.: Über die musikalische Verwendung des Radios, in: Der getreue Korrepetitor. Lehrschriften zur musikalischen Praxis. Gesammelte Schriften Bd. 15, Frankfurt am Main: Suhrkamp 1997, S. 369-401, hier S. 376. 
Bekker sprach in seinem Vortrag »Die Sinfonie von Beethoven bis Mahler« (1917) von der »gesellschaftbildende[n] Fähigkeit des Kunstwerks«, von der »gesellschaftbildende[n] [sic!] $\mathrm{Kraft}^{22}{ }^{22}$ :

"[D]ie sinfonische Gattung ist für den schaffenden Musiker das Mittel, sich durch die Instrumentalmusik einem großen Hörerkreise mitzuteilen. Aus der Vorstellung dieses Hörerkreises heraus konzipiert er das Werk und gestaltet er es im einzelnen. Er komponiert also nicht nur das, was in der Partitur deutlich zu lesen steht, er komponiert auch gleichzeitig ein ideales Bild des Raumes und der Hörerschaft. " ${ }^{23}$

Von hier aus sind Bekkers Ausführungen zur Gemeinschaft zu verstehen, die im Vollzug der Ausführung eine solche wird:

"[Im] Gemeinschaftserlebnis, nicht in dem sogenannten musikalischen Reiz dieses oder jenes Themas liegt der Zauber und die Bedeutung seiner [Beethovens] Kunst. [...] Das Kriterium der großen sinfonischen Kunst liegt [...] nicht in der nach fachlichen Begriffen festzustellenden 'Schönheitı der Faktur oder der Erfindung, es liegt überhaupt nicht in irgendeiner Eigenschaft dessen, was wir als das 'Kunstwerkı im engeren Sinne zu bezeichnen pflegen. Es ist die besondere Art und das Maß der Kraft, in der dieses Kunstwerk Gefühlsgemeinschaften zu bilden vermag, also seine Fähigkeit, aus der chaotischen Publikumsmasse ein einheitliches, bestimmt individualisiertes Wesen zu schaffen, das sich im Augenblick des Hörens, des Kunsterlebens als unteilbare, von gleichen Empfindungen bewegte, gleichen Zielen zustrebende Einheit erkennt. Erst diese gesellschaftbildende [sic!] Fähigkeit des Kunstwerks bestimmt seine Bedeutung und seinen Wert. Die Kraft des Gesellschaftbildens also bezeichne ich als die höchste Eigenschaft des sinfonischen Kunstwerks. ${ }^{24}$

»Reden an die Nation, Reden an die Menschheit könnte man die Symphonien [Beethovens] nennen. ${ }^{25}$ Wulf Konold knüpft an diese Thesen an:

"Beethovens 5. Sinfonie ist [...] beides zugleich: sie ist autonomes Kunstwerk, und sie ist ,fait socialı, ist historische Stellungnahme, hat Appellcharakter, und sie ist - und das hebt sie über die anderen Werke hinaus - das eine durch das andere. Gerade in ihrer Autonomie, in ihrem Verzicht auf aktuelle Stellungnahme in politischem Sinn liegt ihre gesellschaftliche Aktualität". ${ }^{26}$

22 | P. Bekker: Die Sinfonie von Beethoven bis Mahler, S. 11; Herv. i.0.

23 | Ebd., S. 8; Herv. i.0.

24 | Ebd., S. 11; Herv. i.0.

25 | P. Bekker: Beethoven, S. 201.

26 | W. Konold: Einführung und Analyse, S. 191f.; vgl. Th. W. Adorno: Ästhetische Theo- 
»Historische Stellungnahme« ist dieses Werk auch durch die entschiedene Reflexion der Bedingungen und Möglichkeiten des Komponierens selbst. Das Spannungsfeld zwischen individueller Setzung und historisch sowie gesellschaftlich präformiertem Material kann nur aufgebaut werden durch eine »historische Positionsbestimmung ${ }^{27}$, wie sie Beethoven getroffen hat. Beethoven stellt selbstbewusst die Frage nach seinem Platz im »Koordinatensystem der Geschichte ${ }^{28}$, reflektiert so die eigenen »ästhetischen Mittel und Erfahrungskategorien $\ll^{29}$, die sich während des Kompositionsprozesses als veränderbare zeigen.

Musik kann gesellschaftliche Kraft auf musikalische Weise entwickeln, ohne Programm, ohne Text, ohne Titel - kraft ihres Da-Seins als Praxis. Musik ist nur unter Menschen existent, wenn diese sie in Atemlosigkeit und Sprachlosigkeit, mit Staunen und Begeisterung ausführen und erleben. Eben diese Handlungsvollzüge, die sich wiederholen lassen, und das lebendige Geschehen selbst ermöglichen »gesellschaftliche Aktualität« (Konold). Die kulturellen Kontexte ändern sich wie die Rezeptionsweisen. Eine Komposition in Zeitgenossenschaft hereinzuziehen, heißt: deren Brauchbarkeit immer wieder aufs Neue zu entdecken und ihr Angebot zu einer aktuellen Praxis anzunehmen, die Sinn ergibt und zu Wiederholungen einlädt.

II

Beethoven behauptet mit dieser Symphonie Individualität als Komponist, indem er von innen her das Regelwerk angeht; er bleibt in der Form, aber geht gegen die Form vor; er kann sich auf ein etabliertes System stützen, aber treibt es bis an die Grenze, wo es zerbrechen würde, und wird dort zum Subjekt. Dennoch bewahrt die Symphonie ihren Charakter als Rede für alle, als Ansprache und »Appell«:

"Ihre Bedeutung liegt vielmehr in zwei Momenten: zum einen in der radikalen Individualisierung des tradierten Formschemas, das nurmehr die Hülle für einen unverwechselbaren Gehalt bildet; zum anderen im Einsatz der Instrumentalmusik als Sprache, als Appell an die bürgerliche Öffentlichkeit als Träger und Adressat dieser sich bewußt als öffentlich verstehenden Gattung Sinfonie. ${ }^{30}$

rie, S. 335: "Ist Kunst, ihrer einen Seite nach, als Produkt gesellschaftlicher Arbeit des Geistes stets fait social, so wird sie es mit ihrer Verbürgerlichung ausdrücklich.“

27 | E.-M. Houben: Das Alte ist vergangen, S. 60.

28 | Ebd.

29 | H. Lachenmann: Zum Verhältnis Kompositionstechnik - Gesellschaftlicher Standort, S. 95.

30 | W. Konold: Einführung und Analyse, S. 193. 
In den Jahren nach den ersten beiden Symphonien setzt Beethoven sich intensiv mit der Gattung der Symphonie auseinander, auch durch die Arbeit an mehreren Werken gleichzeitig, und versucht, ganz neu zu bestimmen, wie es kompositorisch weitergehen könnte. Geck spricht von dem Unterfangen, »das Wesen des Symphonischen neu [zu] definieren«: »Es geht um die Dialektik von Konventionen und Originalität, Form und Inhalt, kompositorischer Struktur und poetischer Idee, Durchgeistigung und orchestraler Klangvorstellung. «11 Die Konventionen und tradierten Formen bieten den notwendigen Widerstand, sodass das Individuelle aufscheinen kann.

Auf dieser Grundlage kann die Symphonie in ihrem Vollzug Ereignis für jeden Einzelnen werden, der sich in der Emanzipation des Ichs wiederfinden kann. Im festlichen Konzertsaal, der den Prunk höfischer Umgebung nachbildet, kann das Individuum seine neu entdeckte Subjektivität feiern.

Dass sich jetzt ein Orchester dieser Dialektik stellt und die Symphonie ausführt, bedeutet Verkörperung des Spannungsverhältnisses von Besonderem und Allgemeinem, denn dies wird im Zuge der Ausführung wirklich ausgetragen. Und die Klänge, die auf diese Weise zustande kommen, in solcher Atemlosigkeit und mit solchem Esprit, haben diese Spannung in sich aufgenommen und tragen sie weiter.

Abbildung 36: Ludwig van Beethoven: Symphonie Nr. 5 c-moll op. 67, 1. Satz, Takte 1-5
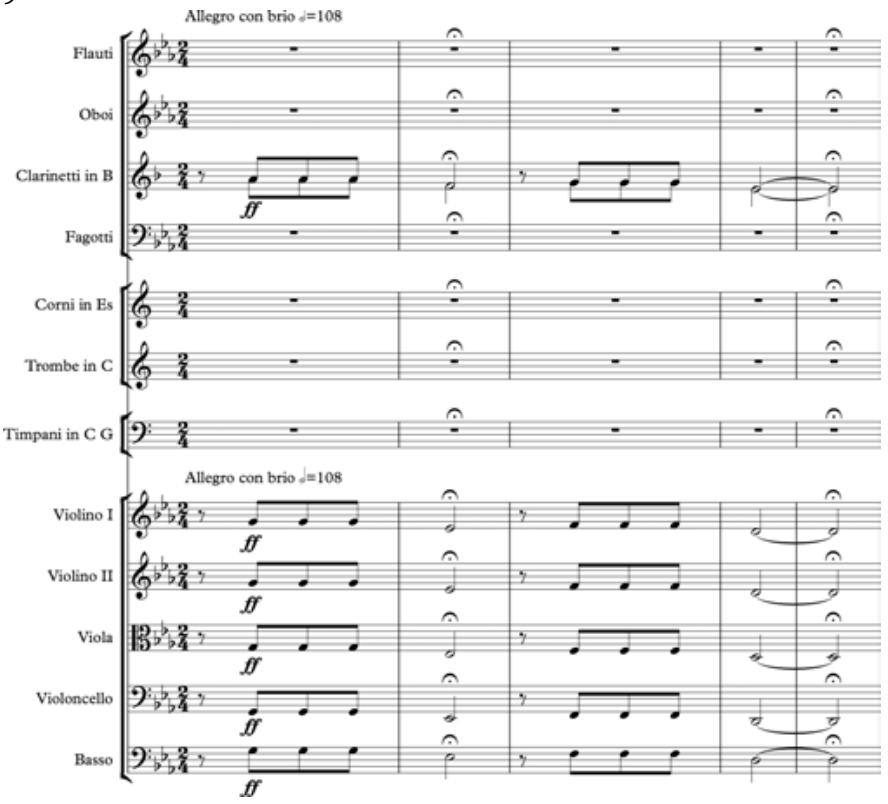

31 M. Geck: V. Symphonie in c-Moll, op. 67, S. $152 f$. 
IV

Geck spricht von »Wahrzeichen « des ersten Satzes, aus denen sich dieser Satz »erschließt«: aus »dem berühmten Motto zu Anfang und dem zunächst weniger auffälligen, jedoch nicht minder markanten Oboen-Adagio in den ersten Takten der Reprise « ${ }^{32}$ nämlich. »Daß diese gleichsam extraterritorialen Wahrzeichen jeweils von einer Fermate abgeschlossen werden, macht deutlich, daß sie ihre eigene Zeit haben, die über den Sonatensatz hereinbricht, um sein selbstbezügliches Wesen zu erschüttern.«

Leicht lässt sich auch von Fragezeichen-Situationen (mit Fermate) sprechen (vgl. Abb. 36). Es sind dies Situationen des Zum-Stillstand-Kommens, in denen die Frage auftaucht: Und jetzt?

Das Oboen-Adagio zu Beginn der Reprise exponiert einen Einzelnen, der nun aus der Gemeinschaft hervortritt. Aber auch die Streicher, die vornehmlich als Gruppe auftreten, entlassen sehr früh schon einen Einzelnen: Am Ende des ersten Themas (Takt 21) hängt ein Klang (das $\mathrm{g}^{2}$ in den ersten Violinen) merkwürdig über, sodass der Eindruck entstehen kann, das Orchester habe die Fermate nicht sauber ausgehalten.

Gleich darauf wieder ein Innehalten, ein Aufenthalt unter einer Fermate (Takte 23-24). Diese Fragezeichen-Situationen (Was jetzt?) provozieren geradezu das Fortstürmen danach. Auch wenn zeitweise Stillstand herrscht: Es geht weiter. Die von Geck angesprochene »eigene Zeit« der Fermaten kann nur gegen den Widerstand des heftigen Fortlaufs (»con brio«) ihre volle Kraft entfalten. Das erneute Losstürmen der gesamten Gruppe wird nach der Zeit der Fermate noch reicher an Energie. Und was es heißen kann, eine Exposition zu wiederholen, wird ganz neu durchlebt. Bis zu den beiden die Exposition abschließenden Pausen verläuft die Bewegung nach der dynamischen Steigerung im Anschluss an den Seitensatz über die Schlussgruppe hinweg ungestört. Und nun, bei der Wiederholung, zurück in die Fragezeichen-Situationen des Beginns. Wieder bleibt alles stehen, wieder die Frage: Und jetzt? Eine wiederum neue Orientierung wird notwendig. Auch wenn zeitweise Sicherheit gegeben ist, wenn es Bestätigung gab, so wird doch wieder neu die Frage gestellt (Wie jetzt?), wird der unbeschwerte Fortlauf gehemmt. Die Wiederholung als Wiederholung wird so von jedem Schematismus befreit: Aufgabe von Struktur, Gewinn an Prozess.

Rätselhaft die blockweise Ablösung von Bläser- und Streicherakkorden gegen Ende der Durchführung, kurz vor dem Übergang zur Reprise: Zuerst erfolgt der Wechsel nach jeweils zwei Takten, dann taktweise (ab Takt 196) (vgl. Abb. 37).

32 | Ebd., S. 155; das folgende Zitat ebd. 
Abbildung 37: Ludwig van Beethoven: Symphonie Nr. 5 c-moll op. 67, 1. Satz, Takte $210-217$

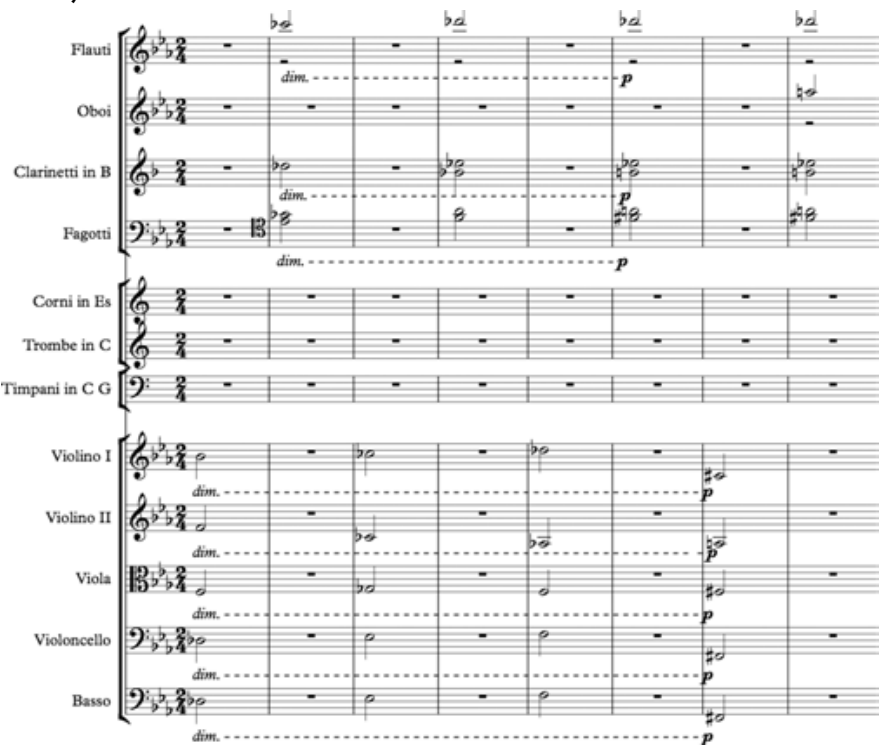

Blockweiser Wechsel (bis Takt 239, mit Unterbrechung durch das Motto): Hier werden die große Gruppe der Streicher und die Gruppe der Einzelnen aus der Bläsergruppe einander gegenübergestellt.

Isoliert für sich betrachtet gewinnt diese Passage große Ähnlichkeit mit der Komposition Hoketus für zwei Gruppen von jeweils fünf Instrumentalisten (1976) von Louis Andriessen. ${ }^{33}$ Andriessen unterzog Verfahren der amerikanischen Minimal-Kunst einem praktischen Test, und zwar durch die Konzentration auf einen einzigen musikalischen Aspekt, in diesem Fall den Hoketus. Hierbei wechseln zwei Stimmen in schnellem Tempo einander ab, sodass sie nie gleichzeitig spielen, einander aber komplementär ergänzen. ${ }^{34}$

Die angesprochene Passage aus der Durchführung der Symphonie wird vergleichbar mit einer Komposition wie dieser, in der ebenfalls zwei Gruppen das Tun der jeweils anderen spiegeln: ein nicht nur musikalisches, sondern vor allem auch soziales Geschehen.

33 | 2 Panfl., 2 Klaviere, 2 E-Pianos, 2 E-Gitarren, 2 Perkussionen [congas], 2 Saxophone ad lib.

34 | Ensemble Offspring: Louis Andriessen - Hoketus. https://www.youtube.com/ watch?v=73L2Mbi86HU vom 16.11.2016. 


\section{V}

Fragezeichen-Situationen zuhauf auch im dritten Satz Allegro; wiederum Vereinzelungen. Gleich zu Beginn die tiefen Streicher allein, ein Antworten der höheren Streicher und einiger Bläser - und schon ein Innehalten: Wohin jetzt? Der Vorgang wiederholt sich (Takte 9-18). Und nun treten die zwei Hörner allein mit dem Motto auf und knüpfen an, setzen fort, finden Unterstützung durch die anderen. Doch gleich nach dem Tutti-Einsatz wird die Bewegung erneut unterbrochen, es kommt erneut zum Stillstand (Takt 52). Wieder eine Situation der Ortlosigkeit, in der die Beteiligten sich wieder neu vergewissern müssen, was denn nun sei, wie es nun weitergehe. Dies alles sind Fragezeichen: Wo sind wir jetzt? Entstehen diese Fragen tatsächlich in der Auseinandersetzung der Musiker mit der musikalischen Situation, dann ist das Innehalten kein Als-ob-Innehalten, sondern wirkliche Ratlosigkeit und Ortlosigkeit: Praxis.

Das missglückte Fugenthema zu Beginn des Trios wird im weiteren Verlauf fragmentiert. Wiederholt (Takt 162ff., Violoncelli und Kontrabässe; Takt 198ff., Violoncelli und Kontrabässe) bleibt die Bewegung stecken, weil das Thema abbricht. Einzelne (aus der Gruppe der Bläser), die mit thematischer Substanz aus dem Scherzo und dem Fugenthema in den Vordergrund treten, führen zur Überleitung mit dem Motto aus dem ersten Satz, das nunmehr einzelnen Stimmen anvertraut wird. Bläser treten in Vereinzelung auf: Klarinette (Motto, Takt 255ff.), Fagott (Takt 259ff.), Oboe (Motto, Takt 263ff.), wiederum Fagott (Takt $267 f f .$, dann Thema des Scherzos zusammen mit Vc. Takt 281ff.), Horn (Takt 286ff.), Oboe (Motto, Takt 287ff.), Fagott (Takt 293), Horn (Motto, Takt 295ff.). Dieses In-Erscheinung-Treten von Einzelnen inmitten des Gruppenverbandes ist das Thema der gesamten Symphonie geworden. Solche Vereinzelung zeigt sich noch einmal im Paukensolo der Überleitung zum vierten Satz. Aus dem Motto, wie es aus dem ersten Satz vertraut ist, entwickelt die Pauke eine Tonrepetition, während das Thema des Scherzos in den ersten Violinen fragmentiert wird. Wieder eine Situation des Innehaltens, aber ganz anders als die Fragezeichen-Situationen, die eine Art Ortlosigkeit spüren ließen. Dieser Stillstand entwickelt allmählich einen Sog, der unaufhaltsam zum »attacca« führt und die Gruppe in den Jubel des letzten Satzes hineinstürzen lässt.

Die Symphonie entwickelt diese Energie vor allem durch zwei Momente: durch das Spannungsverhältnis von Stillstand/Innehalten/Verweilen und Fortlauf/Bewegung sowie durch das Beziehungsgeschehen zwischen einem oder mehreren Einzelnen (vornehmlich aus der Gruppe der Bläser) und der Gemeinschaft des Orchesters. Beide Momente sind bereits von Anfang an da: beim ersten Erscheinen des »Mottos« (Geck), im überhängenden Violinenklang (1. Satz, Takt 21), der in die Pause hineinragt. Manifest werden sie im Adagio der Oboe in der Reprise (1. Satz, Takt 268). Ab da sind sie ständig präsent. 
Die Praxis: Diese Verhandlungen, Infragestellungen, Störungen zu üben und zu (durch-)leben, auszuhalten. Auch wenn immer wieder eine Zeit des Stillstands einbricht, auch wenn Bewegungen ins Stocken geraten, Störungen den Fortlauf hemmen: Es gibt ein unzerstörbares und unvorhersehbares Potential, aus dem wir schöpfen. Dies untereinander und miteinander auszuhandeln, macht die Praxis dieser Symphonie aus.

\section{VI}

Nicht nur die Symphonie als autonomes Kunstwerk war gesellschaftlich »durch ihr bloßes Dasein«, wie Adorno es formulierte. ${ }^{35}$ Auch die Ausführenden, auch die Zuhörer zur Zeit Beethovens behaupteten ihr Da-Sein, sie traten durch die gemeinsame Aufführung der Symphonie im öffentlichen Raum in Erscheinung. Ihre Lebensform ist auf diese Weise öffentlich verhandelt worden. Durch die Ausführung sagten sie: Wir sind da. Wir sind in Freiheit da.

Heute kann eine solche öffentliche Verhandlung gemeinsamer Anliegen wieder geschehen, wenn auch unter anderen historischen Bedingungen. Die Ausführung derselben Symphonie heute kann aufs Neue das Da-Sein aller Beteiligten affirmieren:

"Wenn Körper sich versammeln, um ihrer Empörung Ausdruck zu verleihen oder um ihre plurale Existenz im öffentlichen Raum zu inszenieren, dann stellen sie zugleich auch weiter reichende Forderungen: Sie verlangen, anerkannt und wertgeschätzt zu werden, sie machen das Recht geltend, zu erscheinen und ihre Freiheit auszuüben, und sie fordern ein lebbares Leben." ${ }^{36}$

Das In-Erscheinung-Treten hat politische Kraft. Das »Recht zu erscheinen« ist eine politische Forderung. »Für diejenigen, die durch die Norm, die sie verkörpern sollen, in den Hintergrund gedrängt oder herabgewürdigt werden, wird der Kampf zu einem verkörperten Kampf um Anerkennung, zum öffentlichen Beharren auf der eigenen Existenz und Geltung.« Judith Butler untersucht Möglichkeiten von Versammlungen, wobei sie die körperliche Präsenz der Beteiligten in der Öffentlichkeit hervorhebt: Vom »Recht zu erscheinen« hängen Menschlichkeit und Zusammenleben ab. Und ist nicht auch die Aufführung einer Symphonie eine Versammlung? Das Konzert wird die öffentliche Versammlung, hier wird »Anspruch auf die öffentliche Sphäre geltend gemacht. Hier können alle ihr »Recht zu erscheinen« wahrnehmen, die Freiheit feiern durch ihr In-Erscheinung-Treten.

35 | Th. W. Adorno: Ästhetische Theorie, S. 335.

36 | J. Butler: Anmerkungen zu einer performativen Theorie der Versammlung, S. 39; die folgenden Zitate ebd., S. 41, 53, 58. 
An dieser Stelle noch einmal zurück zu den Ausführungen von Small zur Bedeutung von Ort, Zeit und Art der Teilnehmerschar (Ausführende wie Hörer) für das musikalische Geschehen der Ausführung; seine Frage lautete: »What's really going on here? ${ }^{37}$ Was passiert hier eigentlich (wirklich)?

"Like any other building, a concert hall is a social construction, designed and built by social beings in accordance with certain assumptions about desirable human behavior and relationships. These assumptions concern not only what takes place in the building but go deep into the nature of human relationships themselves. ${ }^{38}$

Ein Ort, verbunden mit Hoffnungen und Sehnsüchten: So sind wir auch! Das geht auch! Das Wesen menschlicher Beziehungen selbst wird tangiert. Und jeder andere neue Ort zu einer anderen Zeit ermöglicht neues Sich-Zeigen: So kann es gehen! Anders als 1808, aber mit ebensolcher Kraft zur Hinausweisung.

Die Ausführung dieser Symphonie lässt sich als ein politischer Akt begreifen. Kann sie dies jederzeit überall neu werden, auch unter veränderten politischen Bedingungen? Hieran äußert Adorno Zweifel:

"Bekkers These von der 'gemeinschaftsbildenden Kraftı der Symphonie wäre umzuformen. Die Symphonie ist die ästhetisch gewordene (und bereits neutralisierte) Volksversammlung. Deren Kategorien wären aufzusuchen wie Rede, Debatte, Beschluß (die entscheidende) und Feier. Wahrheit und Unwahrheit der Symphonie liegen in der Agora beschlossen. Was der späte Beethoven abstößt, ist genau der Schein der Volksversammlung, das bürgerliche Ritual.." ${ }^{39}$

Diese »Neutralisierung « lässt sich aber aufheben: Es ist möglich, die Symphonie aktuell für eine performative Verhandlung des Rechts, »in Erscheinung zu treten « (Butler), politisch in Anspruch zu nehmen. Auf diese Weise lässt sich die Sprengkraft der dieser Symphonie innewohnenden Handlungszusammenhänge in Zeitgenossenschaft hereinholen. Politische Kraft der Symphonie kann sich neu auf musikalische Weise zeigen: durch die Körperlichkeit und das Da-Sein der Ausführenden, die sich gemeinsam an ihr Potential erinnern, an »Kräfte, die ihnen innewohnen und die noch ungenutzt sind, während sie verschlissen werden. $\aleph^{40}$ Dieses Potential zeigt sich, wenn man diese Symphonie so ausführt: mit dieser Begeisterung, diesen Verzögerungen und

37 | Chr. Small: Musicking, S. 10; Herv. i.0.

38 | Ebd., S. 29.

39 | Th. W. Adorno: Beethoven, S. 71; Herv. i.0.

40 | H. Lachenmann: Fragen - Antworten, S. 201. 
Störungen, diesem Stehenbleiben und Vorwärtsstürmen, mit dem Risiko des Stockens, dem Wagnis zeitweiliger Desorientiertheit.

\subsection{John Cage: Music for (1984-87)}

\section{Koinzidenz. Gemeinsame Erfahrung eines Wir als Auch-da-Sein}

I

Es gibt 17 Stimmen (Flöte, Oboe, Klarinette, Trompete, Horn, Posaune, 4-mal Schlagwerk, 2 Klaviere, 2 Violinen, Viola, Violoncello und Stimme), die einzeln gespielt, aber auch im Ensemble variabler Größe variabel zusammengestellt werden können. Vorgesehen ist eine Aufführungsdauer von 30 Minuten, Aufführungen mit kürzerer Aufführungszeit sind erlaubt. ${ }^{41}$ Der Titel wird vervollständigt, indem ihm bei einer Aufführung die Anzahl der Spieler hinzugefügt wird, die tatsächlich spielen. Die Stimmen sind einzeln notiert: »Parts for voice and instruments without score (no fixed relation), title to be completed by adding to >Music for - the number of players performing.« Es kann und sollte demnach keine geplanten Zusammenklänge, keine geplanten Korrespondenzen und Interaktionen geben. Cage wünschte ausdrücklich Vereinzelung des Spielers:

"Each player should prepare his part by himself and learn to play it with his own chronometer. There should be no joint rehearsal until all the parts have been carefully prepared. They are then to be played as though from multiple centres in space. The players may sit anywhere within the auditorium with respect to the audience and to each other. " ${ }^{42}$

Im November 2000 wurde im Kunstraum Düsseldorf die Komposition als $\mathrm{Mu}$ sic for Ten aufgeführt. ${ }^{43}$ Im Laufe des Jahres gab es vorher zehn Aufführungen von Music for One, also Aufführungen aller beteiligten Stimmen einzeln, abschließend im November dann Music for Ten: Aufführung aller zehn Stimmen gleichzeitig.

Cage unterscheidet »zwei Arten von Musik« (»two kinds of music«) in jeder Stimme: einen einzelnen, ausgehaltenen Ton (piano), dem eine Pause voraus-

41 J. Cage: Music for, voice, Partitur, Aufführungshinweise; das folgende Zitat ebd.

42 | Ebd.

43 | Joanna Becker, Violine; Joep Dorren, Stimme; Rebecca Dunne, Horn; Julia Eckhardt, Viola; Marcus Kaiser, Violoncello; Jürg Frey, Klarinette; Roman Marreck, Trompete; Tobias Liebezeit, Schlagwerk; Normisa Pereira da Silva, Flöte; Craig Shepard, Posaune. 
geht und folgt und der einige Male wiederholt wird, und eine gewisse Menge von Klängen, die in Proportions-Notation notiert sind. Proportions-Notation bedeutet hier: Die Abstände zwischen Klängen geben proportional die Dauern an. Die Einteilung in »zwei Arten von Musik« gilt für alle Stimmen:

"It [each 'piecer] begins and ends at any time within the time brackets given. It is made up of one or the other or of both of two kinds of music: a) a single held ton p, preceded and followed by silence, repeated any number of times, and b) a number of tones in proportional notation (space $=$ time), not to be repeated, characterized by a variety of pitches, dynamics, timbres and durations within a limited range. ${ }^{44}$

Music for gehört zu den Kompositionen Cages, in denen er mit »time brackets « gearbeitet hat: Einzelne Phrasen der Stimme stehen in einer solchen ZeitKlammer, die an den Enden entweder feste Zeitangaben verzeichnet (wie 1'45" am Beginn und 1'55" am Schluss) ${ }^{45}$ oder einen variablen Spielraum fürs Beginnen und Schließen angibt (wie irgendwann zwischen 1'55" und 2'40" anfangen und irgendwann zwischen 2'25" und 3'10" schließen). ${ }^{46}$ Die feste Angabe sieht also einen »Zeitpunkt«, die flexiblere Angabe eine »Zeitspanne« vor:

"Danach gibt eine feste Klammer einen Zeitpunkt für den frühestmöglichen Anfang und einen Zeitpunkt für das spätestmögliche Ende einer Passage an [...]. Eine flexible Klammer hingegen gibt eine Zeitspanne an, innerhalb derer man [...] beginnen muß, und eine Zeitspanne, innerhalb derer man enden muß." " ${ }^{47}$

Für die Praxis bedeutet dies, dass die Koordination der Ausführenden ganz flexibel gegeben ist; dass eine Interaktion in Grenzen wohl möglich, aber nicht eigentlich intendiert ist. Zusammenklang ergibt sich, passiert weitgehend. Zumal bei einer größeren Anzahl an Ausführenden und einer gewissen Verteilung im Raum jeder einzelne Spieler für sich inmitten all der anderen ist. Cage sieht, wie bereits erwähnt, eine Spielweise vor, bei der jeder Spieler einen eigenen Ort findet.

Die Praxis: Jeder Mitspieler übt sich darin, Vertrauen in Koinzidenz zu haben. Koinzidenz hier verstanden als Zusammenfallen von Klangereignissen an verschiedenen Orten im Raum, ein Aufeinandertreffen, das so nicht geplant sein kann. Es ist nicht vorauszusehen, welche Begegnungen sich ergeben. Eine Aufführung mit mehreren Beteiligten trägt ein Ausführender

44 | J. Cage: Music for, piano I, Partitur, Aufführungshinweise.

45 | Dies gilt etwa für die zweite Klavierphrase von piano I; vgl. J. Cage: Music for, piano I, Partitur, S. 1.

46 | J. Cage: Music for, piano I, Partitur, dritte Klavierphrase.

47 | M. Erdmann: Il silenzio ritrovato, S. $187 \mathrm{f}$. 
mit, wenn er auf Koinzidenz vertraut. Man kann es nicht auf Koinzidenz abgesehen haben, es nicht darauf anlegen. Koinzidenz geschieht, lässt sich nicht wiederholen.

II

Welches Gewicht kommt den Pausen zwischen den Klängen und zwischen den einzelnen »Arten von Musik« (Cage) von Music for zu? Es gibt unterschiedliche Arten von Pausen. Die Trompetenstimme beginnt mit der von Cage so bezeichneten ersten Art von Musik, einem länger ausgehaltenen einzelnen Klang, dem eine Pause vorausgeht und eine Pause folgt. Diese gesamte Phrase wird etliche Male wiederholt. Die dem Klang vorausgehende Pause kann innerhalb der »Zeitspanne " o'oo" und o'45" einsetzen. Eine Stille, die dieser Pause vorausgehen kann, kann den Beginn der Stimme überhaupt ausmachen. Die sich an den zu wiederholenden Klang anschließende zweite Art von Musik (Klänge in Proportions-Notation) endet frühestens bei o'3o" und spätestens bei 1'15". Der Spieler setzt mit wiederum einer Phrase aus der ersten Art von Musik (Einzelklang, umrahmt von Pausen) fort, welche frühestens bei ı'oo" und spätestens bei 2'15" beginnt. Es liegt also im Ermessen des Ausführenden, wie er die beiden Arten von Musik miteinander verbindet.

Auf Pausenlängen zwischen Phrasen kann ein Ausführender selbst einwirken. Einzig die Pausen in der ersten »Art von Musik« (Cage) vor und nach dem lang auszuhaltenden Klang sind verbindlich. Neben der traditionell notierten Pause gibt es also immer auch vom Spieler selbst zu bestimmende Freiräume des Still-Bleibens. Nicht zu vergessen die Zäsuren: Atemzäsuren innerhalb einer Phrase der zweiten Art von Musik.

Die Einzelstimme ist radikal einzeln: Der Einzelne spielt frei von Gesten, indem er sich jedem Klang einzeln zuwendet, auch wenn die Klänge manchmal sehr schnell aufeinander folgen. Der einzelne Spieler beabsichtigt keinerlei Integration in ein Ensemble - und die einzelnen Klänge sind wie die Spieler isoliert voneinander.

III

Erika Fischer-Lichte berichtet von einer Aufführung von Untitled Event, die Cage 1952 »während der Sommerschule des Black Mountain Colleges« initiierte: In dieser Komposition arbeitete Cage auch mit time brackets. ${ }^{48}$ Fischer-Lichte spricht vom »Prinzip der Zusammenhangslosigkeit« und zitiert Cage: »Alles ist getrennt, überhaupt alles von allem. Die Szene ist ja nicht so angelegt, daß die verschiedenen theatralischen Elemente einander stützen oder tragen oder sich auch nur aufeinander beziehen, sondern jedes hat seinen eigenen Status,

48 | E. Fischer-Lichte: Ästhetik des Performativen, S. 228ff.; das folgende Zitat ebd. 
seine völlig unabhängigen Zustände von Aktivität. « ${ }^{49}$ Diese Äußerung Cages über Untitled Event wirft ein Licht auf Music for, denn auch hier sind alle Spieler und alle Klänge voneinander getrennt, es gibt keine Partitur, in deren Schriftbild die einzelnen Stimmen übereinander angeordnet wären (lediglich »Parts for voice and instruments $~^{50}$ ), und keine komponierten Zusammenhänge zwischen den Klängen. Zu erleben ist, wie diese Trennung aller voneinander eine Öffnung aller zueinander bewirkt. Alles Tun der Beteiligten, alle Prozesse, alle Orte im Raum werden transparent durch die Trennung.

Die Musik öffnet sich für Geschehnis und für ein Zugleich, das sich jedem Zugriff sofort entzöge, das nur eingeladen werden kann. Für die Praxis heißt das aber auch, sich diesem Schwebezustand zwischen Tun und GeschehenLassen auszusetzen.

49 | J. Cage, zitiert in: E. Fischer-Lichte, ebd.; Herv. i.0.; vgl.: Die Opernzeitung Frankfurt, Oktober/November 1987, Nr. 1/2, Frankfurt a.M. 1987, S. 11.

50 | J. Cage: Music for, voice, Partitur, Aufführungshinweise. 


\section{Solo}

Violine allein - oder: für Stimme solo (unbegleitet); oder: für einen Pianisten. Auch: für Orgel. Hier fehlt üblicherweise ein Zusatz für Orgel allein bzw. für Orgel solo. Vor allem Klavier und Orgel sind die Instrumente, die eher solistisch auftreten, wenn sie nicht Begleitungsfunktionen oder im Klavier- bzw. Orgelkonzert ihren Part übernehmen. Der Kontrabass hingegen ist erst in der zeitgenössischen Musik als Solo-Instrument auf die Bühne getreten.

Unterscheidungen wie »für Klavier« oder »für einen Pianisten« (nach der Nennung des Titels) oder spezifische Titel wie »klavierstück« oder »klavier« zeigen, dass die Aufgabe des Solisten, dessen Situation beim Spielen und dessen Beziehung zum Publikum sowie die jeweilige Funktion des Instruments in die Angaben zu Titel und Besetzung eingehen können.

Solo: Man ist als Ausführender allein. Dies ist eine Herausforderung. Da ist kein Mitspieler - sofern das Publikum nicht in irgendeiner Weise mit einbezogen wird.

Beim Vergleich unterschiedlicher Solo-Kompositionen tritt eine große Vielfalt auf. Ein Ausführender kann im Zuge der Ausführung einen Weg gehen, das Stück führt ihn dann einen Weg. Er kann an einem bestimmten Ort verweilen, kann sich auch, beim Wechsel zu einem anderen Abschnitt im Musikstück, an einem anderen Ort wiederfinden, ohne dahin im Verlauf des Spiels gelangt zu sein. Kann in sich verschlossen, eher nach innen gewandt bleiben, kann sich aber auch öffnen. Kann sich allein als Einzelner an ein Publikum wenden oder für sich bleiben, für sich spielen, wobei in diesem Fall ein Publikum während der Aufführung zugegen sein könnte, ohne Adressat zu werden. Alleinsein kann mit Verzicht auf Kommunikation einhergehen, kann aber auch Öffnung eines Leerraums für ein (vielleicht ersehntes) Gegenüber bedeuten. 


\subsection{Claude Debussy: SyrinX pour flûte Seule (1913) - Anastassis Philippakopoulos: song 6 for bass flute OR ALTO FLUTE OR FLUTE (2010)}

\section{Sich-selbst-Zuhören - Atembögen - das abwesende Du}

I

Als »Geburtsstätte der Musik« bezeichnete Ernst Bloch den Klang der Panflöte. Nach Ovids Metamorphosen erzählt er folgendes »Märchen«:

"Pan jagte sich mit Nymphen, stellt einer dieser, der Baumnymphe Syrinx, nach. Sie flieht vor inm, sieht sich durch einen Fluß gehemmt, fleht die Wellen an, ihre liquidas sorores', sie zu verwandeln, Pan greift nach ihr, da hält er nur Schilfrohr in Händen. Während seiner Klagen um die verlorene Geliebte erzeugt der Windhauch im Röhricht Töne, deren Wohlklang den Gott ergreift. Pan bricht das Schilf, hier längere, dort kürzere Rohre, verbindet die wohlabgestuften mit Wachs und spielt die ersten Töne, gleich dem Windhauch, doch mit lebendigem Atem und als Klage. [...] Ovid hat, mit der Einheit von Syrinx und Nymphe, das Ziel bezeichnet, auf das die Tonreihe, seit je ein Linienziehen im Unsichtbaren, sich zubewegt. Es ist ein widerspruchsvoll-utopisches: dies Flötenspiel ist das Vorhandensein eines Verschwundenen; was über die Grenze hinaus ist, wird von dieser Klage eingeholt, in diesem Trost gefaßt. Als Klang ist die verschwundene Nymphe geblieben ". ${ }^{1}$

Syrinx von Claude Debussy: Allein-Sein, Sich-Selbst-Zuhören ${ }^{2}$ - noch über den Schluss hinaus (»perdendosi«, »Très retenu«) (vgl. Abb. 38).

Abbildung 38: Claude Debussy: Syrinx pour flûte seule, Takte 33-35

\section{Très retenu}

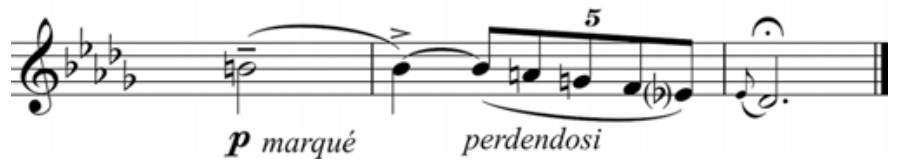

Wirklich allein sein, ohne Ausrichtung auf ein Publikum: Etliche Ausführende scheinen es zu riskieren. Bei einigen wird ganz deutlich, wie der Spieler, die Spielerin sich selbst zuhört. Andere wiederum spielen einem Publikum ein

1 | E. Bloch: Das Prinzip Hoffnung, 3. Band, S. 1245.

2 | Begriff nach Istvàn Zelenka. "The trumpet shall sound!": "Diese Komposition ist eine unter den Stücken des (Sich-Selbst-)Zuhörens". E.-M. Houben/I. Zelenka: 1 Milieu, S. 351. 
Stück vor, das Publikum ist ausdrücklich Adressat. Unterschiedliches Tun ist zu beobachten und zu hören.

Die weiten Bögen der Melodie werden vom Atem getragen. Der Atem bestimmt die Länge der Phrasen, die ganz dem Körper gehören. Der Titel »Syrinx« bezieht sich so nicht nur auf den Namen der Nymphe oder die besondere Flöte aus Schilfrohr oder generell auf die Flöte als Objekt, sondern verheißt auch Verkörperung von Ruf, von Anruf.

Innehalten am Ende eines Atembogens: Der Atmende kann sich des Fortgangs wieder neu vergewissern. So tastet sich der Ausführende in der großen Atmung des Stücks voran: Atembogen für Atembogen. Im stillen Verweilen ereignet sich das Staunen über den Fortgang. Keine Atemzäsur ist wie eine andere: Mal gibt es kürzere Atemzäsuren, mal ein längeres Innehalten (Fermate) - so nach zwei aufeinander folgenden Trillern (vgl. Abb. 39).

Abbildung 39: Claude Debussy: Syrinx pour flûte seule, Takte 23-25

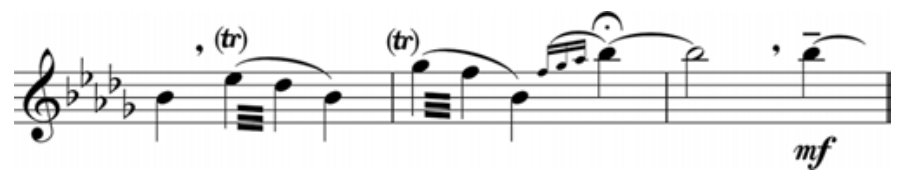

Eher kurz die Zäsuren im Umfeld der Orte »Cédez«, »Rubato« (Takt 14ff.). Hier dreht sich die Melodik im Kreise, man knüpft an etwas an, das gerade eben erst war, als würde ein Faden fortgesponnen. So geschieht Formung aus den Atembögen heraus, von der Körperlichkeit des Atmenden her. Die Atembögen sind Einzelereignisse. Einer reiht sich an den anderen.

Und so schreite ich als Ausführender voran: Schritt für Schritt, Atembogen für Atembogen - an einzelnen Orten verweilend. Der Handlungsraum des Ausführenden erschließt sich beim Durchmessen der Komposition, deren Werden man hier beobachten kann. Die Zeit vergeht natürlich, eine unabweisliche Tatsache. Mit jedem Atemzug werden wir älter, verströmen wir unser Leben. Diese Leiblichkeit zeigt sich von Atembogen zu Atembogen, zugleich zeigt sich die Begrenztheit des Körpers wie des Lebens. Musik wirft auf den eigenen Körper zurück.

Gerhard Rühms Atemstudie so lange wie möglich (1962) lässt einen Atembogen gänzlich versiegen, zeigt so den Verwandlungsprozess, den dieser durchläuft:

"so lange wie möglich ist eine letzte sprachliche reduktionsstufe. nur ein einziger laut, das ‘ar, wird wohlklingend artikuliert und so lange wie möglich (bis zum völligen versie- 
gen des atems) gehalten. eine elementare demonstration des verbrauchs von sschönheit، und frische، durch dauer, durch die zeit. ${ }^{3}$

So setzt die Ausführung von Syrinx neben einem Werden auch einen Prozess des Verbrauchs, der Abnutzung frei. Der Verschleiß ist Teil der Erinnerung. ${ }^{4}$

Abbildung 40: Anastassis Philippakopoulos: song 6 for bass flute or alto flute or flute
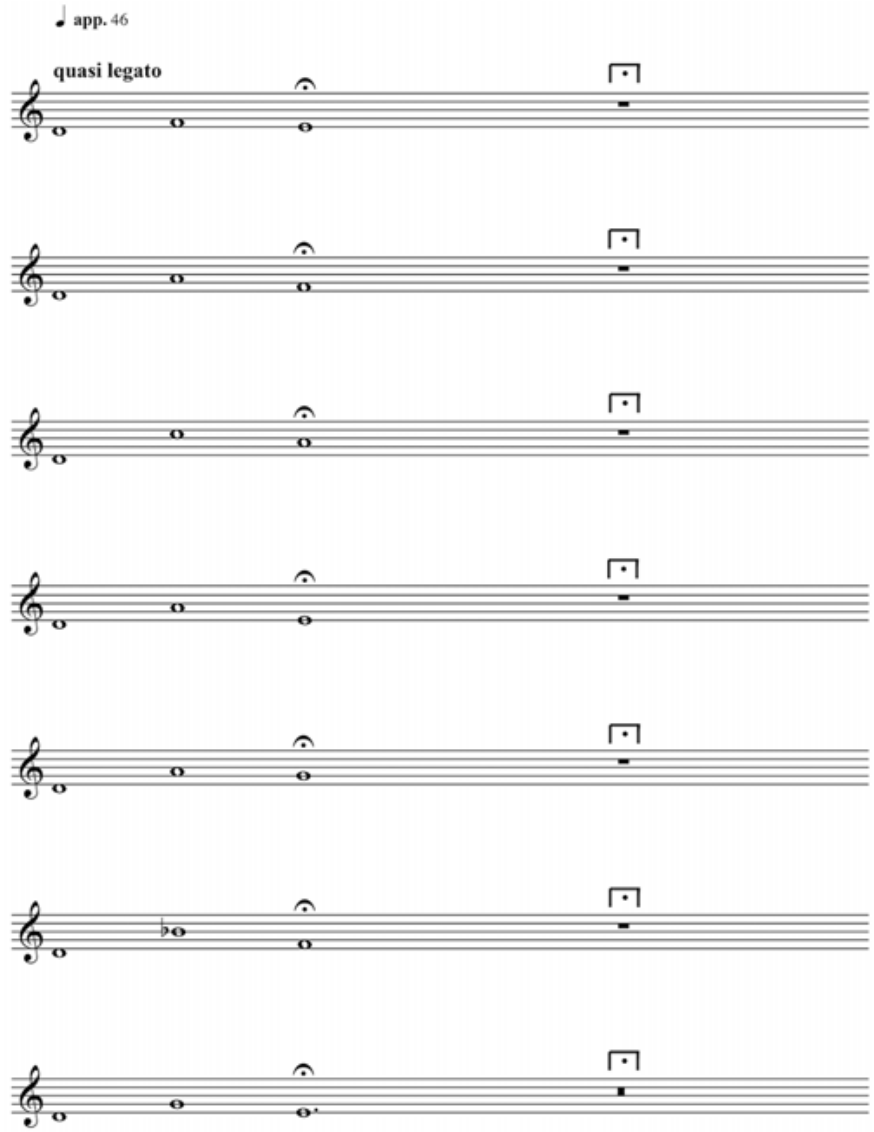

ew17.014; mit freundlicher Genehmigung der Edition Wandelweiser, Haan 2010

3 | G. Rühm: botschaft an die zukunft, S. 56; vgl. E.-M. Houben: Alte Musik mit neuen Ohren, S. 86.

4 | Vgl. H. Lachenmann: Fragen - Antworten, S. 201. 
II

Ein Sich-Selbst-Zuhören wiederum, aber diesmal mit sehr langen Phasen der Stille, welche die Länge einer Pausenzäsur (zum Atmen) bei weitem überschreiten: song 6 for bass flute or alto flute or flute (2010) von Anastassis Philippakopoulos (vgl. Abb. 40). Die runde Fermate gibt ungefähr die doppelte Länge eines Tons, einer Pause an, die eckige etwa die dreifache oder vierfache Länge. ${ }^{5}$ Insgesamt gilt: »poco rubato. tranquillo sehr zart. poco espressivo«.

Unterbricht Stille die Phrasen? - oder strömen die Atmungen in die weite Stille hinein? Jedem Ruf folgt Stille; der Wechsel Ruf - Stille - Ruf - Stille setzt sich beharrlich fort. Stille entfaltet einen eigenen Raum des Hörens, eines Hörens, das in die Weite geht.

Ruf - Stille - Ruf - Stille: »each phrase a call, an address, a reaching out. each silence an intense listening, an opening up to be addressed in turn. in this music the deepest and most paradoxical sense of human solitude finds its purest expression: being alone in the awareness of one's not being alone. ${ }^{6}$ Jede Phrase Ruf, jede Stille Raum für ein Hinaus-Hören, für ein Warten auf eine Antwort: Beuger spricht hier von einer paradoxen Situation, die im Hin und Her von Ruf und Stille entsteht. Im Allein-Sein in Stille ist die Möglichkeit des Rufes gegeben, die Möglichkeit auch, weiter zu hören, über die Grenze des eigenen Rufes hinaus - um eben auch angesprochen $\mathrm{zu}$ werden (»to be addressed in turn«): Allein-Sein in Ausrichtung auf ein Gegenüber. Ich rufe - und höre im Allein-Sein, wie ich nicht allein bin. Ich höre in der Stille einen Anruf an mich: So wird mein erneuter Ruf eine Antwort und so weiter.

Dies ist keine Kommunikation, es ist ein Für-sich-Sein (per se) in Beziehung auf jemanden hin. Bei der Ausführung zeigt sich, wie wichtig der Raum der Stille ist, den die Komposition öffnet. Hier, in diesem offenen Raum, wird hörbar, dass und wie der Klang die Leere für ein Du hervorbringt. Ausführung als ein Sich-selbst-Zuhören bringt die notwendige Leere zum Vorschein. Wenn er nicht ruft, ist der Ausführende hörend anwesend. Das Nicht-Spielen ist ebenso wichtig wie das Spielen und Rufen. Ausrichtung auf ein Du: Rufend hören, hörend rufen.

5 | A. Philippakopoulos: song 6, Partitur; das folgende Zitat ebd.

6 | A. Beuger: Booklet zur CD; Herv. i.0. 


\subsection{Johann Jacob Froberger: Lamentation (Partita IN C; FbWV 612) (1654) - Meditation (Partita in D; FbWV 620) (1660)}

\section{Nachhören - "avec discrétion"}

I

- Allemande - »faite sur l'Election et Couronnement de Sa Majesté Ferdinand le Quatrième Roy des Romains se joüe lentement a la discretion« der erste Satz aus der Partita FbWV 611 ${ }^{7}$

- Lamentation - »faite sur la tres douloreuse Mort de sa Majeste, Ferdinand le Quatriesme Roy des Romains 1654, et se joüe lentement avec discretion« - der erste Satz aus der Partita FbWV 612

- Meditation - »faite sur ma mort future, la quelle se joüe lentement avec Discretion â Paris 1 May Anno 1660 - der erste Satz aus der Partita FbWV 620

- Lamentation - »faite sur la tres douloreuse mort de Sa Majeste Imperiale, Ferdinand le Troisiesme, et se joüe lentement avec discretion« FbWV 633

Kompositionen Johann Jacob Frobergers zur Erinnerung, zur Feier besonderer Begebenheiten: Wahl und Krönung Ferdinands des Vierten, Tod Ferdinands des Vierten, eigener zukünftiger Tod, Tod Ferdinands des Dritten. Alle verbindet die Anweisung zur Ausführung »lentement avec (à la) discretion«-zurückhaltend, je nach Empfinden. Der eigene zukünftige Tod kann als Ereignis noch nicht beklagt, aber nachdenklich, besonnen reflektiert werden. Nicht alle Kompositionen, die »lentement avec discretion « zu spielen sind, geben Anlass zur Trauer, was die Allemande aus der Partita FbWV 611 (siehe oben) zeigt, wie auch die Allemande der Partita FbWV 617 mit der Widmung: »faite en honneur de Madame la Duchesse de Wirtemberg, la quelle se joüe lentement et à discretion «. ${ }^{8}$ Froberger versah nicht nur Todesklagen und musikalische Kommentare zu öffentlichen Ereignissen sowie Widmungen mit der Anweisung »lentement avec discretion«. Auch etwa eine Klage über seinen bedauernswerten Zustand in London, nachdem er ausgeraubt und dann von einem Organisten wegen unkonzentrierten Balgtretens entlassen wurde, findet Niederschlag in einem Einleitungsstück zu einer Partita: Plaincte - »faite â Londres pour passer la Melancholie la quelle se joüe lentement avec discretion«. Ebenso eine Allemande als Einleitung zur Partita FbWV 627, die er aus Anlass einer tur-

7 | Dieser und die folgenden Titel nach J. J. Froberger: Neue Ausgabe sämtlicher Werke VI. 2 .

8 | Dieser und die folgenden Titel nach J. J. Froberger: Neue Ausgabe sämtlicher Werke VI.1. Unterschiedliche Schreibweisen des Aufführungshinweises "à (la) (avec) discrétion « in den vorliegenden Kompositionen. 
bulenten und für ihn persönlich sehr aufregenden und gefahrvollen Rheinfahrt komponierte: »faite en passant le Rhin dans un barque en grand peril, la quelle se joüe lentement à la discretion«. Offenbar führte Froberger über die Zuschreibung von Kompositionen zu öffentlichen, aber auch zu persönlichen Ereignissen eine Art musikalisches Tagebuch. Es war ihm wichtig, mit der Komposition eine historische Wegmarke zu setzen.

Übrigens bleibt die Ausführungsanweisung »a discretion« nicht auf Klage, Lamentation, Meditation, Allemande (als Eröffnung einer Partita) beschränkt. Auch in Toccaten werden einzelne Passagen »a (avec) discretion«, »lentement avec discretion«, »lentement et à discretion« gespielt: Abschnitte der Selbstvergessenheit, der Nachdenklichkeit. ${ }^{9}$

Eine weitere Klage, neben derjenigen über den eigenen Tod, fällt als Besonderheit auf: die Klage über einen Raub. Es handelt sich um die Lamentation »sur ce que j'ay esté volé, et se joüe fort lentement, à la discretion sans obserueur aulcune mesure «, den ersten Satz aus der Partita FbWV 614. Nicht nur langsam, sondern sehr langsam ist diese Lamentation zu spielen, »à la discretion« - aber noch verstärkt: ohne irgendein Metrum zu beachten, zeitlich also ganz bindungslos und frei. Solche Ungebundenheit kennzeichnet auch die anderen langsamen Stücke »à la discretion «. ${ }^{10}$ An dieser besonderen Anweisung zeigt sich auch, wie wichtig Froberger diese Freiheit im Spiel und die Ablösung von metrischer Bindung waren.

Aus einem Brief von Sibylla von Württemberg an Constantin Huygens geht hervor, dass die subtilen Verzögerungen und Accelerandi (molto rubato) nicht ohne Übung und Unterricht auszuführen waren. Froberger war ihr Lehrer, sie schreibt:

"Wolte gern das 'Memento mori Froberger bey inme schlagen, so guet mir müglich were. Der Organist zu Cöllen, Caspar Grieffgens, schlagt selbiges Stück auch, und hat es von seiner Handt gelernt, Grif vor Grif. Ist schwer aus den Notten zu finden. Habe es mit sonderlichem Fleis darum betracht, wiewol es deutlich geschriben. Und bleibe auch des Hern Grieffgens seiner Meinung, das wer die Sachen nit von inme Hern Froberger seliger gelernet, unmüglich mit rechter Discretion zuschlagen, wie er sie geschlagen hat. Der liebe Gott gebe das wir alle Music liebhabende uns bey inme im himlischen Musenchor ergötzen megen, Amen. ${ }^{11}$

9 | Vgl. auch Toccata FbWV 102, Toccata FbWV 114, Toccata FbWV 118, Toccata FbWB 113, Toccata FbWV 101, Toccata FbWV 115. J. J. Froberger: Neue Ausgabe. VI.1.

10 | Die Ausführungsanweisung "à (avec) discretion" bedeutet vielleicht am ehesten Zurückhaltung, Zurücknahme, auch Entscheidung in Freiheit.

11 S. von Württemberg, zitiert in R. Rasch: Duizend Brieven over Muziek, Nr. 6626, 23.10.1667. 
II

Die Partita in C (FbWV 612) beginnt, wie gesagt, mit einer Lamentation - »faite sur la tres douloreuse Mort de sa Majeste, Ferdinand le Quatriesme Roy des Romains 1654, et se joüe lentement avec discretion«. Ich bin als Spieler allein.

Höre mir beim Spielen zu. »Sich-selbst-Zuhören«: Dieser Begriff geht auf Istvàn Zelenka zurück, der etliche seiner Kompositionen so konzipiert hat. Er nennt sie »pièces de s'écoute « ${ }^{12}$, Kompositionen, die ihren Sinn primär darin finden, dass der Spieler sich selbst hört. Man führt sie »per se« auf, für sich allein. Ein Publikum kann anwesend sein, muss aber nicht dabei sein.

Hier, in Frobergers Lamentation: Ein Vorantasten von Ton zu Ton. Ein hörendes Spielen, ohne genau zu wissen, welcher Ort im nächsten Takt aufzufinden sein wird. Als Ausführender ist man, so fühlt es sich an, kaum tätig. Ausführende lassen sich von der Musik mitnehmen, manche beobachten ihre Hände und scheinen überrascht über den Weg zu sein, den diese sie führen. Immer wieder Stehenbleiben, Stocken, Zögern: Auch das bietet die Partitur an. Im Spiel tastet sich der Ausführende vor, es ist ein von Moment zu Moment hörendes und greifendes Spielen, ein nachdenkliches, nachhörendes. Ein Klang wird in die Resonanz des letzten hineingesetzt (vgl. Abb. 41).

Abbildung 41: Johann Jacob Froberger: Lamentation (Partita in C; FbWV 612), Takt 1

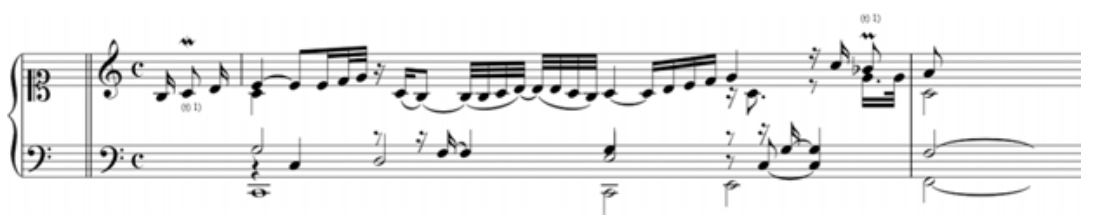

Der Musiker geht immer wieder in neue Richtungen, um sogleich erneut stehen zu bleiben, innezuhalten. Immer neue Facetten von Behutsamkeit, Aufmerksamkeit sind zu entdecken. Das Tempo ist langsam, sehr frei. Hier drängt niemand, zu bemerken ist die Umsichtigkeit, mit der gespielt wird. Auf dem Grund einer sehr feinen Zurückhaltung - »avec discrétion« - reicht dem Ausführenden die Partitur als Landkarte, um sich hier zu orientieren, um in dieser oder jener Landschaft immer wieder zu pausieren, zu warten, zu hören, um immer neu an einem anderen Ort auf besondere Weise alleine zu sein. Akkorde sind ausgefaltet als Arpeggio notiert, aber auch in vertikaler Anordnung der Einzelklänge, wobei bei dieser notierten Simultaneität ein arpeggiertes Einsetzen der Einzelklänge gleichwohl intendiert ist. Aber auch ein solches Arpeggio folgt am jeweils eigenen Ort dem eigenen Tempo, bleibt immer für sich, bleibt ein isolierter Ort auf der Karte der Partitur. Die Akkorde liegen in der Hand,

12 | E.-M. Houben/I. Zelenka: 1 Milieu, S. 37; das Folgende ebd. 
der Spieler lässt sich auf eine Praxis ein: Einübung von Handbewegungen, von spielerischen Gesten, Ausbildung haptischer Fähigkeiten, Sensibilisierung des Tast(en)gefühls.

Die Lamentation ist metrisch ungebunden, frei, sodass eine feste Pulsation verschwimmt, gleichwohl metrisch subtil notiert. Man spielt inspiriert von der Notation, findet die Musik aber jenseits der Notation. Alle Stimmen sind beteiligt, Leittöne treten in allen Stimmen auf, allerdings ohne Zielstrebigkeit, denn die musikalische Entwicklung bleibt bei dieser Art des Vortastens in jedem Augenblick offen. Die Harmonik nimmt überraschende Wendungen. Peter Schleuning stellt Frobergers Klagen »über die Melancholie, den Tod Blancheroches und des Kaisers Ferdinand III « in die Tradition der Tombeau-Komposition: »[S]o überraschend und außergewöhnlich in ihrer Harmonik wie sonst in dieser Schärfe nur die englischen Ensemble-Fantasien der Zeit.« ${ }^{13}$ Mit dem Hinweis auf »Melancholie« wird auch das zeitweilige Stehen-Bleiben des Spielers angesprochen: Verzicht auf zügiges Weitergehen und Zielgerichtetheit. Eher verweilt man in der Resonanz dessen, was hier passiert. Metrische Ungebundenheit, aber auch freies harmonisches Schweifen zeichnen die Lamentation der Partita in C aus.

Eine Aufführung dieses Satzes bedeutet Nachhören, Nachsinnen, Nachdenken. Klänge verhallen - und in dieser Resonanz finde ich mich als Ausführender wieder, um zögerlich meinen Weg zu finden. Ein Publikum kann beim Nachdenken und Nachsinnen mit dabei sein, kann dieses Nachdenken miterleben.

\section{III}

Ferdinand IV, geb. 1633 in Wien, starb sehr früh im Alter von 21 Jahren in Wien. Kurz vor seinem Tod, 1653, wurde er zum römischen König gekrönt. Während die Klage über den Tod Ferdinands, welche die Partita in C (FbWV 612) einleitet, den Tod eines Menschen betrauert, stellt Frobergers Meditation aus der Partita in D (FbWV 620) ein Nachsinnen über den eigenen zukünftigen Tod vor: Meditation »faite sur ma mort future, la quelle se joüe lentement avec Discretion à Paris 1 May Anno $1660 \ll$.

Wie Rebecca Cypess ausführt, ist dieses Stück Teil einer Traditionslinie von Kompositionen, die, wie das Tombeau, wie die soeben angesprochene Lamentation auch, Trauer und Schmerz ausdrückten. ${ }^{14}$ Cypess charakterisiert diese Art der Klage auf besondere Weise, indem sie die metrische Ungebundenheit mit einer Art Aufhebung der Zeit in Zusammenhang bringt. Eine solche »Aufhebung der Zeit« (»suspension of time«) geschieht hier also - eine

13 | P. Schleuning: Die Freie Fantasie, S. 69.

14 | R. Cypess: ,Memento mori Froberger?‘, S. 1. 
gewisse Zeitlang, so lange die Ausführung eben dauert. Ein Hinaustreten aus der Alltagswelt:

"Froberger's harpsichord idiom is closely related to the unmeasured preludes fashionable in France in the second half of the 17th century; although these preludes generally lack definitive programmes and descriptive titles, it is noteworthy that their execution, like the piece for which Froberger prescribes discrétion, involves a general suspension of time. ${ }^{15}$

Das Besondere an Frobergers Komposition ist, dass in dieser Meditation ein musikalisches Nachdenken über den eigenen Tod zelebriert wird. ${ }^{16}$ Gegenstand der Meditation ist nicht ein vergangenes Ereignis, sondern ein zukünftiges. Die Tatsache, dass diese Meditation ausdrücklich mit Ort und Datum der Entstehung versehen ist, verleihe, so Cypess, dieser Komposition den Charakter eines Tagebuchs, das zu Frobergers Zeit als Autobiografie und Zeitdokument beliebt war. Nicht umsonst war seine Zeit eine Epoche wachsenden Zeitbewusstseins, in der historische Ereignisse sorgfältig dokumentiert wurden und Uhren sich großer Beliebtheit erfreuten. Cypess verweist auf die peniblen Tagebucheintragungen von Constantin Huygens, auf die mechanischen Erfindungen von dessen Sohn Christiaan, der 1659 die Pendel-Uhr erfand und ${ }_{16} 65$ die Taschenuhr revolutionierte, auf die Arbeiten mit Sonnenuhren. ${ }^{17}$

Froberger spricht mit Datierung und Lokalisierung einer Komposition sein Interesse an Autobiografie und zeitgenössischer Dokumentation eigenen und öffentlichen Lebens aus, er positioniert sich im Lauf der Geschichte. Zugleich tritt die musikalische Meditation in Parallele zur literarischen Form der Meditation (im Frankreich des ausgehenden 17. Jahrhunderts), eben aufgrund des besonderen Verhältnisses zur Zeit, das Cypess als »paradox « ${ }^{18}$ beschreibt: Die literarische Meditation führe einerseits das Bild der Uhr als Sinnbild für die Flüchtigkeit der Zeit vor Augen, gleichzeitig erlaube sie, sich aus dem Gleichmaß der Uhr zurückzuziehen in einen ungebundenen, zeitlich freien Raum, der dem Leser Freiheit zur Konzentration und Sammlung gab. Ähnlich Frobergers Meditation:

"Froberger's piece, too, embraces an aesthetic of suspended time to allow for concentrated meditation and removal from worldly considerations, especially in calling for exe-

15 | Ebd.

16 | Ebd., S. 7; das Folgende ebd., S. 3 f.

17 | Ebd., S. 4; vgl. Carlo M. Cipolla: Gezählte Zeit. Wie die mechanische Uhr das Leben veränderte. Aus dem Italienischen v. Friederike Hausmann, Berlin: Klaus Wagenbach 1997.

18 | R. Cypess: 'Memento mori Froberger?‘, S. 3. 
cution with discrétion. At the same time, by dating his composition, Froberger showed an interest in time-bound autobiography - in placing himself in the passage of time. ${ }^{19}$

Paradox ist dieses Verständnis von Zeit also wegen der denkwürdigen Doppelung: Auf der einen Seite das Streben nach akkurater Messung, genauer Dokumentation, nach Ein- und Zuordnungen von Zeitläufen, auf der anderen Seite das Streben nach Rückzug, nach einer Aufhebung der Zeit, einem Sich-Verlieren in der Zeit, bei dem der Chronometer keine Rolle mehr spielt.

Frobergers Meditation über den eigenen Tod erlaubt (ihm selbst schließlich auch) einen kurzen Rückzug aus den alltäglichen Aktivitäten und Beschäftigungen, die täglich in den Strudel der Zeit reißen. Eine Zeitlang wird die Zeit suspendiert, »eingefroren« gleichsam, wie Cypess sagt:

"Froberger's 'Meditation r requires only a brief removal of the player from day-to-day activities - those activities commonly marked by the passage of time." - "By suspending time through performance 'with discretion', he closed himself off - if only briefly - from the notion of time as a regular, predictable progression, governed and symbolized by the clock. The work enables the contemplation of death - repeatable in every performance - through the dreamlike state of devotional meditation. It served the player as a tool to situate himself in the present instant, freezing time long enough to understand his place in it. " ${ }^{20}$

Die Komposition ermöglicht dem Spieler, den eigenen Tod zu betrachten. Das Stück wird zum Werkzeug für eine bestimmte Praxis: Memento mori.

\section{IV}

Cypess beschreibt hier eine musikalische Praxis, die jeder jederzeit für sich wiederholen kann. Mit und bei dieser Beschäftigung verschaffe ich mir eine Auszeit. Ich ziehe mich auf eine Zeitinsel zurück, auf der ich eine Zeitlang frei verweilen kann, geschützt vor dem unerbittlichen Ticken der Uhr. Die Partitur ist ein Angebot, bietet mir als Ausführendem Gelegenheit, mich im Bewusstsein der Zeitlichkeit in der Zeit zu verlieren. Jeder Ton könnte der letzte sein, die ihm folgende Stille vorübergehende Unterbrechung oder endgültiges Ankommen.

Paradox bleibt es nach wie vor, dass ich mich in der Zeit verlieren kann beim gleichzeitigen Hören auf Verflüchtigungsprozesse. Ich spiele immer in Resonanz, ins Nachhallen, Nachschwingen, Nachklingen der letzten Klänge hinein, wenn ich weiterspiele. Eigentlich höre ich bei diesem Mir-Selbst-Zuhören, das ein Nach-Hören wird, sehr wohl das Verrinnen von Lebenszeit. Ich

19 | Ebd.

20 | Ebd., S. 7. 
kann hören, wie ich älter werde. Höre unentwegtes Verschwinden der Klänge - aber auch Erscheinen der nächsten. Auf diese Weise höre ich auch meinen eigenen zukünftigen Tod, wie Froberger den seinen heraushören konnte, auch wenn ich es mir nicht mit Worten sage. Man muss es nicht sagen, denn die Musik zeigt es. Die Ausführung wird so auch eine Übung darin, mich und mein Leben (so wie es ist, mit der Einschreibung des Sterbens) und das Leben der anderen anzunehmen in Demut; sie wird eine Übung in Affirmation.

\subsection{ISTVÀn ZeLENKa: "THE tRUMPET SHALL SOUND!" - Stillstück für einen Violoncellisten, MIT GLEICHZEITIGEN UMWELTKLÄNGEN UND ohne Publikum (1990)}

\section{Beschäftigung "per se" - im offenen Raum}

I

»Etwa 20" vor dem Beginn [...] öffnet der Violoncellist ein Fenster oder eine Tür und spielt seine Partie in der Mitte der hereinströmenden gleichzeitigen Umweltklänge. Um 15'oo" [nach 15 Minuten] schließt der Violoncellist das Fenster oder die Tür. $\ll^{21}$ Die Aufführungszeit beträgt also exakt 15 Minuten, es wird mit Stoppuhr gespielt. Einzelklänge und zwei- bis fünftönige Klangfolgen werden zu bestimmten Zeiten gespielt. Zwischen den Klängen bzw. Klangfolgen bleibt es still (vgl. Abb. 42).

Abbildung 42: Istvàn Zelenka: »The trumpet shall sound!«-

Stillstück für einen Violoncellisten, mit gleichzeitigen Umweltklängen und ohne Publikum, Beginn

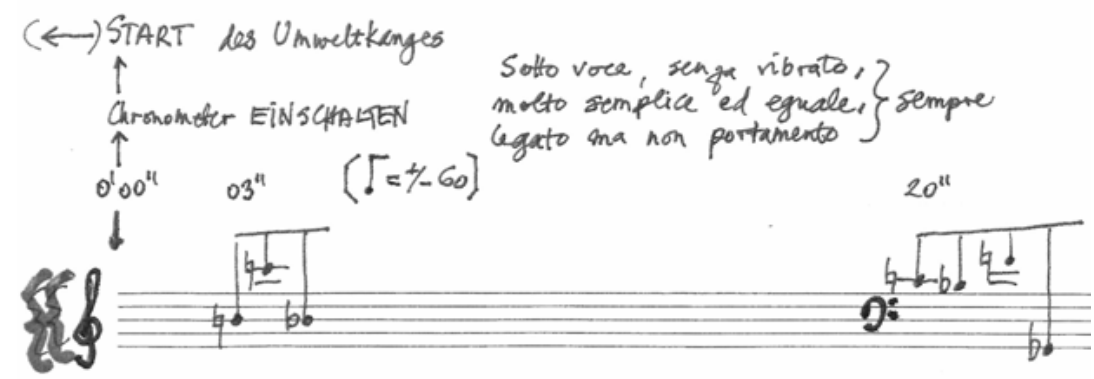

Manuskript; mit freundlicher Genehmigung des Komponisten

21 | I. Zelenka: "the trumpet shall sound!«, Partitur, Ausführungsanweisungen. 
Ein »Stillstück«? Sicherlich gibt es lange und sehr lange Pausen, eine halbe Minute Pause ist nicht ungewöhnlich. Hinzu kommt, dass das Spiel selbst stark zurückgenommen wird, man spielt sehr leise: »sotto voce, senza vibrato, molto semplice ad eguale, legato ma non portamente - sempre «. ${ }^{22}$ Sofern er diese Spielanweisung befolgt, wird der Spieler leicht von den »hereinströmenden« Umweltklängen verdeckt, falls er zum Beispiel an einer verkehrsreichen Straße das Fenster öffnet. Aber wer sollte einen auch hören, da doch ohnehin »ohne Publikum« gespielt wird? Der Ausführende hört sich selbst - damit gehört diese Komposition zu den »pièces de s'écoute«: Kompositionen, »bei deren Ausführung der Spieler sich selbst zuhört, gleichsam >für sich spielt< - >per se $<\ll^{23}$ Beim Spielen übt man, ganz still zu werden in der Beschäftigung, wobei die Musikklänge nicht einmal überwiegen oder in den Vordergrund treten.

Es ist auch nicht so, dass nach Ablauf der Aufführungszeit, nach 15 Minuten also, irgendetwas Bestimmtes erreicht sein sollte. Für »The trumpet shall sound!« gilt, was für alle Kompositionen Zelenkas bestimmend bleibt: »Produktion von: NEIN $\ll$ - »Beschäftigung mit: JA«. ${ }^{24}$ Das Tun ist das Entscheidende, und zwar ohne definitiven Abschluss, ohne antizipiertes und anzustrebendes Ergebnis. Wie Zelenka es an anderer Stelle formuliert hat: »[N]icht immer >besser< interpretierte Wiederholungen des Gleichen, sondern eine unermüdliche Beschäftigung innerhalb eines Kontextes oder im Rahmen von Variationen dieses Kontextes wird angestrebt«. ${ }^{25}$ Man übt aus, führt aus, tut (es), nach Möglichkeit wiederholt und immer (mal) wieder, ohne abschließende Konklusion. So wird dieses Tun zu einer Lebensaufgabe, die Platz im alltäglichen Leben findet. Zelenka hat mit dieser Komposition »The trumpet shall sound!« eine Praxis formuliert: das Angebot zu einer friedfertigen, friedlichen, dabei aufmerksamen und behutsamen Beschäftigung gemacht. Dies vor allem zeichnet die Komposition als »Stillstück« aus, gerade deshalb geht so viel Energie und Lebenskraft von ihr aus. Sie macht das Angebot, konkret etwas zu tun, zugleich (still und aufmerksam) zu sein.

Wozu? »Wir Komponisten, also kreativ zusammensetzende Akteure und Zeugen unserer Zeit/Welt, könnten/sollten uns über das Was, Wie und besonders Warum unseres Tuns unermüdlich befragen. ${ }^{26}{ }^{26}$ Ist die sorgfältige Beachtung der ästhetischen Aspekte [einer] Komposition ausreichend, um Klänge und Stillen, Wörter, Bewegungen/Gesten und Immobilität/Postierung wie auch Formen und Farben usw. usf. in einen inhaltsreich inspirierenden Kontext zu verwandeln?« Komponisten, Ausführende und Hörer bilden für

22 | Ebd., S. 1.

23 | E.-M. Houben/I. Zelenka: 1 Milieu, S. 37.

24 | E.-M. Houben/I. Zelenka: und/oder, S. 133, 128.

25 | Ebd., S. 20.

26 | Ebd., S. 17; das folgende Zitat ebd., S. 18. 
ihn eine Gemeinschaft; sie alle sind Teilnehmer an der Praxis, sind gleichermaßen Mitmachende; sie alle stellen sich gemeinsam diesen Fragen.

\section{II}

"Doch wo bleibt die Kommunikation, wo der Wunsch, etwas Ausdruckswertes mit dem Publikum zu teilen, Menschen zu bewegen? Der Hinweis, ’per se` zu spielen, zu agieren: zeugt er nicht für eine egozentrische Grundhaltung eines der Welt seinen Rücken zukehrenden Künstlers? Ich höre schon diese Einwände. ${ }^{27}$

Zelenka komponiert gerade für musikalische Laien, um eine Komposition zu einem Anstoß werden zu lassen, »sich mit (m)einer Folge von Aktionsvorschlägen eigenständig persönlich zu beschäftigen.«

»The trumpet shall sound!« für einen Violoncellisten ist zwar keine Komposition, die auch ein Laie ausführen könnte, denn sie verlangt Fähigkeiten eines ausgebildeten Cellisten. Aber Zelenkas Sicht auf das Spiel »per se« im Allgemeinen sagt doch viel über den Hintergrund aus, vor dem auch »The trumpet shall sound!« erscheint. Das Spiel »per se« ist absolut nicht als eine Tätigkeit in völliger Isolation von Mitmenschen und Umwelt zu verstehen. In Zelenkas Werkverzeichnis »1 Auswahl von Kompositionen« werden für eine Aufführung von »The trumpet shall sound!« unterschiedliche Aufführungsorte und -möglichkeiten genannt:

"Diese Komposition ist eine unter den Stücken des (Sich-Selbst-)Zuhörens; sie könnte interpretiert werden:

a/in einem intimen/privaten Raum mit Fenster oder Türe in die Aussenwelt, ohne Publikum, oder in Anwesenheit von einigen nahestehenden Personen;

b/an einem öffentlichen offenen Ort/Platz in der Stadt oder in der Natur, ohne ein dazu speziell eingeladenes Publikum;

$\mathrm{c}$ /integriert in ein Konzertprogramm oder Spektakel, simultan zu anderen, voneinander räumlich entfernten Produktionen;

d/eventuell im Rahmen eines etwas ıbesonderen، Konzertprogrammes. “28

Das »Stillstück« für einen allein ohne Publikum wäre demnach unter mehreren Aufführungsvarianten diejenige größtmöglicher Zurückgezogenheit. Und ist der Ausführende selbst im geschlossenen Raum ohne Kommunikation? weltabgewandt agierend?

27 | I. Zelenka, zitiert in: E.-M. Houben/I. Zelenka: 1 Milieu, S. 55; das folgende Zitat ebd.

28 | Ebd., S. 345ff. 
An dieser Stelle vielleicht der Hinweis auf einen Vergleich, den Zelenka zwischen dem Musik-Machen und dem Lesen zieht; in einer Email an Mark So schreibt er:

"Ich möchte Dir noch davon berichten, dass ich mich - fast wie an einer Nabelschnur hängend - mit dem Lesen verbunden fühle. Die Beziehung, die ein Leser zu einem Buch aufbauen kann, scheint mir eine überaus vielfältige und facettenreiche zu sein; der Leser verbringt Wochen oder Monate mit seinem، Buch, das ein Teil seines täglichen Lebens wird; der Leser wählt jederzeit den Umfang seines täglichen Lesepensums selbst aus, das Lesetempo, den Ausdruck, und könnte zu bereits gelesenen Passagen zurückkehren, könnte so seine eigene persönliche Interpretation ausbilden. Diese vielfältig aktive Beziehung zwischen Leser und Buch ist für mich irgendwie ein Modell auch für musikalische, klangliche, körperliche oder geistige Prozesse." ${ }^{29}$

Die Praxis, die »Beschäftigung« (Zelenka), wird Teil des Alltags, des täglichen Lebens. Auch bei der stillen Tätigkeit allein zu Hause oder irgendwo in der Welt bin ich mit der Welt verbunden. Diese Teilhabe ist zu spüren und zu erleben - durch die Praxis, die Teil des (alltäglichen) Lebens wird.

\subsection{ANtoine Beuger: POUR ÊTRe SEUL(E), SANS RÉSERVE FÜR KLAVIER (2009)}

\section{Allein-Sein: sich verlieren, sich verloren geben}

Das Klavierstück pour être seul(e), sans réserve lässt bereits im Titel die besondere Art des Alleinseins anklingen: »sans réserve«, rückhaltlos. ${ }^{30}$ Zehn Zeilen: zehn Pfade, sich zu verlieren (vgl. Abb. 43).

In der Partitur ist vermerkt: »immer langsam bis sehr langsam. leise bis sehr leise. manche klänge (vielleicht) (etwas) lauter. pedal: gelegentlich, poetisch. phrasierung: innigstes rubato. ${ }^{31}$ Bezüglich der Tondauern gibt es die Unterscheidung zwischen »(nicht zu) kurzen« (schwarzer Notenkopf) und »langen bis sehr langen« (weißer Notenkopf) Dauern. Einzelne Phrasen innerhalb einer Zeile werden durch »atempausen«, die immer »auch (viel) länger« sein können, gegliedert; ab und zu findet sich der Hinweis: »(usw)«, der bedeutet: »so (noch eine weile, noch lange) weitermachen (wenn man will)«.

29 | I. Zelenka: Fragment aus einer Email an den Komponisten Mark So, 17.02.2008, zitiert in: E.-M. Houben/I. Zelenka: 1 Milieu, S. 47.

30 | A. Beuger: pour être seul(e), sans réserve, Partitur.

31 | Ebd.; die folgenden Zitate ebd. 
Abbildung 43: Antoine Beuger: pour être seul(e), sans réserve für klavier, Zeilen 1-5
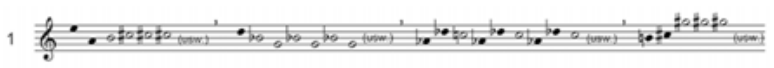

2

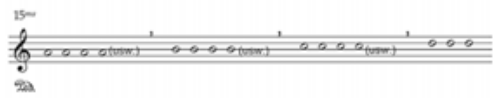

3

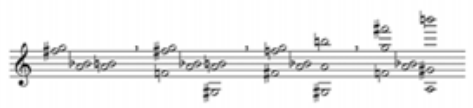

4
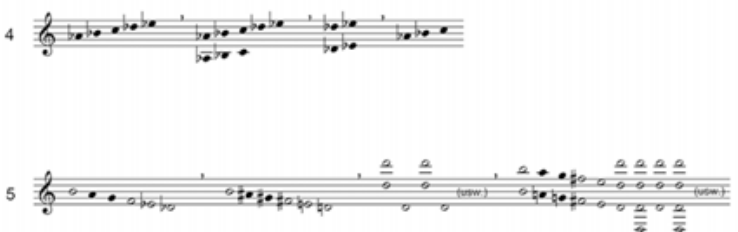

ew01.142; mit freundlicher Genehmigung der Edition Wandelweiser, Haan 2009

Ich gebe mich als Spieler jeder Zeile einzeln hin, folge ihrer Spur eine Zeitlang. Ich verliere mich beim Spielen in den Wiederholungen, die mehr passieren, als dass ich sie bestimmen würde. Klavierspielen geschieht mir. Beim Spielen bleibe ich mir selbst überlassen. ${ }^{32}$

Für diese Handlung des Wiederholens, bei dem ich mich mehr und mehr verliere, brauche ich als Spieler keine Adressaten. Ich bin wirklich ganz für mich allein - »sans réserve «.

Ich gehe durch mein Tun verloren, zugleich gebe ich mich (irgendwann) auch verloren; weiß auch gar nicht, wie lange ich schon spiele, wann etwa ich aufhören werde zu spielen. Solche Zeithorizonte verschwimmen. Das Stück macht mir das Angebot, mich verloren zu geben und die Zeit, die Ausführung, eventuell anwesende Zuhörer zu vergessen. Wozu?

Erfahrung von Verloren-Gehen, von Verloren-Geben zugleich. Ich mache durch das Tun diese Erfahrung und gewinne Vertrauen: Ich darf mich (in der Zeit) verlieren, ich darf verloren gehen. Erfahre Affirmation als ein Loslassen in Vertrauen.

32 | Eine erste Auseinandersetzung mit diesem Stück in: E.-M. Houben: Jürg Frey, S. 98-106. 


\section{Duo}

Wie begegnet die Kunst der Liebe - und umgekehrt?

"und was ist mit der kunst?

was hat sie mit der liebe zu tun?

ist die liebe etwas anderes als der einbruch der zwei in die kontinuität der eins?

was ist die liebesbegegnung, wenn nicht die emporhebung zweier menschen, zweier ahnungslos in ihrer existenz verweilender und um deren ungestörte fortsetzung sich mühender lebewesen, in das ihre angelernten fähigkeiten rücksichtslos überschreitende spiel der spaltung?

mitnichten macht die liebe aus zwei eins. sie macht aus dem einen, der ich bin, zwei, indem sie mich auf immer von meiner geliebten trennt. ${ }^{1}$

Zu-zweit-Sein heißt vor dem Hintergrund dieser Liebeserklärung an die Kunst und an die Liebe von Antoine Beuger: beisammen und getrennt sein zugleich; getrennt beisammen sein. Im Duo fragen beide: Wo bist Du? Und antworten: Ich bin hier. Wir sind nicht eins. Wir sind zusammen in der Zweiheit. Wir sind beieinander, indem wir nicht am gleichen Ort sind. Alain Badiou hebt die Trennung als wesentlichen Aspekt von Zweiheit hervor:

"Die Liebe hat zuerst mit einer Unterscheidung oder einer Trennung zu tun, die der schlichte Unterschied zwischen zwei Personen mit ihrer unendlichen Subjektivität sein kann. [...] Sie haben in der Liebe ein erstes Element, nämlich die Unterscheidung, eine Trennung, einen Unterschied, eine Zwei. Die Liebe behandelt zuerst eine Zwei. Der zweite Punkt ist: Eben weil die Liebe eine Trennung behandelt, kann sie in dem Moment, in dem sich die Zwei zeigt, als solche die Bühne betritt und uns die Welt in neuer Weise erfahren lässt, nur eine zufällige oder kontingente Form annehmen. “

Gibt es eine musikalische Praxis, in der dieses radikale Zu-zweit-Sein existentielle Erfahrung werden kann?

1 A. Beuger: die kunst, die liebe, S. 142.

2 | A. Badiou: Lob der Liebe, S. 31; Herv. i.0. 


\subsection{Federico Mompou: Cantar del Alma. Pour Piano et Chant (1951). Text: Saint Jean de la Croix}

\section{Getrennt-Sein in der Liebe}

I

Das Gedicht von Johannes vom Kreuz trägt den Titel »Cantar del alma que se huelga de conocer a Dios por fe« (»Lied der Seele, die sich freut, Gott im Glauben zu erkennen«). Federico Mompou hat nicht alle zwölf Strophen vertont. Hier der Text, wie er in Partitur wiedergegeben ist, sowie die Übersetzung ins Deutsche von Antoine Beuger:

Aquella eterna fuente esta escondida que bien sé yo do tiene su manida

Aunque es de noche

Su origen no lo sé pues no le tiene

mas sé que todo origen de ella viene

Aunque es de noche

Sé que no puede ser cosa tan bella

y que cielos y tierra beben de ella

Aunque es de noche

Sé ser tan caudalosas sus corrientes que infiernos cielos riegan y las gentes

Aunque es de noche

El corriente que nace de esta fuente

bien sé que es tan capaz y tan potente

Aunque es de noche
Sie liegt verborgen, jene Allzeitquelle, doch weiß ich wohl, wo sie zuhause ist, wenn es auch Nacht ist.

Ihren Ursprung weiß ich nicht, sie hat ja keinen,

ich weiß aber, dass jeder Ursprung ihr entspringt,

wenn es auch Nacht ist.

Ich weiß, dass nichts von solcher Schönheit sein kann,

Himmel und Erde laben sich an ihr, wenn es auch Nacht ist.

Ich weiß: so reich sind ihre Wasserströme, dass sie bewässern Höllen, Himmel, Völker,

wenn es auch Nacht ist.

Der Strom, zur Welt gebracht von dieser Quelle,

ich weiß, gleich weit und allgewaltig ist er,

wenn es auch Nacht ist. 
Aquesta viva fuente que yo deseo en este pan de vida yo la veo Aunque es de noche ${ }^{3}$
Die wilde Quelle, nach der ich mich sehne, in diesem Brot des Lebens seh' ich sie, wenn es auch Nacht ist. ${ }^{4}$

\section{II}

Ein Klavierlied? Klavier und Stimme kommen nie zusammen, spielen niemals gleichzeitig. Das Klavier setzt alleine ein: Der langsame, metrisch gebundene Klaviergesang, der sich von Note zu Note vorwärtsbewegt, ist als Vorspiel ungewöhnlich lang. Die Sängerin wartet, hört zu. Das Klavier spielt einen vierstimmigen Satz, der an einen Choral erinnert, wobei die Vierstimmigkeit stellenweise zur Fünf- und zur Sechsstimmigkeit ausgeweitet, aber auch bis zur Zweistimmigkeit zurückgenommen wird. Der Pianist verliert die Fäden nach einem vielstimmigen Akkord, tastet manchmal (an Stellen der Zweistimmigkeit) mit nur einer Stimme in einer Hand im luftleeren Raum.

Spätestens beim Einsatz der Stimme wird für beide das Getrennt-Sein offenbar. Frei und unbegleitet schwebt die Stimme, nur an Kürzen und Längen sowie an Zäsuren orientiert: »dans le style grégorien «. ${ }^{5}$ Drei der insgesamt sechs von Mompou ausgewählten Strophen werden beim ersten Erscheinen der Stimme zusammengefasst.

Danach ereignet sich ein Schnitt, der die gänzliche Trennung der beiden zutage treten lässt: Das Klavier wiederholt den choralartigen Satz des Beginns - allein. Es gibt kein Zugleich. Die Wiederholung des Eigenen offenbart die innige Trennung der beiden, die in diesem Liebeslied wirklich Zwei sind.

Auch die Stimme wiederholt, weiterhin allein, den Gesang »dans le style grégorien« (die zweite Hälfte des vertonten Ausschnitts); und wiederum wiederholt sich auch das Klavier. Stärker kann die Trennung nicht sein.

Diese zwei sind beisammen getrennt voneinander; sind beieinander, dabei nicht am gleichen Ort: sind Liebende. Dies Klavierlied als Duo lässt viel Freiraum, dieser Liebesbeziehung nachzuspüren - in Stille, die Musik geworden ist.

III

»Federico Mompou - nach Meinung von Olivier Messiaen einer der anregendsten zeitgenössischen Komponisten für Klavier - hat einen seiner Klavierzyklen Música callada (Verschwiegene Musik) genannt - eine Huldigung an den spanischen mystischen Dichter San Juan de la Cruz. $\ll^{6}$ Mauricio Rosenmann

3 | F. Mompou: Cantar del Alma, Partitur, S. 2ff.

4 | A. Beuger: Cantar del Alma, Ms.

5 | F. Mompou: Cantar del Alma, Partitur, S. 2.

6 | M. Rosenmann: Lieder ohne Ton, S. 3. 
weist auf die wichtige Quelle der Anregungen für Mompou hin: Johannes vom Kreuz.

Dem Zyklus Música callada hat Mompou folgenden Vermerk hinzugefügt:

"Il est assez difficile de traduire et d'exprimer le vrai sens de 'Música Callada، dans une langue autre que l'espagnole. Le grand poète mystique, San Juan de la Cruz, chante dans une de ses belles poésies: 'La Musica Callada, la Soledad Sonorar cherchant à exprimer ainsi l'idée d'une musique qui serait la voix même du silence. La musique gardant pour soi sa voix 'Callada‘, c'est à dire 'qui se tait‘ pendant que la solitude se fait musique." ${ }^{7}$

Mompou beschreibt die Schwierigkeit, den Titel »Música callada« zu übersetzen und in einer anderen als der spanischen Sprache den Sinn zu finden. Und er verweist auf den »Geistlichen Gesang« (»Cántico espiritual«) des Johannes vom Kreuz, in dem eine »Música callada«, eine ganz stille Musik, als »Stimme des Schweigens selbst« angesprochen werde (dies ist direkt in der 14. Strophe der Fall). »Música callada«: eine Musik, die schweige, während die Einsamkeit, das Alleinsein zu Musik werde. Die 14. Strophe des »Geistlichen Gesangs« lautet:

"la noche sosegada,

en par de los levantes de la aurora,

la música callada,

la soledad sonora,

la cena que recrea y enamora;

die Nacht in tiefer Ruhe,

beinahe schon der Morgenröte weichend,

Musik ganz still und lautlos,

das tönende Alleinsein,

das Abendbrot, das gut tut und verliebt macht." ${ }^{8}$

Cantar del alma: Stilles Alleinsein als Duo.

7 | F. Mompou: Música Callada, Partitur, S. 2; vgl. H. Henck: Programmnotiz.

8 | A. Beuger: San Juan de la Cruz. El cantico espiritual, S. 164, 165. 


\subsection{JÜrg FreY: Buch deR RäUME UNd ZeIteN für ZWEI Ausführende (1999) - Jürg Frey: Ohne Titel (ZWEi ViOLINEN) (1995/96)}

\section{Auch-da-Sein - nicht identifizierbare Differenz}

I

In der Gleichzeitigkeit bleibt jeder für sich. Es gibt keine Kommunikation, kein Aufeinander-Hin zwischen den Ausführenden. Jeder ist in einer eigenen Welt - in einem eigenen Raum, in einer eigenen Zeit:

'Jede Aufführung dauert 55'. An jeder Aufführung sind zwei Ausführende beteiligt. Aus den folgenden Stimmen werden zwei ausgewählt: Flöte, Bassklarinette, Trompete, Posaune, Stimme, Schlagzeug 1, Schlagzeug 2, Schlagzeug 3, Schlagzeug 4, Klavier 1, Klavier 2, Klavier 3, Klavier 4, Akkordeon, Violine, Viola, Violoncello, Tonband 1, Tonband 2. Die beiden Stimmen werden simultan gespielt. Die Dynamik ist leise." ${ }^{9}$

Wenn ich hier übe, meine Stimme zu spielen bzw. zu singen, während zugleich jemand anders seine Stimme spielt oder singt, übe und erlebe ich weniger ein Getrennt-Sein als vielmehr ein Auch-da-Sein.

Die Partitur bietet einem Spieler die einzelnen Zeiten und Räume auf ganz unterschiedliche Weise an. Mal verliere ich mich als Spieler (hier als Pianist) fast, wenn die Tondauern als Halbe und (übergebundene) punktierte Sechzehntel notiert sind (mit der Tempoangabe Viertel $=44$ ), während aber keine Taktgliederung, kein Puls vorliegt (vgl. Abb. 44).

Abbildung 44: Jürg Frey: Buch der Räume und Zeiten für zwei Ausführende, Klavier 3, S. 1 (Ausschnitt)

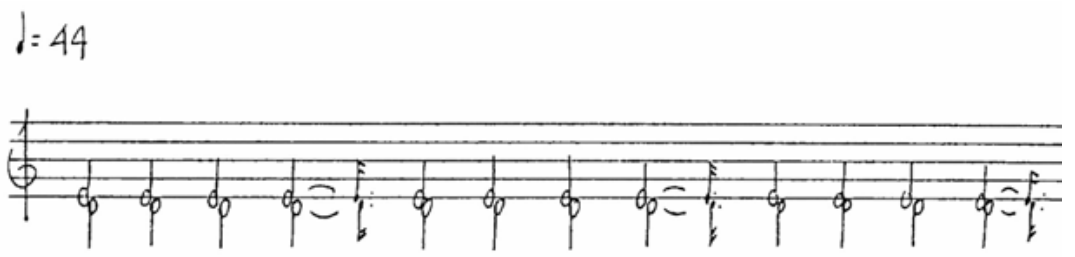

ew02.043; mit freundlicher Genehmigung der Edition Wandelweiser, Haan 1999

Im selben Stück sehe ich mich später mit einer ganz anderen Ordnung der Tondauern konfrontiert: Ganze sind hier zu bestimmten Zeiten (Spiel mit Stoppuhr) zu spielen, wobei die Tempoangabe Viertel = 6 o für die Ganzen gilt.

9 | J. Frey: Buch der Räume und Zeiten, Partitur. 
Bis zum Einsatz einer nächsten Ganzen, die bei dieser Tempoangabe 4 Sekunden dauert, bleibt es still (vgl. Abb. 45).

Abbildung 45: Jürg Frey: Buch der Räume und Zeiten für zwei Ausführende, Klavier 3, S. 3 (Ausschnitt)

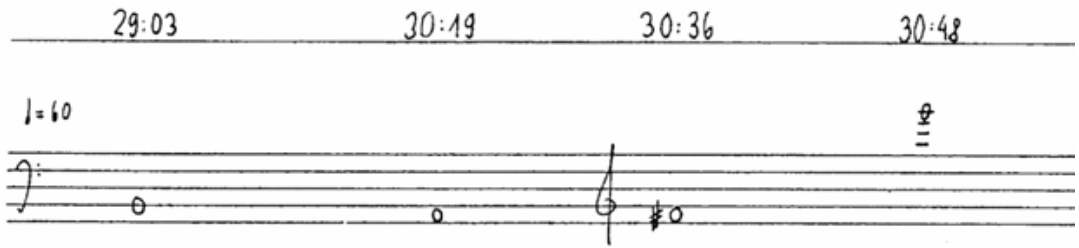

ew02.043; mit freundlicher Genehmigung der Edition Wandelweiser, Haan 1999

Schlagzeug 4 macht das Angebot verschiedener Klang- und Stille-Phasen an den Spieler; diese Phasen werden mit der Stoppuhr voneinander abgegrenzt, sodass ich zwischen kontinuierlichem, auch länger anhaltendem Spielen (Streichen) und Nicht-Spielen (mit einer Ausnahme bei 17:०o) wechsle (Abb. 46).

Abbildung 46: Jürg Frey: Buch der Räume und Zeiten für zwei Ausführende, Schlagzeug 4, S. 2

$$
\begin{array}{ll}
38: 00-42: 00 & 3 \text { Chinesische gongs: } 20-0-0 \\
42: 00-45: 00 & - \\
45: 00-55: 00 \quad \text { Grosse Trommel : } & \vdots
\end{array}
$$

ew02.043; mit freundlicher Genehmigung der Edition Wandelweiser, Haan 1999

Als Bassklarinettist bin ich fast ganz im Stillen versunken, wenn ich meine Stimme spiele (die Bassklarinette ist klingend notiert) (vgl. Abb. 47). 
Abbildung 47: Jürg Frey: Buch der Räume und Zeiten für zwei Ausführende, Bassklarinette, S. 1 (Ausschnitt)

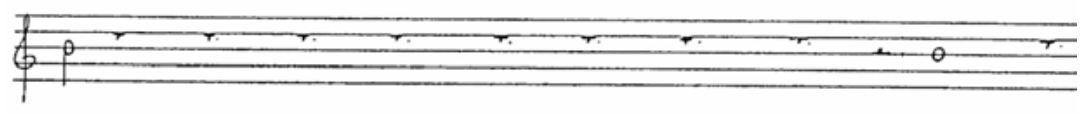

ew02.043; mit freundlicher Genehmigung der Edition Wandelweiser, Haan 1999

Erst zum Schluss hin, nach 41 Minuten, finde ich mehr Halt durch die Regelmäßigkeit der tiefen Impulse (vgl. Abb. 48).

Abbildung 48: Jürg Frey: Buch der Räume und Zeiten für zwei Ausführende, Bassklarinette, S. 4 (Ausschnitt)

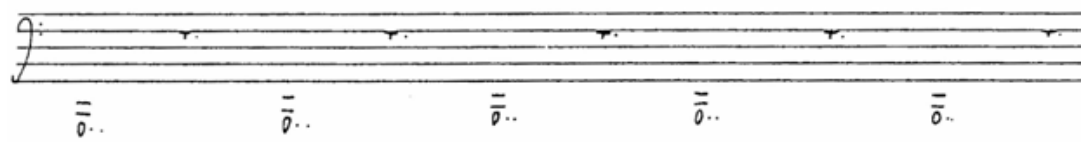

ew02.043; mit freundlicher Genehmigung der Edition Wandelweiser, Haan 1999

$\mathrm{Zu}$ erleben und $\mathrm{zu}$ erlernen ist, was es heißen kann, im Beisein des anderen Spielers ganz allein zu sein. Nur in Versunkenheit - anders kann man das nicht spielen.

Ein weiteres Beispiel: die Posaunenstimme. Die Stoppuhr gibt den jeweiligen Einsatz eines Klanges an, aber ich habe als Spieler die Aufgabe, von Klang zu Klang das Tempo zu wechseln, werde also in der Stille zwischen den Klängen das jeweils neue Tempo innerlich vorbereiten (vgl. Abb. 49).

Abbildung 49: Jürg Frey: Buch der Räume und Zeiten für zwei Ausführende, Posaune (Ausschnitt)

$$
\text { Tempo: } \begin{array}{r}
1: d=60 \\
2: J=52
\end{array}
$$
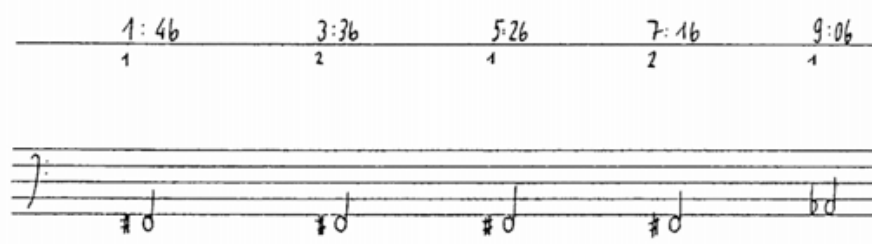

ew02.043; mit freundlicher Genehmigung der Edition Wandelweiser, Haan 1999 
Ganz eigen auch die Viola, ein letztes Beispiel: Hingabe an sehr lange, ausgehaltene Klänge und Pausen, 55 Minuten lang - und nur das (vgl. Abb. 50).

Abbildung 50: Jürg Frey: Buch der Räume und Zeiten für zwei Ausführende, Viola, S. 1 (Ausschnitt)

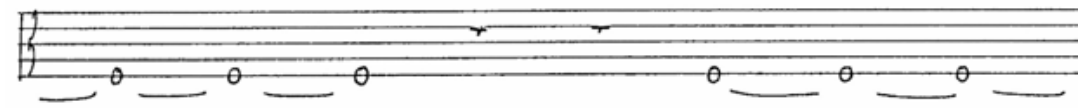

ew02.043; mit freundlicher Genehmigung der Edition Wandelweiser, Haan 1999

So bleibt jeder für sich.

Es durchdringen sich die zwei jeweiligen »Räume und Zeiten« auf unterschiedliche Weise. Immer nur zwei Spieler zugleich - jeder für sich: Was entsteht? Im Ineinander-Wirken und Aufeinander-Einwirken entsteht eine Art mobiler Plastik: keine bloße Addition der jeweiligen zwei Räume und Zeiten, sondern eine wechselseitige Durchdringung - bei ausdrücklicher Trennung voneinander. Dazu ist das Tun des jeweils anderen Spielers nötig, der im Verlauf der Ausführung seinen Raum erbaut. Die Spieler sind als Architekten beschäftigt, sie erschaffen ihren je eigenen Raum. Dies unterscheidet diese Beziehung von einer Liebesbeziehung.

II

Ohne Titel (Zwei Violinen): Die beiden durchwandern gemeinsam verschiedene klangliche Landschaften. Zunächst spielen sie beide Flageolett-Klänge, mal beide denselben, mal, leicht abweichend, nicht denselben (vgl. Abb. 51).

Abbildung 51: Jürg Frey: Ohne Titel (Zwei Violinen), S. 1 (Ausschnitt)

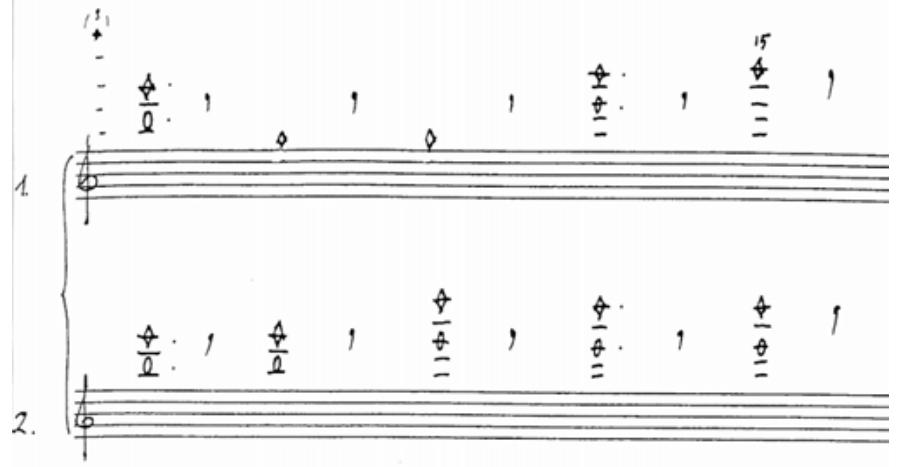

ew02.028; mit freundlicher Genehmigung der Edition Wandelweiser, Haan 1996 
Danach eine neue Landschaft: Beide üben sich darin, zugleich dasselbe zu spielen (vgl. Abb. 52): »[k]ein Flageolett, der eine Finger drückt die Saite ganz, der andere dämpft den Klang. Es entsteht eine Mischung aus Ton und Rauschen. Unabhängige Bogenwechsel der beiden Ausführenden. ${ }^{10}$

Abbildung 52: Jürg Frey: Ohne Titel (Zwei Violinen), S. 2 (Ausschnitt)

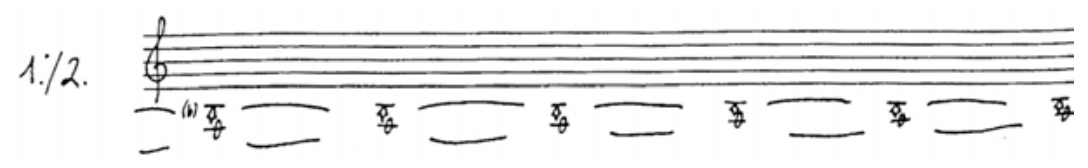

ew02.028; mit freundlicher Genehmigung der Edition Wandelweiser, Haan 1996

Eine feine Differenz, die man nicht identifizieren kann, die aber da ist, weil es eben zwei Ausführende sind. Hier werden nicht identifizierbare Differenzen gespielt, sondern im Gegenteil dieselben notierten Klänge - aber von zwei Spielern.

In der nächsten Landschaft spielen beide arco (mit dem Bogen) und pizzicato (gezupft), auch col legno battuto (mit dem Holz geschlagen) (vgl. Abb. 53). Für die gestrichenen Klänge gilt: »[A]uf einem Bogenstrich (es wird ein ganz leicht perforierter Klang entstehen).«

Abbildung 53: Jürg Frey: Ohne Titel (Zwei Violinen), S. 3 (Ausschnitt)

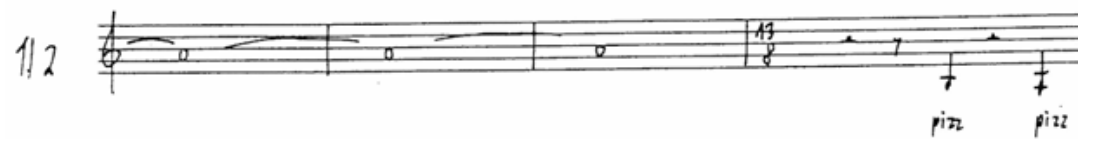

ew02.028; mit freundlicher Genehmigung der Edition Wandelweiser, Haan 1996

Es folgt ein Raum, in dem beide Spieler wiederum dasselbe spielen (»non div[isi]«): Klänge, die im Glissando den jeweils nächsten im Vierteltonabstand erreichen (vgl. Abb. 54).

Abbildung 54: Jürg Frey: Ohne Titel (Zwei Violinen), S. 4 (Ausschnitt)

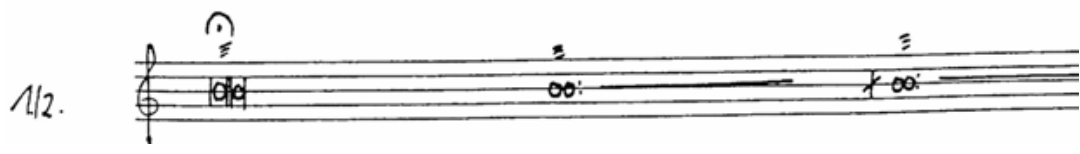

ew02.028; mit freundlicher Genehmigung der Edition Wandelweiser, Haan 1996

10 | J. Frey: Ohne Titel, Partitur, S. 1; das folgende Zitat ebd. 
Zuletzt spielen beide Repetitionen, bei minimalen Temposchwankungen. Die Klanggruppen zu je fünf Klängen im Sechzehntel-Zeitmaß $\left(5 /{ }_{16}\right.$; Viertel $=58$ und Viertel $=54$ ) werden jeweils von einer Viertel-Pause, die einen $4 / 16$-Takt ausfüllt, getrennt (vgl. Abb. 55).

Abbildung 55: Jürg Frey: Ohne Titel (Zwei Violinen), S. 5 (Ausschnitt)

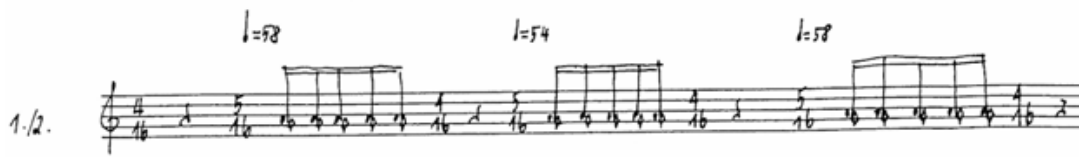

ew02.028; mit freundlicher Genehmigung der Edition Wandelweiser, Haan 1996

In (fast) all diesen Räumen tun beide dasselbe. Nicht ihr Tun unterscheidet sie, sondern allein die Tatsache, dass sie nicht Eins sind. Je mehr sie sich im Spielen einig sind, je weniger sie sich im Spielen unterscheiden, desto tiefer wird das Nicht-eins-Sein, das Zwei-Sein der beiden zu spüren sein.

\subsection{Ludwig van Beethoven: Violinsonate NR. 10 G-Dur OP. 96, 2. SATZ (AdAGIO ESPRESSIVO) (1812)}

\section{Aufeinander-zu-Gehen. Näherungen}

Das Klavier, zu Beginn allein, bereitet nicht nur vor, es singt. Sehr schlicht fängt es mit einer Bewegung an, die später für beide gilt (vgl. Abb. 56).

Abbildung 56: Ludwig van Beethoven: Violinsonate Nr. 10 G-Dur op. 96, 2. Satz (Es-Dur), Takte 1-8

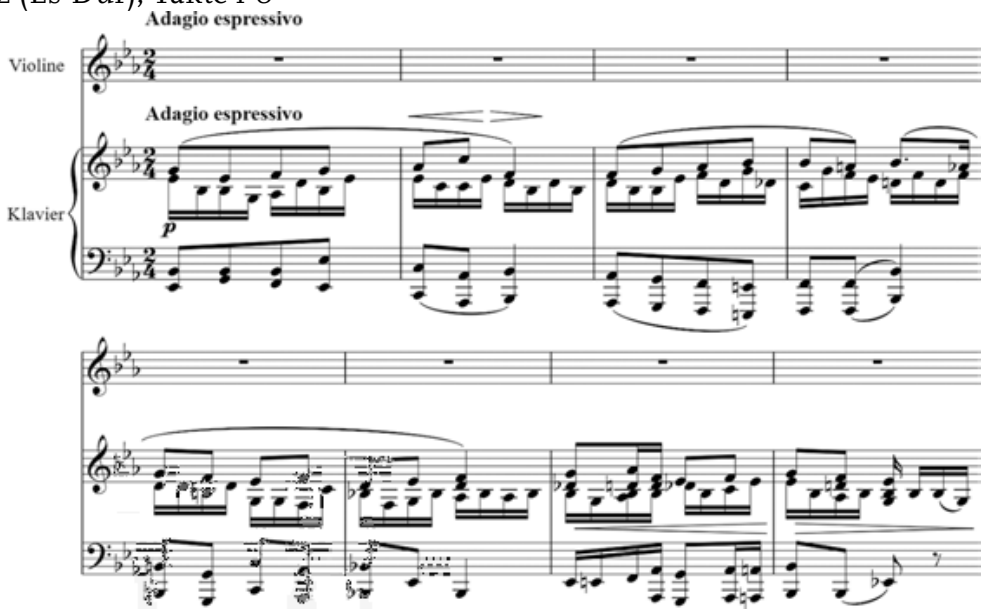


Ohne Sechzehntelbewegung würde dieser Gesang des Klaviers choralhaft auftreten, die Sechzehntel aber sind jedes Mal eine Hinführung zum je nächsten Ton. Ebenso führt der Bass in Achteln sanft jeweils von der unbetonten zur betonten Achtel. Die Violinistin hört dem Pianisten zu.

Sie nimmt (Takt 9) genau die Schlusswendung (die Töne $\mathrm{g}^{1}-\mathrm{f}^{1}-\mathrm{es}^{1}$; dann die Bewegung in Sechzehnteln, die vorher Begleitung war) auf, bestätigt damit, das Lied gehört zu haben. Nun singt das Klavier noch einmal die Phrase, eine Oktave höher. An dieser Stelle (Takt 11) kommt eine erste Kommunikation zu einem berührenden Abschluss: Ich habe Dich gehört, wie Du mir Dein Lied zugesungen hast (vgl. Abb. 57).

Abbildung 57: Ludwig van Beethoven: Violinsonate Nr. 10 G-Dur op. 96, 2. Satz (Es-Dur), Takte 9-11

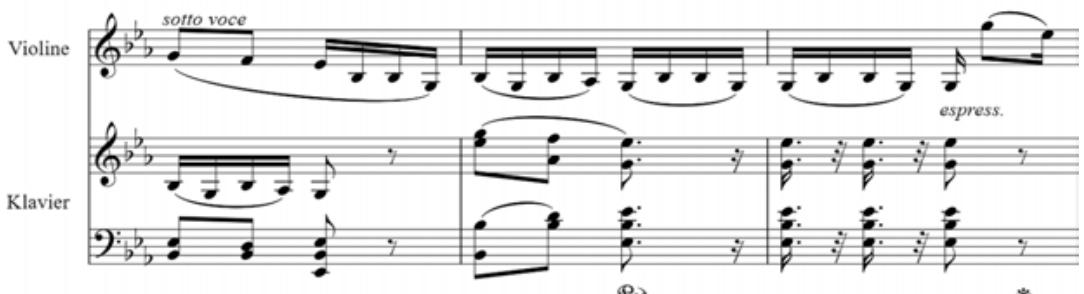

Red.

Es ist schwer auszudrücken, warum dieses Zusammenspiel einen als Hörer berührt. Es ist ja nicht damit getan zu sagen, dass sie so wunderbar zusammen musizieren, sondern es geht darum, den Ton zu finden für eine Beschreibung, wie die beiden hier beisammen sind.

Die rhythmische Figur ab Takt 12 im Klavier, von der Violine (Auftakt zur Melodie, Takt 11) übernommen (beim ersten Auftreten auch als melodisches Zitat mit den ersten Tönen g und es, nur eine Oktave tiefer), stützt jetzt die Violine, ist reine Begleitung geworden. Es ist eine ganz andere Kommunikationssituation als vorher entstanden, eine neue Welt wurde betreten. Die Violine singt hier eine neue Melodie, das Klavier begleitet mit einer zarten Figur. Es ist wie eine Berührung. Die Rollen sind also vertauscht worden, jetzt singt die Violine, das Klavier begleitet (vgl. Abb. 58).

Bei der nachfolgenden Akkord-Progression (ab Takt 21), welche eine Modulation in Gang setzt, hat sich die Art des Zusammenspiels wiederum gewandelt. Beide zusammen widmen sich jetzt der Progression. Das Klavier kann die Töne nicht halten, weil der Klavierklang naturgemäß nach dem Anschlagen verschwindet, deshalb werden jetzt Zweiunddreißigstel gespielt, um den Klang zu halten, ihm dieselbe Intensität zu verleihen, die der Violinklang leicht durch den Bogen zuwege bringt. Die Violine übernimmt eine Aufgabe, die das Klavier nicht erfüllen kann. 
Abbildung 58: Ludwig van Beethoven: Violinsonate Nr. 10 G-Dur op. 96 , 2. Satz (Es-Dur), Takte 12-15

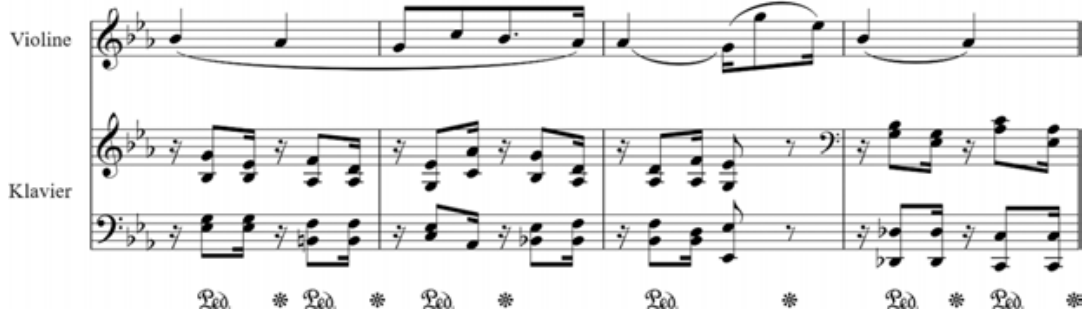

Überleitung zur Reprise (Takte 32-36; 36-37): Wie unter einer Fermate führt die Violine, auf dem Ton a insistierend, einen Stillstand herbei, um endlich, nach immer weiter ausgreifenden Figurationen, mit der hervorgehobenen Septime as zum deutlichen gemeinsamen Einschwenken in die Reprise überzuleiten (vgl. Abb. 59).

Abbildung 59: Ludwig van Beethoven: Violinsonate Nr. 10 G-Dur op. 96 , 2. Satz (Es-Dur), Takte 34-36

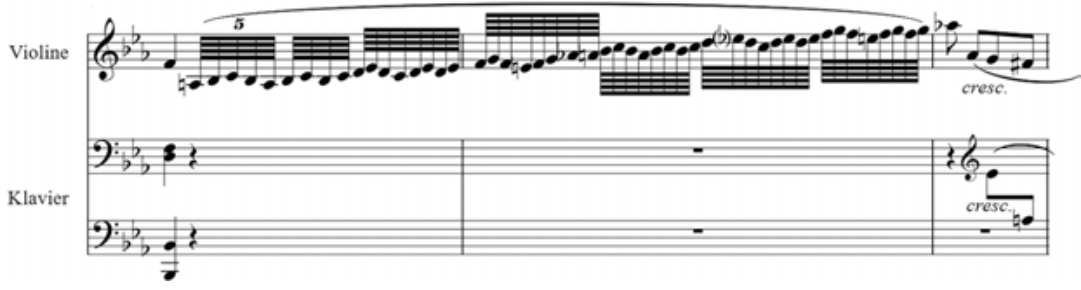

Diese Einführung des Tones as ist ein kurzer Schock. Der Violinton hängt einen Augenblick lang in der Luft, das Klavier hat keinerlei Einfluss auf das Geschehen. Die beiden spüren eine Zeitlang, wie sie in der Schwebe bleiben. In der Reprise werden die Rollen vertauscht. Wer vorher gesungen hat, begleitet nun - und umgekehrt.

An verschiedenen Orten der Komposition ereignen sich unterschiedliche Begegnungen, unterschiedliche Formen des Beisammen-Seins. Die Schlussakkorde etwa erfordern über sieben Takte hinweg ein gleichzeitiges Einsetzen, die Figurationen (zuerst in der Violine, dann im Klavier) erleichtern den Weg von einem Akkord zum nächsten. Hier ist man beisammen wie bei einer gemeinsamen Atmung.

Dieses Adagio bietet auf subtile Weise eine Praxis des Zu-zweit-Seins an, wobei jeder für sich ist und bleibt. Es zeigt, wie man als voneinander Geschiedene beisammen sein kann.

Jeder ist ganz für sich - und ganz auf den anderen ausgerichtet. 


\section{Trio}

Beim Zu-dritt-Sein dominiert nicht mehr, wie beim Duo, das Getrennt-Sein; die Gemeinsamkeit beginnt. Drei müssen sich einen Raum teilen. Für eine Erzählung braucht es drei, wissen Theatermacher.

Ein Dritter kommt hinzu - und schon ist der Verbund der zwei gestört, es kann etwas passieren. Während die Trennung das große Thema des Duos ist, thematisiert das Trio die Instabilität. Das Trio ist ein gefährdeter Körper. Kollisionen, Reibungen, aber auch Ausgleich und Schutz vor Gefährdung werden im Trio aktuell.

Die drei sind radikal aufeinander angewiesen.

\subsection{Franz Schubert: Trio in Es D 929 OP. 100, 2. SATZ (ANDANTE CON MOTO) (1827)}

\section{Unterschiedliche Schicksale - gemeinsam}

Ein Melodieton im Violoncello, noch einer - jeder Ton muss sehen, wie er weiterkommt. Der zähe Fortlauf dieses Themas, das auf das schwedische Volkslied »Se solen sjunker« (»Sieh die Sonne sinken«) zurückgehen soll ${ }^{1}$, findet einen Widerhall in den Tonrepetitionen des begleitenden Klaviers, die nicht unbedingt staccato, wie notiert, sondern auch non legato gespielt werden. ${ }^{2}$ Der Vortrag des Liedes im Violoncello verläuft hier zu Beginn mit Klavierbegleitung (Takte 1-20). Ein Duo übt sich in Einigkeit. Das auftaktige Motiv des Oktavsprungs abwärts (Takte 15-16) bremst den Fortgang; wie eine Fermate wirkt hier der Wechsel des Motivs vom Cello zum Klavier, zurück zum Cello, erneut zurück zum Klavier. Die Achtelnote ist auftaktig und dennoch mit einem Akzent versehen. Beide atmen hier: Ein- und Ausatmen, Ein- und Ausatmen (vgl. Abb. 6o).

1 | A. Feil: Kammermusik, S. 256.

2 Schubert Moscow Trio Piano Piano Trio op 100 ii andante con moto Московское Tpиo. https://www.youtube.com/watch?v=80odHh0JYSQ vom 07.04.2017. 
Abbildung 6o: Franz Schubert: Trio in Es D 929 op. 100, 2. Satz (c-moll), Takte 1-20
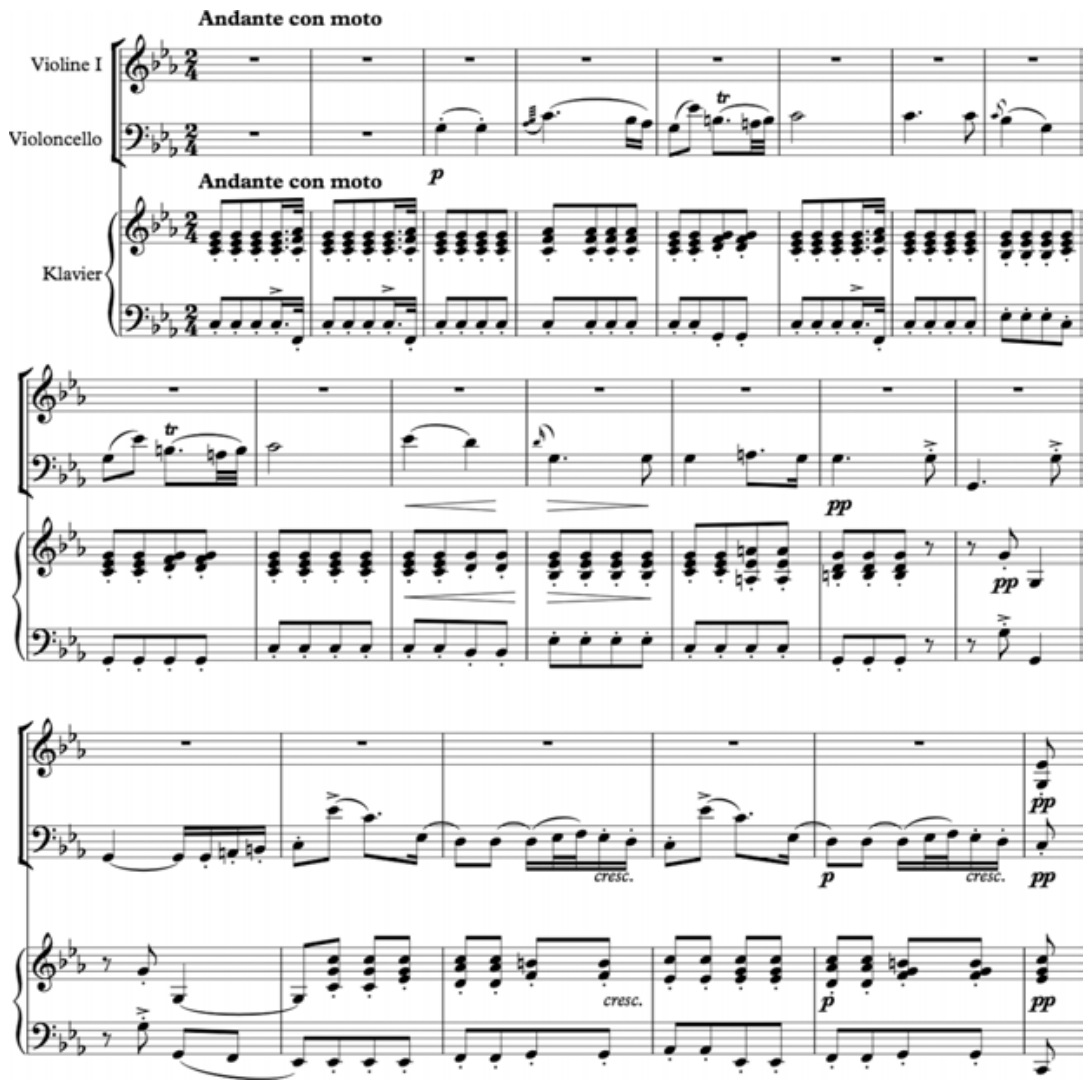

Nach dem Auftritt des Duos wechselt die Begleitung in die beiden Streicher, die sich nun zum Duo verbinden. In der Praxis zeigt sich: Begleiten ist keine untergeordnete Tätigkeit. Vielmehr tragen die Streicher jetzt das Lied mit Repetitionsketten, die Ton für Ton erscheinen und in denen jeder Einzelklang zum Leben kommen muss. Die beiden Streicher zitieren also den Klavierklang vom Beginn des Satzes; aber dieser wird unter ihren Händen etwas völlig anderes, wird das Spiegelbild vom Anfang. Auch die schwedische Melodie ist jetzt, vom Klavier im Oktavunisono vorgetragen, ganz anders geworden. So wie vorher auf dem Violoncello ist die Melodie auf dem Klavier nie zu spielen. Das Klavier tritt kühl auf, die Begleitung sehr intensiv und eindringlich. Die Streicher sind hier zu zweit. Einer, das Klavier, ist allein.

Mit dem Beginn des zweiten Themas (Takt 41ff.) gehen Violine und Klavier eine enge Verbindung ein. Die Violine und der Bass im Klavier sind komplementär aufeinander bezogen, jetzt sind diese beiden zusammen. Das Cello ist 
frei, es könnte auch nicht spielen. Aber es verstärkt die Akzente zusammen mit der Violine, Akzente, welche auftaktig sind (als Achtel), aber auch auf voller Zählzeit gespielt werden. Das Cello ist hier nicht so eng mit der Violine verbunden wie bei der Begleitung der schwedischen Melodie zuvor, es steht zwischen Violine und Klavier, fügt sich hier ein - Akzente verstärkend, kommentierend, Farben gebend.

Wenig später (Takt 52ff.) gesellt sich das Cello ausdrücklich der Violine und dem Klavier zu, sie sind jetzt zu dritt. Dieses Spiel ändert sich bald wieder, Violine und Cello gehen in eine komplementäre Bewegung, während das Klavier begleitet (Takt 57ff.). Ab hier gibt es unterschiedlichste Konstellationen auf engstem Raum: Duo Violine und Klavier (Bass) komplementär, Cello Triolenbewegung (Takt 68ff.); kurze Begegnung Cello und Klavier (Bass) (Takt 77); Cello und Violine im Unisono - komplementär zum Klavier (Takt 78-80).

Die nun folgende Pause und der Pianissimo-Übergang zum neuen Ansatz (Takte 81-84), ein Übergang, in dem jede Stimme eine andere Rolle übernimmt (Harfenarpeggios im Klavier, absteigende Tonleiter im Cello, Liegeklang in der Violine), sind Atemzäsuren vor der großen Steigerung. Zum ersten Mal übernimmt das Klavier beide Aufgaben, den Vortrag des Liedes und dessen Begleitung, während die Streicher zusammen einen Kontrapunkt spielen (Takt 86ff.), der hier zum ersten Mal erscheint.

Die drei betreten jetzt einen Raum, in dem jeder befreit eigene Wege geht, das Klavier sogar zwei Wege auf einmal. Zunächst (Takt 106) stimmen Violine und Violoncello gemeinsam das Lied an, während das Klavier mit einem atmosphärischen Klangfeld grundiert:

"[D]ie beiden Streichinstrumente sind parallel geführt, und das Klavier begleitet in tremolierenden Akkorden. Die sentimentale Melodie des schwedischen Volksliedes wirkt in solch nervöser Sphäre wie Sprechgesang. Als ob sie sich nimmer halten ließe, setzt sie sich in scharf skandierten Quartolen fort. Das Klavier kontrapunktiert mit gehackten Triolen, welche aus dem Tremolo entwickelt sind. Die Diffusion steigert sich zu einem Äußersten, wenn alle Instrumente eigene Zeitverläufe spielen und selbst der Klavierpart noch geteilt wird: die Oberstimme enthält die Quartolenmelodie, die Unterstimme die Triolenbegleitung. Die Geige fügt dem noch einen Dialog von roh staccatierten Zweiklängen, ebenfalls in Triolenbewegung, zu, und das Cello setzt aufgeregte Tremolo-Figuren dagegen. In dermaßen wirrer Polyphonie der Zeit ist das Lied gänzlich zersetzt. “ ${ }^{3}$

Dieter Schnebel hat in zwei »Versuchen über Schubert « - ^Af der Suche nach der befreiten Zeit« und »Klangräume - Zeitklänge« - Kompositionen Schuberts auf deren besondere Art der Strukturierung unterschiedlicher Zeitverläufe hin untersucht. In diesem Zusammenhang spricht er auch Stillstand von

3 | D. Schnebel: Auf der Suche nach der befreiten Zeit, S. 78. 
Zeit an, Zonen, in denen Zeit gleichsam suspendiert wird: »Zeitstrukturen der Art, wie sie in der letzten Klaviersonate beinahe dominieren, verdünnen gewissermaßen die Zeit, durchlöchern, ja kupieren sie, so daß gähnende Stille hervortritt: Leere als Wesen von unartikulierter Zeit.« ${ }^{4}$ Die soeben erwähnte Stelle aus Schuberts Andante-Satz (in »wirrer Polyphonie der Zeit«) zieht er als Beispiel für das »andere Extrem« heran (vgl. Abb. 61): »die konzentrierte [Zeit], indem heterogene Verläufe sich zu chaotischer Komplexion verdichteten, bis Zeit fast selbst zerführe.«

Abbildung 61: Franz Schubert: Trio in Es D 929 op. 100, 2. Satz (c-moll), Takte 119-121

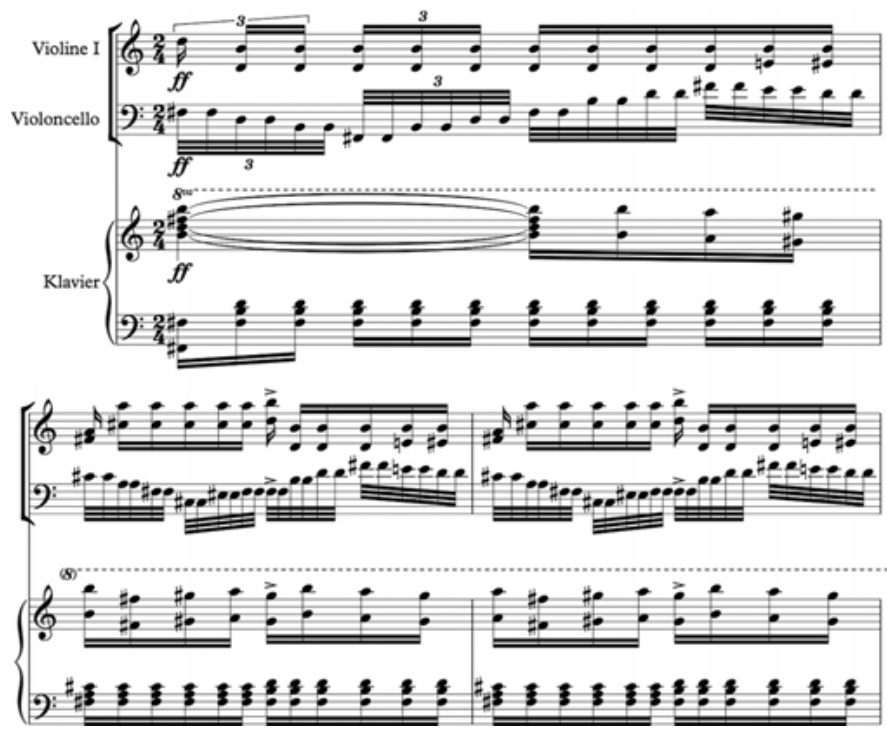

Das schwedische Lied tritt im weiteren Verlauf nicht wieder auf, abgesehen von Fragmenten in der Coda (Takt 196ff.), wohl aber erscheinen die bisher erprobten Formen des Zusammenspiels wieder. Klavier und Cello gehen komplementär zusammen (Takt 129ff.) wie zuvor Klavier und Violine; das Klavier begleitet das komplementär zueinander spielende Duo Violine und Cello (Takt 145 ff.) wie vordem.

Was Schnebel als »Diffusion« und »wirre Polyphonie der Zeit« beschreibt, ist ein Extrem des Zusammenspiels, eine Aufspaltung des Trios in drei Einzelne, genau genommen sogar in vier Einzelne, wenn man die Aufspaltung der Klavierstimme in zwei Schichten berücksichtigt. In beruhigter und still dahinfließender Zeit ist Individualisierung vor allem bei den Übergängen zu

4 | Ebd., S. 77f.; das folgende Zitat ebd., S. 78. 
finden, in denen jeder der drei Spieler die zufallende Aufgabe des Überleitens für sich löst (Takte 82-84; 193-195) (vgl. Abb. 62a, 62b).

Abbildung 62a: Franz Schubert: Trio in Es D 929 op. 100, 2. Satz (c-moll), Takte $82-83$

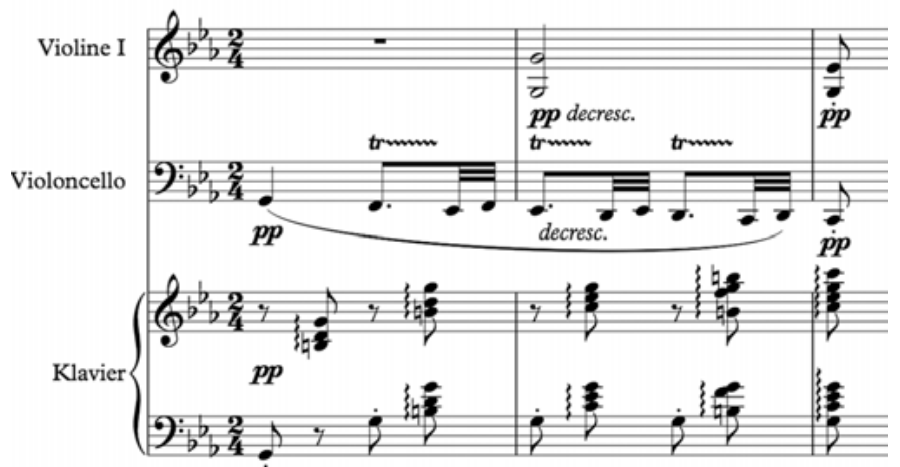

Abbildung 62b: Franz Schubert: Trio in Es D 929 op. 100, 2. Satz (c-moll), Takte 193-195

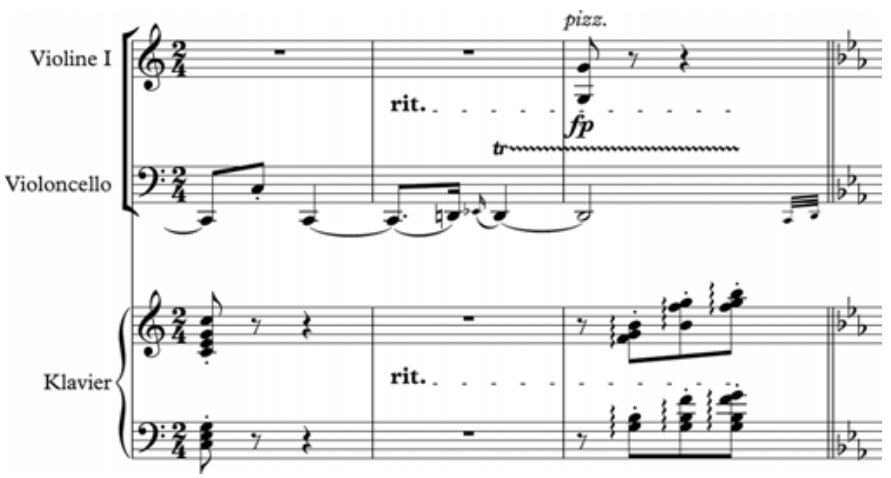

Das Trio kann vorübergehend ein Duo werden, mit und ohne Begleitung, mit verschiedener Art von Begleitung; ein Einzelner kann sich in unterschiedlicher Weise einem Duo zugesellen; drei können als drei Einzelne auftreten, die gänzlich unterschiedliche Wege gehen. Verschiedene Orientierungen in diesem Dreierverbund ermöglichen unterschiedliche Farbgebungen, Akzentuierungen, Entwicklungen, Atmosphären, bewirken auch Mobilität der thematischen Gestaltungen, die mehr oder weniger hervortreten oder sich verhüllen können. Das schwedische Lied zum Beispiel ist auf dem von Schnebel beschriebenen Höhepunkt zunächst gut herauszuhören, verschwindet aber dann mehr und mehr im Trubel der sehr eigen agierenden Stimmen. 
Das vielgestaltige Zusammenleben der drei Spieler treibt eine Geschichte hervor, der aufgrund der Transparenz des Trios bis ins kleinste Detail hinein $\mathrm{zu}$ folgen ist.

\subsection{Arnold Schönberg: Streichtrio OP. 45 (1946)}

\section{Trio-Körper in Pulsation: drei Körper sein, ein Körper werden. Ein Körper bleiben?}

I

Hier ist der Puls Garant dafür, dass die äußerst instabile Situation trotz allem gerade noch aufrechterhalten werden kann. Es ist der gemeinsame Puls, der den Trio-Körper zusammenhält. Immer wieder scheren einzelne Körperteile aus und ziehen sich wieder zurück in den Trio-Körper. Jeder ist zugleich einer und drei. Jeder kann jederzeit die Gruppe verlassen und wieder in den Verbund eintreten: für jeden ein Geschehen auf engstem Raum.

Gleich zu Beginn bilden Violine und Viola mit der Trillerbewegung (»quasi trill«) ein Duo, das Cello setzt sich mit einem weiträumig aufgefächerten, durch Flageoletts aufgelösten Thema dagegen (Takt 1). Im nächsten Takt wandert die weit gespreizte Gestalt in die Viola, wobei das Cello aber nur zum Teil eine Duo-Bindung zur Violine eingeht (Takt 2) (vgl. Abb. 63).

Abbildung 63: Arnold Schönberg: Streichtrio op. 45, Takte 1-2

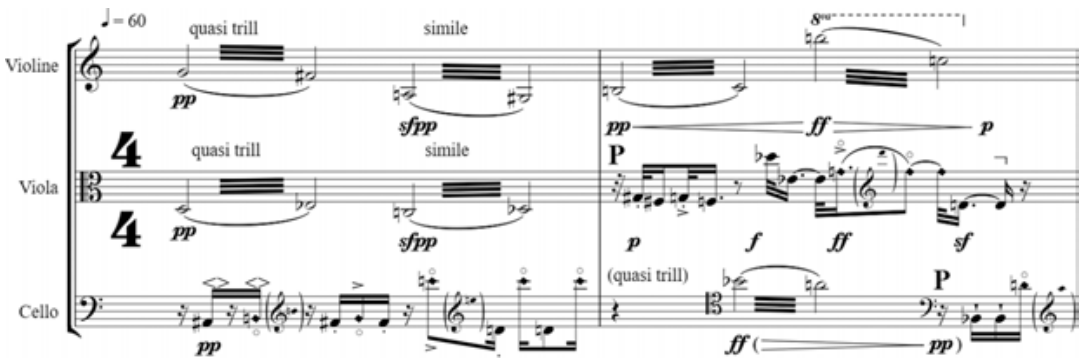

Schönberg STRING TRI0, OP. 45, Copyright (C) 1946 by Boelke-Bomart, Inc.

Copyright (C) renewed. All Rights Reserved. Used by permission of Boelke-Bomart, Inc.

Bei intensiver Bindung der drei Spieler aneinander gibt es immer wieder Individualisierungen (zum Beispiel die Alleingänge der Violine, Takte 8-11). Selten sind alle zusammen (wie in den Takten 37-40), dies sind ganz spezielle Momente (vgl. Abb. 64). 
Abbildung 64: Arnold Schönberg: Streichtrio op. 45, Takte 37-40

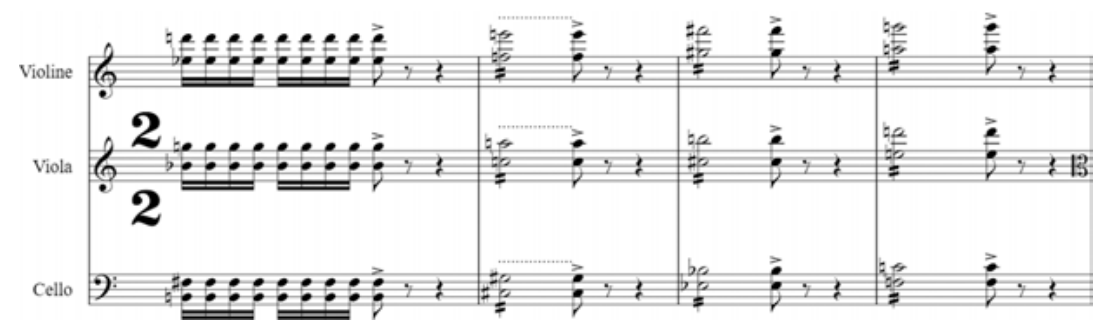

Schönberg STRING TRI0, OP. 45, Copyright (C) 1946 by Boelke-Bomart, Inc.

Copyright (C) renewed. All Rights Reserved. Used by permission of Boelke-Bomart, Inc.

Die nachfolgende Phrase (Takte 41-44) zeigt, wie schnell die Orientierungen wechseln, damit das Spiel am Puls entlang möglich bleibt: Duo Viola und Cello (Takt 41), Duo Violine und Viola (Takt 42), Duo Violine und Cello (Takt 43), Duo Viola und Cello (Takt 44).

Augenblicke der Individualisierung und stets wechselnde Duo-Bildungen führen zu einem Geschehen zwischen Aufspaltung und Zusammensein. Dabei ändert sich die Pulsation ständig (Taktwechsel, Tempowechsel). Auch treten vielfältige Spielweisen (wie »col legno battuto « [mit dem Holz geschlagen], »col legno tratto ponticello « [mit dem Holz auf dem Steg - hier mit dem ausdrücklichen Hinweis, wirklich auf dem Steg und nicht nahe dem Steg zu spielen], pizzicato [gezupft] und viele mehr), Flageoletts und dynamische Gegensätze auf. Ohne den durchgehenden Puls wäre dieses aufregende Wechselspiel nicht möglich. Oft spielt man gegen den Puls. Die Pulsation drückt sich auch in der Körpersprache der Spieler aus.

Wie positionieren sich die Spieler im Raum? Gewinnt das Trio an Kraft durch größere Entfernung der Spieler voneinander? - durch eine Positionierung des Cellos in der Mitte? ${ }^{5}$ Von der räumlichen Entfernung der Ausführenden voneinander hängt vieles ab. Je weiter sie auseinander sitzen, desto mehr könnte diese Distanz der Aufführung zugutekommen, eben weil sie wie ein einziger Körper miteinander verbunden sind. Keiner kann diesen Verbund für längere Zeit verlassen.

5 | Vgl. Schoenberg String Trio by Trio Battuto. Natsuki Kumagai, violin, Hannah Nicholas, viola, and Alexander Hersh, cello at New England Conservatory's Jordan Hall, Chamber Music Gala 12/10/2012. https://www.youtube.com/watch?v=L_yCNIXjJGo vom 07.04.2017. 
II

Schönberg soll Hanns Eisler auf eine enthusiastische Bemerkung bezüglich des Trios geantwortet haben: »Wissen Sie, ich war so schwach, ich weiß gar nicht, wie ich das geschrieben hab. Ich hab irgendwas zsammgeschrieben. ${ }^{6}$ Hans Heinz Stuckenschmidt, Biograf Schönbergs, ergänzt: »Und er zeigte Eisler, wie Akkorde Injektionen schildern. ${ }^{7}$ Das Streichtrio entstand 1946 unmittelbar nach einer schweren Erkrankung Schönbergs: »Puls und Atem setzten aus. Der Arzt machte eine Injektion in das Herz selbst und brachte Schönberg zum Leben zurück.«

Die Rede von der das gesamte Trio beherrschenden Pulsation drängt wiederum die Frage auf: Was tun die drei Ausführenden hier? Wozu? Sie bilden einen dreifachen Körper: einen amorphen Körper, der ständig gefährdet ist; einen Körper, der auseinanderzubrechen droht. Die drei Spieler haben die Entscheidung getroffen, sich zu einem solch fragilen, instabilen Körper zusammenzufinden. Was sie zusammenhält, ist der Puls.

Sie bilden als Trio-Körper weniger Kommunikationsstrukturen aus, übernehmen vielmehr Körperfunktionen unterschiedlicher Art. Das Trio stellt die Ausführenden vor große Herausforderungen: Wie kommt man damit zurecht, dass das Subjekt zerfällt, dass es im Leben ständig neue Wendungen nehmen kann, dass man (sich) nie sicher sein kann? Es führt die Ausführenden in Situationen der Instabilität und Unvorhersehbarkeit, in denen unvermittelt verschiedene Regungen und Impulse auftauchen können.

Was tun in einer Welt des Risikos, der Gefährdung, der krisenhaften Existenz? Mit der Ausführung dieses Trios begibt sich jeder Einzelne in eine gewagte Unternehmung - völlig auf die anderen angewiesen.

\subsection{Mathias Spahlinger: 128 erfüllte augenblicke. SYSTEMATISCH GEORDNET, VARIABEL ZU SPIELEN. FÜR STIMME, KLARINETTE UND VIOLONCELLO (1975)}

\section{Kontinuität als Utopie. Werden von (je eigenen) Ordnungen}

128 erfüllte augenblicke: Der Titel dieses Trios ist ein Versprechen, formuliert eine Utopie. Sagt, was das Trio-Spiel in der Praxis werden könnte, wenn man das Angebot ernst nimmt. Vielleicht findet ein Trio-Ensemble dann gemeinsam einen ganz besonderen Zugang, bereitet nicht eine bestimmte Version für einen Programmpunkt in einem Konzert vor. Denn das Angebot geht viel weiter: Die Partitur macht das Angebot zu einer intensiven und dauerhaften

6 | A. Schönberg, zitiert in: H. H. Stuckenschmidt: Schönberg, S. $435 f$.

7 | Ebd., S. 436; das folgende Zitat ebd., S. 435. 
Beschäftigung mit diesen vielen losen Seiten und fordert dazu heraus, sich deren Anspruch zu stellen. Wie lassen sich die »128 Augenblicke« ins Leben hereinholen? Wie kann aus diesem Stück eine Praxis werden?

Die Partitur: 128 lose Seiten. Eine jede präsentiert die Notation eines bestimmten Augenblicks; diese Augenblicke können von sehr kurzer Dauer sein oder sich länger ausdehnen (die Dauer schwankt zwischen 2" und 4'20"). In der Vorbemerkung zur Partitur wird das Zustandekommen der 128 augenblicke erläutert: Aus einem »gedachten kontinuum «zwischen a) weniger und mehr verschiedenen Tonhöhen, b) längeren und kürzeren Dauern, c) Tonhöhen und Geräuschen werden einzelne Stationen, und zwar für jede der hier genannten Dimensionen jeweils vier, herauskristallisiert. ${ }^{8}$ Da diese Kristallisationspunkte einmal mit zunehmender, einmal mit abnehmender Tendenz auftreten, ergeben sich insgesamt 4 × 4 × 4 × $2=128$ Augenblicke. Ein Würfel veranschaulicht die Dimensionen: weniger - mehr verschiedene Tonhöhen werden in der Höhe, längere - kürzere Dauern in der Breite, bestimmte Tonhöhen - Geräusche in der Tiefe dargestellt. So lässt sich jeder Augenblick mit einer dreistelligen Zahl (beispielsweise .134 oder .223) bezeichnen - hinzugefügt wird jeweils noch das Zeichen für zu- oder abnehmende Tendenz: < und > (vgl. Abb. 65).

Abbildung 65: Mathias Spahlinger: 128 erfüllte augenblicke. systematisch geordnet, variabel zu spielen. für stimme, klarinette und violoncello $(.213<)$

\section{$.213<$}

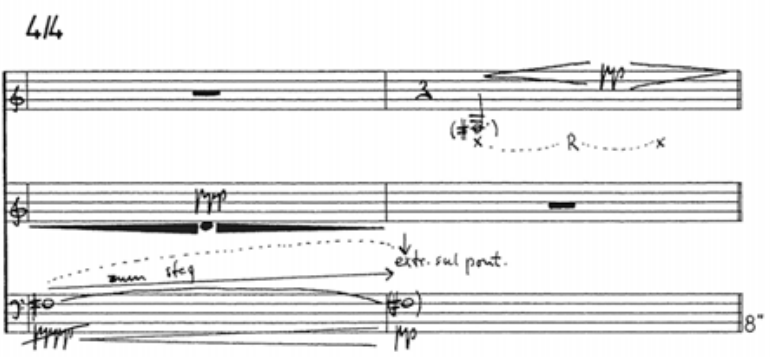

Spahlinger "128 erfüllte augenblicke", KM 2403, (c 1989 by Breitkopf \& Härtel, Wiesbaden, Abdruck mit freundlicher Genehmigung

Ein Kontinuum zwischen Extremwerten lässt sich nicht darstellen. Jeder Punkt im dreidimensionalen Würfel ist nur ein Schnitt im vorgestellten Kontinuum. Wir haben es also bei dieser Partitur mit Partikeln, Ausschnitten zu tun, die auch nichts anderes sein wollen. Nur indem diese Partikel isoliert (aus

8 | M. Spahlinger: 128 erfüllte augenblicke, Partitur, vorbemerkung. 
dem gedachten Kontinuum herausgeschnitten) werden, können sie überhaupt dargestellt und dann gegebenenfalls zu »erfüllten« werden:

"daß sich diese dreidimensionale form nicht im musikalischen verlauf darstellen läßt, trennt die augenblicke, als einander ausschließen wollende, voneinander und öffnet sie zugleich - in einer traurigen freiheit - füreinander. sie sind in jeder beliebigen, von den spielern zu wählenden reihenfolge und anzahl, auch wiederholt, zu spielen." ${ }^{9}$

Die einzelnen Augenblicke wenden sich einander zu: Aber dies kann nur durch ihre Trennung voneinander gelingen, anders ist diese Öffnung nicht zu haben. In diesem Sinne spricht Spahlinger auch von einer »traurigen freiheit«.

Die Anlage der Komposition lädt dazu ein, Augenblicke zu konstituieren, die Augenblicke (und sonst nichts) sein dürfen. Es geht darum, Orte aufzusuchen, Ortlosigkeiten gemeinsam auszuhalten. Blättern: Hier sind wir jetzt. Man ist immer nur dort, wo man gerade immer neu jetzt ist: auf diesem einen Blatt. Die Notation empfiehlt diese Haltung auch. Mit Ausnahme der längeren Augenblicke ist jeder Augenblick auf einem weißen Notenblatt von einem großen Rand umgeben, der aussieht wie ein Passepartout. Hier wird die Isolation optisch sichtbar. Diese Isolation wirklich leben: Das ist die Praxis hier.

Praxis konkret: Begutachtung, Erproben aller Seiten, Auswahl von Seiten, Einigung auf ausgewählte Seiten, Einigung bezüglich Reihenfolge, Wiederholungen, Gesamtdauer vielleicht; auch Einigung hinsichtlich der Frage, ob die Entscheidung bezüglich der Wiederholung von Augenblicken vor oder während des Spielens erfolgen soll.

Jeder Augenblick steht für sich. Was passiert zwischen einem Augenblick und seiner Wiederholung, zwischen einem Augenblick und dem nächsten anderen? Spahlinger sagt in den Vorbemerkungen etwas dazu, wenn er von der »Trennung« der Augenblicke spricht. Durch die Trennung erst kommt die Öffnung zustande.

Kontinuität und einzelner (gedachter) Punkt in der Kontinuität treten in ein Spannungsverhältnis zueinander. Spahlinger setzt sich mit dieser (in diesem musikalischen Sinne eben auch politischen) Komposition für ein Denken und ein Leben ein, die nicht dem Geteilt-Sein nachgeben. Die Teilung wird vollzogen, um die Utopie von Kontinuität zu entwickeln. Um ein produktives Verhältnis zwischen Kontinuität und Diskontinuität zu entwickeln.

»traurige freiheit«: In diesem Augenblick jetzt bin ich frei, bin ich nicht in eine Struktur eingebunden; aber der Preis, den ich bezahle, ist die Isolation. Die Trennung der Augenblicke macht deren Beziehung zueinander überhaupt erst möglich. Das Trennende ist das Verbindende. 
Das Befreiende: All diese Seiten haben nicht den Anspruch, etwas anderes zu sein als Schnitte in einem Kontinuum. Kein Augenblick will hervorstechen, etwas Besonderes sein. Details sind sogar unwichtig: »daß alles ebensogut anders sein könnte - könnte alle notwendig entstehenden text-kontext-hierarchien als >temporär $<$ und >gradweise herrschend < [hölderlin] durchschaubar machen. ${ }^{10}$ Jeder Augenblick ist als Angebot der Partitur völlig unprätentiös, hat keinen anderen Anspruch als Schnitt zu sein. Hierin liegt die große Chance zu entdecken, was erst beim Spielen aufgeht; zu erfahren, wie der Augenblick ein »erfüllter« werden kann.

10 | M. Spahlinger, zitiert in: P. N. Wilson: Booklet zur CD. 



\section{Quartett}

"[I]ch will [...] nichts gegen die großen, für Orchester geschriebenen Werke sagen, aber ich zweifle nicht daran, daß das Streichquartett, in dem jeder die volle Verantwortung für seine Stimme hat, eine subtilere und höher entwickelte Form der musikalischen Kommunikation ist. " ${ }^{1}$

Yehudi Menuhins besondere Wertschätzung der Kommunikationsmöglichkeiten im Streichquartett (im Vergleich mit denjenigen im großen Orchester) gründet sich auf die ausgewogene Zuordnung einer jeden einzelnen Stimme zu jeder anderen einzelnen Stimme. Streben nach Individualisierung und Integrationstendenz halten sich die Waage. Dabei ist der Zusammenhalt der Vierergruppe weniger gefährdet als das Band, welches das Trio zur Gruppe vereint; im Quartett stabilisiert sich der Verbund.

Wie tun sie das? Noch einmal neu stellt sich die Frage nach der Sitzordnung, nach der Platzierung jedes Einzelnen. Wie kommen Zuordnung des Einzelnen zu den anderen und Balance der Gruppe insgesamt am besten zur Geltung?

Ensembles lösen diese Frage auf unterschiedliche Weise. Die bevorzugten Varianten: Das Violoncello außen, auf der rechten Seite, gegenüber der ersten Violine $^{2}$ - oder die Viola außen, auf der rechten Seite, daneben das Cello. ${ }^{3}$ Auch durchaus eine Möglichkeit: Der Cellist sitzt als zweiter Spieler von links, neben der ersten Violine; der Bratschist folgt, mit der zweiten Violine schließt sich der Halbkreis. $^{4}$

$\mathrm{Zu}$ welcher Ordnung sich ein Ensemble auch entschließt: Die vier Spieler teilen sich den gemeinsamen Raum, in dem sie in je eigener Verantwortung aufeinander angewiesen sind.

1 | Y. Menuhin: Ich bin fasziniert von allem Menschlichen, S. $110 \mathrm{f}$.

2 | Quatuor Ebène: Ludwig van Beethoven String quartet Nr. 15 a-minor 0p. 132. https://www.youtube.com/watch?v=yB556rR00AE vom 20.09.2017.

3 | Beethoven String Quartet Op.59 No.1 "Razumovsky". https://www.youtube.com/ watch?v=oXLKu-HgInM vom 20.09.2017.

4 | Haydn string quartet in g minor, 0p.74, No. 3 -Rider by Abel quartet. https://www. youtube.com/watch?v=F8rdKOXpJoA vom 20.09.2017. 


\subsection{Ludwig van Beethoven: Streichquartett Nr. 10 Es-Dur OP. 74 ("HaRfEnquartetT"), 1. Satz, Einleitung Poco Adagio (1809)}

\section{Aufeinander-angewiesen-Sein in Freiheit}

I

Betrachten wir nur die ersten zwei Takte: Jeder Einzelne spielt eine eigene Melodie (vgl. Abb. 66).

Abbildung 66: Ludwig van Beethoven: Streichquartett Nr. 10 Es-Dur op. 74, 1. Satz, Einleitung Poco Adagio, Takte 1-2

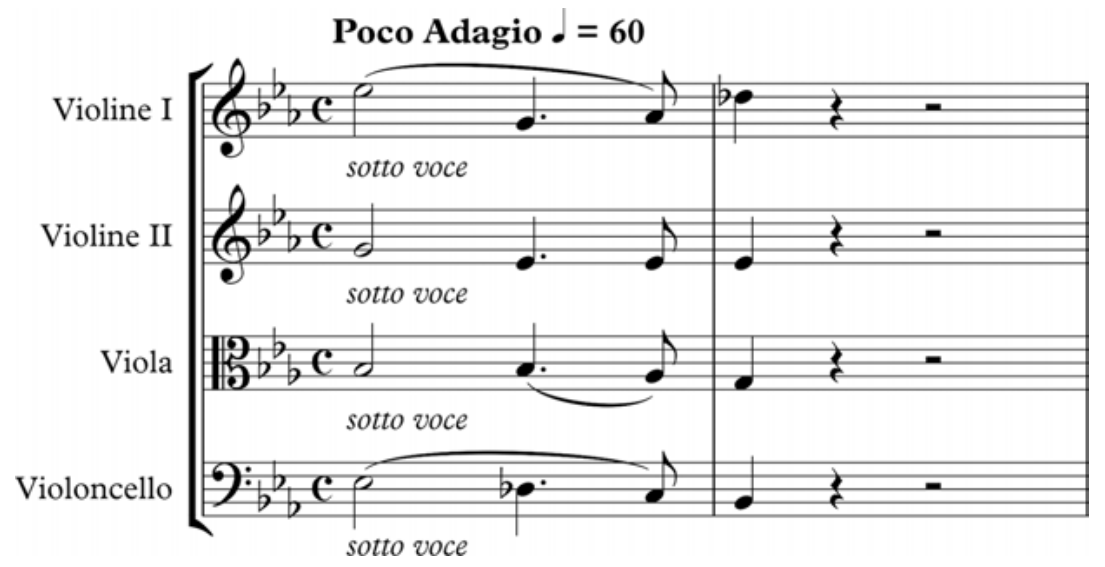

Die erste Violine geht vom Grundton über die Terz zur Septime; die zweite Violine von der Terz in den Grundton (mit Tonrepetition - ein Ausklingen); die Viola von der Quinte zur Terz; das Violoncello vom Grundton über die Septime zur Quinte. Es ergibt sich daraus ein harmonischer Vorgang (vgl. Abb. 67a, 67b, 67c, 67d). Wer diese Stelle lediglich harmonisch betrachtet, spielt im Kopf Klavier. Hier kommen vier verschiedene melodische Wendungen zusammen. ${ }^{5}$

Abbildung 67a: Stimme Violine I

Violine I

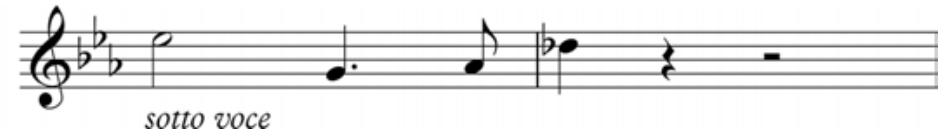

5 | Das Quartetto Energie Nove sitzt in Form eines vierblättrigen Kleeblatts: Beethoven - String Quartet Op. 74 The Harp - Quartetto Energie Nove. Hans Liviabella \& Barbara Ciannamea - violins, Ivan Vukcevic - viola, Felix Vogelsang - cello. https://www.youtube. com/watch?v=nP32f9IdPJ4 vom 08.04.2017. 
Abbildung 67b: Stimme Violine II

Violine II

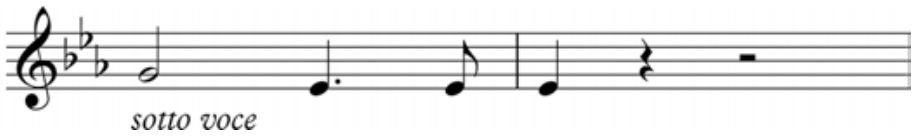

Abbildung 67c: Stimme Viola

Viola

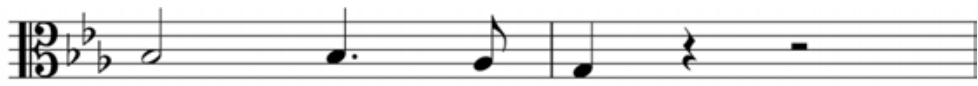

sotto voce

Abbildung 67d: Stimme Violoncello

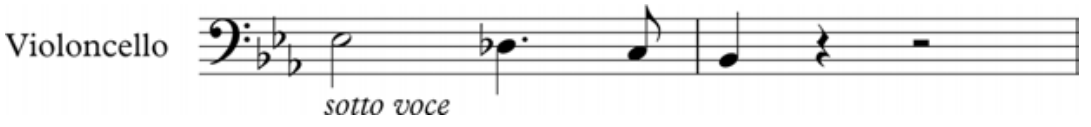

Diese vier Wendungen sind hörend zu spielen: zu singen. Man hört dann nicht länger Melodie und Begleitung und auch keine vierstimmigen Akkorde mehr. Hier von den Einzelnen auszugehen, heißt: anfangen zu singen. Und beim Singen der vier einzelnen Wendungen dringt das Ohr in diesen gemeinsamen Gesang der vier Spieler ein. Grundakkord und Septakkord tauchen nicht nur als harmonische Gefüge auf, sondern sie formieren sich auch als Ergebnisse von vier Melodiebildungen.

In den nächsten beiden Takten werden wieder vier einzelne Stimmen geführt. Entscheidend ist die Wendung der zweiten Violine zum $\mathrm{e}^{1}$ hin; damit erscheint neben Grundakkord und Septakkord der verminderte Akkord - aber wiederum als Ergebnis von eigenständiger Melodiebildung (vgl. Abb. 68).

Abbildung 68: Ludwig van Beethoven: Streichquartett Nr. 10 Es-Dur op. 74, 1. Satz, Einleitung Poco Adagio, Takte 3-4

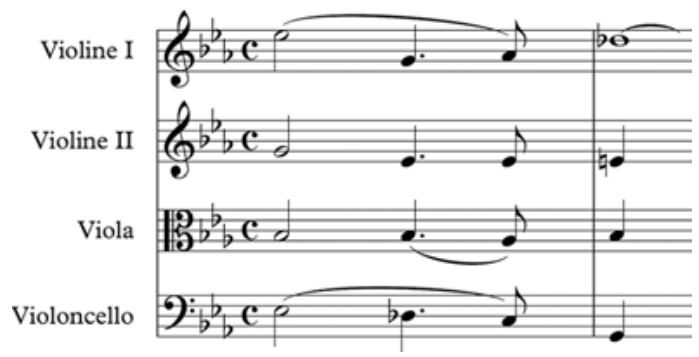

Die Espressivo-Phrase (Takt 12 mit drei Achteln Auftakt - Takt 13) bringt wieder unterschiedliche Melodien ins Spiel (vgl. Abb. 69). 
Abbildung 69: Ludwig van Beethoven: Streichquartett Nr. 10 Es-Dur op. 74, 1. Satz, Einleitung Poco Adagio, Takte 12-13

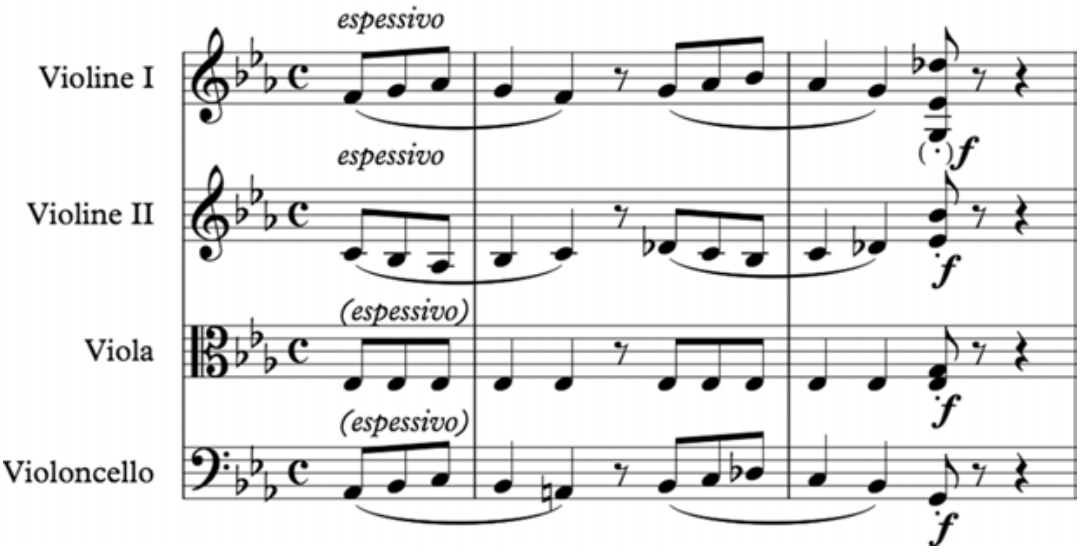

Diese werden wenig später (Takte 15-17) weitergegeben: Die Violoncello-Phrase tritt in der zweiten Violine, die Viola-Phrase (Tonrepetition) in der ersten Violine als Liegeklang, die Wendung der zweiten Violine im Violoncello, die Wendung der ersten Violine in der Viola auf (vgl. Abb. 70).

Abbildung 70: Ludwig van Beethoven: Streichquartett Nr. 10 Es-Dur op. 74, 1. Satz, Einleitung Poco Adagio, Takte 15-17

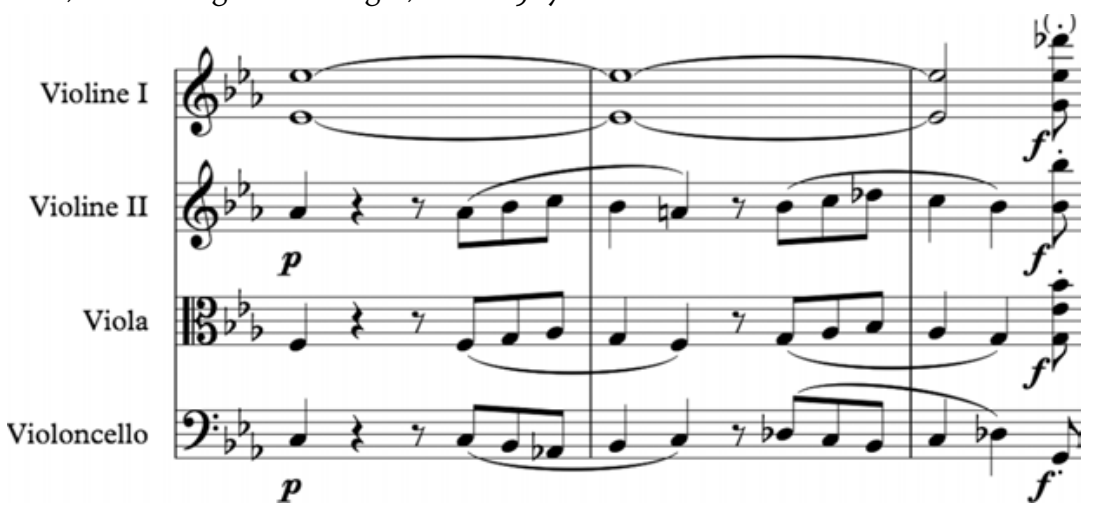

Wiederholung also mit Stimmentausch. Eine bloße harmonische Analyse geht vorbei am Tun der vier Einzelnen.

Auch das Motiv des Beginns taucht in den verschiedenen Stimmen auf: In der Viola (Takt 14), in der Violine (Takt 18), im Violoncello dann mehrmals hintereinander (ab Takt 21) bis zum Eintritt des Allegro-Abschnitts. Bis auf die Einschübe der Forte-Akkorde, sogar mit Doppel- und Dreifachgriffen (Takte 13, 17), ist jeder einzeln - aber einzeln im Verbund. 
Die Einsätze der Spieler beim Übergang zum Allegro sind jeweils sehr prekär, weil die Intonation eines jeden den Zusammenklang unmittelbar prägt und verändert. Hier muss man ganz sensibel und ohne Zögern zueinander finden (vgl. Abb. 71).

Abbildung 71: Ludwig van Beethoven: Streichquartett Nr. 10 Es-Dur op. 74, 1. Satz, Einleitung Poco Adagio, Takte 21-24

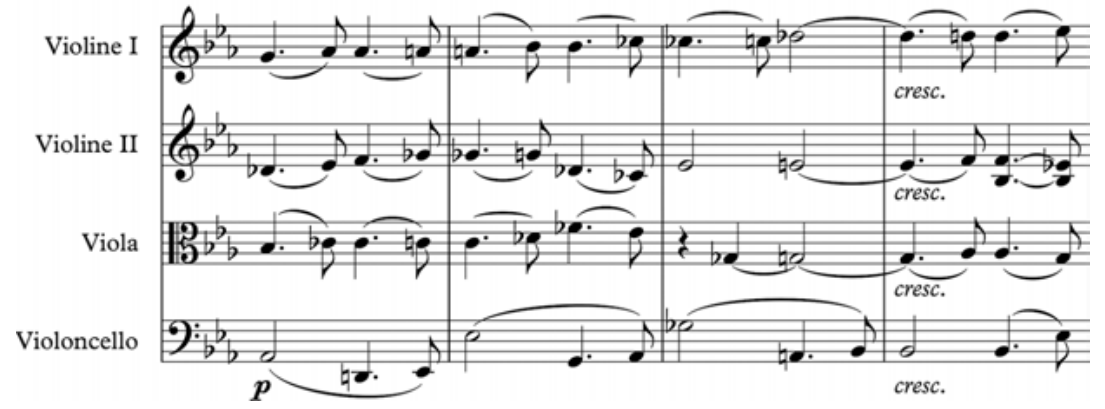

Dies alles geschieht so frei und zwanglos. Obwohl doch ein jeder auf die anderen Mitspieler angewiesen ist. Der Zusammenklang trägt diese freimütige, freizügige Abhängigkeit.

\section{II}

Judith Butler, die für eine Auflösung des Dualismus von Abhängigkeit und Freiheit plädiert, spricht von einer bestimmten Art von »Abhängigkeit« als »Fähigkeit zum Handeln « ${ }^{6}$ : »Wenn das Handeln als eigenständig definiert und damit ein fundamentaler Unterschied zur Abhängigkeit impliziert wird, basiert unser Selbstverständnis als Handelnde auf einer Verleugnung jener lebendigen und interdependenten Beziehungen, von denen unser Leben abhängt. « Zwischen »Handeln und Interdependenz« wird einseitige Orientierung überwunden. Eigenständigkeit einseitig definiert löst sich vom Beziehungsnetz ab, das durch Vertrauen Bestand hat und dem Vertrauen Bestand gibt.

In diesem »Poco Adagio« lassen sich Einzelne frei in Abhängigkeiten fallen, in deren Spielräumen sie dann handeln. »Nur im Kontext einer lebendigen Welt entwickelt sich der Mensch als handelndes Wesen, dessen Abhängigkeit von anderen und von lebenden Prozessen überhaupt erst die Fähigkeit zum Handeln entstehen lässt. $\ll^{8}$ Genau das geschieht hier - auch und gerade auf unbegriffliche Weise.

6 | J. Butler: Anmerkungen zu einer performativen Theorie der Versammlung, S. 62.

7 | Ebd., S. 63; das folgende Zitat ebd.

8 | Ebd., S. 62. 


\subsection{Helmut Lachenmann: Gran Torso. MUsiK für StreichqUartett (1971/72; ReV. 1978)}

\section{In-Erscheinung-Treten im Freien}

\section{I}

»Composing in the Tonus Virgineus «" ${ }^{9}$, Komponieren im jungfräulichen Ton: Das meint ein Komponieren in der Morgenfrühe, wenn alles noch frisch und neu ist. Bedeutet: Nichts so (an-)nehmen, als wäre es so: »New virginity< means, in his [Lachenmann's] case, a rejection of anything adopted without reflection. $\ll^{10}$

"Gran Torso, 1971/72 komponiert und 1978 revidiert, gehört mit Air, Kontrakadenz, Pression und Klangschatten zu einer Werkreihe, deren Materialbegriff sich von der Konvention zu lösen versucht, indem er statt vom Klang von den mechanischen und energetischen Bedingungen bei der Klang-Erzeugung ausgeht. . ${ }^{11}$

Lachenmann geht hier im Werkkommentar zu Gran Torso auf die »musique concrète instrumentale« ein, bei der die Art der Hervorbringung der Klänge ins Zentrum des Komponierens, Ausführens und Hörens gestellt wird. Werke wie diese haben also die übliche und gewohnte Klanglandschaft verlassen. Er nutzt zur Notation dieses Streichquartetts neben den gewohnten Schlüsseln einen »Stegschlüssel«, einen »Saitenschlüssel« und eine Art der »schematischen Darstellung der flachen Oberseite des Stegs « für das Violoncello. ${ }^{12}$

Die Ausführenden können ihre Instrumente neu entdecken: Sie haben die Möglichkeit zu einer »jungfräulichen« Entdeckung all dessen, was an klanglichen und geräuschhaften Momenten verborgen war, jetzt aber erscheinen darf. Sie kommen mit den Aktionen und Aktionsresultaten neu in Berührung, die immer schon, auch etwa beim Spiel einer Bach-Partita, ihr Dasein behaupteten, allerdings eher verborgen. Sie werden ermutigt, all das im eigenen Spiel zu entdecken, was üblicher- und traditionellerweise eher nicht erscheinen durfte, können ganz hineingehen in eine Klangund Geräuschlandschaft, die bis dato übersehen, überhört, überspielt oder gar unterdrückt, ausgesperrt wurde. Das ist zunächst das Angebot dieser Musik. Es ist nicht Lachenmanns Ziel, das Klang- und Geräuschrepertoire einer Violine, einer Viola oder eines Cellos aufzulisten; vielmehr geht es um

9 | P. Becker: Helmut Lachenmann. String Quartets, S. 1.

10 | Ebd.

11 | H. Lachenmann: Gran Torso, S. 386.

12 | Lachenmann, Gran Torso, Partitur, Erläuterungen zu Notation und Aufführungspraxis, S. 1. 
das »In-Erscheinung-Treten « $^{13}$ eines verschütteten, unbeachtet gebliebenen Reichtums. Die Ausführungsanweisungen sprechen gleich an, animieren Leser und Spieler - etwa diese zu Bogendruck und Streichaktionen:

"Bei Streichaktionen auf anderen Stellen des Instruments orientiert sich der Bogendruck am vorgeschriebenen Resultat, wie es an den entsprechenden Stellen in der Partitur beschrieben ist. Wichtig: die Vorschrift ,tonlos` bzw. ssphärisch in Verbindung mit der Bezeichnung respressivo meint höchste Intensität, also durchaus intensiven Bogendruck. Dieser darf jedoch niemals zur Zerstörung der vorgesehenen Wirkung, also zu verzerrenden Brumm- oder Kreischtönen führen. Wegen der langen Streichpartien auf dem Saitenhalter im Violoncello ab Takt 97 und in der Viola ab Takt 104 sollten diese beiden Instrumente Saitenhalter aus Holz haben, die eine deutliche, im Fall der Viola quasi solistische Gestaltung des tonlos-espressivo-Geräusches ermöglichen. Eine unmerkliche Modifikation durch die eventuell mitschwingende Eigenfrequenz des Instrumentenkorpus kann unter Umständen nützlich sein und ist im Hinblick auf das erstrebte 'sphärische، Klangresultat zulässig. " ${ }^{14}$

"Pizzicato fluido wird ebenfalls mit der linken Hand ausgeführt. Zuvor bzw. unmittelbar nach dem Anzupfen der Saite wird mit der rechten Hand die Spannschraube - in einigen Fällen auch die Bogenstange - quasi wie ein Gleitstahl bei der Gitarre auf die Saite aufgesetzt und verschoben. Durch solche Teilung der Saite ergibt sich eine neue, approximativ angedeutete Tonhöhe und durch die anschließende Verlagerung resultiert ein glissando."

\section{II}

Beim Spielen sind die Musiker über große Strecken hinweg auf ihre einzelnen Aktionen konzentriert. Eine Art der Kommunikation wie ganz am Schluss, wenn sie in wechselnden Konstellationen gleichzeitige Impulse ausführen, gibt es sonst kaum. Vier Einzelne sind unterwegs, das vorgegebene Metrum hält sie zusammen.

Dabei ist kein körperlicher Puls zu spüren. Das Metrum bleibt äußerlich, denn es erfüllt rein organisatorische Zwecke, dient der Koordination. Der Aktionsnotation, die auf subtile und minutiöse Weise festhält, wie die Aktionen verlaufen, widerspricht ein metrisches Raster. Der Spieler durchlebt große Teile des Stücks in diesem Zeitraster, dessen Genauigkeit die Aufmerksamkeit für die Klangaktionen beeinträchtigt. Auf der anderen Seite: Der Anspruch dieses Rasters ist Synchronisierung, nicht Zusammenspiel. Aus diesem Widerspruch zwischen der frei sich entfaltenden, Verschüttetes

13 | J. Butler: Anmerkungen, S. $37 \mathrm{f}$.

14 | H. Lachenmann: Gran Torso, Partitur, Erläuterungen, S. 3; das folgende Zitat ebd., S. 4. 
zutage fördernden Aktion und dem Raster heraus wirkt die Notation wie eine vorwegnehmende Transkription eines möglichen Aufführungsergebnisses in traditioneller Notation, eine Transkription, die nun genau nachzuspielen ist. Würde es für die Musik wirklich etwas ausmachen, wenn die Musiker sich gleichsam unkoordiniert ihren Aktionen zuwenden und die Klänge einander in Koinzidenz begegnen würden? Freies »In-ErscheinungTreten« »jungfräulicher« Klänge - aber nur unter bestimmten Konditionen?

Im »Paradies « ist das Raster aufgesprengt: Etwa nach dem ersten Drittel des Quartetts (ca. S. 7ff.) wird ein Raum betreten, den Lachenmann - auch in Bezug auf andere Kompositionen - als »Paradies « beschreibt. ${ }^{15}$ Genau hier, da sich die Befreiung ereignet, werden Aktionen mit der Anweisung "gelegentlich« versehen: »unhörbar weiter >schreiben<, gelegentlich hörbar werden « - so heißt es in der Partitur zu den Aktionen der Violinen. ${ }^{16}$ Die Anweisung "gelegentlich « ist eine ganz präzise, zugleich befreiende Anweisung für einen Spieler. Hier löst sie den Widerspruch zwischen dem »In-Erscheinung-Treten « der Klänge und Geräusche und dem metrischen Raster mit Bedingungen für das Erscheinen. Hier, im »Paradies«, werden Widerstand gegen Normierungen und ganz neues Selbstbewusstsein konkret spürbar.

Etwa zu Beginn der Spur der Solo-Bratsche wird das »Paradies« betreten. Die Viola prägt eine ganz eigene Linie aus, flautando und pianissimo, während die Violinen leise »Schreib«-Bewegungen vollziehen - »auf Saitenoberfläche zw. Steg u. Griff-Finger «. ${ }^{17}$ Das Cello schweigt. Später tritt das Cello hinzu, mit einer Bewegung arco flautando »auf Saitenhalter (weit unten) ppp (sphärisches Geräusch, Bogendruck knapp unterhalb realer Tongebung) «. ${ }^{18}$ Ein Stehenbleiben: Hier können sich alle verlieren (vgl. Abb. 72).

15 | Vgl. H. Lachenmann: Paradiese auf Zeit.

16 | H. Lachenmann: Gran Torso, Partitur, S. 9.

17 | Ebd., S. 7; "flaut. sschreiben «" ebd.

18 | Ebd., S. 9. 
Abbildung 72: Helmut Lachenmann: Gran Torso. Musik für Streichquartett, S. 10 , Zeile 2

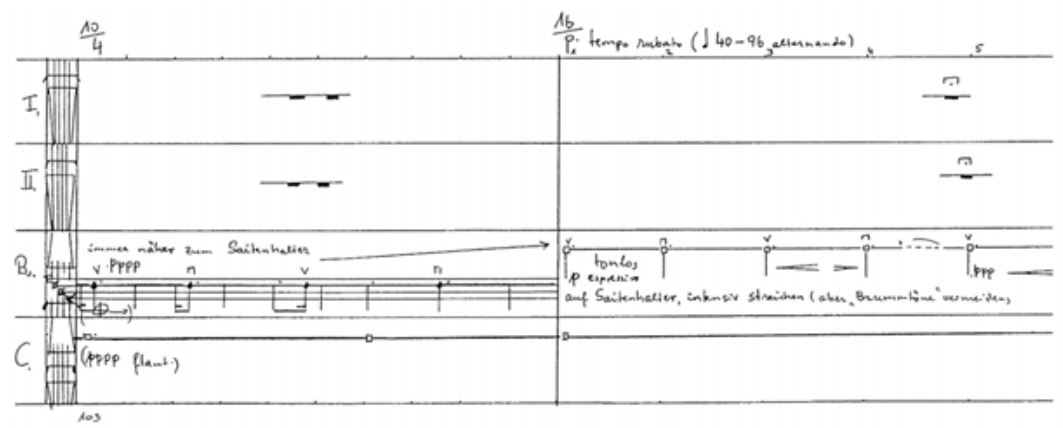

Lachenmann "Gran Torso", KM 2233, (c) 1972 by Musikverlage Hans Gerig, Köln 1980 assigned to Breitkopf \& Härtel, Wiesbaden, Abdruck mit freundlicher Genehmigung

"Mir liegt an dieser Stelle vor allem an der Deutlichkeit der Abstufung von 'Stille، und 'Leere،. Der Stillstand ist kein 'morendo،, sondern bedeutet einen weiteren qualitativen Sprung. Er ist mehr als die gefärbte Stille zuvor: Er ist Leere. Hier sind wir endlich im Zentrum einer unberührten Wüste. Die emotionale Wirkung [...] habe ich nicht inszeniert, sondern die ist 'gelungen , bei der Absicht, ganz mechanisch, quasi wie mit einem Regler in der Hand, die Musik rauf Null zu bringen`, als isolierte Idee gewiß nicht originell, aber hier praktiziert gleichsam im heiteren Spiel: Es ist eine glückliche Musik. Und nach außen, auf der Rückseite solcher Radikalität, reagiert sie auf die Umgebung. Heiter, wie sie sich versteht, macht sie Ernst. Aber wenn schon nicht die Musik - das Stück geht weiter, endlich Nicht-Musik geworden. Fast möchte ich denken, bis dahin war die Komposition nur ein einziger Exorzismus, um endlich befreite Musik schreiben zu können, und jetzt erst konnte ich - subjektiv gesehen - machen, 'was ich wollte`. "19

Hier, im Gespräch mit Heinz-Klaus Metzger, der die Stelle als »Antiklimax«, als »Negation eines Höhepunkts«, als »Zustand fast wie Tod« oder »Koma« missversteht, ${ }^{20}$ nimmt Lachenmann konkret Bezug auf diesen Augenblick der Befreiung in Gran Torso. Dieser Augenblick hat nichts zu tun mit Erstarrung oder Tod, im Gegenteil: Der Raum wird weit und groß, die Ausführenden könnten noch weiter auseinander sitzen. Auch Bedingungen für ein In-Erscheinung-Treten der Klänge, wie sie das metrische Raster noch stellte, haben sich hier verflüchtigt. Wenn die Bratsche ihr Lied singt, sind alle völlig frei, befinden sich alle in einer offenen Situation, von der eine große Ruhe ausgeht.

19 | H. Lachenmann: Fragen - Antworten, S. 199.

20 | Ebd., S. 198. 
In diesem Augenblick sind alle an einem Ort, an dem nichts mehr passiert, an dem nur noch der Ort zählt.

\section{III}

Im Gespräch mit Peter Szendy kommt Lachenmann erneut auf solche Situationen zu sprechen:

"Situationen, die nicht mehr von mir selbst strukturiert sind, sondern deren Struktur, so wie sie sich ergibt, in einem bestimmten Moment aus der Intensität der Situation heraus entsteht und nun Teil der Komposition bildet. Das sind meist Haltepunkte, Fermaten oder mehr oder weniger komplexe Ostinati: Sie lenken die Aufmerksamkeit auf verborgene oder vernachlässigte Einzelheiten, die normalerweise als bloße Randerscheinungen an der Peripherie des musikalischen Prozesses blieben und von der Wahrnehmung übergangen würden. Wenn jedoch solche Situationen in meinen Werken eintreten, dann als Resultate einer bewußten Hör-Sensibilisierung, wobei sie entgegen ihres statischen Anscheins eine komplexe Wahrnehmungs-Aktivität auslösen. Möglicherweise beziehen sich solche Momente insgeheim auf die Erfahrung Cage, aber anders als bei inm sind sie in meiner Musik vorläufige Paradiese, 'Paradiese auf Zeit, zu denen ich finde, und die ich wieder verlasse. ${ }^{21}$

Angesprochen werden Befreiungen des Hörens und der Hörer (»Hör-Sensibilisierung«), angesprochen wird daneben eine Befreiung des Komponisten. Wenn die »Intensität der Situation« komplexe Hörerfahrungen ermöglicht, so sind aber die Ausführenden in entscheidender Weise beteiligt. Sie setzen diese Situation frei, sie selbst erfahren auch und zuerst Befreiung als Möglichkeit von Koinzidenz der Klänge.

Der Formulierung »Paradiese auf Zeit« wäre entgegenzuhalten: Ein »vorläufiges« Paradies, ein »Paradies auf Zeit«, ist kein Paradies. Nach der »Hinausweisung« der Musik auf »Strukturen, Zusammenhänge, das heißt: auf Wirklichkeiten und Möglichkeiten um uns und in uns selbst «22 gibt es kein Zurück mehr. Aufenthalt im »Paradies« verändert, löst das Versprechen auf Wandel wirklich ein. Befreiung kann nicht rückgängig gemacht oder vergessen werden.

21 | H. Lachenmann: Paradiese auf Zeit, S. 209.

22 | H. Lachenmann: Vier Grundbestimmungen des Musikhörens, S. 62. 


\section{7. Über Grenzen hinaus}

Brian Ferneyhoughs Komposition Time and Motion Study II for Solo 'Cello and Electronics (1973-1976) mit dem scherzhaften inoffiziellen Untertitel »electric chair music « ${ }^{1}$ konfrontiert den Spieler mit einer Überfülle an Informationen und Anforderungen. Anspannung des Spielers ist erwünscht, nicht nur seitens des Komponisten, sondern auch seitens des Ausführenden selbst. Beide verbindet eine Art sportliches Interesse, dem Druck der Anforderung standzuhalten. Der Ausführende begibt sich in eine Situation, die aussichtslos ist. Die Forderungen, noch lauter, noch schneller, noch härter zu spielen, können nicht erfüllt werden, denn das tatsächliche Spiel wird immer nicht laut genug, nicht schnell genug, nicht hart genug sein. Ferneyhough komponiert eine Praxis; er antizipiert, wie es sein wird, wenn man das spielt. Wenn von Herausforderungen (»challenges«) oder Vorschlägen (»suggestions«) die Rede ist ${ }^{2}$, so wird damit einmal mehr deutlich, wie stark der Spieler einbezogen ist; solche Art des Komponierens richtet sich an Willige, die da mitmachen und mitmachen wollen. Komponist wie Ausführende setzen gemeinsam aufs Risiko, hoffen, irgendwann und irgendwo über das Menschenmögliche hinauszugelangen, fast hinausgeschleudert zu werden. Diesen Flug kann man nicht bestellen, aber man kann (vielleicht) darauf hoffen, dass die Ausführenden unter der übergroßen Anstrengung und der Überfülle an Herausforderung eine Zeitlang ins Fliegen geraten. Die Entscheidung, dieses Stück zu spielen, ist die Entscheidung für diese ganz bestimmte Praxis.

Nicht jede Komposition, die ein hohes technisches Können verlangt, will eine Einladung zum Fliegen sein. Eines der schwierigsten aus dem Bereich der Klaviermusik ist wohl Herma (1961) von Iannis Xenakis. Die Tonhöhen erstrecken sich über alle Oktavlagen des Klaviers, das Tempo ist enorm schnell. Erleichtert wird die Aufführung des ca. sechs Minuten dauernden Klavierstücks durch die Pausen, in denen Zeit zum Atemholen gegeben ist. Herma ist nicht

1 Optic Nerve_Music_Ferneyhough_2 Electric Chair Music. A documentary on Brian Ferneyhough's avant-garde composition ,Time \& Motion Study Il f for cello \& electronics. https://www.youtube.com/watch?v=sykB4znEk2Q vom 29.11.2016.

2 | Ebd. 
mit Ansprüchen an Virtuosität verbunden, versteht sich auch nicht als Einladung zu Risiko und Wagnis. Es verlangt allerdings ein Äußerstes an Bravour: vom Pianisten, aber auch vom Instrument.

\subsection{Risiko? Hans-Joachim Hespos: SEILTANZ. SZENISCHES ABENTEUER (1982)}

Auf eigene und eigenwillige Weise will Hans-Joachim Hespos jede Aufführung von Musik als »Hinaufführung « oder »Weiterführung « ${ }^{3}$ verstanden wissen. Er distanziert sich seit langem von einer Konzertaufführung mit Ensemble und Dirigent: Die Leitung eines Ensembles oder Orchesters durch einen Dirigenten lehnt er als undemokratisch ab - und in seinen eigenen Kompositionen hat ein Dirigent, so er denn eine Funktion übernimmt, alles andere zu tun als zu dirigieren. ${ }^{4}$ Im Gespräch mit Roland Wächter und Thomas Meier (22.11.1986, Zürich) wird deutlich, was er mit Zumutungen für die Ausführenden beabsichtigt:

"Mich interessieren diese Fast-Identifikationen. D.h., es muß auch für den Musiker anfangen, ein Wagnis zu sein, Musik zu machen. [...] Mich interessiert diese Distanzverringerung. Wenn man Musik erzeugt, macht man etwas durch und muß sich in diesen zum Teil sehr gefährlichen Prozeß einlassen. Und wenn diese Distanz sehr eng geworden ist, zwischen dem Ausführenden und dem Werk, dann verringert sich auch die Distanz zum Publikum. Und so etwas wird unmittelbar wahrgenommen als Ereignis. Denken Sie bitte nur daran: Musiker waren im Altertum gleichgestellt der Priesterkaste." ${ }^{5}$

Im Gespräch mit Ute Schalz-Laurenze (Februar 1985) kommt zur Sprache, dass Hespos Praktiken komponiert, die den Ausführenden Risikobereitschaft und Wagnis abverlangen. Es fällt der Begriff des Rituals, dem Hespos »einen neuen Aspekt abgewinnen möchte«: »Das wäre dann das, was ständig zu praktizieren wäre als eine risikoreiche Praxis. ${ }^{6}$ Es geht ihm also auch um musikalische Praxis als Lebensform. Der Brückenschlag zum Tanz liegt nahe:

"Ich glaube, jedes Ritual ist in seiner ursprünglichen Lebendigkeit stets aktuell. Beispielsweise in afrikanischen Tänzen, da geht es um Leben, Tod, Ernte, Glück, Unglück, Schicksal. Das sind Aktionen um das Nichtwissen, wie der nächste Augenblick ist [...]. Das hat etwas von Beschwörung, von Unvermögen, von Wunsch und von Verzweiflung.

3 | H.-J. Hespos: ..redeZeichen.., S. 129.

4 | Vgl. E.-M. Houben: hespos, S. $124 \mathrm{f}$.

5 | H.-J. Hespos: ..redeZeichen.., S. 129.

6 | Ebd., S. 122. 
Alles auf einen Draht gebracht, ist das sehr existentiell und risikohaft. Es gibt im afrikanischen Bereich noch heute Tänze, die im Grunde das Scheitern, das tödliche Scheitern des Tänzers im Programm haben. ${ }^{7}$

»Jede [der Kompositionen Hespos'] ist Tanz zwischen Leben und Tod, Seiltanz zwischen Erde und Himmel: lädt zum Fliegen ein. ${ }^{8}$ Diesen Sprung hinaus sucht wohl mit am eindringlichsten die Partitur zu seiltanz. szenisches abenteuer (1982) einzufangen. Nicht umsonst ist diese Komposition »den jeweils ausführenden « gewidmet ${ }^{9}$ : Komponist und Ausführende bilden eine Gemeinschaft, die über das gemeinsam eingegangene Risiko weit hinausgelangen will.

In einem ersten Abschnitt (bis Ziffer 21 in der Partitur) ist die Hölle los. ${ }^{10}$ Ein fürchterlicher Tanz: »ffff!«, »forts[etzung] drastisches liniengebrüll«; »ffff!«, »gesteigert stets zu rücksichtslosem liniengebrüll«; »ffff!«, »alle außer Tba + $\mathrm{Cb}$ : forts[etzung] eines instrumentalen spiels ohne instrument, (mirlitonig ${ }^{11}$ ), jaul-heul-kreischendes inferno bei wechselnd verbogenen mundstellungen; ekstatische zerrgesten turnend, blödwurmiges bodenwälzen, aufbäumendes versticken; alles von platzendem wahnwitz, stets unterschiedlich und heftig gedehnt «, »zu den instrumenten tastend . $^{12}{ }^{2}$ freies gegeneinander «, »auf das kontrastreichste hemmungslos, rücksichtslos forciert gesteigert! « »ffff! « ${ }^{13} \mathrm{Im}$ Zuge der Entwicklung des »liniengebrülls« tritt der »spieler« in aktion: »verläßt seinen platz, geht zornig entschlossen zu dem an der eingangswand aufgestellten baumstamm, packt ihn hoch, schlägt ihn auf den boden auf, wechselt die position und rammt ihn nun mit gewaltigem horizontalschwung gegen den oeltank. beginnt ein exercitium! - voll erregter unruhe $-\ll{ }^{14}$ Hier taucht es auf: das Wort »exercitium«. Hespos berichtet (Gespräch mit Roland Wächter und Thomas Meier) von einer Aufführung in Darmstadt:

"[Ein Musiker] ist sogar im Stahltank drin, der muß sich herausschweißen, ein anderer muß sich mit einem übermannshohen und überschweren Eichenbalken abgeben, der inm unter Umständen die Haut zerfetzt, u.U. inm die Hand zerquetscht. Musikausübung ist längst nicht mehr von einer Beiläufigkeit, sondern gerät, glaube ich, gerade in heu-

7 | Ebd.

8 | E.-M. Houben: hespos, S. 25.

9 | Ebd., S. 338; vgl. H.-J. Hespos: seiltanz, Partitur.

10 | Vgl. E.-M. Houben: hespos, S. $26 f$.

11 | Beim Mirliton wird beim Hineinsprechen oder -singen eine Membran in Schwingung versetzt, wodurch sich der Klang verändert.

12 | H.-J. Hespos, seiltanz, Partitur, S. 9.

13 | Ebd., S. 10.

14 | Ebd., S. 9; siehe H.-J. Hespos: seiltanz, "anmerkungen“ zur Partitur, Ziffer 13. 
tiger Zeit wieder zu einem Risiko, das die Chance enthält, uns weiterzuführen. Insofern halte ich es mit den Priestern. ${ }^{15}$

Ein Spieler entscheidet sich: Will ich mich darauf jetzt einlassen? Und geht zur Probe wie zu einer Ausbildung. Bis zur Aufführung ist es ein langer Weg. Und dann wird auch die Aufführung selbst wieder zu einem Prozess voller Risiko und Gefahr, zu einem »Exercitium«, das einer Teufelsaustreibung gleichkommt.

Aber beim Inferno bleibt es ja nicht. Da ist der zweite Abschnitt (ab Ziffer 22): eine nicht enden wollende Folge von »Gesängen ${ }^{16}$. Ausführende tasten sich hörend fort, hören weit hinaus, Ohren werden zu Antennen: »p von erlauschender intensität. sämtl. spielpausen in faszinierender anspannung « ${ }^{17}$ [alle]; »fast unmerklich übergehen zu kristallinem, komplex sirrendem obertonspiel $\aleph^{18}\left[\right.$ Perc]; »stille kundend aushören! « $\left[\right.$ Apos $_{1}$, Tpos $\left._{2}\right]$; »immer wieder zu anderen farb-zeit-feldern gestalten « [Cb]; »unterschiedlichste, unvergleichliche ereignisse metallisch, sirr-filigran, kaum auszumachen « [Perc]; »schier unermeßlich fern - nah (unerwartete aushörungen)«, »dumpf summendem erdschwinggebrumm (mattes grummeln, weich an randrückseite) « [Perc]. ${ }^{19}$ Hier, im zweiten Abschnitt, könnte es zu einer Musik kommen, die aushörend, horchend, wartend ertastet wird. Hespos hat zu Beginn des zweiten Abschnitts, unter Ziffer 22, in eine Probenpartitur handschriftlich eingetragen: »notierte sprachlosigkeit «. ${ }^{20}$ Vorher sind die Musiker außer sich geraten, sie haben ihre Grenzen erreicht, sie können wirklich nicht mehr. Und jetzt: Sprachlosigkeit. Die Welt zeigt nur noch Vieles: Vielfalt, Variabilität, Veränderung.

Dass einer oder eine Gruppe mittels Risikobereitschaft und Wagnis versucht, über das menschenmögliche Maß hinauszukommen, ist sicher mehr als bloßer Einspruch gegen einen müde gewordenen Musikbetrieb. Ich möchte Hespos' Rede von »Fast-Identifikation« und »Distanzverringerung « aufgreifen: Wenn so etwas möglich wird, bedeutet dies vielleicht, dass die Membran zwischen der Alltagswelt und der Welt der Aufführung, zwischen dem Menschen und dem Musiker dünn wird, vielleicht auch durchsichtig. Die Praxis ist ganz nah an den Musiker herangekommen, berührt ihn psychisch, körperlich, rückt ihm auf den Leib. Lebenswelt und Musikwelt verschwimmen fast. Schritt über die Schwelle.

15 | H.-J. Hespos: ..redezeichen.., S. 130.

16 | Begriff hier nach: CD Hans-Joachim Hespos: Seiltanz. Ensemble 13. Manfred Reichert. WDR, cpo 999 245-2.

17 | H.-J. Hespos: seiltanz, Partitur, S. 13.

18 | Ebd., S. 14; die folgenden Zitate ebd., S. 15, 16, 22.

19 | Perc, Cb, Apos, Tpos: Perkussion (Schlagwerk), Kontrabass, Alt- und Tenorposaune.

20 | Vgl. E.-M. Houben: notierte sprachlosigkeit. 
Doch: Wie hältst du's mit dem Risiko? Diese Gretchenfrage kann auch meinen: Es gibt andere Risiken noch als eine verletzte Hand, ein taubes Ohr. Zum Beispiel das Risiko, dass sich in musikalischer Praxis zwischen Menschen etwas ereignet, das dann ausstrahlt und Konsequenzen hat; dass sich in musikalischer Praxis existentiell etwas verändert zwischen Menschen; dass ich durch musikalische Praxis etwas verstehe, was mich so berührt, dass ich danach anders bin; dass etwas (vielleicht) anders wird.

Hier liegt gewiss eine Grenzüberschreitung: im Selbst-Sein. »Der Mensch und die Dinge selbst $\ll^{21}$ sind da, treten auf, treten in Erscheinung. Das ist das Risiko.

\subsection{Virtuosität? Franz Liszt: EtUdes d'exÉcution TRANSCENDANTE $(1826,1838,1851)$}

Franz Liszts Etüdensammlung Etudes d'exécution transcendante $(1826,1838$, 1851; die zweite und dritte Fassung unterscheiden sich nur unerheblich, die erste Fassung ist ein Jugendwerk) ${ }^{22}$ versteht sich sicherlich nicht als Anregung, mit sich und dem Klavier alleine zu sein; anders denn als Vortrag für ein Publikum ist diese Musik wohl nicht denkbar.

Liszts Vortrag muss auf das Publikum wie eine Zaubervorstellung gewirkt haben. Robert Schumann würdigt vor allem die innige Verbindung zwischen Spieler und Instrument, Hand und Klavier (1839):

"H ö r e n muß man solche Compositionen, sie sind mit den Händen dem Instrument abgerungen, sie müssen uns durch sie auf inm entgegen klingen. Und auch s e $\mathrm{h}$ e $\mathrm{n}$ muß man den Componisten; denn wie der Anblick jeder Virtuosität erhebt und stärkt, so erst jener unmittelbare, wo wir den Componisten selber mit seinem Instrumente ringen, es bändigen, es jedem seiner Laute gehorchen sehen. Es sind wahre Sturm- und GrausEtuden, Etuden für höchstens zehn oder zwölf auf dieser Welt; schwächere Spieler würden mit innen nur Lachen erregen. ${ }^{23}$

Auch heute noch werden die Ansprüche an die Spieltechnik hervorgehoben, wobei eine Aufführung vielleicht in Gefahr gerät, zum Event zu verkommen:

"Preludio hat kein anderes Ziel, als die Fingerfertigkeit zu üben, um die folgende feurige und stürmische Etüde in a-moll mit stärkster Wirkung spielen zu können. Pianisten von höchstem Niveau werden die 1838er Fassung vorziehen, die nicht nur schwieriger,

21 | Vgl. E.-M. Houben: hespos, S. $234 \mathrm{ff}$.

22 | S. Gut: Franz Liszt, S. $397 f$.

23 | R. Schumann: Etuden für das Pianoforte, S. 166. Herv. i.0. 
sondern auch pikanter und wilder ist. [...] Die 10. Etüde in $\mathrm{f}$-moll ist wild, gewaltig und so virtuos geschrieben, dass sie selbst für Busoni ,kaum zu überwindende Schwierigkeiten bietetı. ${ }^{24}$

Virtuosität wird hier mit Wildheit, Schwierigkeit, Schnelligkeit verbunden. Sie kann aber auch andere Facetten haben, im Stillen und Leisen wirksam sein. Diese Sammlung von Etüden zeigt, dass es Liszt durchaus nicht nur um eine Steigerung von Tempo, Grifftechnik, Spielfertigkeit zu tun ist. Was diese Etüden vor allem sind: eine Übung im Klavierspiel. Das klingt banal?

Harmonies du soir zum Beispiel, die elfte Etüde, ist eine Übung darin, mit oder auf dem Klavier zu singen. Es zeigt sich hier ein ganz eigener Anspruch an die Klaviertechnik. Mitten in der Etüde gibt es eine Stelle, die in den eigentlichen Anspruch des Stücks hineinführt: »Più lento con intimo sentimento«. Die Melodie liegt in der rechten Hand, die linke begleitet: »accompagnamento quasi Arpa«. Wie eine Harfe also soll die linke Hand zupfen, während die rechte ihren Gesang vorträgt. Im Vergleich zur einstimmigen Melodie ist die Begleitung dicht und schwer - und soll nun in etwas Flüchtiges und Luftiges verwandelt werden (vgl. Abb. 73).

Abbildung 73: Franz Liszt: Etudes d'exécution transcendante, Etude XI, Harmonies du soir, Takte 59-62

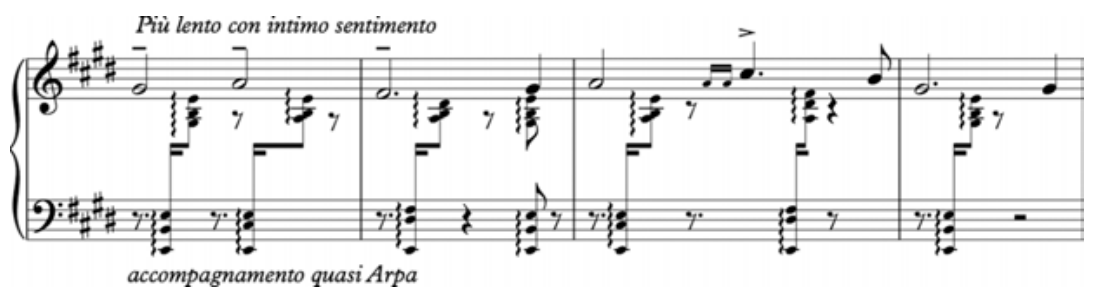

Diese besondere Art der Orientierung am Melodischen durchzieht die gesamte Etüde auf immer andere Weise. Gleich zu Beginn (Takte 2, 4): Die Melodie liegt in der rechten Hand in der Oberstimme - und diese Melodie soll klingen, obwohl die rechte Hand mit Akkordspiel zur Genüge beschäftigt ist (vgl. Abb. 74). 
Abbildung 74: Franz Liszt: Etudes d'exécution transcendante, Etude XI, Harmonies du soir, Takte 2-3

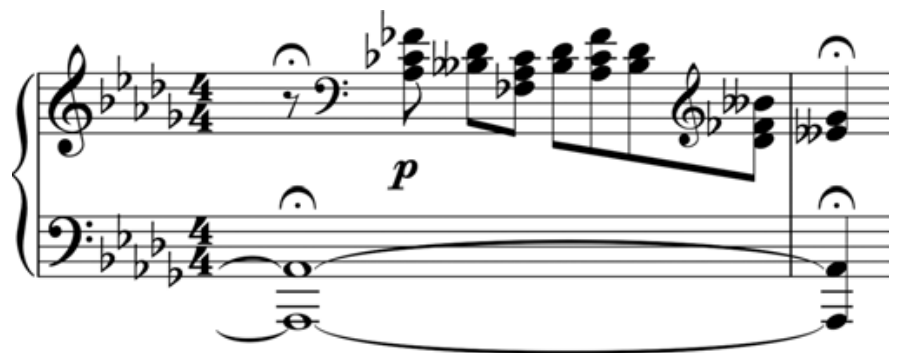

Etwas später (Takt 1off.) liegt die Melodie über Akkorden im linken Daumen. Die Übung: Den Gesang etwas hervortreten zu lassen und zugleich alles andere (den tiefen Bordunklang, die hohen Unisono-Klänge, die Arpeggien) wie nebenbei auch zu spielen (vgl. Abb. 75a, 75b).

Abbildung 75a: Franz Liszt: Etudes d'exécution transcendante, Etude XI, Harmonies du soir, Takte 10-11

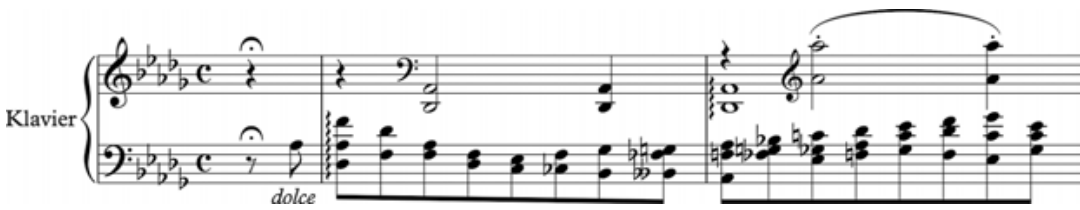

Abbildung 75b: Melodie allein, Takte 10-15

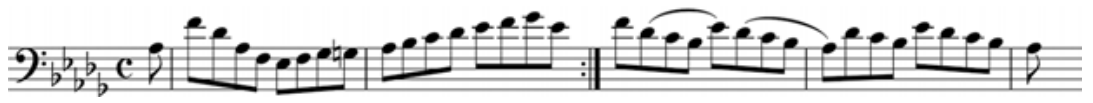

An anderer Stelle (Takt 24ff.) werden zwei Melodien um eine Sechzehntel gegeneinander versetzt parallel geführt. Die erste Melodie liegt in der Oberstimme in der rechten Hand, ihre Konturen verschwimmen ein wenig in der Arpeggiobewegung. Die zweite Melodie liegt in der Mitte der linken Hand beginnend mit des ${ }^{1}\left(\operatorname{des}^{1}-\operatorname{des}^{1}-c^{1}-\operatorname{ces}^{1}-b-\right.$ heses - as - g-ges - f ...). Auch diese verschwimmt, vielleicht noch mehr als die erste, man ahnt nur noch die Konturen. Eine klare Melodie wird durch eine andere begleitet, doch beide werden in Arpeggien eingehüllt (vgl. Abb. 76). 
Abbildung 76: Franz Liszt: Etudes d'exécution transcendante, Etude XI, Harmonies du soir, Takte 24-25

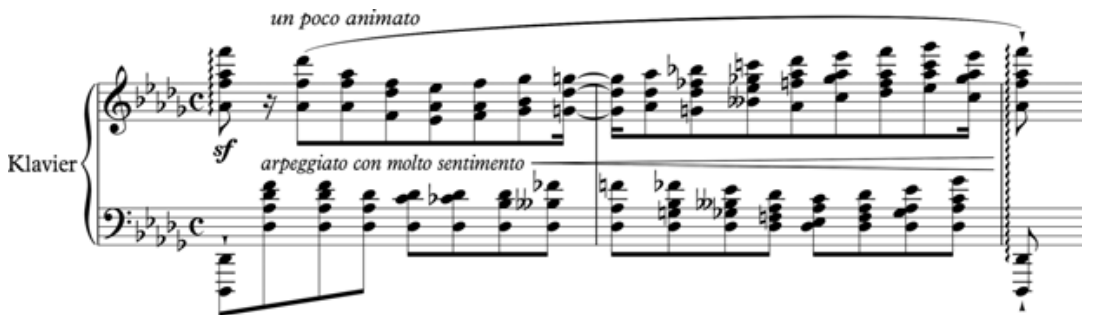

Was Melodie ist und was Begleitung: Diese Unterscheidung wird hier fast unmöglich gemacht. Gleichzeitig gibt es an dieser Stelle noch einen Bordun, der Anklänge an volksmusikalische Elemente hervorruft. Die Zusammenführung all dieser Einzelheiten wird eine ganz diffizile Aufgabe.

Virtuosität zeigt sich nicht (nur) als Fähigkeit, immer schwerere, schnellere Passagen zu bewältigen. Virtuosität zeigt sich in Harmonies du soir anders: Offensichtlich ist hier die Fähigkeit gefragt und auszubilden, jedem einzelnen Finger besondere Aufgaben zuzuteilen und ganz subtil Gesangliches im Akkordischen versinken zu lassen, aber nur so weit, dass es immer noch durchschimmert.

Wie hält man einen Klang am Klavier, dass er bleibt und nicht vergeht? Diese Frage begleitet den Musiker nicht nur während dieser elften Etüde, sondern während der Aufführung der gesamten Etüden-Sammlung. In jeder Etüde werden sangliche Melodien durch Akkordbrechungen, Tonrepetitionen, Triller, Tremoli, schnelle Läufe, durch Figurationen aller Art am Leben gehalten. Diese Klavierstücke wären an einer Orgel oder an einem Cembalo oder einem anderen Tasteninstrument nicht darzustellen. Jedes Klavierstück sagt: So ist Klavier! Der Körper des Spielers und der Instrumentenkörper zeigen sich.

Das Klavier ist ein Instrument, das dem Hörer das Verschwinden der Klänge vor Ohren führt. Der Klavierklang verklingt, er lässt sich nicht halten, verflüchtigt sich sogleich nach dem Anschlag der Taste. Beim Klavierspielen lasse ich den Klang immer wieder entwischen. Und kann hören: Im Verklingen lebt er, verändert er sich. ${ }^{25}$ Die Klaviertechniken, die hier herangezogen werden, haben die Aufgabe, die Energie aufrechtzuerhalten, dem ständigen Verschwinden des Klavierklangs etwas entgegenzusetzen. Harmonies du soir ist eine spezielle Auseinandersetzung mit dem verschwindenden Klang.

Es tritt eine besondere Art von Virtuosität hervor, die in der Fähigkeit wurzelt, sich dem Verschwinden auszusetzen, das Verschwinden auszuhalten und damit wie auch immer umzugehen.

25 | Vgl. E.-M. Houben: Presence - Silence - Disappearance. 


\subsection{UnVORhersehbarkeit? Karlheinz Stockhausen: SPIRAL FÜR EINEN SOLISTEN (1968)}

Eine »spiralförmige « Steigerung der »intuitiven, denkerischen, sensiblen und gestalterischen Fähigkeiten« erhoffte sich Stockhausen durch die wiederholte Aufführung von Spiral; er wollte dem Ausführenden die Möglichkeit eröffnen, durch die Praxis der Umwandlung und Verwandlung der Klangprozesse zu einer »künstlerischen Lebensform « zu finden. ${ }^{26}$ Tatsächlich wurde Spiral eine Zeitlang täglich ausgeführt, wurde so zu einer in den Tagesablauf integrierten Praxis:

"Während der Weltausstellung EXPO 70 in Osaka, Japan, wurden täglich von 15.30 bis ca. 21.00 Uhr Werke Stockhausens von 20 Musikern im Kugelauditorium des Deutschen Pavillons für über eine Million Zuhörer live aufgeführt. Eines dieser Werke war SPIRAL, das mehr als 1300 Mal vom 14. März bis zum 14. September 1970 täglich in verschiedenen Versionen gespielt oder gesungen wurde. ${ }^{27}$

Spiral gehört zu einer Reihe von Kompositionen, die von Stockhausen selbst als »Prozeß-Kompositionen ${ }^{28}$ bezeichnet werden. Bei der Ausführung ergibt sich eine Art Geschehen, das vielleicht amorph zu sein scheint. Ein Vergleich zweier Versionen, ausgeführt von verschiedenen Solisten ${ }^{29}$, bestätigt den ersten Eindruck: Spiral wirkt ganz frisch, kein Klang ist ausgeschlossen, alle Klänge können erscheinen. Als Ausführender wird man in komplexe Veränderungsprozesse gezogen, die man nicht vorhersehen kann. In der Partitur sind nicht Klänge notiert, sondern diese Veränderungsprozesse. »In SPIRAL werden Ereignisse, die ein Solist mit einem Kurzwellenradio empfängt, imitiert, transformiert und transzendiert. Außer dem Radio kann er ein beliebiges Instrument, mehrere Instrumente, Instrument und Stimme oder nur die Stimme benutzen. ${ }^{30}$

Stockhausens Zeichen zur Ausführung zeigen, wie sehr er vom Spieler ausgeht, wie stark er sich in den Solisten hineinversetzt. (Dies zeigt auch schon die Besetzungsangabe: »für einen Solisten«.) Ein Zeichen, eine Fermate mit Pfeil nach links, bedeutet: »Man erinnert sich während der Pause an das vorige Ereignis und spielt/singt dann, was man behalten hat.« Die Fermate mit Pfeil nach rechts: »Man stellt sich während der Pause das folgende Ereignis in allen Einzelheiten vor und spielt/singt es dann, der Vorstellung gemäß.« Und

26 | K. Stockhausen: SPIRAL, S. 136.

27 | K. Stockhausen: Spiral, Partitur.

28 | K. Stockhausen: SPIRAL, S. 136.

29 | Vgl. CD Stockhausen 15: Spiral (2 Versionen). Pole. WDR, p 1994, K. Stockhausen.

30 | K. Stockhausen: Spiral, Partitur, S. 1; die folgenden Zitate ebd., S. 3. 
so gibt es auch das »SPIRAL-ZEICHEN« - gemäß der Aufgabe, Ereignisse zu »transzendieren«:

"Wiederhole das vorige Ereignis mehrmals, transponiere es jedesmal in allen Parametern zugleich UND TRANSZENDIERE ES ÜBER DIE GRENZEN DEINER BISHERIGEN SPIEL-/GESANGS-TECHNIK und dann auch ÜBER DIE BEGRENZUNGEN DEINES INSTRUMENTES/DEINER STIMME HINAUS [...]. Hierbei sind auch alle visuellen, theatralischen Möglichkeiten angesprochen. BEHALTE VON NUN AN, WAS DU IN DER ERWEITERUNG DEINER GRENZEN ERFAHREN HAST, UND VERWENDE ES IN DIESER UND ALLEN ZUKÜNFTIGEN AUFFÜHRUNGEN VON ,SPIRAL، " ${ }^{31}$

Eine Aufführung ist daher von vornherein auf Wiederholung angelegt: Man führt Spiral immer wieder aus, sodass nicht nur die Ereignisse innerhalb einer Aufführung spiralförmig in Bewegung sind, sondern auch die Ereignisse von Aufführung zu Aufführung. Damit hat Stockhausen eine »künstlerische Lebensform« formuliert und initiiert.

Merkwürdig mutet indes das Spiral-Zeichen in der Partitur an. Vielleicht kommt es im Verlauf der Veränderungsprozesse zu Überschreitungen der gewohnten Spiel- oder Singpraxis, des Klangrepertoires, der Umsetzungsmöglichkeiten. Doch wie lässt sich die Aufforderung zu solcher Überschreitung in einer Partitur unterbringen? Ein Prozess enthält sieben Spiral-Zeichen, mit Wiederholung (es ist da capo zu spielen) ergeben sich 14 Zeichen, also 14 Aufforderungen zur Überschreitung. So führt das Zeichen, das in konkreter zeitlicher Anordnung in der Partitur platziert ist, eine Paradoxie mit sich, transportiert aber auch ein großes Vertrauen in die Ausführenden, die sich der Sache annehmen.

31 | Ebd., S. 4; Herv. i.0. 


\section{In der "Arche des Augenblicks"}

Die »Arche des Augenblicks « ${ }^{1}$ bleibt als stets neu Vergängliches. In dieser »Arche« sitzen wir alle in einem Boot: »Wir altern zusammen. $\ll^{2}$ In einer gemeinsamen Zeit und an einem bestimmten Ort musikalischer Praxis sind alle, die mit dabei sind, »Gerettete « ${ }^{3}$, Überlebende, Noch-Einmal-Davongekommene - für den Augenblick. Was wir tun in musikalischer Praxis, das tun wir füreinander und miteinander. Dieses Tun: ein »Hinausweisen«4 ${ }^{4}$, ein Aufmerken auf das »SO IST « und »SO GESCHIEHT « 5 . Hier zeigt sich das Potential dieser Stunde, hier zeigt sich Sinn: »Der ist vielleicht der, den Menschen an sich zu erinnern, an Kräfte in ihm, die ungenutzt sind, während er verschlissen wird. $\ll^{6}$ Affirmation und Erinnerung an all das, was wir auch sind, was wir auch tun können, als Potential für Zukünftiges.

Jeder Augenblick steht für sich. Hier, in dieser »Arche« gemeinsamen Tuns, sind alle frei. Die Trennung der Augenblicke voneinander macht deren Beziehung zueinander erst möglich. So drängt die Praxis auf Wiederholung, bewahrt sie zugleich die Trauer über die Isolation der musikalischen Augenblicke voneinander. Jede Ausführung ist auch ein Abschied.

In musikalischer Praxis feiern wir gemeinsam unsere Machtlosigkeit. Machtlosigkeit - nicht Ohnmacht. Die Machtlosigkeit ist kein Zustand, sondern ein Werden, ein Prozess, ein Tun; geht es doch um ein Los-Werden. Wir werden all das los, was wir zu besitzen glauben. Musikalische Praxis: ein Verlieren und Verloren-Geben. ${ }^{\text {? }}$

Claus-Steffen Mahnkopf sieht »Macht und Ohnmacht der Kunst« im Spannungsfeld verschiedener Zerreißproben: »[g]esellschaftlich, lebenspraktisch,

1 | "In der Arche des Augenblicks", in: N. Sachs: Fahrt ins Staublose, S. $50 f$.

2 | A. Schütz: Über die mannigfaltigen Wirklichkeiten, S. 252.

3 | N. Sachs: Fahrt ins Staublose, S. 50.

4 | Nach H. Lachenmann: Vier Grundbestimmungen des Musikhörens, S. 62.

5 | Nach H.-J. Hespos: AUGEN DER WÖRTER, Partitur.

6 | H. Lachenmann: Fragen - Antworten, S. 201.

7 | Vgl. E.-M. Houben: Hector Berlioz, S. 168ff. 
moralisch [...], technisch«, aber auch ökonomisch, kulturpolitisch gesehen. ${ }^{8}$ An einer Stelle der »Kritischen Theorie über Musik«, im Kapitel »Die Dialektik der Macht«, heißt es:

"Der Lebensnerv aller Kunst, ihre schöpferische Triebkraft inmitten des Lebens ist die Ohnmacht, die schiere, noch undifferenzierte Wut, nicht zu können, ja nicht zu dürfen, was um jeden Preis aber getan werden muß; die Verzweiflung, zwar tun zu dürfen, was die Autonomie der Kunst ermöglicht, damit aber allein zu stehen, ohne Aufführung, ohne Distribution, als Text auf der Diskette oder Partitur im Schrank; die Empörung über die Mittelmäßigkeit dessen, was die Macht passieren läßt; die tägliche Erfahrung der Dummheit gegenüber den eigenen Werken." ${ }^{9}$

Aus der musikalischen Praxis heraus lässt sich dieser Satz auch anders sagen: Der Lebensnerv unseres Tuns ist die Machtlosigkeit, die wir feiern, zelebrieren, heraufbeschwören; ist die Freude darüber, jederzeit und überall tun zu dürfen, was für uns Sinn ergibt, und dieses Tun wiederholen zu können. Die Ausrichtung auf Wiederholung lässt uns immer wieder neu Unabgeschlossenheit und Unabschließbarkeit spüren, das befreit zu Fortsetzungen. Wir handeln gemeinsam, als ein »Wir« (Schütz). Und diese gemeinsame Praxis erschließt Sinnhorizonte des Zukünftigen.

Macht und Ohn-Macht bleiben in einer Gegenüberstellung als dualistisches Denk- und Handlungsmuster an die Gesetze gebunden, die eine Lebenswelt wie die unsrige bestimmen, eine Welt, die John Blacking zutreffend als »world of cruelty and exploitation in which the tawdry and the mediocre are proliferated endlessly for the sake of financial profit ${ }^{10}$ beschreibt. Die OhnMacht als Widerpart der Macht nährt diese noch; an einem wie auch immer gearteten Widerstand erstarken Machtstrukturen. Musikalische Praxis bedeutet nicht Widerstand gegen etwas, sondern Affirmation von etwas: Ja-Sagen zu Vertrauen und Hoffnung auf »Wandel . $^{11}$

Musik ist wirklich unterfordert, wenn sie Erlösung, Religionsersatz oder Katastrophe sein oder Karriere und Erfolg untermauern und gewährleisten soll. Musikalische Praxis ist eine Praxis der Machtlosigkeit, in der man Macht loswird. (Sich-)Verloren-Geben wird ein Tun, das auf Zukünftiges ausgerichtet ist.

8 | C.-S. Mahnkopf: Kritische Theorie der Musik, S. $213 \mathrm{ff}$.

9 | Ebd., S. 217.

10 | J. Blacking: How musical is man?, S. 116.

11 | J. Volbers: Performative Kultur, S. 3. 


\section{Werkeverzeichnis}

Bach, Johann Sebastian: Toccata et Fuga in d (BWV 538). Neue Ausgabe sämtlicher Werke. Hg. v. Johann-Sebastian-Bach-Institut Göttingen und v. BachArchiv Leipzig. Serie IV: Orgelwerke. Bd. 5. Präludien, Toccaten, Fantasien und Fugen I. Hg. v. Dietrich Kilian, Kassel/Basel/Tours/London: Bärenreiter 1972. BA 5028, S. 76-89.

Bach, Johann Sebastian: Toccata et Fuga in F (BWV 540). Neue Ausgabe sämtlicher Werke. Hg. v. Johann-Sebastian-Bach-Institut Göttingen und v. BachArchiv Leipzig. Serie IV: Orgelwerke. Bd. 5. Präludien, Toccaten, Fantasien und Fugen I. Hg. v. Dietrich Kilian, Kassel/Basel/Tours/London: Bärenreiter 1972. BA 5028, S. 112-129.

Bach, Johann Sebastian: Fantasia et Fuga in g (BWV 542). Neue Ausgabe sämtlicher Werke. Hg. v. Johann-Sebastian-Bach-Institut Göttingen und v. BachArchiv Leipzig. Serie IV: Orgelwerke. Bd. 5. Präludien, Toccaten, Fantasien und Fugen I. Hg. v. Dietrich Kilian, Kassel/Basel/Tours/London: Bärenreiter 1972. BA 5028, S. 167-179.

Bach, Johann Sebastian: Orgelbüchlein (BWV 599-644). Neue Ausgabe sämtlicher Werke. Hg. v. Johann-Sebastian-Bach-Institut Göttingen und v. BachArchiv Leipzig. Serie IV: Orgelwerke. Bd. 1. Orgelbüchlein. Sechs Choräle von verschiedener Art (Schübler-Choräle). Choralpartiten. Hg. v. HeinzHarald Löhlein, Kassel/Basel/Tours/London: Bärenreiter 1983. BA 5056.

Bach, Johann Sebastian: Praeludium und Fuge 1 C-Dur (BWV 846), Praeludium 1. Neue Ausgabe sämtlicher Werke. Hg. v. Johann-Sebastian-Bach-Institut Göttingen und v. Bach-Archiv Leipzig. Serie V: Klavier- und Lautenwerke Bd. 6.1. Das Wohltemperierte Klavier I (BWV 846-869). Hg. v. Alfred Dürr, Kassel/Basel/London/New York: Bärenreiter 1989. BA 5070, S. 2-5, hier S. 2-3.

Bach, Johann Sebastian: Praeludium und Fuga 12 f-Moll (BWV 881), Preludio 12. Neue Ausgabe sämtlicher Werke. Hg. v. Johann-Sebastian-Bach-Institut Göttingen und v. Bach-Archiv Leipzig. Serie V: Klavier- und Lautenwerke Bd. 6.2. Das Wohltemperierte Klavier II (BWV 870-893). Fünf Praeludien und Fughetten BWV 870 a, 899-902. Anhang: Frühfassungen und Va- 
rianten zum Wohltemperierten Klavier II. Hg. v. Alfred Dürr, Kassel/Basel/London/New York: Bärenreiter 1995. BA 5086, S. 69-75, hier S. 69-71.

Beethoven, Ludwig van: Symphonie Nr. 5 c-moll op. 67, in: Beethoven Werke. Gesamtausgabe. Begr. v. Joseph Schmidt-Görg. Hg. v. Bernhard R. Appel im Auftrag des Beethoven-Archivs Bonn. Abteilung I. Bd. 3. Symphonien III. Hg. v. Jens Dufner (= Veröffentlichungen des Beethoven-Hauses in Bonn), München: Henle 2013, S. 1-105.

Beethoven, Ludwig van: Streichquartett Nr. 10 Es-Dur op. 74, in: Beethoven Werke. Hg. v. Beethoven-Archiv Bonn unter Leitung v. Joseph SchmidtGörg. Abteilung VI. Bd. 4. Streichquartette II. Hg. v. Paul Mies (= Veröffentlichungen des Beethoven-Hauses in Bonn), München-Duisburg: Henle 1968, S. 97-123.

Beethoven, Ludwig van: Violinsonate Nr. 10 G-Dur op. 96, 2. Satz (Adagio espressivo), in: Beethoven Werke. Hg. v. Beethoven-Archiv Bonn unter Leitung v. Joseph Schmidt-Görg. Abteilung V. Bd. 2. Werke für Klavier und Violine II. Hg. v. Sieghard Brandenburg (= Veröffentlichungen des Beethoven-Hauses in Bonn), München: Henle 1974, S. 144-147.

Beethoven, Ludwig van: Klaviersonate Nr. 32 c-moll op. 111, in: Beethoven, Klaviersonaten. Bd. II. Nach Eigenschriften und Originalausgaben hg. v. B. A. Wallner. Fingersatz v. Conrad Hansen, München: Henle 1953, S. 309-329.

Beuger, Antoine: pour être seul(e), sans réserve für klavier, Haan: Edition Wandelweiser 2009. ew01.142.

Beuger, Antoine: gentle traces of transient being for 10 players, Haan: Edition Wandelweiser 2016. ew01.177.

Cage, John: Music for. Parts for voice and instruments without score (no fixed relation), title to be completed by adding to »Music for - the number of players performing:

Voice: New York: Henmar Press 1985; Frankfurt a.M.: Edition Peters. No. $67040 \mathrm{P}$.

Flute: New York: Henmar Press 1984; Frankfurt a.M.: Edition Peters/Henry Litolff's/Schwann/C. F. Kahnt. No. 67040P.

Oboe: New York: Henmar Press 1987; Frankfurt a.M.: Edition Peters/Henry Litolff's/Schwann/C. F. Kahnt. No. 67040P.

Clarinet: New York: Henmar Press 1984; Frankfurt a.M.: Edition Peters/Henry Litolff's/Schwann/C. F. Kahnt. No. 67040P.

Horn in F: New York: Henmar Press 1987; Frankfurt a.M.: Edition Peters/Henry Litolff's/Schwann/C. F. Kahnt. No. 67040P.

Trumpet in C: New York: Henmar Press 1987; Frankfurt a.M.: Edition Peters/ Henry Litolff's/Schwann/C. F. Kahnt. No. 67040P. 
Trombone: New York: Henmar Press 1984; Frankfurt a.M.: Edition Peters/ Henry Litolff's/Schwann/C. F. Kahnt. No. 67040P.

Percussion I: New York: Henmar Press 1984; Frankfurt a.M.: Edition Peters. No. 67040P.

Percussion II: New York: Henmar Press 1984; Frankfurt a.M.: Edition Peters. No. 67040P.

Percussion III: New York: Henmar Press 1984; Frankfurt a.M.: Edition Peters. No. 67040P.

Percussion IV: New York: Henmar Press 1987; Frankfurt a.M.: Edition Peters. No. 67040P.

Piano I: New York: Henmar Press 1984; Frankfurt a.M.: Edition Peters. No. $67040 \mathrm{P}$.

Piano II: New York: Henmar Press 1987; Frankfurt a.M.: Edition Peters. No. $67040 \mathrm{P}$.

Violin I: New York: Henmar Press 1984; Frankfurt a.M.: Edition Peters/Henry Litolff's/Schwann/C. F. Kahnt. No. 67040P.

Violin II: New York: Henmar Press 1987; Frankfurt a.M.: Edition Peters/Henry Litolff's/Schwann/C. F. Kahnt. No. 67040P.

Viola: New York: Henmar Press 1987; Frankfurt a.M.: Edition Peters. No. 67040P.

Violoncello: New York: Henmar Press 1984; Frankfurt a.M.: Edition Peters. No. $67040 \mathrm{P}$.

Cardew, Cornelius: Sextet - The Tiger's Mind, London 1967: Hinrichsen/Peters. Cardew, Cornelius: The Great Learning, EMC (experimental music catalogue) CCoO25. http://experimentalmusic.co.uk/wp/emc-catalogue-list/classicemc-anthologies-and-other-publications/

Chopin, Frédéric: Prélude Nr. 2 a-moll, in: Fryderyk Chopin, Sämtliche Werke. Auf Grund der Autographen und Erstausgaben mit kritischen Revisionsberichten hg. v. I. J. Paderewski unter Mitwirkung von Ludwik Bronarski und Jósef Turczynski. Mit Nachbildungen von Bildnissen und Autographen. MCMXLIX. I Präludien für Klavier. Hg. v. I. J. Paderewski, L. Bronarski, J. Turczynski, Warschau/Krakau: Polnischer Musikverlag, S. 16.

Debussy, Claude: Syrinx pour flûte seule, Paris: Société des Éditions Jobert 1927, 1954. J. J. 344

Ferneyhough, Brian: Time and Motion Study II for Solo 'Cello and Electronics, London: Hinrichsen Edition/Edition Peters 1978. No. 7223. 
Frey, Jürg: Ohne Titel (Zwei Violinen), Haan: Edition Wandelweiser 1996. ew02.028.

Frey, Jürg: Buch der Räume und Zeiten für zwei Ausführende, Haan: Edition Wandelweiser 1999. ewo2.043.

Frey, Jürg: klavierstück 2 für klavier, Haan: Edition Wandelweiser 2001. ewo2.069.

Froberger: Neue Ausgabe sämtlicher Werke. VI. 1. Clavier- und Orgelwerke abschriftlicher Überlieferung. Neue Quellen, neue Lesarten, neue Werke (Teil 1). Im Auftrag der Gesellschaft für Musikgeschichte in Baden-Württemberg hg. v. Siegbert Rampe. Urtext. Kassel/Basel/London/New York/ Prag: Bärenreiter 2010. BA 9213.

Froberger: Neue Ausgabe sämtlicher Werke. VI. 2. Clavier- und Orgelwerke abschriftlicher Überlieferung. Neue Quellen, neue Lesarten, neue Werke (Teil 2). Im Auftrag der Gesellschaft für Musikgeschichte in Baden-Württemberg hg. v. Siegbert Rampe. Urtext. Kassel/Basel/London/New York/ Prag: Bärenreiter 2010. BA 9269.

Darin:

Partita in C FbWV 612, S. 58-62.

Partita in D FbWV 620, S. 70-73.

Hespos, Hans-Joachim: seiltanz. szenisches abenteuer, delmenhorst: hespos 1982. H $019 \mathrm{E}$.

Hespos, Hans-Joachim: AUGEN DER WÖRTER. experimentelle komödie in fünf lichtakten, delmenhorst: hespos 1991. H $058 \mathrm{E}$.

Lachenmann, Helmut: Gran Torso. Musik für Streichquartett. Partitur/Score, Wiesbaden: Breitkopf \& Härtel 1980. Kammermusik-Bibliothek 2233.

Liszt, Franz: Etudes d'exécution transcendante (mit/with/avec Grandes Etudes 2 $\&$ 7). Nach den Quellen hg. und mit Hinweisen zur Interpretation versehen v. Christian Ubber. Fingersätze v. Detlef Kraus. Wiener Urtext Edition. Ein Gemeinschaftsunternehmen der Verlage Schott Musik International, Mainz und Universal Edition, Wien 2005. UT 50233.

Mompou, Federico: Cantar del Alma. Pour Piano et Chant, Paris: Editions Salabert 1961. E.A.S. 16598.

Mompou, Federico: Música Callada pour Piano. $1^{\text {er }}$ Cahier, Paris: Editions Salabert 1959. E.A.S. 16171.

Mozart, Wolfgang Amadeus: Serenade in B für zwei Oboen, zwei Klarinetten, zwei Bassetthörner, vier Hörner, zwei Fagotte und Kontrabaß KV ${ }_{3} 61$ 
$\left(370^{a}\right)$, in: Neue Ausgabe sämtlicher Werke. In Verbindung mit den Mozartstädten Augsburg, Salzburg und Wien hg. v. der Internationalen Stiftung Mozarteum Salzburg. Werkausgabe in 20 Bänden. Band 17: Kirchensonaten. Ensemblemusik. Kammermusik I, Kassel u.a.: Bärenreiter 1991. Serie VII. Ensemblemusik für größere Solobesetzungen. Werkgruppe 17: Divertimente und Serenaden für Blasinstrumente. Bd. 2. Vorgelegt v. Daniel N. Leeson und Neal Zaslaw, S. 141-222.

Nono, Luigi: .....sofferte onde serene... per pianoforte e nastro magnetico. Riproduzione del manoscritto dell'autore, Milano: Ricordi 1977, Seconda edizione 1992.

Philippakopoulos, Anastassis: song 6 for bass flute or alto flute or flute, Haan: Edition Wandelweiser 2010. ew17.014.

Schönberg, Arnold: Streichtrio op. 45. New revised edition by Jacques Louis Monod (1979). Philharmonia Partituren in der Universal Edition, Wien/ London: Philharmonia. No. 491.

Schubert, Franz: Trio in Es. D 929 - op. 100. Neue Ausgabe sämtlicher Werke. Hg. v. der Internationalen Schubert-Gesellschaft. Sämtliche Kammermusikwerke. Studienausgabe in 3 Bänden. Bd. 3. Kammermusik mit Klavier, Kassel: Bärenreiter 1996. BVK 1283, S. 17-90.

Schumann, Robert: Kreisleriana. Fantasien für Piano-Forte op. 16. Hg. v. RoeMin Kok und Michael Beiche. Neue Ausgabe sämtlicher Werke. Begr. v. Ako Mayeda und Klaus Wolfgang Niemöller. Hg. v. der Robert-SchumannGesellschaft Düsseldorf in Verbindung mit dem Robert-Schumann-Haus Zwickau. Serie III: Klavier- und Orgelwerke. Werkgruppe 1: Werke für Klavier zu zwei Händen. Bd. 3, Mainz: Schott 2016, S. 25-61.

Spahlinger, Mathias: 128 erfüllte augenblicke. systematisch geordnet, variabel zu spielen. für stimme, klarinette und violoncello. Spielpartitur, Wiesbaden/ Leipzig/Paris: Breitkopf \& Härtel 1989. Kammermusik-Bibliothek 2403.

Stockhausen, Karlheinz: Spiral für einen Solisten, Wien: Universal Edition 1973. UE 14957.

Stroë, Aurèle: $3^{\text {ème }}$ Sonate pour Piano (en palimpseste), Ms.

Webern, Anton: Fünf Stücke für Orchester op. 10. Philharmonia Partituren in der Universal Edition, Wien/London: Philharmonia. No. 449. 
Wolff, Christian: For 1, 2 or 3 people, New York/London/Frankfurt/Leipzig: Edition Peters 1964. No. 6822.

Wolff, Christian: Stones, aus: Prose Collection, in: Ders., Cues. Writings \& Conversations - Hinweise. Schriften und Gespräche (= Edition MusikTexte 005), Köln: MusikTexte 1998, S. 464-481, hier S. 470; die deutsche Übersetzung ebd., S. 471.

Zelenka, Istvàn: »The trumpet shall sound!« - Stillstück für einen Violoncellisten mit gleichzeitigen Umweltklängen und ohne Publikum, 1990, Ms.

Zelenka, Istvàn: »und an 5 frei gewählten aufeinander folgenden Tagen, zu 5 unterschiedlichen, eigenständig bestimmten Tageszeiten zwischen Frühmorgen und Spätabend, spielen Sie per se pro Tag je eine der 5 Sequenzen dieser Komposition mit beliebiger Reihenfolge der einzelnen Seiten « für 1 Pianistinten, 2008, Ms.; in: Houben/Zelenka: 1 Milieu - ein Buch nicht nur zum Lesen, Zürich: Edition Howeg 2009, S. 125-130. 


\section{Literatur}

Adorno, Theodor W.: Ästhetische Theorie. Gesammelte Schriften Band 7. Hg. v. Rolf Tiedemann unter Mitwirkung v. Gretel Adorno, Susan Buck-Morss und Klaus Schultz (= suhrkamp taschenbuch wissenschaft), Frankfurt am Main: Suhrkamp 1997.

Adorno, Theodor W.: Einleitung in die Musiksoziologie. Zwölf theoretische Vorlesungen, in: Ders.: Dissonanzen. Einleitung in die Musiksoziologie. Gesammelte Schriften Band 14. Hg. v. Rolf Tiedemann unter Mitwirkung v. Gretel Adorno, Susan Buck-Morss und Klaus Schultz (= suhrkamp taschenbuch wissenschaft), Frankfurt am Main: Suhrkamp 1997, S. 169-433.

Adorno, Theodor W.: Beethoven. Philosophie der Musik. Fragmente und Texte.

Hg. v. Rolf Tiedemann. Nachgelassene Schriften. Hg. v. Theodor W. Adorno Archiv, Abteilung I: Fragment gebliebene Schriften Band 1, Frankfurt am Main: Suhrkamp 1994.

Bachmann, Ingeborg: »Die wunderliche Musik«, in: Dies., Werke. Hg. v. Christine Koschel, Inge von Weidenbaum, Clemens Münster. Band 4. Essays. Reden. Vermischte Schriften. Anhang, München/Zürich: Piper 1993, S. 45-58.

Badiou, Alain: Das Sein und das Ereignis. Übersetzt v. Gernot Kamecke, Berlin: diaphanes 2005.

Badiou, Alain: Dritter Entwurf eines Manifests für den Affirmationismus. Hg. und um ein Gespräch mit Alain Badiou erweitert v. Frank Ruda und Jan Völker. Aus dem Französischen v. Ronald Voullié, Berlin: Merve 2007. PMCid:PMC1855455

Badiou, Alain: Paulus. Die Begründung des Universalismus. Aus dem Französischen v. Heinz Jatho, Zürich/Berlin: diaphanes 2009.

Badiou, Alain: Lob der Liebe. Ein Gespräch mit Nicolas Truong. Aus dem Französischen v. Richard Steurer. Hg. v. Peter Engelmann, Paris: Flammarion 2009; Wien: Passagen 2011.

Bail, Ulrike: >Die verzogene Sehnsucht hinkt an ihren Ort. Literarische Überlebensstrategien nach der Zerstörung Jerusalems im Alten Testament, Gütersloh: Gütersloher Verlagshaus 2004 . 
Barthes, Roland: »Rasch«, in: Heinz-Klaus Metzger/Rainer Riehn (Hg.), Musik-Konzepte Sonderband. Robert Schumann II, München: text+kritik 1982 , S. 264-274.

Becker, Peter: Helmut Lachenmann. String Quartets. Composing in the Tonus Virgineus. The String Quartets of Helmut Lachenmann, Collection BBVA Foundation-Neos. Translation from the German: J. Bradford Robinson, www.fbbva.es - www.neos-music.com

Bekker, Paul: Beethoven, Berlin: Schuster \& Loeffler o. J.

Bekker, Paul: »Die Sinfonie von Beethoven bis Mahler« (1917), in: Ders., Neue Musik. Gesammelte Schriften Band 3, Stuttgart/Berlin: Deutsche VerlagsAnstalt 1923, S. 1-40.

Benjamin, Walter: Über den Begriff der Geschichte. Hg. v. Gérard Raulet, in: Ders., Werke und Nachlass. Kritische Gesamtausgabe Band 19. Im Auftrag der Hamburger Stiftung zur Förderung v. Wissenschaft und Kultur hg. v. Christoph Gödde und Henri Lonitz in Zusammenarbeit mit dem Walter Benjamin Archiv, Berlin: Suhrkamp 2010.

Berg, Stefan: »Orientierung in Klangräumen. Der Beitrag der Orientierungskompetenz zur Öffnung des Ohrs«, in: Musik \& Kirche, H. 5 (2008), S. 324-329.

Berg, Stefan: »Was heißt: sich in Musik orientieren?«, in: Ingolf U. Dalferth/ Stefan Berg (Hg.), Gestalteter Klang - gestalteter Sinn. Orientierungsstrategien in Musik und Religion im Wandel der Zeit, Leipzig: Ev. Verlagsanstalt 2011, S. 15-53. PMid:23487563 PMCid:PMC3594102

Berg, Stefan: Spielwerk. Orientierungshermeneutische Studien zum Verhältnis von Musik und Religion (= Religion in Philosophy and Theology 6o), Tübingen: Mohr Siebeck 2011.

Berger, Peter L.: Erlösendes Lachen. Das Komische in der menschlichen Erfahrung. Aus dem Amerikanischen v. Joachim Kalka, Berlin/New York: de Gruyter 1998.

Bertram, Georg W.: Kunst als menschliche Praxis. Eine Ästhetik (= suhrkamp taschenbuch wissenschaft 2086), Berlin: Suhrkamp 2014.

Besseler, Heinrich: »Grundfragen des musikalischen Hörens « (1926), in: Bernhard Dopheide (Hg.), Musikhören (= Wege der Forschung 429), Darmstadt: Wiss. Buchgesellschaft 1975, S. 48-73.

Beuger, Antoine/Vriezen, Samuel: »Asking questions, trying answers«. Email Correspondence January - November 2011, in: KunstMusik. Schriften zur Musik als Kunst 15 (2013), S. 16-41.

Beuger, Antoine: »die kunst, die liebe«, in: Eva-Maria Houben/Burkhard Schlothauer (Hg.), MusikDenken. Texte der Wandelweiser-Komponisten (= Reihe Wandelweiser, Band 1), Zürich: Edition Howeg 2008, S. 142-143. 
Beuger, Antoine: Booklet zur CD. Anastassis Philippakopoulos. songs and piano pieces. Katrin Zenz, bass flute. Anastassis Philippakopoulos, piano. edition wandelweiser records: Haan EWR 1408.

Beuger, Antoine: Cantar del Alma (Johannes vom Kreuz). Übersetzung ins Deutsche, Ms.

Beuger, Antoine: »San Juan de la Cruz. El cantico espiritual (Canciones entre al alma y el Esposo)«. Übersetzung ins Deutsche, in: Eva-Maria Houben/ Burkhard Schlothauer (Hg.), Antoine Beuger. Werkanalysen und Hintergründe (= Reihe Wandelweiser, Band 2), Zürich: Edition Howeg 2013, S. 160-175.

Blacking, John: How musical is man? Seattle and London: University of Washington Press 1973, 1974.

Bloch, Ernst: Das Prinzip Hoffnung. 3 Bände (= suhrkamp taschenbuch wissenschaft 3), Frankfurt am Main: Suhrkamp 1973.

Bloois, Joost de/Hemel, Ernst van den: »)Kunst creëert altijd, en doet dit altijd voor iedereen . Een interview met Alain Badoiu«, in: Joost de Bloois/Ernst van den Hemel (Hg.), Alain Badiou: Inesthetiek: filosofie, kunst, politiek, Amsterdam: octavo 2012, S. 45-69.

Brueggemann, Walter: Praying the Psalms, Winona (Minnesota): Saint Mary's Press 1986.

Butler, Judith: Anmerkungen zu einer performativen Theorie der Versammlung. Aus dem Amerikanischen v. Frank Born, Berlin: Suhrkamp 2016.

Cage, John: »Noch mehr über Satie«, in: Richard Kostelanetz: John Cage. Übersetzung v. Iris Schnebel und Hans Rudolf Zeller, Köln: Du Mont 1973, S. 122-124.

Cage, John: »Gespräch mit John Cage. Richard Kostelanetz«, in: Richard Kostelanetz, John Cage. Übersetzung v. Iris Schnebel und Hans Rudolf Zeller, Köln: Du Mont 1973, S. 27-65.

Cage, John: Silence. Aus dem Amerikanischen v. Ernst Jandl (= edition suhrkamp. Neue Folge, Band 477), Frankfurt am Main: Suhrkamp 1987.

Cook, Nicholas: »Music as Performance«, in: Martin Clayton/Trevor Herbert/ Richard Middleton (Hg.), The Cultural Study of Music. A Critical Introduction, New York/London: Routledge 2003, S. 204-214. PMCid:PMC149028

Cook, Nicholas: »Musikalische Bedeutung und Theorie«, in: Alexander Becker/Matthias Vogel (Hg.), Musikalischer Sinn. Beiträge zu einer Philosophie der Musik (= suhrkamp taschenbuch wissenschaft 1826), Frankfurt am Main: Suhrkamp 2007, S. 80-128.

Cook, Nicholas: Beyond the Score. Music as Performance, New York: Oxford University Press 2013.

Cypess, Rebecca: »>Memento mori Froberger?< Locating the self in the passage of time«. Early Musik Advance Access, Oxford: University Press 2012, http://em.oxfordjournals.org/by guest on February 25 
Dahlhaus, Carl: Analyse und Werturteil (= Musikpädagogik. Forschung und Lehre, Band 8), Mainz: Schott 1970.

Dahlhaus, Carl: »Plädoyer für eine romantische Kategorie. Der Begriff des Kunstwerks in der neuesten Musik«, in: Ders., Schönberg und andere. Gesammelte Aufsätze zur Neuen Musik mit einer Einleitung v. Hans Oesch, Mainz: Schott 1978, S. 270-278.

Dahlhaus, Carl: Die Idee der absoluten Musik, Kassel: Bärenreiter; München: dtv 1978.

Dahlhaus, Carl: »Das >Verstehen von Musik und die Sprache der musikalischen Analyse«, in: Peter Faltin/Hans-Peter Reinecke (Hg.), Musik und Verstehen. Aufsätze zur semiotischen Theorie, Ästhetik und Soziologie der musikalischen Rezeption, Köln: Hans Gerig 1973, S. 37-47.

Dahlhaus, Carl: Grundlagen der Musikgeschichte (= Musik-Taschen-Bücher Theoretica, Band 15), Köln: Gerig 1977.

Dahlhaus, Carl/Eggebrecht, Hans Heinrich: Was ist Musik? (Taschenbücher zur Musikwissenschaft, Band 100), Wilhelmshaven: Heinrichshofen 1985.

Deckert, Hans Erik: Mensch und Musik, Steinbergkirche-Neukirchen: Novalis 2016.

Döpke, Doris: Booklet zur CD. Nono. Como una ola de fuerza y luz .....sofferte onde serene... Contrappunto dialettico alla mente. Maurizio Pollini, Slavka Taskova, Nino Antonellini, Claudio Abbado. Deutsche Grammophon 423 238-2 2oth century classics.

Eggebrecht, Hans Heinrich: »Über begriffliches und begriffsloses Verstehen von Musik«, in: Ders., Musikalisches Denken. Aufsätze zur Theorie und Ästhetik der Musik (= Taschenbücher zur Musikwissenschaft, Band 46), Wilhelmshaven: Heinrichshofen 1977, S. 113-129.

Eggebrecht, Hans Heinrich: »Musikalisches Denken«, in: Ders., Musikalisches Denken. Aufsätze zur Theorie und Ästhetik der Musik (= Taschenbücher zur Musikwissenschaft, Band 46), Wilhelmshaven: Heinrichshofen 1977, S. 131-151.

Eggebrecht, Hans Heinrich: Musik verstehen, München: Piper 1995.

Eggebrecht, Hans Heinrich: Die Musik und das Schöne, München/Zürich: Piper 1997 .

Erdmann, Martin: »Il silenzio ritrovato. Cages >Zahlenstücke«, in: Stefan Schädler/Walter Zimmermann (Hg.), John Cage. Anarchic Harmony. Ein Buch der Frankfurt Feste '92/Alte Oper Frankfurt, Mainz: Schott 1992, S. 187-189.

Faltin, Peter: »Musikalische Syntax: Die bedeutungsgebende Rolle der tönenden Beziehungen« (1978), in: Vladimir Karbusicky (Hg.), Sinn und Bedeutung in der Musik. Texte zur Entwicklung des musiksemiotischen Denkens (= Texte zur Forschung, Band 56), Darmstadt: Wissenschaftliche Buchgesellschaft 1990, S. 152-160. 
Feil, Arnold: »Kammermusik«, in: Walther Dürr/Arnold Feil (Hg.), Franz Schubert. Musikführer. Unter Mitarbeit von Walburga Litschauer, Stuttgart: Reclam 2002, S. 242-265.

Fischer-Lichte, Erika: »Ritualität und Grenze«, in: Erika Fischer-Lichte/Christian Horn/Sandra Umathum/Matthias Warstat (Hg.), Ritualität und Grenze (Theatralität, Band 5), Tübingen/Basel: A. Francke 2003, S. 11-30.

Fischer-Lichte, Erika: Ästhetik des Performativen (= edition suhrkamp 2373), Frankfurt am Main: Suhrkamp 2004.

Fischer-Lichte, Erika: Performativität. Eine Einführung, Bielefeld: transcript 2012.

Gebske, Jennifer: Performativität zwischen Zitation und Ereignis. Vergleich der Performativitätsbegriffe von Judith Butler und Erika Fischer-Lichte. Magisterarbeit im Studiengang Magister Artium der Friedrich-AlexanderUniversität Erlangen-Nürnberg. Philosophische Fakultät und Fachbereich Theologie. Institut für Theater- und Medienwissenschaft, Erlangen 2009, https://opus4.kobv.de/opus4-fau/frontdoor/index/index/docId/1593

Geck, Martin: Von Beethoven bis Mahler. Die Musik des deutschen Idealismus, Stuttgart/Weimar: Metzler 1993. https://doi.org/10.1007/978-3-47603482-3

Geck, Martin: Bach. Leben und Werk, Reinbek bei Hamburg: Rowohlt 2000.

Geck, Martin: »V. Symphonie in c-Moll, op. 67. Analyse und Essay«, in: Renate Ulm (Hg.), Die 9 Symphonien Beethovens. Entstehung, Deutung, Wirkung. Vorwort v. Lorin Maazel. Im Auftrag des Bayerischen Rundfunks (= Bärenreiter Werkeinführungen), Kassel 2005: Bärenreiter, S. 151-180.

Geck, Martin: Robert Schumann. Mensch und Musiker der Romantik. Biografie, München: Siedler 2010.

Goodman, Nelson: Sprachen der Kunst. Entwurf einer Symboltheorie. Übersetzung v. Bernd Philippi (= suhrkamp taschenbuch wissenschaft 1304), Frankfurt am Main: Suhrkamp 2015.

Goodman, Nelson: Weisen der Welterzeugung. Übersetzung v. Max Looser (= suhrkamp taschenbuch wissenschaft 863), Frankfurt am Main: Suhrkamp 2014 .

Gut, Serge: Franz Liszt (= Musik und Musikanschauung im 19. Jahrhundert, Band 14), Sinzig: Studio 2011.

Haas, Bernhard: »Über Mikrotonalität und Vieltönigkeit, oder: Wie die Musik von Bach bis Wagner das Hören und Denken der vielen Töne beeinflusst hat«, in: Cordula Pätzold/Caspar Johannes Walter (Hg.), Mikrotonalität Praxis und Utopie (= Stuttgarter Musikwissenschaftliche Schriften, Band 3), Mainz: Schott 2014, S. 136-152.

Heimann, Mogens: Exercises for String Quartet. Edited by Hans Erik Deckert. Translation by Stephan Schwarz and V. A. Barker. Re-edition of score by Françoise Schubert. Produced by Franz Marcus for The Chamber Music 
Network - ACMP and The Danish Branch of European String Teachers' Association - ESTA, New York 2007.

Heinemann, Michael: »Chopins Fragilität«, in: Jörn Peter Hiekel/Wolfgang Lessing (Hg.), Verkörperungen der Musik. Interdisziplinäre Betrachtungen, Bielefeld: transcript 2014, S. 85-102.

Heinichen, Johann David: Neu erfundene und Gründliche Anweisung/Wie ein Music-liebender auff gewisse vortheilhafftige Arth könne zu vollkommener Erlernung des General-Basses, Entweder Durch eigenen Fleiß selbst gelangen/oder durch andere kurtz und glücklich dahin angeführet werden /dergestalt/Daß er so wohl die Kirchen als TheatralischenSachen/insonderheit auch das Accompagnement des Recitativs-Styli wohl verstehe/und geschickt zu tractiren wisse. Wobei zugleich auch andere schöne Vortheil in der Music an die Hand gegeben/Und alles Mit vielfachen Exempeln, und hierzu mit Fleiß auserlesenen nützlichen Composition-Regeln erläutert worden. Nebst einer Ausführlichen Vorrede, Hamburg: Verlegung Benjamin Schillers im Dohm 1711.

Henck, Herbert: »Vom Klang der Stille. John Cages 4'33"«, in: Wulf Herzogenrath (Hg.), Raum Zeit Stille. Ausstellung zum Jahr der Romanischen Kirchen in Köln. 23. März bis 2. Juni 1985, Kölnischer Kunstverein, Köln 1985 , S. 81-86.

Henck, Herbert: Programmnotiz und Booklettext Federico Mompou. Música Callada - Herbert Henck, Piano, ECM (1995) New Series 1523. Neu durchgesehen im November 2001, m. frdl. Genehmigung ECM, München, http://www.herbert-henck.de/Programme/MompouMusica/mompoumu sica.html

Hespos, Hans-Joachim: ..redeZeichen... Texte zur Musik 1969-1999. Hg. v. Randolph Eichert und Stefan Fricke (= Quellentexte zur Musik des 20. Jahrhunderts, Band 8.1), Saarbrücken: PFAU 2000.

Houben, Eva-Maria: Die Aufhebung der Zeit. Zur Utopie unbegrenzter Gegenwart in der Musik des 20. Jahrhunderts, Stuttgart: Steiner 1992. PMCid:PMC1881307

Houben, Eva-Maria: gelb. Neues Hören. Vinko Globokar. Hans-Joachim Hespos. Adriana Hölszky, Saarbrücken: PFAU 1996.

Houben, Eva-Maria: Alte Musik mit neuen Ohren. Schubert - Bruckner - Wagner - ..., Saarbrücken: PFAU 2000. PMCid:PMC1727786

Houben, Eva-Maria: hespos. eine monographie, Saarbrücken: PFAU 2003.

Houben, Eva-Maria (Hg.): immer wieder anders - überraschend neu. Noch einmal 5 Jahre Komponisten-Porträts an der Universität Dortmund, Dortmund: NonEM 2004.

Houben, Eva-Maria: »notierte sprachlosigkeit. Hans-Joachim Hespos' seiltanz: ein szenisch-akustisches Abenteuer«, in: Hans Bäßler/Ortwin Nimczik/ 
Peter W. Schatt (Hg.), Neue Musik vermitteln. Analysen - Interpretationen - Unterricht, Mainz/London/Madrid: Schott 2004, S. 112-122.

Houben, Eva-Maria: Hector Berlioz. Verschwindungen: Anstiftungen zum Hören, Dortmund: NonEM 2005.

Houben, Eva-Maria: »Wie wunderlich ist die neue Musik? Gedanken zu Ingeborg Bachmanns Essay Die wunderliche Musik (1956) mit Blick auf Musik der Gegenwart«, in: Susanne Kogler/Andreas Dorschel (Hg.), Die Saite des Schweigens. Ingeborg Bachmann und die Musik, Wien: Steinbauer 2006, S. 298-318.

Houben, Eva-Maria/Schlothauer, Burkhard (Hg.): MusikDenken. Texte der Wandelweiser-Komponisten (= Reihe Wandelweiser, Band 1), Zürich: Howeg 2008.

Houben, Eva-Maria/Zelenka, Istvàn: 1 Milieu - ein Buch nicht nur zum Lesen, Zürich: Howeg 2009.

Houben, Eva-Maria: »Presence - Silence - Disappearance. Some thoughts on the perception of >nearly nothing « 25.4.2010, Dublin, Ms., http://www.wandelweiser.de/eva-maria-houben/ texts-e.html

Houben, Eva-Maria: »Das Alte ist vergangen... Franz Schubert: Der Doppelgänger D 957, No. 13 (1828)«, in: Dietrich Korsch/Klaus Röhring/Joachim Herten (Hg.), Das Universum im Ohr. Variationen zu einer theologischen Musikästhetik, Leipzig: Ev. Verlagsanstalt 2011, S. 47-68.

Houben, Eva-Maria/Schlothauer, Burkhard (Hg.): Antoine Beuger. Werkanalysen und Hintergründe (= Reihe Wandelweiser, Band 2), Zürich: Howeg 2013.

Houben, Eva-Maria (Hg.): Jürg Frey. Werkbetrachtungen. Reflexionen. Gespräche (= Reihe Wandelweiser, Band 3), Zürich: Howeg 2013.

Houben, Eva-Maria/Zelenka, Istvàn: und/oder - 1 Sammlung (= Reihe Wandelweiser, Band 5), Haan: Wandelweiser 2016.

James, William: The Principles of Psychology Volume I. F. H. Burkhardt/ F. Bowers/I. K. Skrupskelis (Hg.), The Works of William James, Cambridge (Massachusetts)/London: Harvard University Press 1981.

James, William: The Principles of Psychology Volume II. F. H. Burkhardt/F. Bowers/I. K. Skrupskelis (Hg.), The Works of William James, Cambridge (Massachusetts)/London: Harvard University Press 1981.

Jankélévitch, Vladimir: Die Musik und das Unaussprechliche. Aus dem Französischen v. Ulrich Kunzmann. Mit einem Nachwort v. Andreas Vejvar, Berlin: Suhrkamp 2016.

Karbusicky, Vladimir: »Einleitung: Sinn und Bedeutung in der Musik«, in: Vladimir Karbusicky (Hg.), Sinn und Bedeutung in der Musik. Texte zur Entwicklung des musiksemiotischen Denkens (= Texte zur Forschung, Band 56), Darmstadt: Wissenschaftliche Buchgesellschaft 1990, S. 1-36. 
Karkoschka, Erhard: Zur Entwicklung der Kompositionstechnik im Frühwerk Anton Weberns, Tübingen (Diss.) 1959.

Kirnbauer, Martin: »Vieltönigkeit statt Mikrotonalität. Konzepte und Praktiken $>$ mikrotonaler< Musik des 16. Und 17. Jahrhunderts«, in: Cordula Pätzold/ Caspar Johannes Walter (Hg.), Mikrotonalität - Praxis und Utopie (= Stuttgarter Musikwissenschaftliche Schriften, Band 3), Mainz: Schott 2014, S. 85-113.

Koepping, Klaus-Peter/Rao, Ursula: »Zwischenräume«, in: Erika Fischer-Lichte/Christian Horn/Sandra Umathum/Matthias Warstat (Hg.), Ritualität und Grenze (Theatralität, Band 5), Tübingen/Basel: A. Francke 2003, S. 235-250.

Kolneder, Walter: Anton Webern. Einführung in Werk und Stil (= Kontrapunkte. Schriften zur deutschen Musik der Gegenwart), Rodenkirchen: Tonger 1961.

Konold, Wulf: »Einführung und Analyse. Zur Überlieferung des Notentextes«, in: Ludwig van Beethoven, Sinfonie Nr. 5 c-Moll, op. 67. Taschen-Partitur. Originalausgabe, Mainz: Schott 1979, S. 143-193.

Kostelanetz, Richard: John Cage. Übersetzung v. Iris Schnebel und Hans Rudolf Zeller, Köln: Du Mont 1973.

Kramer, Lawrence: Music as Cultural Practice. 1800-1900, Berkeley/Los Angeles/Oxford: University of California Press 1990.

Kramer, Lawrence: Classical Music and Postmodern Knowledge, Berkeley/Los Angeles/London: University of California Press 1995.

Kramer, Lawrence: Musical Meaning. Toward a Critical History, Berkeley/Los Angeles/London: University of California Press 2002.

Kramer, Lawrence: Why Classical Music Still Matters, Berkeley/Los Angeles/ London: University of California Press 2007. https://doi.org/10.1525/califor nia/9780520250826.001.0001

Kramer, Lawrence: Interpreting Music, Berkeley/Los Angeles/London: University of California Press 2011.

Kraus, Karl: Die Dritte Walpurgisnacht. Mit einem Nachwort hg. v. Heinrich Fischer, München: Kösel 1952.

Lachenmann, Helmut: »Klangtypen der Neuen Musik«, in: Ders., Musik als existentielle Erfahrung. Schriften 1966-1995. Hg. und mit einem Vorwort versehen v. Josef Häusler, Wiesbaden: Breitkopf \& Härtel 1996, S. 1-20.

Lachenmann, Helmut: »Vier Grundbestimmungen des Musikhörens«, in: Ders., Musik als existentielle Erfahrung (1996), S. 54-62.

Lachenmann, Helmut: »Zum Verhältnis Kompositionstechnik - Gesellschaftlicher Standort«, in: Ders., Musik als existentielle Erfahrung (1996), S. 9397. 
Lachenmann, Helmut: »Hören ist wehrlos - ohne Hören. Über Möglichkeiten und Schwierigkeiten«, in: Ders., Musik als existentielle Erfahrung (1996), S. 116-135.

Lachenmann, Helmut: »`Vom Greifen und Begreifen - Versuch für Kinder««, in: Ders., Musik als existentielle Erfahrung (1996), S. 162-167.

Lachenmann, Helmut: »Fragen - Antworten (Gespräch mit Heinz-Klaus Metzger)«, in: Ders., Musik als existentielle Erfahrung (1996), S. 191-204.

Lachenmann, Helmut: »Paradiese auf Zeit (Gespräch mit Peter Szendy)«, in: Ders., Musik als existentielle Erfahrung (1996), S. 205-212.

Lachenmann, Helmut: »Musik als existentielle Erfahrung (Gespräch mit U1rich Mosch)«, in: Ders., Musik als existentielle Erfahrung (1996), S. 213226.

Lachenmann, Helmut: »Nono, Webern, Mozart, Boulez. Text zur Sendereihe $>$ Komponisten machen Programm«, in: Ders., Musik als existentielle Erfahrung (1996), S. 270-278.

Lachenmann, Helmut: »Gran Torso. Musik für Streichquartett (1971/72)《, in: Ders., Musik als existentielle Erfahrung (1996), S. 386.

Lachenmann, Helmut: »Komponieren am Krater«, in: MusikTexte 151 (2016), S. 3-5.

Luckner, Andreas: »Drei Arten, nicht weiterzuwissen. Orientierungsphasen, Orientierungskrisen, Neuorientierungen«, in: Werner Stegmaier (Hg.), Orientierung. Philosophische Perspektiven (= suhrkamp taschenbuch wissenschaft 1767), Frankfurt am Main: Suhrkamp 2005, S. 225-241.

Mahnkopf, Claus-Steffen: Kritische Theorie der Musik, Weilerswist: Velbrück Wissenschaft 2006.

Mahrenholz, Simone: Musik und Erkenntnis. Eine Studie im Ausgang von Nelson Goodmans Symboltheorie (= M\&P Schriftenreihe für Wissenschaft und Forschung), Stuttgart/Weimar: Metzler 1998. PMid:9644481

Mahrenholz, Simone: »Musik-Verstehen jenseits der Sprache. Zum Metaphorischen in der Musik«, in: Michael Polth/Oliver Schwab-Felisch/Christian Thorau (Hg.), Klang - Struktur - Metapher. Musikalische Analyse zwischen Phänomen und Begriff (= M\&P Schriftenreihe für Wissenschaft und Forschung), Stuttgart/Weimar: Metzler 2000, S. 219-236. https://doi. org/10.1007/978-3-476-01901-1_11

Mahrenholz, Simone: »Der Körper des Komponisten und der Widerstreit zwischen Sprache und Materie in der Neuen Musik«, in: Ausdruck, Zugriff, Differenzen - der Komponist Wolfgang Rihm. Symposion, 14.-15. September 2002. Alte Oper Frankfurt am Main, Mainz: Schott 2003, S. 23-40.

Menuhin, Yehudi: Ich bin fasziniert von allem Menschlichen. Gespräche mit Robin Daniels. Mit einem Vorwort v. Lawrence Durrell. Aus dem Englischen v. Hans-Jürgen Baron von Koskull (= Serie Musik Piper Schott 8259), München: Piper; Mainz: Schott 1989. 
Merriam, Allan P.: The Anthropology of Music, Evanston (Illinois): Northwestern University Press 1964. PMCid:PMC1210549

Mersch, Dieter: Was sich zeigt: Materialität, Präsenz, Ereignis, München: Fink 2002. PMid:12140118

Mersch, Dieter: »Körper zeigen«, in: Erika Fischer-Lichte/Christian Horn/ Matthias Warstat (Hg.), Verkörperung (Theatralität, Band 2), Tübingen-Basel: A. Francke 2001, S. 75-89.

Nauck, Gisela: »>Es darf keine Siege mehr geben...<. Zur Vermittlung des Friedensgedankens ohne Botschaft - einige Gedanken in acht Kapiteln«, in: Hartmut Lück/Dieter Senghaas (Hg.), Den Frieden komponieren? Ein Symposium zur musikalischen Friedensforschung, 16.-18. Januar 2009, Mainz: Schott 2010, S. 107-123.

Nono, Luigi: »Auf dem Weg zu Prometheus. Gespräch zwischen Luigi Nono und Massimo Cacciari aufgezeichnet von Michele Bertaggia«, in: Massimo Cacciari/Luigi Nono (Hg.), Prometeo. Frankfurt Feste '87. Alte Oper Frankfurt. 12./13. August 1987, S. 54-71.

Polth, Michael/Schwab-Felisch, Oliver/Thorau, Christian (Hg.): Klang - Struktur - Metapher. Musikalische Analyse zwischen Phänomen und Begriff, Stuttgart/Weimar: Metzler 2000.

Rasch, Rudolf: Duizend Brieven over Muziek, van, aan en rond Constantin Huygens. Sibylla van Württemberg (Héricourt) aan Constantin Huygens (Den Haag), Nr. 6626, 23.10.1667, http://resources.huygens.knaw.nl/brief wisselingconstantijnhuygens/brief/nr/6626.

Rihm, Wolfgang: »Musikalische Freiheit« [1983/1996], in: Ulrich Mosch (Hg.), ausgesprochen. Schriften und Gespräche Band 1 (= Veröffentlichungen der Paul Sacher Stiftung, Band 6, 1), Winterthur/Schweiz: Amadeus 1997; Mainz: Schott 1998, S. 23-39.

Rihm, Wolfgang: »Spur, Faden. Zur Theorie des musikalischen Handwerks« [Juni 1985/1996], in: Ulrich Mosch (Hg.), ausgesprochen. Schriften und Gespräche Band 1 (1997/98), S. 69-77.

Rihm, Wolfgang: »Schaffen als Krise. Vermutungen und Fragliches zu Schaffen und Machen« [1990/1997], in: Ulrich Mosch (Hg.), ausgesprochen. Schriften und Gespräche Band 1 (1997/98), S. 99-110.

Rihm, Wolfgang: »Was >sagt< Musik? Eine Rede« [1991], in: Ulrich Mosch (Hg.), ausgesprochen. Schriften und Gespräche Band 1 (1997/98), S. 172-181.

Rihm, Wolfgang: »Neo-Tonalität?« [1984/1997], in: Ulrich Mosch (Hg.), ausgesprochen. Schriften und Gespräche Band 1 (1997/98), S. 185-193.

Rihm, Wolfgang: »Fremde Blätter (über Robert Schumann)« [1984], in: Ulrich Mosch (Hg.), ausgesprochen. Schriften und Gespräche Band 1 (1997/98), S. 229-233.

Rihm, Wolfgang: »... zu wissen. Gespräch mit Rudolf Frisius« (1985), in: Ulrich Mosch (Hg.), ausgesprochen. Schriften und Gespräche Band 2 (= Veröf- 
fentlichungen der Paul Sacher Stiftung, Band 6, 2), Winterthur/Schweiz: Amadeus 1997; Mainz: Schott 1998, S. 97-148.

Rihm, Wolfgang: »Musik zur Sprache bringen. Aus einem Gespräch mit Heinz Josef Herbort« (1987), in: Ulrich Mosch (Hg.), ausgesprochen. Schriften und Gespräche Band 2 (1997/98), S. 200-206.

Rihm, Wolfgang: »Der Ort der Musik. Gespräch mit Roland Zag« (1995), in: Ulrich Mosch (Hg.), ausgesprochen. Schriften und Gespräche Band 2 (1997/98), S. 249-273.

Rihm, Wolfgang: »Tasten (zu: verschiedenen Klavierwerken)«, in: Ulrich Mosch (Hg.), ausgesprochen. Schriften und Gespräche Band 2 (1997/98), S. 419-422.

Rihm, Wolfgang: Offene Enden. Denkbewegungen um und durch Musik, hg. v. Ulrich Mosch (= Edition Akzente), München/Wien: Carl Hanser 2002.

Rößler, Almut: »Zur rhythmischen Freiheit in der Wiedergabe von Messiaens Orgelmusik«, in: Dies., Beiträge zur geistigen Welt Olivier Messiaens. Mit Original-Texten des Komponisten, Duisburg: Gilles \& Francke 1984, S. 155162.

Rosenmann, Mauricio: Lieder ohne Ton: Anmerkungen zu Federico Mompou, Ralf R. Ollertz, Carlos Saura und Frédéric Chopin (= fragmen, Heft 10), Saarbrücken: PFAU 1995 .

Rüdiger, Wolfgang: »organische identität? Versuch über den Musiker-Körper und die Körperlichkeit der Musik«, in: NZfM 4, 167 (2006), S. 30-39.

Rühm, Gerhard: botschaft an die zukunft. gesammelte sprechtexte, Reinbek bei Hamburg: Rowohlt 1988.

Sachs, Nelly: Fahrt ins Staublose. Die Gedichte der Nelly Sachs, Frankfurt am Main: Suhrkamp 1961.

Schleuning, Peter: Die Freie Fantasie. Ein Beitrag zur Erforschung der klassischen Klaviermusik (= Göppinger Akademische Beiträge, Nr. 76), Göppingen: Alfred Kümmerle 1973.

Schmidt, Christian Martin: Brennpunkte der Neuen Musik (= Musik-TaschenBücher Theoretica, Band 16), Köln: Hans Gerig 1977.

Schnebel, Dieter: »Auf der Suche nach der befreiten Zeit. Erster Versuch über Schubert«, in: Heinz-Klaus Metzger/Rainer Riehn (Hg.), Musik-Konzepte Sonderband. Franz Schubert, München: edition text+kritik 1979, S. 69-88. Schnebel, Dieter: »Klangräume - Zeitklänge. Zweiter Versuch über Schubert«, in: Heinz-Klaus Metzger/Rainer Riehn (Hg.), Musik-Konzepte Sonderband. Franz Schubert, München: edition text+kritik 1979, S. 89-106.

Schnebel, Dieter: »Rückungen - Ver-rückungen. Psychoanalytische und musikanalytische Betrachtungen zu Schumanns Leben und Werk«, in: HeinzKlaus Metzger/Rainer Riehn (Hg.), Musik-Konzepte Sonderband. Robert Schumann I, München: text+kritik 1981, S. 4-89. 
Schnebel, Dieter: »Ritual - Musik«, in: Barbara Barthelmes/Helga de la MotteHaber (Hg.), Musik und Ritual. Fünf Kongressbeiträge, zwei freie Beiträge und ein Seminarbericht (= Veröffentlichungen des Instituts für Neue Musik und Musikerziehung Darmstadt, Band 39), Mainz: Schott 1999, S. 9-17. Schütz, Alfred: »Über die mannigfaltigen Wirklichkeiten«, in: Ders., Gesammelte Aufsätze I. Das Problem der sozialen Wirklichkeit. Mit einer Einführung v. Aron Gurwitsch und einem Vorwort v. H. L. van Breda. Aus dem Amerikanischen übersetzt und mit einem Nachwort zur Übersetzung v. Benita Luckmann und Richard Grathoff, Universität Konstanz, Den Haag: Martinus Nijhoff 1971, S. 237-298.

Schütz, Alfred: »Symbol, Wirklichkeit und Gesellschaft«, in: Ders., Gesammelte Aufsätze I. Das Problem der sozialen Wirklichkeit (1971), S. 331-411.

Schütz, Alfred: »Don Quixote und das Problem der Realität«, in: Ders., Gesammelte Aufsätze II. Studien zur soziologischen Theorie. Hg. v. Arvid Brodersen. Übertragung aus dem Amerikanischen v. Alexander von Baeyer, Den Haag: Martinus Nijhoff 1972, S. 102-128.

Schütz, Alfred: »Gemeinsam Musizieren. Die Studie einer sozialen Beziehung«, in: Ders., Gesammelte Aufsätze II. Studien zur soziologischen Theorie (1972), S. 129-150.

Schütz, Alfred: »Mozart und die Philosophen«, in: Ders., Gesammelte Aufsätze II. Studien zur soziologischen Theorie (1972), S. 151-173.

Schütz, Alfred: »Strukturen der Lebenswelt«, in: Ders., Gesammelte Aufsätze III. Studien zur phänomenologischen Philosophie. Hg. v. Ilse Schütz. Einleitung und Übertragung aus dem Amerikanischen v. Alexander von Baeyer, Den Haag: Martinus Nijhoff 1971, S. 153-170.

Schütz, Alfred/Luckmann, Thomas: Strukturen der Lebenswelt. Band 1 (= suhrkamp taschenbuch wissenschaft 284), Frankfurt am Main: Suhrkamp 1979.

Schütz, Alfred/Luckmann, Thomas: Strukturen der Lebenswelt. Band 2 (= suhrkamp taschenbuch wissenschaft 428), Frankfurt am Main: Suhrkamp 1994.

Schumann, Robert: Etuden für das Pianoforte, in: Ders., Gesammelte Schriften über Musik und Musiker. Bände 3 und 4. Reprint der Ausgabe Leipzig 1854. Mit einem Nachwort v. Gerd Nauhaus und einem Register v. Ingeborg Singer, Wiesbaden: Breitkopf \& Härtel 1985, Band 3, S. 150-168.

Small, Christopher: Musicking. The Meanings of Performing and Listening, Middletown, Connecticut: Wesleyan University Press 1998.

Stäbler, Gerhard: »`Um verlorene Schlüssel zu suchen, lohnt es sich, ein ganzes Haus umzukehren« (Gerd Zacher). Bach zum 300. Geburtstag«, in: Ders., Fantasia g-Moll. Praeludium und Fuga a-Moll. Analytische Interpretationen, Duisburg: edition Aktive Musik o. J. 
Stegmaier, Werner (Hg.): Orientierung. Philosophische Perspektiven (= suhrkamp taschenbuch wissenschaft 1767), Frankfurt am Main: Suhrkamp 2005 .

Steiner, George: Von realer Gegenwart. Hat unser Sprechen Inhalt? Mit einem Nachwort von Botho Strauß. Aus dem Englischen von Jörg Trobitius (= Edition Akzente), München/Wien: Carl Hanser 1990.

Stenzl, Jürg: Luigi Nono (= rowohlts monographien 50582), Reinbek bei Hamburg: Rowohlt 1998.

Stockhausen, Karlheinz: Momentform, in: Ders., Texte zur elektronischen und instrumentalen Musik. Band 1. Aufsätze 1952-1962 zur Theorie des Komponierens. Hg. und mit einem Nachwort versehen v. Dieter Schnebel, Köln: DuMont 1963, S. 189-210.

Stockhausen, Karlheinz: SPIRAL für einen Solisten (1968), in: Ders., Texte zur Musik 1963-1970. Band 3. Einführung und Projekte. Kurse. Sendungen. Standpunkte. Nebennoten. Hg. v. Dieter Schnebel, Köln: DuMont 1971, S. 135-142.

Stuckenschmidt, Hans Heinz: Schönberg. Leben. Umwelt. Werk. Mit 42 Abbildungen (= Serie Musik Piper Schott), München: Piper; Mainz: Schott 1989 . Uhden, Pit: Musik als Praxis. Schriften online: Musikpädagogik - 3. Masterarbeit. Hochschule für Musik und Theater >Felix Mendelssohn Bartholdy< Leipzig, Leipzig 2015.

Volbers, Jörg: Performative Kultur. Eine Einführung, Wiesbaden: Springer Fachmedien 2014. https://doi.org/10.1007/978-3-658-01072-0

Wagner, Richard: »Oper und Drama. Dritter Theil. Dichtkunst und Tonkunst im Drama der Zukunft«, in: Ders., Gesammelte Schriften und Dichtungen. Band 4 (Faksimiledruck der Ausgabe von 1887, Leipzig), Hildesheim: Georg Olms 1976, S. 103-229.

Walser, Robert: Gedichte und Dramolette, hg. v. Robert Mächler, in: Ders.: Das Gesamtwerk, hg. v. Jochen Greven. Band VII (= Werkausgabe Edition Suhrkamp), Zürich/Frankfurt a.M.: Suhrkamp 1978.

Wilson, Peter Niklas: Booklet zur CD. Mathias Spahlinger. inter-mezzo. 128 erfüllte augenblicke. in dem ganzen ocean von empfindungen eine welle absondern, sie anhalten. wergo (WER 6513-2) (Deutscher Musikrat Edition Zeitgenössische Musik).

Wolff, Christian: Cues. Writings \& Conversations - Hinweise. Schriften und Gespräche. Übersetzungen v. Monika Lichtenfeld, Ursula Stiebler, Gisela Gronemeyer, Markus Trunk (Edition MusikTexte 005), Köln: MusikTexte 1998.

Wolff, Christoph: Johann Sebastian Bach. Aus dem Amerikanischen v. Bettina Obrecht, Frankfurt am Main: Fischer 2000.

Zacher, Gerd: »Die Form der g-moll-Fantasie (BWV 542a) für Orgel«, in: Heinz-Klaus Metzger/Rainer Riehn (Hg.), Musik-Konzepte 79/80. Bach 
gegen seine Interpreten verteidigt. Gerd Zacher. Aufsätze 1987-1992, München: text+kritik 1993, S. 20-30.

Zenck, Martin: »tasten - tasten. Körpermusik und gestische Schrift in Klavierwerken von Wolfgang Rihm und Pierre Boulez«, in: NZfM 4, 167 (2006), S. 47-52.

Zenck, Martin: Nom Berühren der Klaviertasten und vom Berührtwerden von Musik. Mit einer Einleitung zum weit verbreiteten Anathema >Musik und Körper in der Philosophie und in der Musikwissenschaft«, in: Jörn Peter Hiekel/Wolfgang Lessing (Hg.), Verkörperungen der Musik. Interdisziplinäre Betrachtungen, Bielefeld: transcript 2014, S. 117-136.

Zenck, Martin/Fichte, Tobias/Kay-Uwe Kirchert: »Gestisches Tempo. Die Verkörperung der Zeit in der Musik - Grenzen des Körpers und seine Überschreitungen «, in: Erika Fischer-Lichte/Christian Horn/Matthias Warstat (Hg.), Verkörperung (Theatralität, Band 2), Tübingen/Basel: A. Francke 2001, S. 345-368.

Zielinski, Tadeusz A.: Chopin. Sein Leben, sein Werk, seine Zeit. Aus dem Polnischen von Martina Homma und Monika Brockmann, Mainz: Schott 2008.

Zimmermann, Bernd Alois: Die Notwendigkeit, eine Invektive zu verfassen, in: Ders., Intervall und Zeit. Aufsätze und Schriften zum Werk, hg. v. Christof Bitter, Mainz: Schott 1974, S. 125-134. 


\section{Musikwissenschaft}
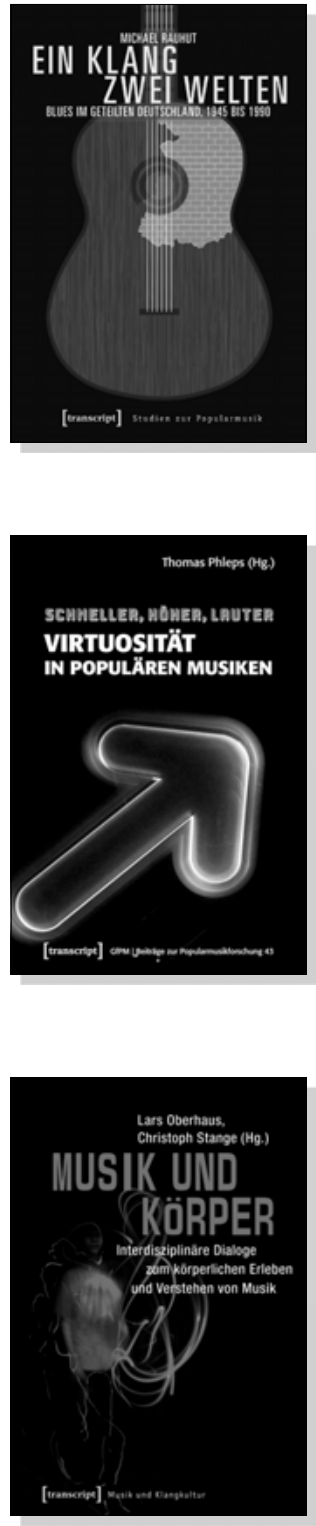

Michael Rauhut

\section{Ein Klang - zwei Welten}

Blues im geteilten Deutschland, 1945 bis 1990

2016, 368 S., kart., zahlr. Abb.

$29,99 €(D E), 978-3-8376-3387-0$

E-Book: 26,99 € (DE), ISBN 978-3-8394-3387-4

Thomas Phleps (Hg.)

\section{Schneller, höher, lauter}

Virtuosität in populären Musiken

August 2017, 188 S., kart., zahlr. Abb.

$19,99 €(D E), 978-3-8376-3592-8$

E-Book: $17,99 €(D E)$, ISBN 978-3-8394-3592-2
Lars Oberhaus, Christoph Stange (Hg.)

\section{Musik und Körper}

Interdisziplinäre Dialoge zum körperlichen Erleben und Verstehen von Musik

Juli 2017, 342 S., kart.

$34,99 €(D E), 978-3-8376-3680-2$

E-Book: 34,99 € (DE), ISBN 978-3-8394-3680-6 


\section{Musikwissenschaft}

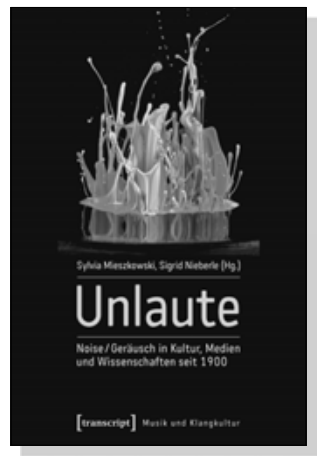

Sylvia Mieszkowski, Sigrid Nieberle (Hg.)

\section{Unlaute}

Noise / Geräusch in Kultur, Medien

und Wissenschaften seit 1900

(unter Mitarbeit von Innokentij Kreknin)

März 2017, 380 S., kart.

$34,99 €(D E), 978-3-8376-2534-9$

E-Book: 34,99€ (DE), ISBN 978-3-8394-2534-3

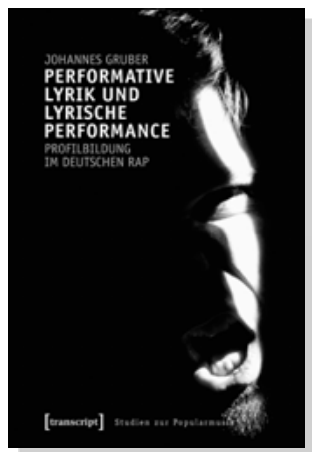

Johannes Gruber

Performative Lyrik und lyrische Performance

Profilbildung im deutschen Rap

2016, 392 S., kart., zahlr. z.T. farb. Abb.

$34,99 €(D E), 978-3-8376-3620-8$

E-Book: 34,99 € (DE), ISBN 978-3-8394-3620-2

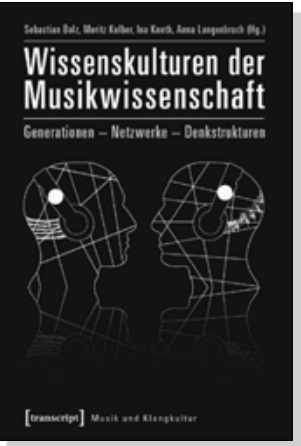

Sebastian Bolz, Moritz Kelber,

Ina Knoth, Anna Langenbruch (Hg.)

Wissenskulturen der Musikwissenschaft

Generationen - Netzwerke - Denkstrukturen

2016, 318 S., kart.

$34,99 €(D E), 978-3-8376-3257-6$

E-Book: 34,99 € (DE), ISBN 978-3-8394-3257-0 